CARLOS ANDRES CUENCA CABRERA

DUCTILE FAILURE PREDICTION USING PHENOMENOLOGICAL FRACTURE MODEL FOR STEELS: CALIBRATION, VALIDATION AND APPLICATION 
CARLOS ANDRES CUENCA CABRERA

\section{DUCTILE FAILURE PREDICTION USING PHENOMENOLOGICAL FRACTURE MODEL FOR STEELS: CALIBRATION, VALIDATION AND APPLICATION}

Dissertação apresentada à Escola Politécnica da Universidade de São Paulo para obtenção do título de

Mestre em Ciências

Área de concentração:

Engenharia Naval e Oceânica

Orientador: Prof. Dr.

Diego Felipe Sarzosa Burgos 
CARLOS ANDRES CUENCA CABRERA

\section{DUCTILE FAILURE PREDICTION USING PHENOMENOLOGICAL FRACTURE MODEL FOR STEELS: CALIBRATION, VALIDATION AND APPLICATION}

Dissertação apresentada à Escola Politécnica da Universidade de São Paulo para obtenção do título de

Mestre em Ciências

Área de concentração:

Engenharia Naval e Oceânica

Orientador: Prof. Dr.

Diego Felipe Sarzosa Burgos 
Este exemplar foi revisado e corrigido em relação à versão original, sob responsabilidade única do autor e com a anuência de seu orientador.

São Paulo, de de

Assinatura do autor:

Assinatura do orientador:

Catalogação-na-publicação

Cuenca Cabrera, Carlos

DUCTILE FAILURE PREDICTION USING PHENOMENOLOGICAL FRACTURE MODEL FOR STEELS: CALIBRATION, VALIDATION AND APPLICATION / C. Cuenca Cabrera -- versão corr. -- São Paulo, 2014. $127 \mathrm{p}$.

Dissertação (Mestrado) - Escola Politécnica da Universidade de São Paulo. Departamento de Engenharia Naval e Oceânica.

1.Mecânica da fratura 2.Método dos elementos finitos 3.SMCS (Método) I.Universidade de São Paulo. Escola Politécnica. Departamento de Engenharia Naval e Oceânica II.t. 
To Irene and Saori 


\section{ACKNOWLEDGEMENT}

I would like to express my sincere gratitude to my advisor Prof. Dr. Diego Sarzosa for the continuous support of my MSc. study and related research, for his patience, motivation, and immense knowledge.

Besides my advisor, I would like to thank the Laboratório de Fenômenos de Superfície from Departamento de Engenharia Mecatrônica (EPUSP) for helping me with the utilization of the Abaqus software.

My sincere thanks also go to the Departamento de Engenharia Naval e Oceânica (USP) for give me the opportunity to comply my postgraduate studies.

Also, I thanks to the Secretaría de Educación Superior, Ciencia, Tecnología e Innovación (SENESCYT) for the scholarship.

Last but not least, I would like to thank my family for supporting me throughout my study and stay in Brazil. 


\section{ABSTRACT}

The present thesis shows the analysis, calibration, and application of the stress modified critical strain criterion to predict ductile failure for an A285 steel. To obtain the mechanical behavior of the material, experimental tests were carried out by implementation of 5 different types of geometries: smooth round bar, notched round bar $(R=1,2,3 \mathrm{~mm})$, and, deep and shallow cracked $S E(B)$ specimens. Then, for the calibration process of the mechanical properties finite element models were generated, using 3D solid elements with 8 nodes (C3D8), matching the geometry and the properties of the tested specimens. To calibrate the elastoplastic behavior was used the experimental and numerical response obtained from the smooth and notched round bar specimens; and, for the damage calibration was used the responses obtained from both deep and shallow crack $\mathrm{SE}(\mathrm{B})$ specimens. Once the mechanical properties were calibrated, then there were obtained the SMSC criterion factors represented by the equation $\varepsilon_{P}^{\text {crit }}=2,46 \exp \left(-1,788 \frac{\sigma_{m}}{\sigma_{e}}\right)$, and, the damage condition which is represented by the displacement at failure $\left(\delta_{C T}=0.12\right)$ and exponential softening factor $(\zeta=0.45)$. This calibrated model was able to recover the $\operatorname{SE}(B)$ experimental responses that validate the use of the characterized material in a complex structure. Then, the fully characterized material was applied in two pipelines which have external initial circumferential elliptical crack; being the first one pipe with shallow crack and the second one with deep crack. Finally, both pipes were submitted to tension loads to predict the ductile damage behavior, obtaining the necessary load to the crack start growing, and the evolution of the failure.

Keywords: Fracture, Damage, SMCS (Method), Ductile, FEM 


\section{RESUMO}

A presente dissertação apresenta o processo de análise, calibração e aplicação das propriedades mecânicas, incluindo o comportamento elastoplástico e de dano, para o aço A285, utilizando o critério "Stress modified critical strain" (SMCS). Para obter o comportamento mecânico do material, testes experimentais foram realizados com a implementação de 5 tipos diferentes de geometrias: barra cilíndrica sem entalhe, barra cilindrica com entalhe $(R=1,2,3 \mathrm{~mm})$ e corpos de prova $S E(B)$ com trinca inicial profunda e rasa. Para o processo de calibração das propriedades mecânicas foram gerados modelos de elementos finitos, utilizando elementos sólidos 3D com 8 nós (C3D8), que representam de forma adequada a geometria e as propriedades dos corpos de prova testados. Para calibrar o comportamento elastoplástico e iniciação do dano, utilizou-se a resposta experimental e numérica obtida para as amostras de barra cilíndrica com e sem entalhe; e, para a calibração da evolução do dano, foram utilizadas as respostas obtidas para os espécimes SEB de trincas profundas e rasa. Este modelo calibrado foi capaz de recuperar as respostas experimentais dos corpos de prova $S E(B)$, o que valida o uso do material caracterizado em uma estrutura complexa. Uma vez calibradas as propriedades mecânicas, foram obtidos os fatores

do critério SMSC representados pela equação $\varepsilon_{P}^{\text {crit }}=2,46 \exp \left(-1,788 \frac{\sigma_{m}}{\sigma_{e}}\right)$, e, a condição de dano que é representada pelo deslocamento na falha $\delta_{C T}=0.12 \mathrm{e}$ o fator de amolecimento exponencial $\zeta=0.45$. Depois, o material totalmente caracterizado foi aplicado em dois dutos que possuem trinca elíptica circunferencial inicial externa; sendo o primeiro tubo com trinca superficial e o segundo com trinca profunda. Finalmente, ambos os tubos foram submetidos a cargas de tensão para prever o comportamento do dano dúctil, obtendo a carga necessária para o início do crescimento da trinca e a evolução da falha.

Palavras chave: Fratura, Dano, SMCS (Método), Dúctil, FEM 


\section{FIGURE INDEX}

Figure 1 Examples of Ductile fracture: a) failure of $X 60$ grade line pipe tested at $13^{\circ} \mathrm{C}$, [4]; b) Ductile damage after collision of USS Fitzgerald and containership ........3

Figure 2 Mechanism of ductile damage under high and moderate stress triaxiality, a) Nucleation by matrix-particle decohesion in a copper matrix (left) and from particle $\left(\mathrm{Al}_{2} \mathrm{O}_{3}\right)$ fracture in aluminum matrix (right); b) void growth in a ductile steel; (c) illustration of voids coalescence by internal necking of matrix between two voids, [3].

Figure 3 SEM observations of the development of voids due to (a) matrix-particle decohesion; (b) particle cracking; (c) mixed mode (taken from Cao [3]).

Figure 4 Definitions of Lode angle $\theta L$ in the space of principal stress(left) and Lode stress parameter $\mu$ (in the Mohr circle (right) (taken from Cao [3]).

Figure 5 Model of bond forces being overloaded until its breaking by an external load applying on atoms of a material, [1].

Figure 6 Engineering Stress-Strain curve for both Brittle and Ductile material (Source: https://sites.google.com/site/polymorphismmyhomepage/investigating-material-

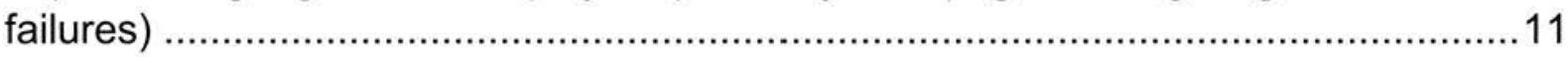

Figure 7 Different approaches for modeling ductile failure [21] ............................12

Figure 8 Stress-strain curve with progressive damage degradation, [28] .................17

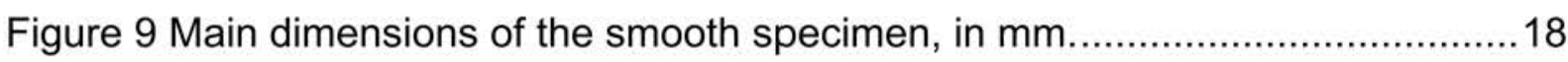

Figure 10 Notched tensile specimen's main dimensions, in $\mathrm{mm}$............................20

Figure 11 Machined testing specimens; a) Smooth specimens: 2 laterals, 2 transversals; b) Notched specimens: R1 = 1mm, R2=2mm, R3=3mm ....................21

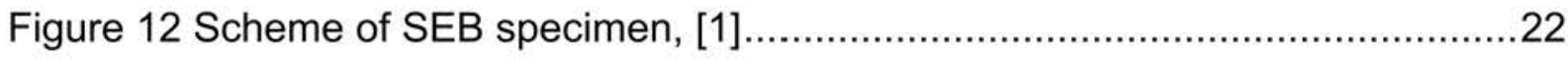

Figure 13 Universal Servo-Hydraulic test system, maximum force capacity is 2.50

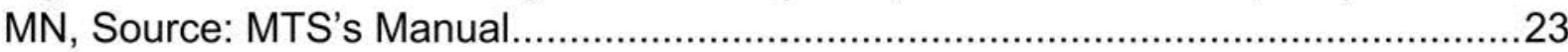

Figure 14 Servo-Hydraulic test system, extensometer and tensile test smooth specimen mounted to be tested

Figure 15 Stress-Strain Engineering curves for tensile specimen tests, a) Smooth tensile bar results, and, b) Notched tensile bar results.

Figure 16 Experimental Stress-Strain Engineering curves for both, smooth and notched tensile specimen test

Figure 17 Load coupled system for Three-point bending tests with SEB specimen, a) total coupled system, b) local coupled system with the SEB specimen and the clip gage, and c) local coupled system with a reference dimension..............................27

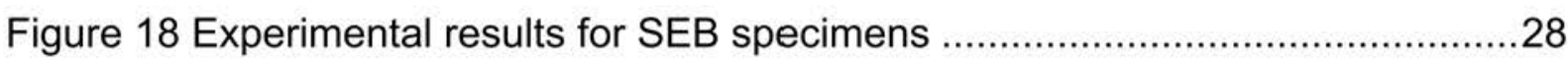

Figure 19 Tensile test specimen's schematic geometries .....................................29

Figure 20 Tensile test specimen's geometries employed for FE analysis, a) smooth, b) R1, c) R2, and d) R3 
Figure 21 SEB specimen's schematic geometries

Figure 22 Geometries of the SEB specimens: a) SEB_TR without side groove, b) SEB_TR with side grooves.

Figure 23 Side grooved dimension for the SEB specimens, dimensions in $\mathrm{mm}$........32

Figure 24 Mesh definition of two specimen tests, SEB and Tensile notched bar ......35

Figure 25 Engineering (CP_L1) and True Stress-Strain curves for the analyzed material

Figure 26 Attempts to model the elastoplastic true stress-true strain curve

Figure 27 Equations to model the True Stress-Strain curve for the analyzed material

Figure 28 Extrapolated True Stress-Strain curve for the analyzed material 40

Figure 29 Plastic strain curve for the analyzed material

Figure 30 Numerical smooth model to be analyzed with elastic properties: a) Mesh of the FE model, and, b) Applied loads and constrains on the FE model....

Figure 31 Finite element smooth model response, analyzed with elastoplastic properties, a) an intermediate step which shows the necking at the symmetry plane, b), c) initial and the final step respectively.

Figure 32 Comparison between Numerical and Experimental Engineering Stress-

Strain curve

Figure 33 Minimum and maximum possible values for Stress-Plastic strain curves..46

Figure 34 Minimum and maximum numerical Engineering Stress-strain curves for a notched tensile specimen, $\mathrm{R}=2 \mathrm{~mm}$.

Figure 35 Numerical Engineering Stress-strain curves for a notched tensile specimen, $\mathrm{R}=2 \mathrm{~mm}$, using two different factor modifications

Figure 36 Modified TSSC using a combination of modifier factors

Figure 37 Smoothed Modified TSSC using a combination of modifier factors 50

Figure 38 Modified numerical engineering stress-strain curve for a tensile notched specimen $\mathrm{R}=2 \mathrm{~mm}$

Figure 39 Modified numerical engineering stress-strain curve for smooth tensile specimens

Figure 40 Modified numerical engineering stress-strain curve for tensile notched specimens, a) Notch $\mathrm{R}=1 \mathrm{~mm}$, and, b) Notch $\mathrm{R}=3 \mathrm{~mm}$

Figure 41 Numerical behavior of the smooth specimen due to an applied load ........53

Figure $42 \eta$ vs PEEQ for each notched tensile specimen analyzed

Figure $43 \eta$ vs PEEQ for the smooth specimen subject a tension, numerical result and reference value taken from Cao [3]

Figure 44 Failure initiation point for the notched tensile specimens at the experimental data for: a) radio $\mathrm{R}=1 \mathrm{~mm}, \mathrm{~b}$ ) radio $\mathrm{R}=2 \mathrm{~mm}$, and, c) radio $\mathrm{R}=3 \mathrm{~mm} . .56$ 
Figure $45 \mathrm{~T}$ vs PEEQ curves with their respective failure initiation points, for each notched tensile specimen.

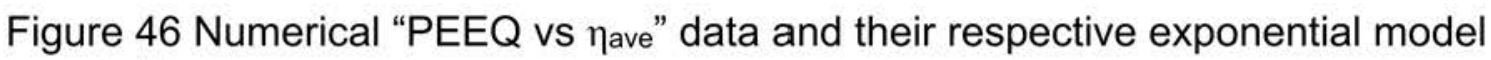
regression.

Figure 47 Types of damage evolution in Abaqus, where, $\zeta=1$ : linear damage evolution, $\zeta<1$ and, $\quad \zeta>1$ : exponential damage evolution.

Figure 48 Comparison of numerical and experimental results for deep crack SEB specimen obtained from the calibrated values and lab test respectively: a) Some of the combinations for $\delta C T$ and $\zeta$ tried, and, b) Comparison between experimental results and numerical results using $\delta C T=0.12$ and $\zeta=0.45$.

Figure 49 Numerical and experimental results comparison for shallow crack SEB specimens with and without side grooves, got from the calibrated values and lab test respectively.

Figure 50 Schematic measurement of the final crack

Figure 51 Measurement locations of final crack front, a), b) SEB specimens with deep crack and side grooves SP5-1 and SP5-2 respectively; c) SEB specimen with shallow crack and no side grooved SP4-2, d) SEB specimen with shallow crack and side grooved SP4-1

Figure 52 Experimental and calculated initial and final crack extension for, a), b) SEB specimens with deep crack and side grooves SP5-1 and SP5-2 respectively ....

Figure 53 Experimental and calculated initial and final crack extension for a) SEB specimen with shallow crack and no side grooves SP4-2, b) SEB specimen with shallow crack and side grooves SP4-1.....

Figure 54 Experimental and numerical final crack extension for, a), b) SEB specimens with deep crack and side grooves SP5-1 and SP5-2 respectively

Figure 55 Experimental and numerical final crack extension for a) SEB specimen with shallow crack and no side grooves SP4-2, and b) SEB specimen with shallow crack and side grooves SP4-1

Figure 56 Responses using different meshing sizes: fine, medium and gross mesh 69 Figure 57 Responses using different element sizes $(0.1,0.2,0.4 \mathrm{~mm})$ in the damage area for shallow crack SEB numerical models

Figure 58 Responses using different mass scaling factors for notched tensile load numerical model (R2), where $K=1000$

Figure 59 Responses for different tries in the damage calibration stage using different

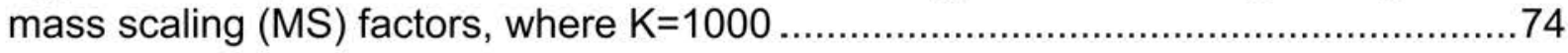

Figure 60 Schema of the round bar dimensions at the symmetry plane $(x=0) \ldots \ldots . .76$

Figure 61 Damage indicator plotted as function of the normalized load applied for tensile load specimens, a) Smooth specimen, b), c), d) R1, R2 and R3 notched specimens, respectively 
Figure 62 References points to analyze the DI for the deep crack SEB specimen with side groove.

Figure 63 References points to analyze the DI for the shallow crack SEB specimens,

a) with side groove, and, b) with no side groove .78

Figure 64 Damage indicator plotted as function of the normalized load applied for deep crack SEB specimens, with side groove.

Figure 65 Damage indicator plotted as function of the normalized load applied for shallow crack SEB specimens, a) side groove, and, b) without side groove .79

Figure 66 Schematic reference axis to analyze the triaxiality distribution at the first element deletion

Figure 67 Triaxiality distributions for deep crack SEB specimen with side grooves, analyzed at the first element deletion through: a) "t" axis, and b) "s" axis

Figure 68 PEEQ distributions for deep crack SEB specimen with side grooves, analyzed at the first element deletion through: a) "t" axis, and b) "s" axis

Figure 69 Triaxiality distributions for shallow crack SEB specimen with side grooves, analyzed at the first element deletion through: a) "t" axis, and b) "s" axis

Figure 70 PEEQ distributions for shallow crack SEB specimen with side grooves, analyzed at the first element deletion through: a) "t" axis, and b) "s" axis

Figure 71 Triaxiality distributions for shallow crack SEB specimen without side grooves, analyzed at the first element deletion through: a) "t" axis, and b) "s" axis...83

Figure 72 PEEQ distributions for shallow crack SEB specimen with no side grooves, analyzed at the first element deletion through: a) "t" axis, and b) "s" axis

Figure 73 PEEQ vs $\eta$ historic values for the deep crack SEB specimen with side grooves, analyzed at the first element deletion, for elements located at " $\mathrm{s}$ " axis

Figure 74 PEEQ vs $\eta$ historic values for the shallow crack SEB specimen with side grooves, analyzed at the first element deletion through, for elements located at " $s$ " axis

Figure 75 PEEQ vs $\eta$ historic values for the shallow crack SEB specimen with no side grooves, analyzed at the first element deletion through, for elements located at " $\mathrm{s}$ " axis

Figure 76 Schematic pipe model with main dimensions, a) 3D model of the pipe with the crack location, b) longitudinal dimensions, c) transversal view, d) initial external girth elliptical crack dimensions

Figure 77 Definition of the numerical model, a) Total pipe with the two planes of symmetry, b) $1 / 4$ symmetry model

Figure 78 Material definition sketch with three different types of material, a) general view of the three zones, b) zoom of the part enclosed in red to observe the damage area

Figure 79 Mesh definition for the structures, a) pipe with initial deep crack, b) pipe with initial shallow crack. 
Figure 80 Boundary conditions and applied load for the analyzed structures, a) complete numerical model with the boundary conditions and the applied load, b) detailed view of the free extreme with the applied load and boundary conditions, c) detailed view of the symmetry plane with the boundary conditions

Figure 81 References points to analyze the DI for the pipes, a) deep initial crack pipe, b) shallow initial crack pipe.

Figure 82 Damage indicator plotted as function of the normalized load applied for both pipes, a) pipe with deep crack, b) pipe with shallow initial crack

Figure 83 Schematic reference axis to analyze the triaxiality distribution at onset of failure for $\mathrm{P} 1$ for the pipes, a) Numerical model for the pipe with the interest area enclosed in the red rectangle, b) zoom of the enclosed area in the red rectangle.....96

Figure 84 Triaxiality distributions for the deep initial crack pipe, analyzed at the first element deletion through: a) "t" axis, and b) "s" axis

Figure 85 PEEQ distributions for the deep initial crack pipe, analyzed at the first element deletion through: a) "t" axis, and b) "s" axis

Figure 86 Triaxiality distributions for the shallow initial crack pipe, analyzed at the first element deletion through: a) "t" axis, and b) "s" axis

Figure 87 PEEQ distributions for the shallow initial crack pipe, analyzed at the first element deletion through: a) "t" axis, and b) "s" axis

Figure 88 Crack growing process in the deep initial crack pipe, a) initial configuration, b) intermediate crack growth status

Figure 89 Crack growing process in the shallow initial crack pipe, a) initial configuration, b) intermediate crack growth status

Figure 90 Load vs displacement of the free extreme for: a) deep initial crack pipe, and, b) deep initial crack pipe 100

Figure 91 Crack growing process in the deep initial crack pipe in different Load Status (LS), a) LS=0; b) LS=0,44; c) $L S=0,50$; d) $L S=0,63$; e) $L S=0,68$; and f) $\mathrm{LS}=0,75$.

Figure 92 Crack growing process in the shallow initial crack pipe in different Load Status (LS), a) LS=0; b) LS=0,50; LS=0,60; LS=0,70; $L S=0,80$; and $L S=0,84$ 110 


\section{TABLE INDEX}

Table 1 Description of tensile bar specimen used 20

Table 2 Shallow crack specimen with and without side groove dimensions, in $\mathrm{mm}$. 22

Table 3 SEB - Deep Crack Specimen with side groove dimensions, in $\mathrm{mm}$. .22

Table 4 Tensile type laboratory tests. .24

Table 5 Type of SEB specimens tested .27

Table 6 Elastic material properties for Steel A285. .32

Table 7 Chemical properties for samples of the tested specimens .33

Table 8 Boundary condition according specimen type .33

Table 9 "a" and "n" values for the 2th to 4th sections' Power functions 39

Table 10 Upper and lower limits to use the power equations to model the TSSC .....40

Table 11 Values of the possible factors to modify the TSSC 48

Table 12 Modifier factors for TSSC and intervals where they are valid .49

Table 13 Equivalent failure initiation points according to the analyzed graph .57

Table 14 PEEQ and Mean triaxiality values for each notched tensile specimen .58

Table 15 a) SMCS model equation; b) PEEQ vs $\eta_{\text {ave equation for the analyzed }}$ material

Table 16 Quantity of nodes and elements for three attempts of meshing techniques

Table 17 Main dimensions for the pipes having an initial external girth elliptical crack 88

Table 18 Quantity of nodes and elements for each analyzed pipe .90 


\title{
SYMBOLS AND ABBREVIATIONS
}

\section{Latin Symbols (Capital Letters)}

\author{
A: $\quad$ Modifier factor that affects the base of the power function " $a$ " \\ $B$ : Modifier factor which affects only the exponent of the power fuction " $n$ " \\ E: $\quad$ Young's Modulus \\ NRB: $\quad$ Notched round bar specimens \\ R: $\quad$ Radio of the round bar specimens \\ SEB: $\quad$ Single edge bending specimens \\ SMCS: $\quad$ Stress modified critical strain criterion \\ TSSC: $\quad$ True stress strain curve
}

\section{Latin Symbols (Small Letters)}

a: $\quad$ Base of the power law equation to model the elastoplastic part of the true stress-true strain curve

$n$ : $\quad$ Exponent of the power law equation to model the elastoplastic part of the true stress-true strain curve

$t_{s g}: \quad$ Deep of the side groove dimension in SEB specimen 


\section{Greek Symbols (Small Letters)}

$\alpha$ : Material dependent constant which is the base of the power equation which defines

$\beta$ : $\quad$ Material dependent constant which is the exponent of the power equation which defines the SMCS criterion

$\delta_{C T}: \quad$ Displacement at failure

$\varepsilon_{e}^{p l}, \mathrm{PEEQ}: \quad$ Equivalent plastic strain

$\varepsilon_{E}: \quad$ Elastic strain

$\varepsilon_{P}: \quad$ Plastic strain

$\varepsilon_{P}^{\text {crit }}$ : Critical value of the equivalent plastic strain

$\varepsilon_{T}: \quad$ True strain

$\eta$ Stress triaxiality

$\bar{\eta}, \eta_{\text {ave }}: \quad$ Mean stress triaxiality

$\sigma_{\mathrm{e}}: \quad$ Von Mises stress

$\sigma_{y}: \quad$ Yielding stress

$\sigma_{m}: \quad$ Hydrostatic stress mean stress

$\sigma_{T}: \quad$ True stress

$\mu$ : $\quad$ Lode stress parameter

$\theta_{L}: \quad$ Lode angle

$\omega_{D}$, DI: Damage indicator

$\zeta: \quad$ Exponential softening factor 


\section{INDEX}

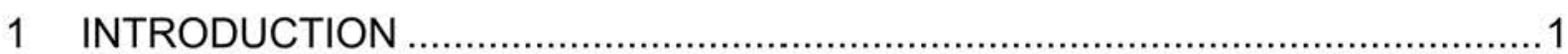

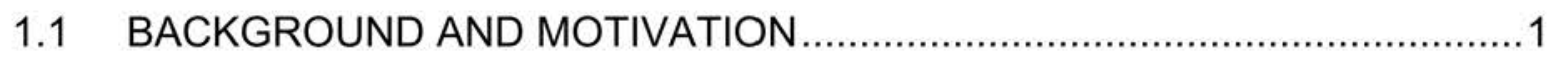

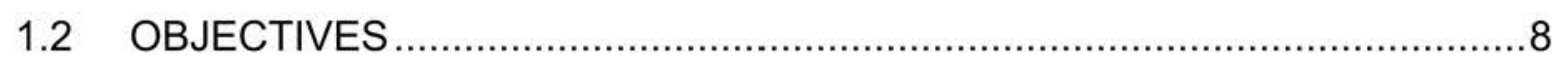

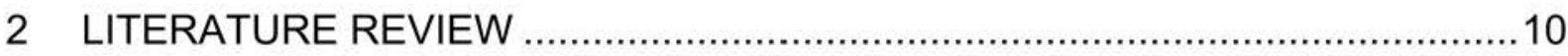

2.1 STATE OF ART OF DUCTILE DAMAGE MODELING ...............................11

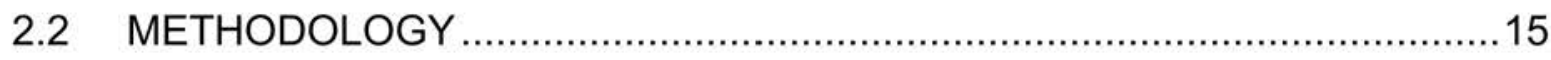

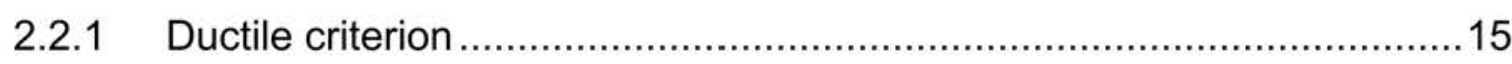

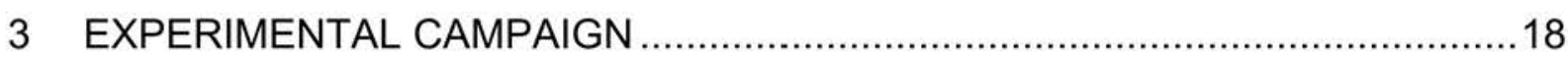

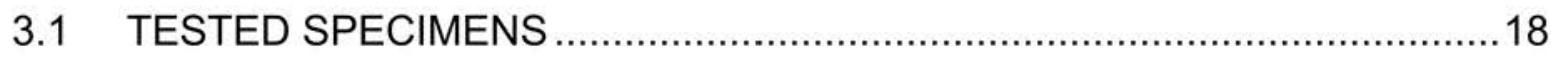

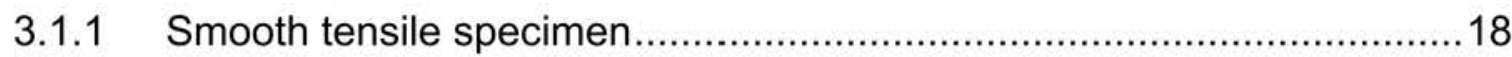

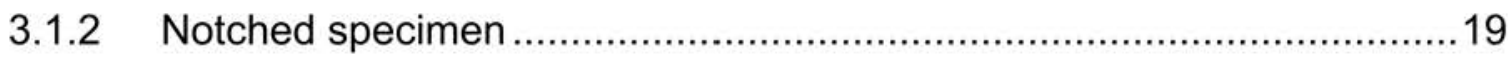

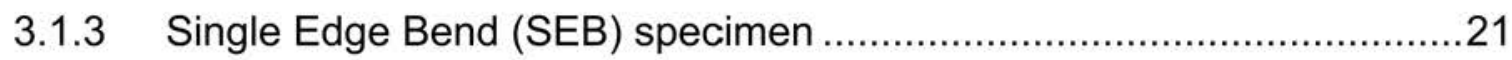

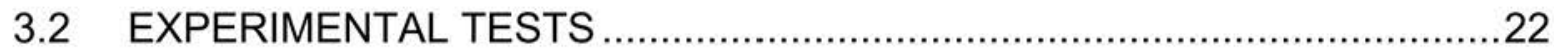

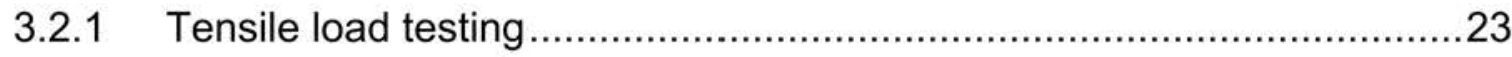

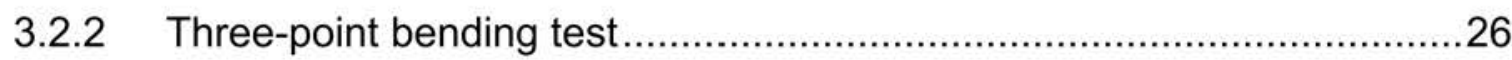

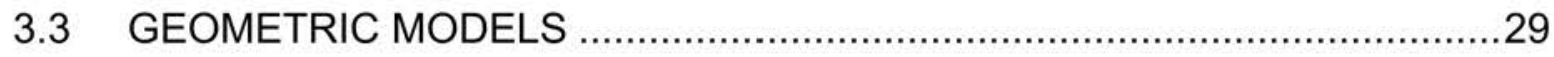

3.3.1 Tensile tests specimen (Smooth and notched specimens) ....................29

3.3.2 Three-point bend test geometries (SEB specimens) ….........................30

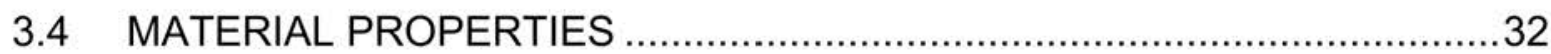

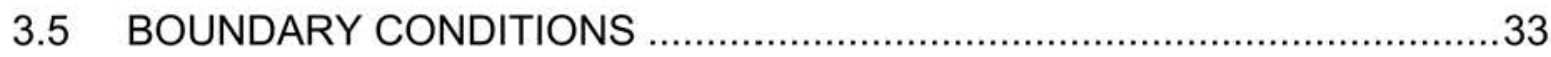

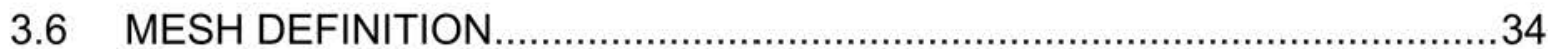

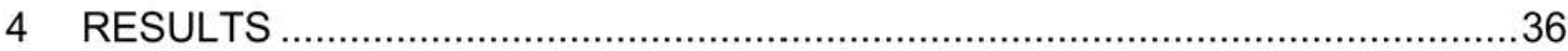

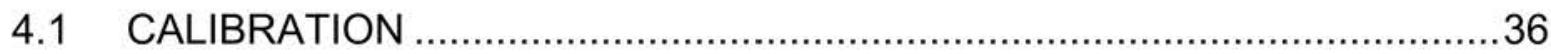

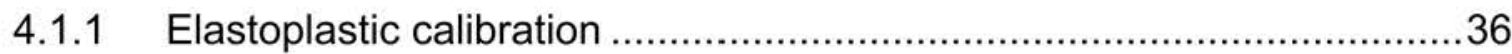

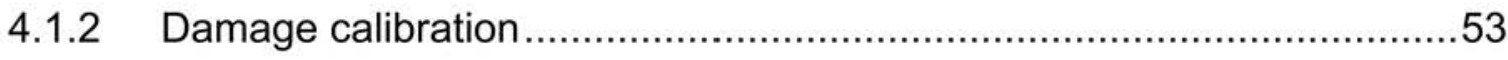

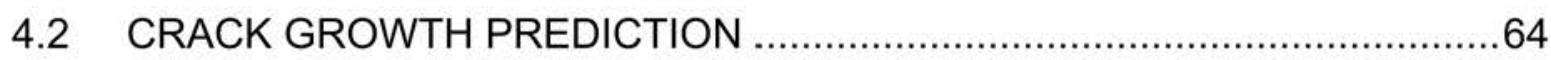

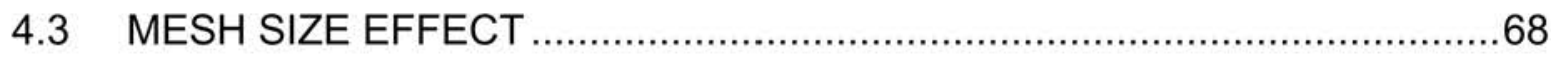

4.3.1 Mesh size effect on elastoplastic calibration ........................................68

4.3.2 Elements size effect on damage calibration ........................................70

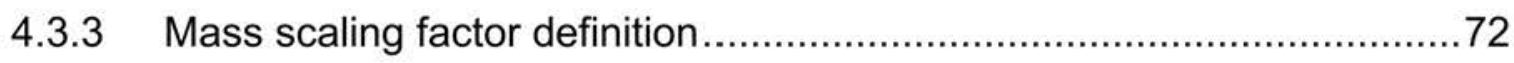

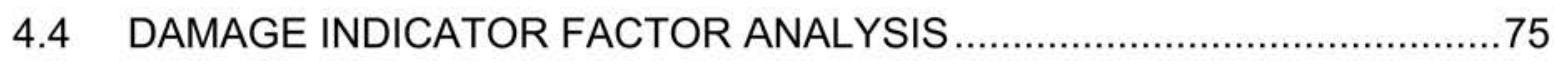

5 APPLICATION

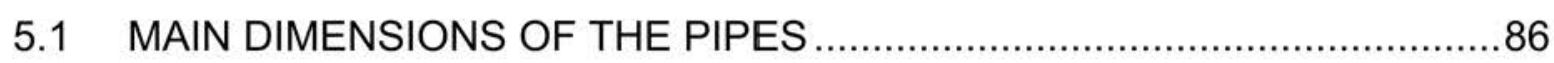




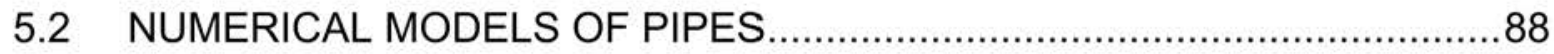

5.3 NUMERICAL RESULTS FOR THE ANALYZED PIPES..............................93

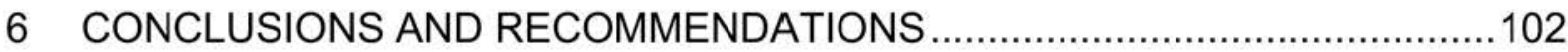

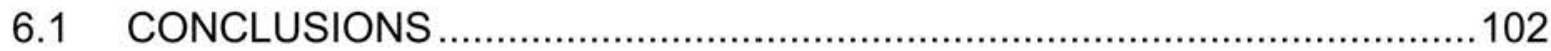

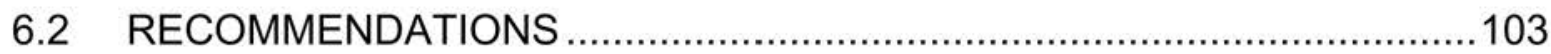

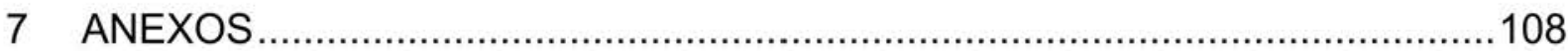

7.1 CHEMICAL PROPERTIES OF THE MATERIAL .....................................108

7.2 CRACK GROWING PROCESS IN THE DEEP INITIAL CRACK PIPE ......109

7.3 CRACK GROWING PROCESS IN THE SHALLOW INITIAL CRACK PIPE 110 


\section{INTRODUCTION}

\subsection{BACKGROUND AND MOTIVATION}

Fatigue and fracture are important modes of failures that must be analyzed in critical engineering structures, such as nuclear pressure vessels, offshore/onshore pipelines, aircrafts, ships and so on, during the design phase. Usually, designers do consider that structural components are flaw-free for scantlings definitions. Thus, the sections for each structural element are selected following recommendations from standards (ABS/DNV) or by detailed rational procedures to withstand predicted loads associated to the environment where the structure is intended to operate over its desired life. Both design approaches assume linear-elastic behavior of the material, so the yield stress can be used as a failure criterion. Moreover, analyzing structures with non-damage, the yield criterion produces conservative predictions in most of the engineering applications.

However, the idealized flaw-free condition is barely achieved specially in welded structures and composite materials. Thus, microstructural defects are an inherent part of materials used to build new structures; small flaws might be introduced during construction that might not be detected by periodic inspections or just appear naturally after some time of normal operation. Procedures to estimate the strength of materials must consider the presence of defects in order to make reliable predictions about its behavior when compared to real mechanical response. Fracture mechanics approach provides the relation between the loading, flaw, and material strength.

Fracture mechanics theory has traditionally been used to predict the onset of failure, crack propagation, remaining strength, and expected life. It also helps to take decisions about extension program of critical structures (nuclear installations). The stress intensity factor $K$ is used when the global response of the structure can be assumed as linear (elastic). On the other hand, the J-Integral or the Crack Tip Opening Displacement (CTOD) have been extensively used for elastic-plastic conditions. The cornerstone of one-parameter fracture mechanics is the transferability of toughness 
properties between different geometries (small specimens and large structures) under different loading modes (bending, shear and tensile stresses). This is the so-called Kdominance or J-dominance conditions of fracture [1]. Therefore, the stress/strain condition at the crack-tip can be defined uniquely by $\mathrm{K}$ or $\mathrm{J}$ at the moment of fracture.

Nowadays, the computational capacity has considerably increased when compared to the 1990's, allowing us to solve challenge problems in the engineering field. In that direction, researchers have dedicated a lot of effort to improve the predictive abilities of fracture models. As Peerlings [2] correctly pointed out, a second fundamental approach for fracture modeling has emerged in which fracture is considered as the ultimate consequence of material damage. The loss of load-bearing capacity in each material point on the structure is accounted for in the constitutive model instead of defining the mechanical constitutive response and fracture criterion in a separate way. Thus, the onset of failure (crack initiation) and crack propagation can be naturally modeled from continuum mechanics theory.

This research was focused on the analysis of a specific mode failure called Ductile Fracture. Figure 1 shows a couple of examples of ductile failure in the offshore (controlled failure) and naval (accidental failure) industry. Ductility is understood as an intrinsic ability of materials to undergo a certain amount of plastic deformation without fracture or without formation of a visible crack [3]. The fracture of ductile material happens after micro voids or shear bands develop in the metal matrix, around inclusions or other discontinuities such as second-phase particles.

At microstructural scale, ductile failure can be associated with voids nucleation, voids growth and voids coalescence mechanism particularly for high and moderate constraint conditions; another mechanism of ductile damage is the one concerning shear band formation under low constrain. At large scale, the damage is represented as the progressive degradation of a material, which exhibits a decrease in material stiffness and strength [3]. 


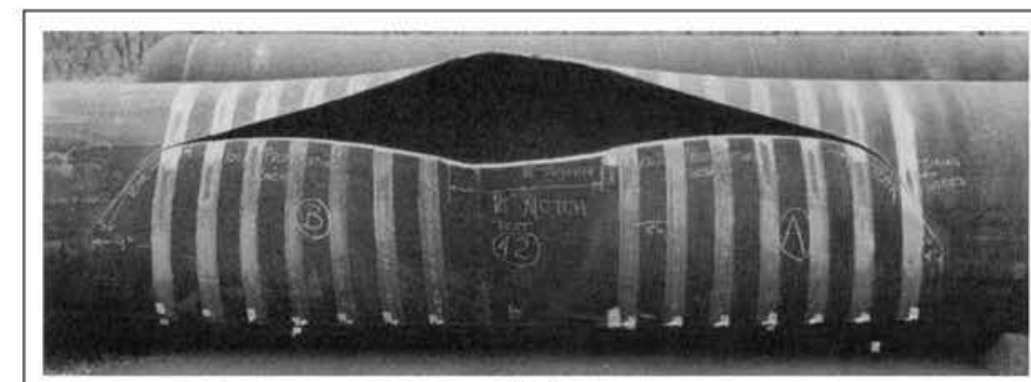

(a)

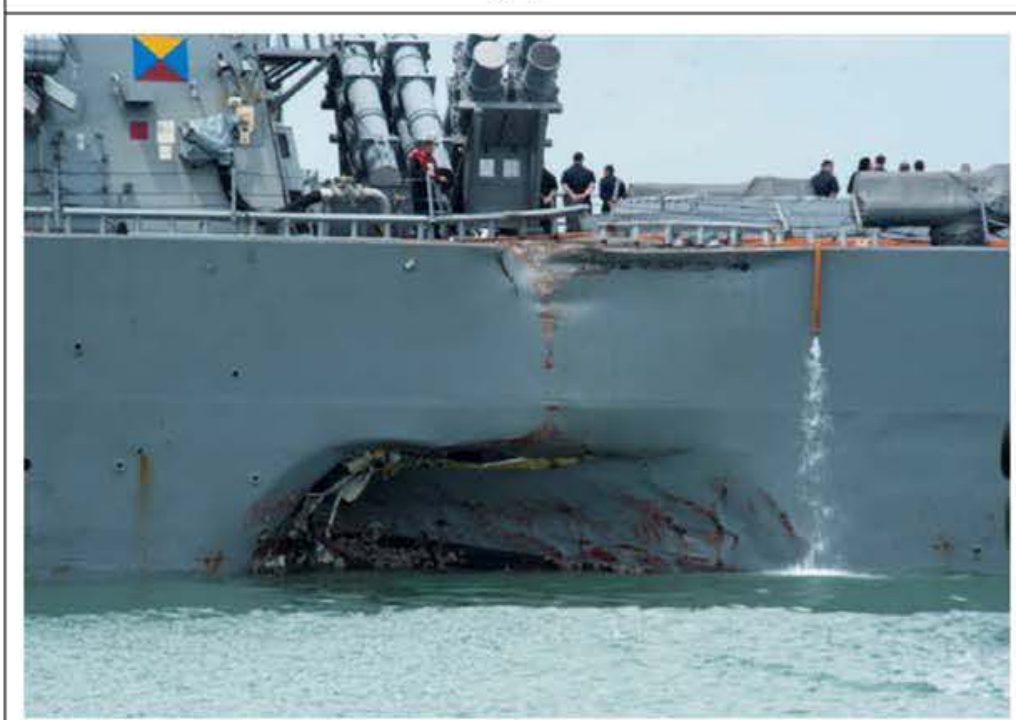

(b)

Figure 1 Examples of Ductile fracture: a) failure of $X 60$ grade line pipe tested at $13^{\circ} \mathrm{C},[4]$; b) Ductile damage after collision of USS Fitzgerald and containership ${ }^{1}$

Figure 2 shows the typical stages of ductile damage for intermediate and high stress triaxiality $(\eta)$ conditions ${ }^{2}$. From a mechanical point of view, voids are typically created from second-phase particles or inclusions when submitted to stresses exceeding the interfacial bond strength between the particle and the matrix. Thus, voids nucleation is strongly dependent on material composition at microscopically level. The rate of nucleation might dependent on particle strength, particle shape and size, rigidity mismatch between particle and matrix, and hardening of the surrounding matrix. Even though voids can be created early during the loading, by plastic deformation of matrix, these initial voids are so small that they have no important influence on the bulk response of the material (macroscopic).

\footnotetext{
${ }^{1}$ Taken from http://worldmaritimenews.com/wp-content/uploads/2017/11/us_navy_001-1024x712.png

${ }^{2}$ Note that stress triaxiality for uniaxial tension, around $\eta=\frac{1}{3}$, could be considered as a low value, on the other hand, the stress state in front of cracked specimens, having highly constrained elements, is representative of high stress triaxiality, around $\eta=3$.
} 
The second stage of ductile damage for intermediate and high constraint situations is void growth. Plastic deformation and hydrostatic stress drive the rate of void growth. As the initial void volume is small when compared to continuum volume of the matrix, each void will growth independent of each other without interaction. Upon further loading, voids will start to interact with their neighbors resulting in strain localizations along a line of voids and local necking instabilities develop [1]. Thus, the last stage of ductile damage, called coalescence, is presented with the link of voids, and creating the condition for crack extension. Void might increase its size in two or three times before linking with other voids for ductile metals. On the other hand, for stiff materials the coalescence process starts very early after nucleation.

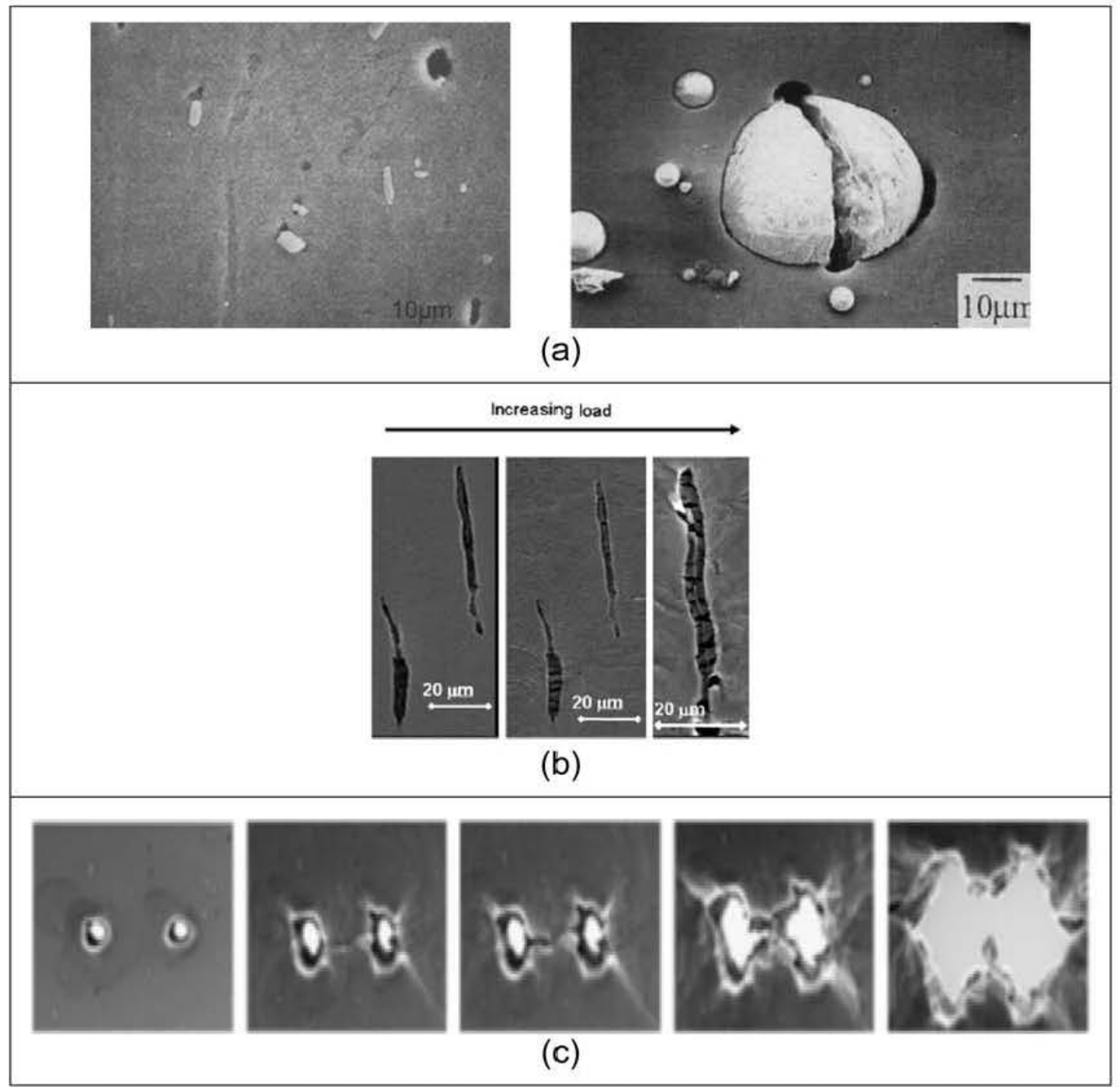

Figure 2 Mechanism of ductile damage under high and moderate stress triaxiality, a) Nucleation by matrix-particle decohesion in a copper matrix (left) and from particle $\left(\mathrm{Al}_{2} \mathrm{O}_{3}\right)$ fracture in aluminum matrix (right); b) void growth in a ductile steel; (c) illustration of voids coalescence by internal necking of matrix between two voids, [3]. 
For low-stress triaxiality, ductile fracture happens according to a different mechanism. Variations in void shape drive the process with a relatively small volume change. According to Kweon et al. [5] damage at zero and negative stress triaxiality happens by grain to grain interaction creating hydrostatic tensile stress inside grains. Figure 3 shows the voids initiation process for a shear test on a high-strength low alloy steel. It is possible to appreciate, after unbound or cracking, a non-uniform growth happens (void shape change) and void rotation.

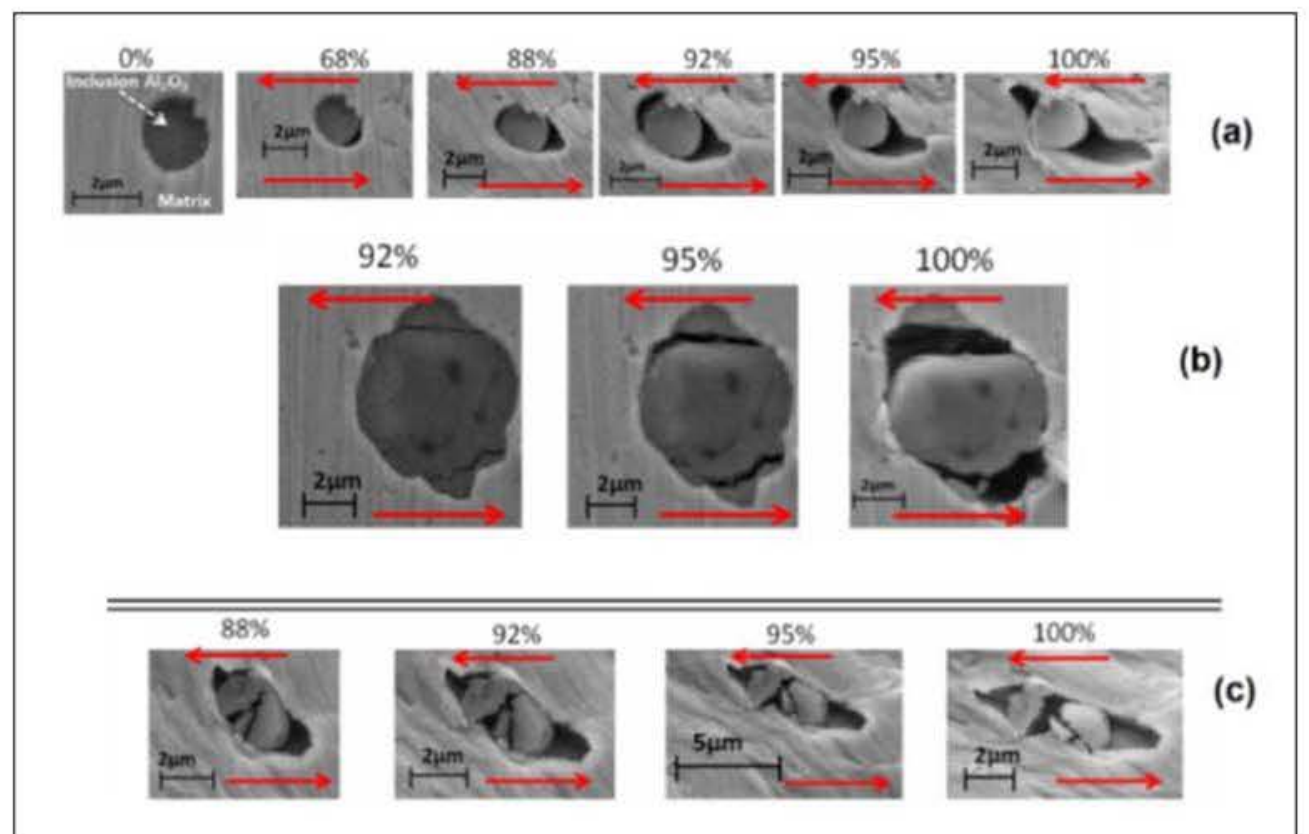

Figure 3 SEM observations of the development of voids due to (a) matrix-particle decohesion; (b) particle cracking; (c) mixed mode (taken from Cao [3]).

Recent efforts made by the fracture mechanics community - Bai \& Wierzbicki [6], Coppola et al. [7], Nahshon \& Hutchinson [8], Xue [9], [10] - to improve the understanding and prediction capabilities of ductile fracture models under low and negative stress triaxiality conditions, promote the introduction of an additional parameter, named Lode angle, into the theoretical framework of ductile damage to get more accurate predictions in a large range of applied loading (bending, axial, torsional). For a given stress triaxiality $(\eta)^{3}$ value, there exist infinite stress combinations of the principal stresses $\left(\sigma_{1}, \sigma_{2}, \sigma_{3}\right)$ which define different stress states.

${ }^{3} \eta=\frac{\sigma_{m}}{\sigma_{e}} ;$ where $: \sigma_{m}=\frac{\sigma_{1}+\sigma_{2}+\sigma_{3}}{3} ; \sigma_{e}=\sqrt{\frac{\left(\sigma_{1}-\sigma_{2}\right)^{2}+\left(\sigma_{2}-\sigma_{3}\right)^{2}+\left(\sigma_{3}-\sigma_{1}\right)^{2}}{2}}$ 
To characterize the applied loading uniquely at each material point the lode angle is introduced. Moreover, as experimental tests have shown Paredes et al. [7], [11], critical strain to fracture $\bar{\varepsilon}_{\text {critical }}$ is function of $\eta$ and the loading condition, i.e. axial and shear loading might fail at different $\bar{\varepsilon}_{\text {critical }}$. Therefore, the stress state is defined unambiguously by the stress triaxiality $(\eta)$ and Lode stress parameter $(\mu)^{4}$. Figure 4 shows graphically the definitions of Lode angle and Lode stress parameter.

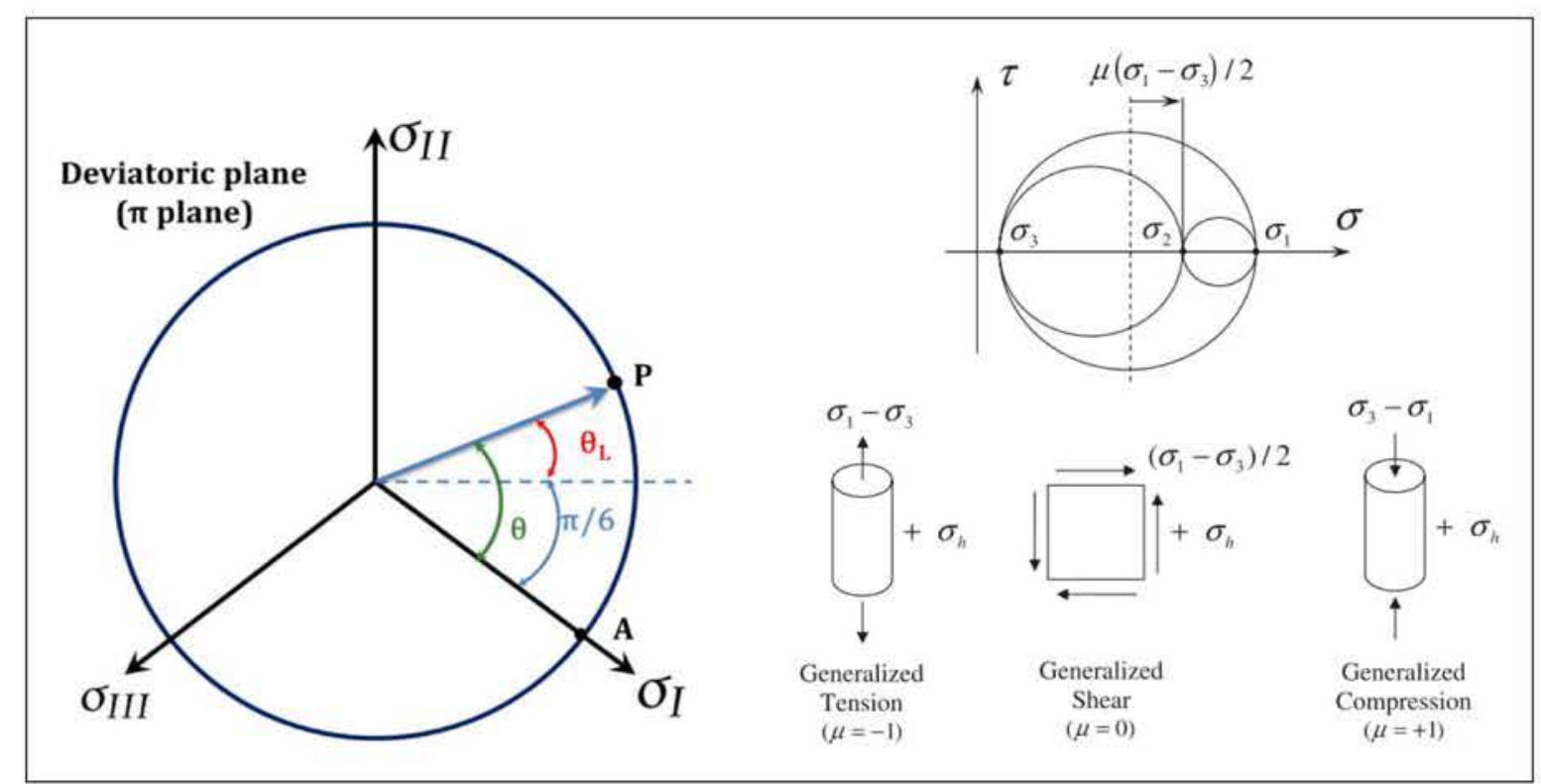

Figure 4 Definitions of Lode angle $\theta_{L}$ in the space of principal stress(left) and Lode stress parameter $\mu$ (in the Mohr circle (right) (taken from Cao [3]).

Cao [3] has studied the applicability of different ductile damage models on manufacturing processes, cold metal forming industry, for complex loadings paths involving shear effects. The author focused on trying to catch the shear damage mechanism by introducing the Lode angle dependency on the formulation of different damage criteria.

Recently, Paredes et al. [12] - [11], have successfully applied a damage ductile model, based upon a modified version of the Mohr-Coulomb failure criterion dependent of $\eta$ and $\theta$, to study the damage of mild steels under different constraint conditions using typical fracture specimens $S E(T), C(T)$ and $S E(B)$.

${ }^{4} \mu=\frac{2 \sigma_{2}-\sigma_{1}-\sigma_{3}}{\left(\sigma_{1}-\sigma_{3}\right)} ; \tan \left(\theta_{L}\right)=\frac{1}{\sqrt{3}} \frac{2 \sigma_{2}-\sigma_{1}-\sigma_{3}}{\left(\sigma_{1}-\sigma_{3}\right)} ; \theta=\theta_{L}+\frac{\pi}{6}$ 
Although ductile fracture understanding has increased in the last years, especially for low constraint conditions, there are not open available implementations of these new models on commercial software programs and calibration of model parameters can be tricky and expensive. However, more simple models can still make reliable predictions about the loss of load-bearing capacity of materials. Specifically, in applications where are necessary heavy structures, like nuclear power plants and offshore pipelines used for deep water oil and gas exploration, the Gurson-Tveegard model, [13]-[16], and the Stress-Modified critical strain (SMCS) approach are reliable numerical models for studying ductile fracture problems.

In this study, we focus on the use of SMCS model for prediction of ductile fracture. A detailed explanation of plasticity and damage parameters calibration is given. The ability of phenomenological SMCS approach for prediction of ductile fracture is analyzed in this research for specimens with different stress triaxiality ahead of the crack tip. As the version of the used SMCM model is independent of the Lode angle parameter, the main assumption of this study is that the expected mechanism of damage is due to void nucleation, void growth, and void coalescence instead of shear band localization. 


\subsection{OBJECTIVES}

The overall objective of the present work is to study the fracture behavior of mild steel by using a phenomenological approach. The chosen approach to model the damage at each material point was the Stress-Modified Critical Strain (SMCS) criterion. This well-known damage model has been used effectively in the last years, by several studies, to improve the understanding and role of stress/strain fields on the material failure. Moreover, geometry effects on fracture toughness values have been correctly predicted by applying the SMCS criteria. The following specific goals are needed to achieve the general objective of this study:

1. To carry out laboratory tests using different geometries under various levels of stress triaxiality.

2. To build up detailed finite element models representative of the tested laboratory specimens.

3. To define a numerical methodology for identifying the material parameters (calibration) that characterizes the mechanical behavior of the tested material using the experimental and numerical results.

4. To apply the calibrated material parameters in exploratory assessment of cracked pipe under complex loading.

The rest of this thesis is structured as follows:

In chapter 2, a short revision of the ductile fracture models is made and the SMCS approach is described.

Chapter 3 presents the experimental data needed to calibrate and verify the numerical model, using smooth and notched tensile specimens and Single edged notched specimens, having shallow and deep cracks. This includes the environment and the test rig used to perform the experimental tests, the main dimension of each specimen and the type of results obtained from each laboratory test. 
Chapter 4 describes the adopted procedure to analyze the obtained experimental results in order to define the elasto-plastic and damage behavior of the material; the goal is to match the numerical results with the experimental ones.

Chapter 5 shows the application, using 3D finite element model, of the characterized material using a pipeline to predict its mechanical behavior when it is submitted to an axial loading. 


\section{LITERATURE REVIEW}

Structural components suffer damage when the bond forces that keeps the atoms together are overcame by loads that are applied to the material [1], see Figure 5 . Fracture can be defined as the separation of a body into parts under the action of mechanical loads and as loss of continuity of a body [17]. Two important fracture modes are Brittle and Ductile, being the ductile fracture mode the topic of study in the present manuscript.

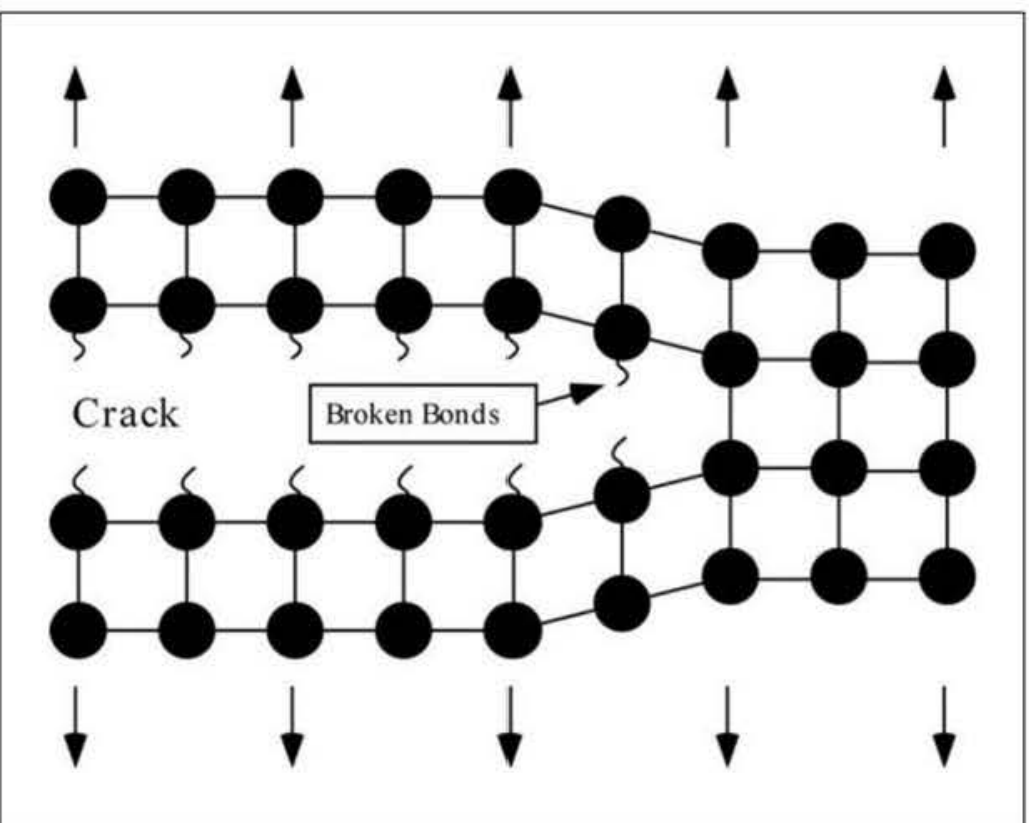

Figure 5 Model of bond forces being overloaded until its breaking by an external load applying on atoms of a material, [1]

In brittle fracture, failure is presented in the material when it still has an elastic behavior without showing a plastic part. In this case it is possible to observe two steps in the failure, the crack initiation, and its respective propagation. We can notice that brittle fracture occurs in a structure untimely with little or sometimes without deformation, and due to this fact the material reaches that failure point in a value which is below of the yield point of that material [18]. 
Ductile failure in a structure is defined as a loss of stiffness due to nucleation, growth and the coalescence of voids that are in the material, which create a crack that is able to propagate according with the load level until it separates a part of the main structure, [19]. It could be produced for different reasons such as chemical changes, temperature or like in this study mechanical loading. In Figure 6 is shown the difference between the brittle and ductile failure.

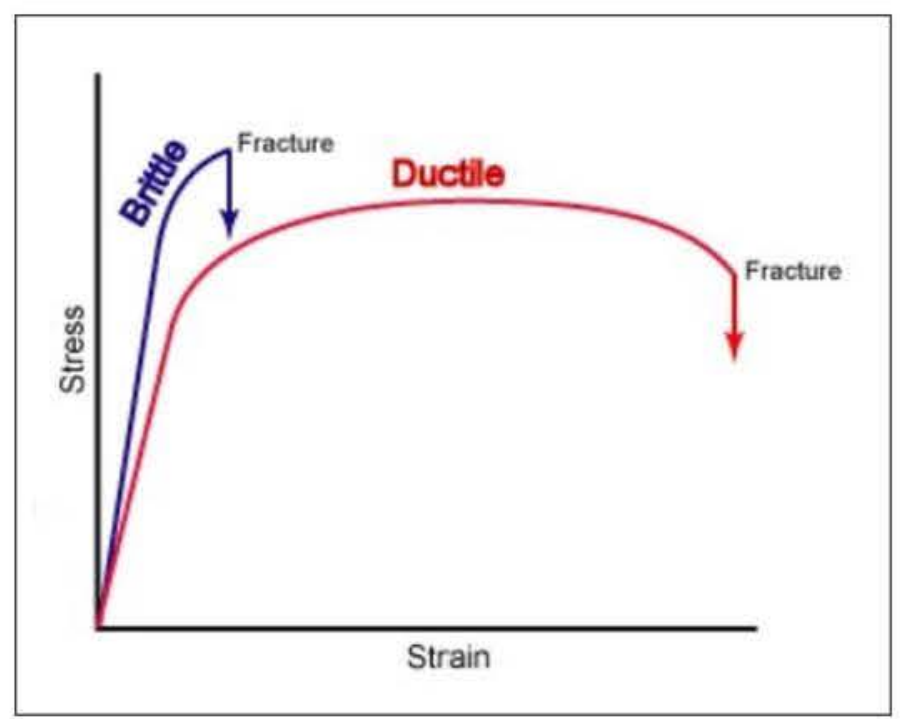

Figure 6 Engineering Stress-Strain curve for both Brittle and Ductile material (Source: https://sites.google.com/site/polymorphismmyhomepage/investigating-material-failures)

\subsection{STATE OF ART OF DUCTILE DAMAGE MODELING}

Let us make a brief review of ductile damage models proposed during the last decades. Detailed explanations can be found in Saxena [20], Anderson [1], and Ochsner [21]. There are three types of approaches for ductile rupture:

1. Continuum models

2. Damage models

3. Fracture mechanics models 
These approaches are illustrated in Figure 7. First, under continuum assumption of material, i.e. there are no voids and microcracks in the material; the methodology consists on defining a global criterion of failure at each material point as a function of stress fields. A function $F$ is defined in terms of stress state to predict the initiation of plastic flow:

$$
F=f\left(\sigma_{i j}, q\right)
$$

Where, $\sigma_{i j}$ is the stress tensor and $q$ is the vector of hardening variables.

Considering that Eq. ( 1 ) can be split in two functions that depend on stress components and material properties, the next simplification is obtained:

$$
F\left(\sigma_{i j}, q\right)=f\left(\sigma_{i j}\right)-k\left(\overline{\varepsilon_{p}}\right)
$$

Here $k\left(\overline{\varepsilon_{p}}\right)$ provides the material strength as function of the equivalent plastic strain, which gives a measure of the amount of permanent strain in an engineering body and should be obtained by experimental tests. It is considered that material "fails", by reaching the plastic regime, when Eq. ( 2 ) is equal to zero:

$$
F\left(\sigma_{i j}, q\right)=f\left(\sigma_{i j}\right)-k\left(\overline{\varepsilon_{p}}\right)=0
$$

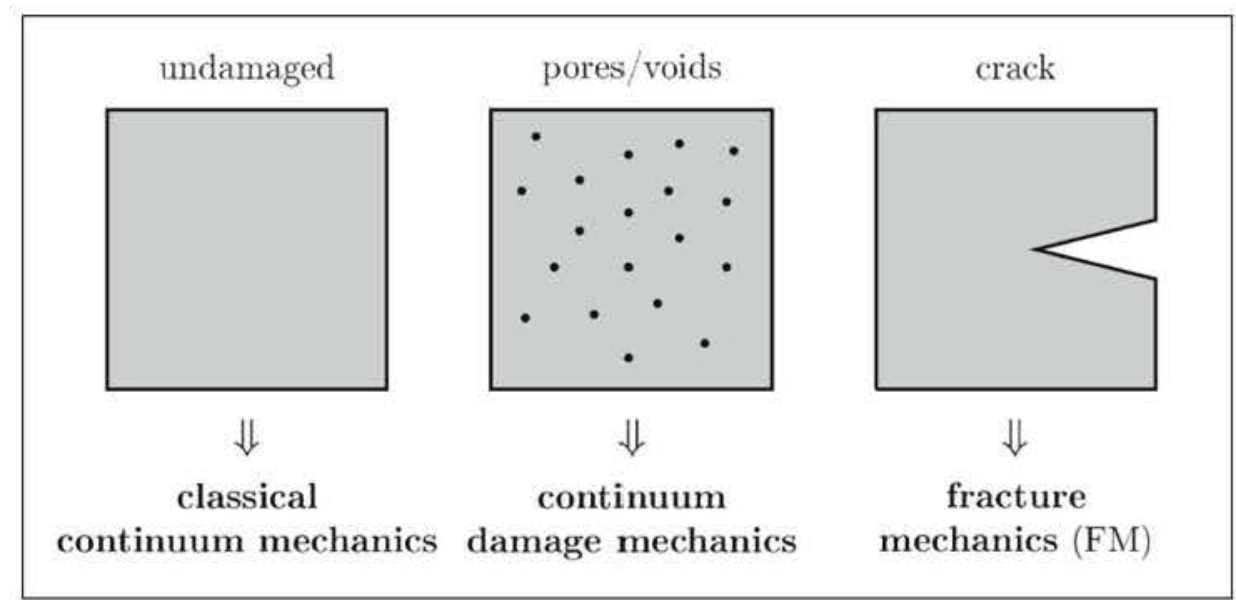

Figure 7 Different approaches for modeling ductile failure [21] 
Under the category "continuum models" of failures can be cited the maximum principal stress criterion, maximum principal strain criterion, and the maximum strain energy criterion. All these models predict failure as soon as the chosen variable reaches a critical value. Failure of the material is based upon information taken from the strain or stress tensor.

Now, let us describe the damage models in a brief manner. The continuum damage models can be separated into two branches: uncoupled and coupled. For uncoupled models the yielding condition, flow rule ${ }^{5}$ and hardening rule ${ }^{6}$ are not depended on the damage parameter. Examples of uncoupled models are the Modified Mohr-Coulomb (MMC) model [6], and Stress-Modified Critical Strain (SMCS) proposed by Mackenzie et al. [22] and Hancock \& Cowling [23]. The name SMCS has already been used in the work of Panontin and Sheppard [24] $]^{7}$. On the other hand, coupled damage models have in their incremental formulation a strong dependence on the variable used to measure the level of damage, like the Gurson and Lemaitre damage models [16], [25].

Let us look at the formulation of the Gurson and SMCS models because they are the most common methodologies for studying ductile fracture.

Gurson-Tvergaard-Needleman (GTN), is a constitutive equation that model the void nucleation, growth, and coalescence. It was presented by Gurson, after some studies about the correlation between porous and the resistance of materials. These equations were modified later by Tvergaard who includes the yield condition and damage evolution. Finally, Needleman included the void nucleation to have an equation which represents all ductile failure process, [15], [16], [26].

This equation is expressed as follow:

$$
\Phi=\left(\frac{\sigma_{\mathrm{e}}}{\bar{\sigma}}\right)^{2}+2 q_{1} f^{*} \cdot \cosh \left(\frac{3 q_{2} \sigma_{m}}{2 \bar{\sigma}}\right)-1-q_{3} f^{* 2}
$$

\footnotetext{
${ }^{5}$ The flow rule serves as a mathematical description of the evolution of the infinitesimal increments of the plastic strain in the course of the load history of the body.

${ }^{6}$ The hardening law allows the consideration of the influence of material hardening on the yield condition and the flow rule.

${ }^{7}$ It is not clear what group or researchers coined the term SMCS. The earliest citation found was the work of Panontin and Sheppard.
} 
Where:

$$
\begin{array}{ll}
\sigma_{\mathrm{e}} & : \text { Von Mises stress } \\
\sigma_{m} & : \text { hydrostatic stress } \\
& \\
\bar{\sigma} & : \text { yield stress on the matrix } \\
f^{*} & : \text { current void fraction }
\end{array}
$$

And $q_{1}=1.5, q_{2}=1.0, q_{3}=q_{1}^{2}$, that are the values typically used for metals.

The GTN model assumes that voids are spherical in materials and remain spherical in the growth process. Nucleation of voids from large inclusions generally occurs at relatively low stress levels, and therefore, voids are often assumed to be present in the material at the onset of loading.

Stress-Modified Critical Strain (SMCS) is a damage model which considers that material failure takes place when the equivalent plastic strain $\left(\bar{\varepsilon}_{P}\right)$ attains a critical value $\varepsilon_{P}^{c r i t}$. This critical strain $\varepsilon_{P}^{\text {crit }}$ is function of the stress triaxiality $(\eta)$ in the following form, [27]:

$$
\varepsilon_{P}^{c r i t}=\alpha \exp \left(\beta \frac{\sigma_{m}}{\sigma_{e}}\right)
$$

Where:

$$
\begin{array}{ll}
\varepsilon_{P}^{\text {crit }} & : \text { is the critical value of equivalent plastic strain } \\
\frac{\sigma_{m}}{\sigma_{e}} & : \text { is the stress triaxiality }(\eta) \\
\alpha, \beta & : \text { are material dependent constants } \\
\sigma_{m} & : \text { is the hydrostatic stress } \\
\sigma_{e} & : \text { is the von Mises equivalent stress }
\end{array}
$$


The SMSC criteria was proposed by Mackenzie [22] and Hancock \& Cowling [23] based upon experimental studies of notched tensile specimens. The SMCS approach is used in the present research to study load carrying capacity of critical structures made of ASTM A285 steel. As explained, this micromechanical model can predict in a reliable way the onset of a fracture in a ductile material. An additional modification is incorporated to include the propagation phase using post-softening criteria available in Abaqus software. Paredes et al. [11] have applied successfully this post-softening technique to predict ductile behavior for typical steel alloy TC128 commonly used in railroad tank car manufacturing.

\subsection{METHODOLOGY}

Two main mechanisms can cause the fracture of a ductile metal: ductile fracture due to the nucleation, growth, and coalescence of voids; and shear fracture due to shear band localization [28]. Based on phenomenological observations, these two mechanisms call for different forms of the criteria for the onset of damage, [29]. The following explanation, about the numerical implementation of the SMCS, has been taken from Abaqus manual.

\subsubsection{Ductile criterion}

The ductile criterion is a phenomenological model for predicting the onset of damage due to nucleation, growth, and coalescence of voids. The model, shown by Eq. ( 6 ), assumes that the equivalent plastic strain at the onset of damage, $\varepsilon_{P}^{c r i t}$, is a function of triaxiality stress and strain rate:

$$
\varepsilon_{P}^{c r i t}=f\left(\eta, \dot{\bar{\varepsilon}}^{p l}\right)
$$


Where, $\eta=\frac{\sigma_{m}}{\sigma_{e}}$ is the stress triaxiality, $\sigma_{m}$ is the hydrostatic stress, $\sigma_{e}$ is the Von Mises equivalent stress, and $\dot{\bar{\varepsilon}}^{p l}$ is the equivalent plastic strain rate. The criterion for damage initiation is met when the following condition is satisfied:

$$
\omega_{D}=\int \frac{d \bar{\varepsilon}^{p l}}{\varepsilon_{P}^{c r i t}\left(\eta, \dot{\bar{\varepsilon}}^{p l}\right)}=1
$$

Where, $\omega_{D}$ is a state variable that increases monotonically with plastic deformation. At each increment during the analysis the incremental growth in $\omega_{D}$ is computed as:

$$
\Delta \omega_{D}=\frac{\Delta \bar{\varepsilon}^{p l}}{\varepsilon_{P}^{c r i t}\left(\eta, \dot{\varepsilon}^{p l}\right)} \geq 0
$$

The damage evolution law defines the rate of degradation of the material strength once the corresponding initiation criterion has been reached. At any given time during the analysis the stress tensor in the material is given by the scalar damage equation assuming isotropic evolution of damage. Defects are equally distributed in all direction:

$$
\sigma=(1-D) \cdot \bar{\sigma}
$$

Where, $D$ is the overall damage variable and $\bar{\sigma}$ is the effective (or undamaged) stress tensor computed in the current increment. $\bar{\sigma}$ are the stresses that would exist in the material in the absence of damage. The material has lost its load-carrying capacity when $D=1$. By default, an element is removed from the mesh if all section points at any one integration location have lost their load-carrying capacity. 
Figure 8 illustrates the characteristic stress-strain behavior of a material undergoing damage. In the context of an elastic-plastic material with isotropic hardening, the damage manifests itself in two forms: softening of the yield stress and degradation of the elasticity, i.e. $\bar{E}=(1-D) E$. The solid curve in the figure represents the damaged stress-strain response, while the dashed curve is the response in the absence of damage.

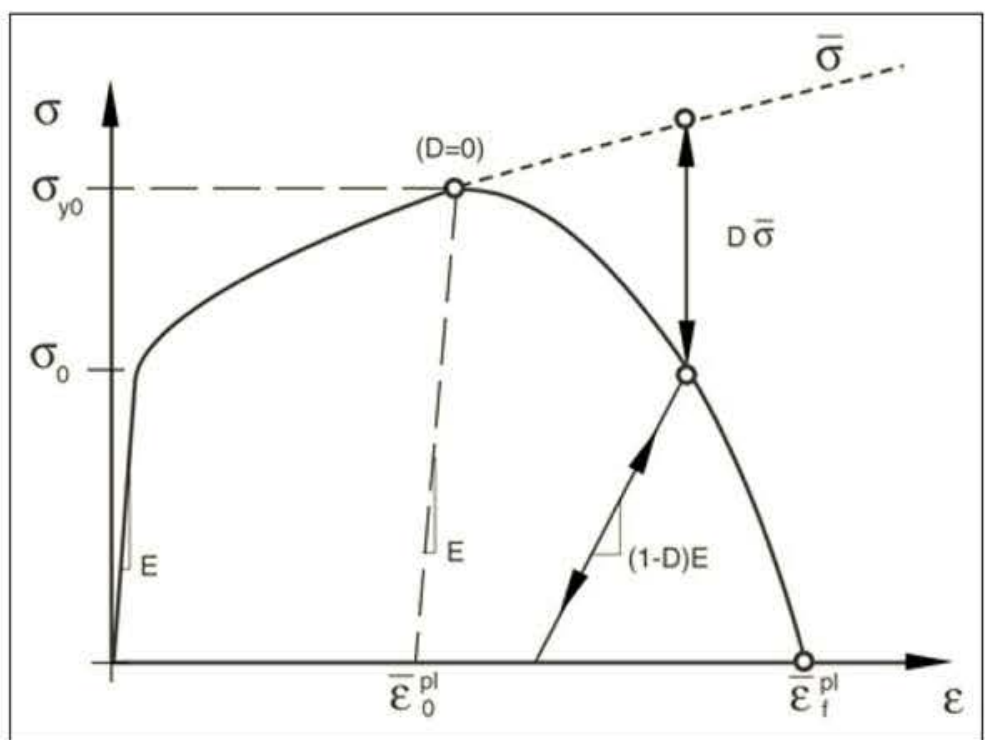

Figure 8 Stress-strain curve with progressive damage degradation, [28]

In Figure $8 \sigma_{y 0}$ and $\bar{\varepsilon}_{0}^{p l}$ are the yield stress and equivalent plastic strain at the onset of damage, and $\bar{\varepsilon}_{f}^{p l}$ is the equivalent plastic strain at failure; that is, when the overall damage variable reaches the unitary value $(D=1)$. In the case of strain, the hypothesis of strain equivalence is applied which states that the strain behavior of a damaged material is represented by the virgin material. The next chapter describes the experimental tests carried out during this study. 


\section{EXPERIMENTAL CAMPAIGN}

The objectives of the experimental tests are to identify the plasticity and damage parameters by a series of mechanical tests of different specimens which have different stress triaxiality levels. The current experimental results aim to identify the parameters of phenomenological SMCS damage model.

\subsection{TESTED SPECIMENS}

All specimens have been machined from a flat plate made from ASTM A285 steel. Two types of specimens had been tested: tensile bars and single edge bending (SEB) specimens. The tensile bars are cylindrical having smooth and notched sections. The smooth specimens were machined in accordance with ASTM E08 standard [30] and the notched specimens, whose geometries will be shown in the next subsections, following previous reported work presented by Kim et al. [31]. The bending specimens were machined with two different notched depth following the ASTM E1820 standard, [32]. A detailed description for each tested specimen is given in the next section.

\subsubsection{Smooth tensile specimen}

These specimens were machined in both directions, transversal and longitudinal, of the plate and were tested 2 specimens in each direction. In total 4 curves were obtained, which let us know the classical engineering curve of the material. The main dimensions of this specimen are shown in Figure 9.

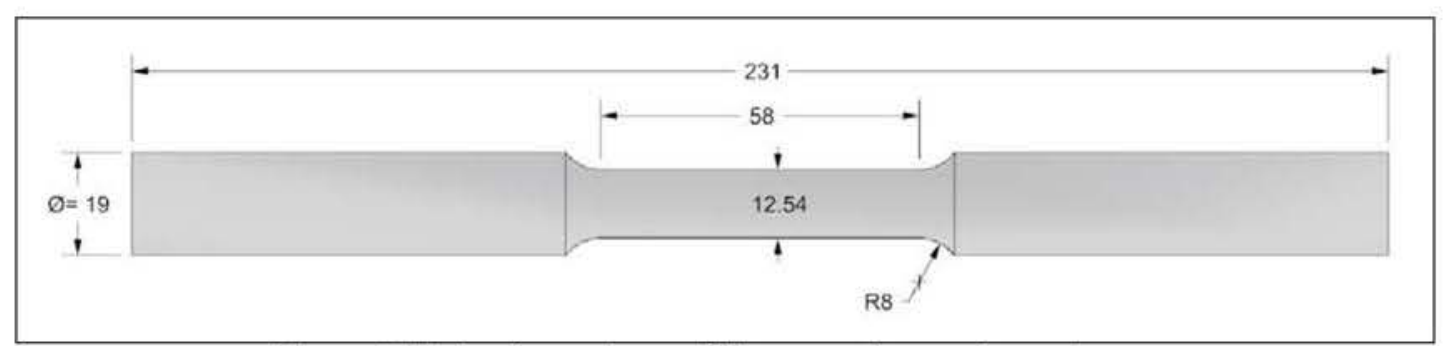

Figure 9 Main dimensions of the smooth specimen, in $\mathrm{mm}$. 


\subsubsection{Notched specimen}

These specimens were made to observe the influence of a notch in the response of the Stress-Strain curve, and to get the relationship between the stress triaxiality and the critical strain to fracture which is going to be used to calibrate the SMCS model. Depending on the notch size, 3 different type of notched specimen were obtained:

i. R1 notched specimen, with a notch radius of $1 \mathrm{~mm}$ at the center of bar.

ii. R2 notched specimen, with has a notch radius of $2 \mathrm{~mm}$ at the center of bar.

iii. R3 notched specimen, with has a notch radius of $3 \mathrm{~mm}$ at the center of bar.

Each type of notched specimen presented 1 transversal and 1 longitudinal to roll direction version.

In these specimens it is needed to notice that only was machined one specimen per each direction; however, once the test was made at the same conditions, the results obtained for each direction in the same specimen were not very different from each other. Also, in all cases the middle cross section material is the same, so, the only different dimension is the radius as it was previously mentioned. The main dimensions of those specimens are shown in Figure 10. 


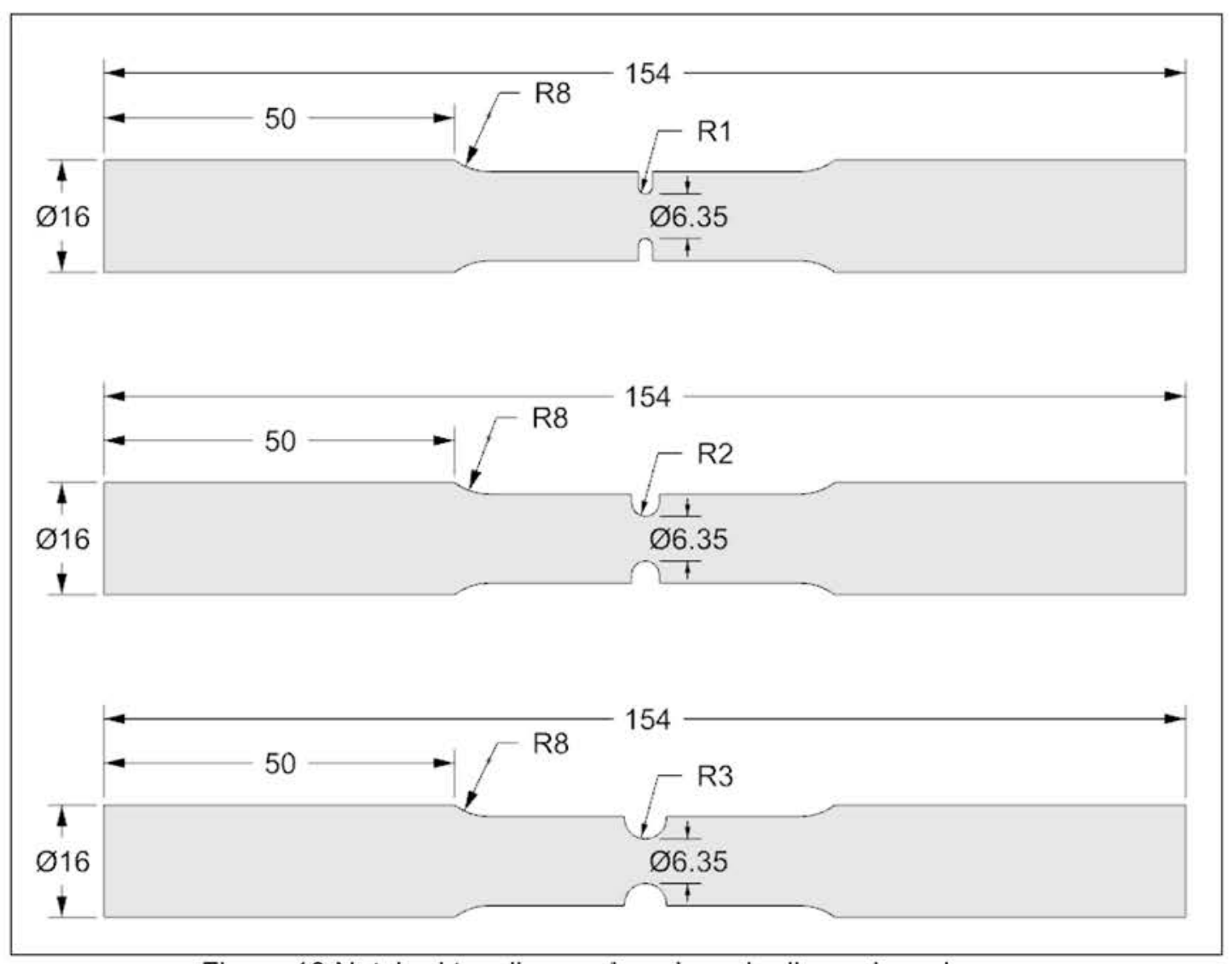

Figure 10 Notched tensile specimen's main dimensions, in $\mathrm{mm}$.

In summary there are 4 type of tensile bar specimen:

\begin{tabular}{|c|l|c|}
\hline Specimen & \multicolumn{1}{|c|}{ Type } & Material \\
\hline $\mathrm{Sp} 0$ & Smooth & \\
\cline { 1 - 2 } $\mathrm{Sp} 1$ & Notch, radius $\mathrm{R}=1 \mathrm{~mm}$ & \multirow{2}{*}{ Steel A285 } \\
\cline { 1 - 2 } $\mathrm{Sp} 2$ & Notch, radius $\mathrm{R}=2 \mathrm{~mm}$ & \\
\cline { 1 - 2 } $\mathrm{Sp} \mathrm{3}$ & Notch, radius $\mathrm{R}=3 \mathrm{~mm}$ & \\
\hline
\end{tabular}

Table 1 Description of tensile bar specimen used

Once, these specimens were machined, they are as we can see in Figure 11: 


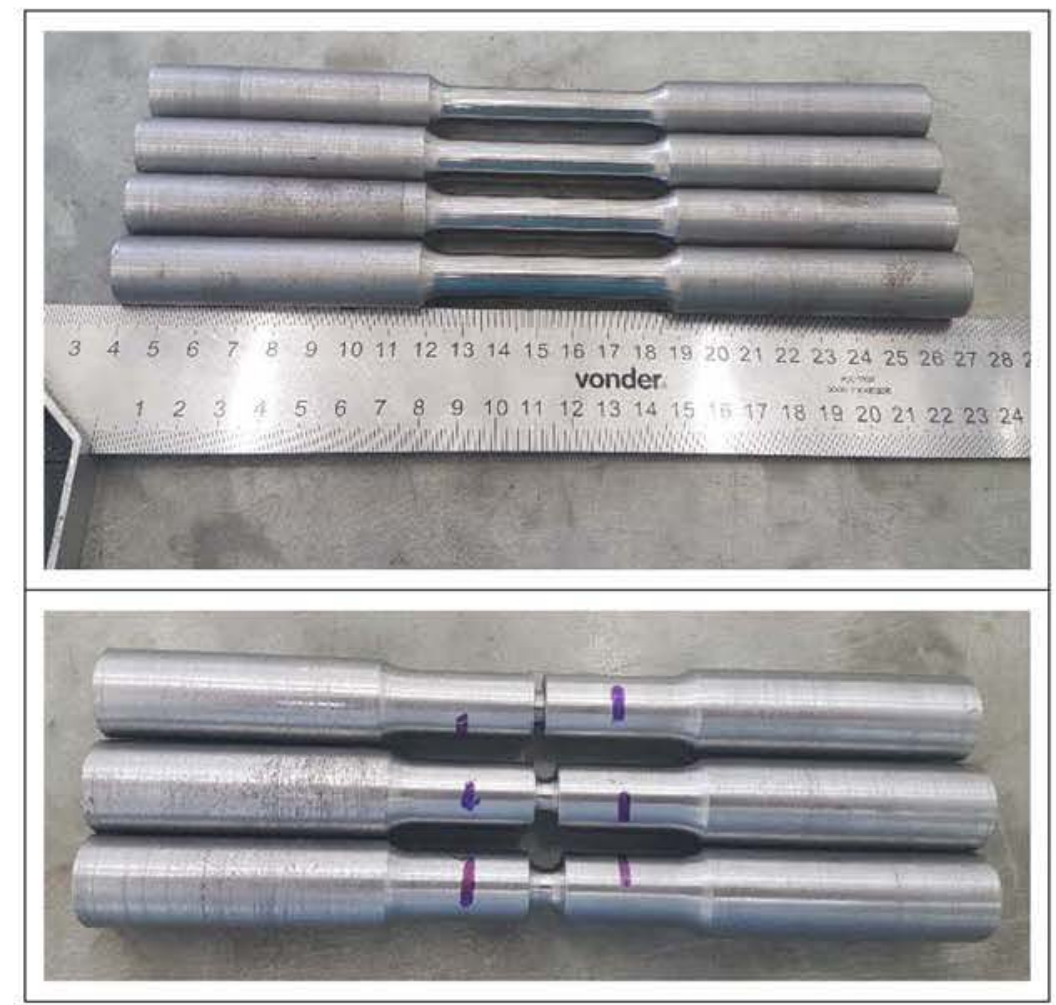

Figure 11 Machined testing specimens; a) Smooth specimens: 2 laterals, 2 transversals; b) Notched specimens: $R 1=1 \mathrm{~mm}, \mathrm{R} 2=2 \mathrm{~mm}, \mathrm{R} 3=3 \mathrm{~mm}$.

\subsubsection{Single Edge Bend (SEB) specimen}

SEB specimens were machined with two different dimensions of initial notch, in order to have specimens with different levels of stress triaxiality. In the same form as the tensile specimens, these specimens were machined in both rolling directions. In detail we have:

i) SEB - Shallow Crack Specimen (SEB-TR). - this specimen was tested in two conditions, with side grooves (SEB-TR-SG) and without side grooves (SEBTR-NSG), where the side groove is a v-shaped notch made at the sides of the specimen to facilitate the propagation of the crack once it has started and produce a plane crack front [33]. A schema of the SEB specimen is shown in Figure 12 and the main dimensions of both types are shown in Table 2. 


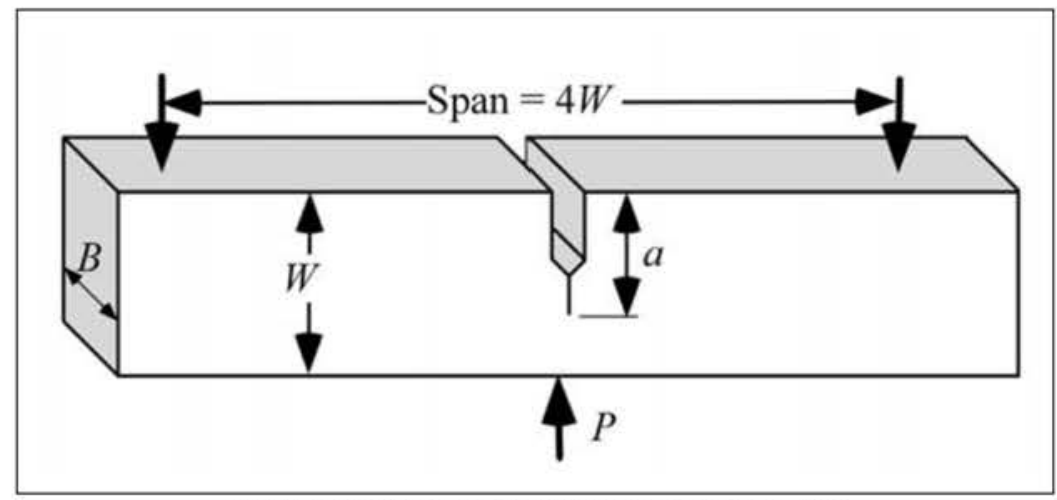

Figure 12 Scheme of SEB specimen, [1]

Table 2 Shallow crack specimen with and without side groove dimensions, in $\mathrm{mm}$.

\begin{tabular}{|c|c|}
\hline$W[\mathrm{~mm}]$ & 19,0 \\
\hline$B$ [mm] & 19,0 \\
\hline$a[\mathrm{~mm}]$ & 3,8 \\
\hline
\end{tabular}

ii) SEB - Deep Crack Specimen (SEB-TP-SG). - this type of specimen was machined only with side grooved and its main dimensions, using the same schema of Figure 12, are shown in Table 3.

Table 3 SEB - Deep Crack Specimen with side groove dimensions, in $\mathrm{mm}$.

\begin{tabular}{|l|r|}
\hline$W[\mathrm{~mm}]$ & 19,0 \\
\hline$B$ [mm] & 19,0 \\
\hline$a[\mathrm{~mm}]$ & 9,7 \\
\hline
\end{tabular}

These specimens are used to calibrate and check if the characterized curve is able to model ductile fracture in the analyzed material.

\subsection{EXPERIMENTAL TESTS}

After specimens had been machined, three different experimental tests were carried out and with them were obtained curves which show the response of stress-strain of the material due to an applied load and some other representatives values according to the specimen type. All laboratory tests were carried out under ambient temperature and under computer control using a Universal Servo-Hydraulic test system whose maximum force capacity is $2.50 \mathrm{MN}$ and shown in Figure 13. 


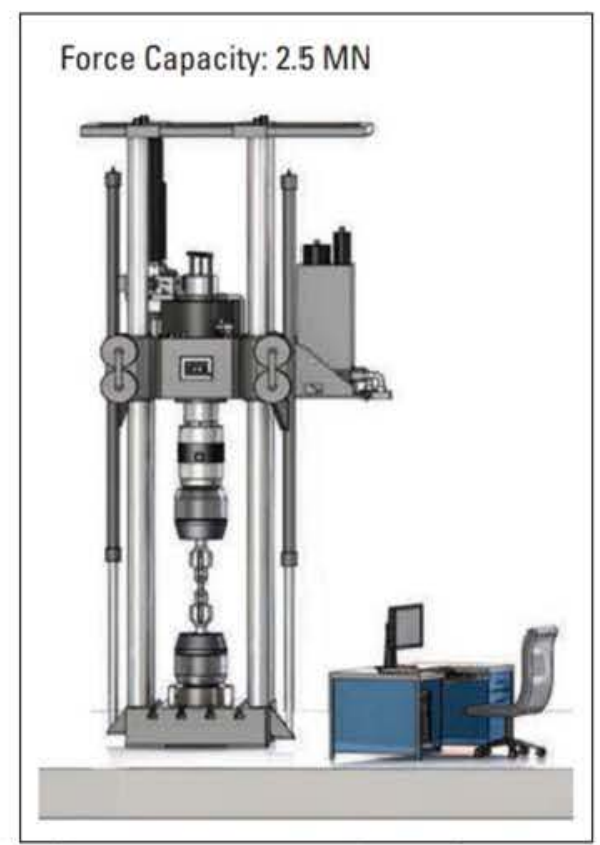

Figure 13 Universal Servo-Hydraulic test system, maximum force capacity is $2.50 \mathrm{MN}$, Source: MTS's Manual

The tests and their respective results, considering the type of load, were performed in the order represented by the sections 3.2.1 and 3.2.2.

\subsubsection{Tensile load testing}

For these specimens samples were tested applying a load in a parallel direction to the vector that define the area of the cross section, always monitoring the load and the strain applied on the specimen by the body. To get those values, the computer directly obtained the load and the strain using two steps for the smooth specimens and using only one step for notched one, as is described below:

i. For the smooth specimens the first part was obtained using an "Extensometer" (maximum capacity $\varepsilon=0.20 \frac{\mathrm{mm}}{\mathrm{mm}}$, and initial separation $L_{0}=$ $25 \mathrm{~mm}$ ) until it reaches a maximum strain of $\varepsilon=0.02 \frac{\mathrm{mm}}{\mathrm{mm}}$. These data are shown at the left of the " $1^{\circ}-2^{\circ}$ step separator" in the Figure $15 a$.

ii. For the final part of the data of smooth specimen was used the measurement given by the hydraulic supports of the machine directly, until the fracture occurs. These data are shown at the right side of the " $1^{\circ}-2^{\circ}$ step separator" in the Figure 15a. 
iii. And for the notched specimens, data was obtained only using the extensometer, from the beginning of the test until the final fracture of the specimen.

Figure 14 depicts one smooth specimen mounted on the MTS machine.

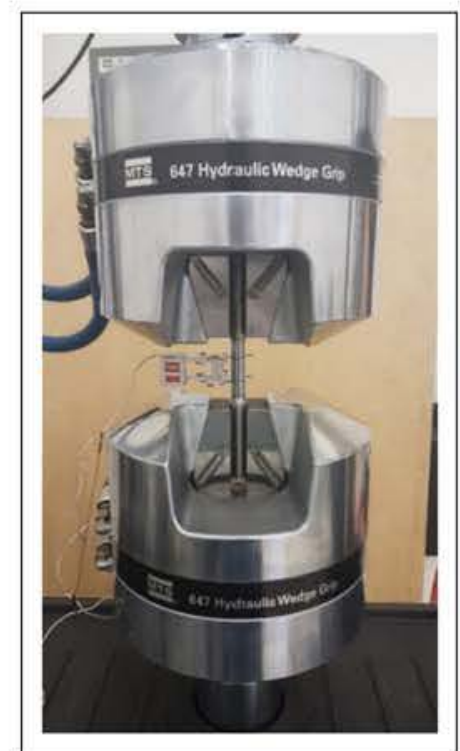

Figure 14 Servo-Hydraulic test system, extensometer and tensile test smooth specimen mounted to be tested

In total, 10 tensile tests were performed, however only 9 final experimental data were used due to one of the notched tensile bar results (R1_CP1) was tested with a high strain rate, which invalidated the data. Finally, 9 experimental results were obtained, and their respective stress-strain curves are shown in Table 4 and Figure 15 respectively:

Table 4 Tensile type laboratory tests

\begin{tabular}{|c|c|c|c|}
\hline Specimen & Type & Direction & Name of the curve \\
\hline Sp 0-1 & \multirow{4}{*}{ Smooth tensile bar } & Longitudinal & CP_L1 \\
\hline Sp 0-2 & & Longitudinal & CP_L2 \\
\hline Sp 0-3 & & Transversal & CP_T1 \\
\hline Sp 0-4 & & Transversal & CP_T2 \\
\hline Sp 1-1 & \multirow{2}{*}{$\begin{array}{c}\text { Notched tensile bar } \\
\mathrm{R}=1 \mathrm{~mm}\end{array}$} & Longitudinal & R1_CP1 (Excluded) \\
\hline Sp 1-2 & & Transversal & R1_CP2 \\
\hline Sp 2-1 & \multirow{2}{*}{$\begin{array}{c}\text { Notched tensile bar } \\
\mathrm{R}=2 \mathrm{~mm}\end{array}$} & Longitudinal & R2_CP1 \\
\hline Sp 2-2 & & Transversal & R2_CP2 \\
\hline Sp 3-1 & \multirow{2}{*}{$\begin{array}{c}\text { Notched tensile bar } \\
R=3 \mathrm{~mm}\end{array}$} & Longitudinal & R3_CP1 \\
\hline Sp 3-2 & & Transversal & R3_CP2 \\
\hline
\end{tabular}




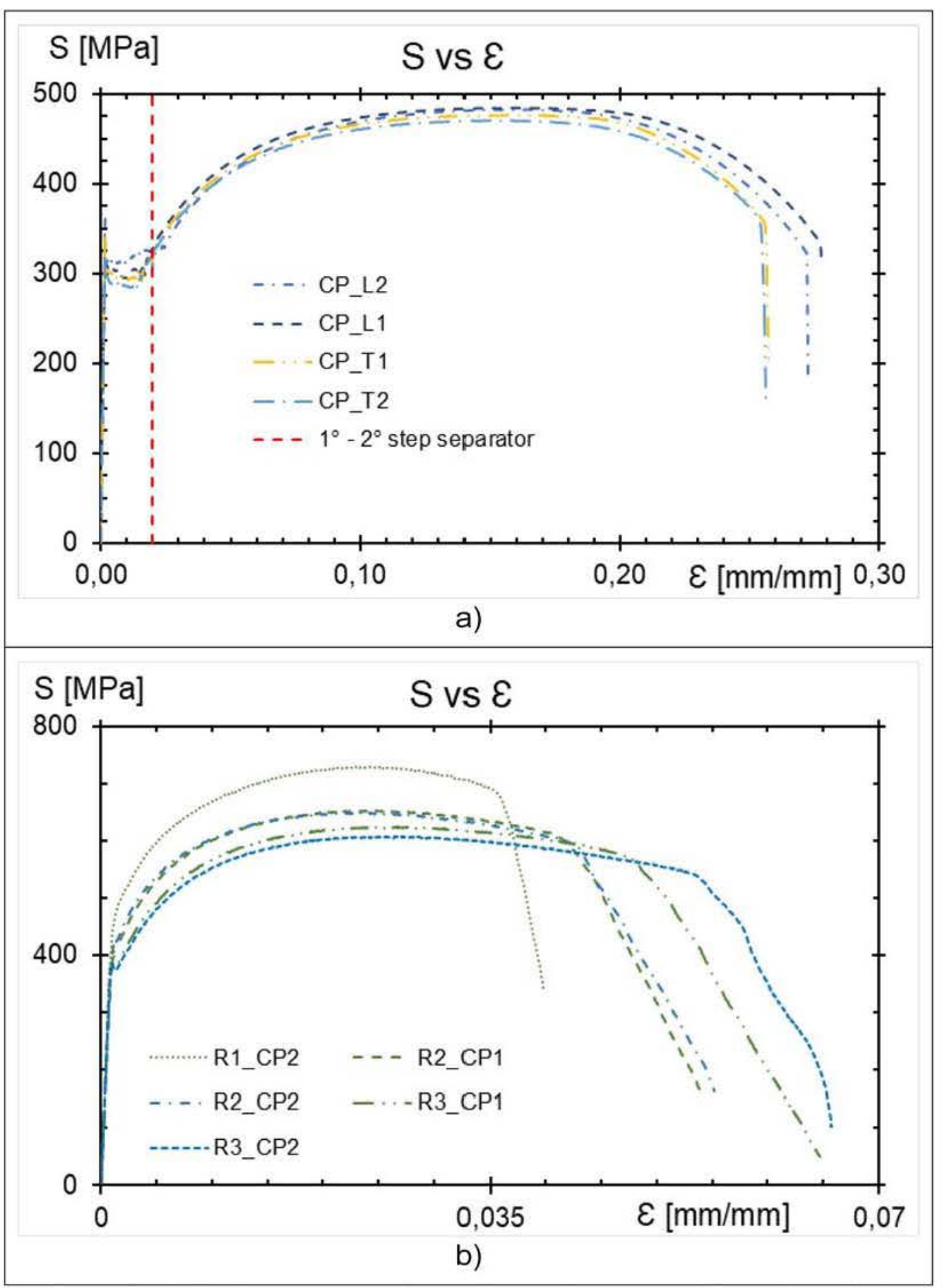

Figure 15 Stress-Strain Engineering curves for tensile specimen tests, a) Smooth tensile bar results, and, b) Notched tensile bar results.

As previously described, for the smooth specimen tests, data was obtained with both measurement methods: extensometer and the mobile part of the machine; and, for the notched specimen tests data all points were obtained with the extensometer, because the maximum strain value in all those tests are less than the maximum capacity of the measuring device. 
In order to get an idea of the difference between stress-strain levels between the tensile experimental tests, Figure 16 shows the tensile tests results with the same axis of strain. As can be seen the smooth specimen reaches higher levels of strain at the instant of failure when compared to the NRB specimens. On the other hand, the notched round specimens attain higher values of ultimate tensile strength than the smooth specimen. Moreover, the ultimate tensile strength increases with the reduction of notch radii of each specimen.

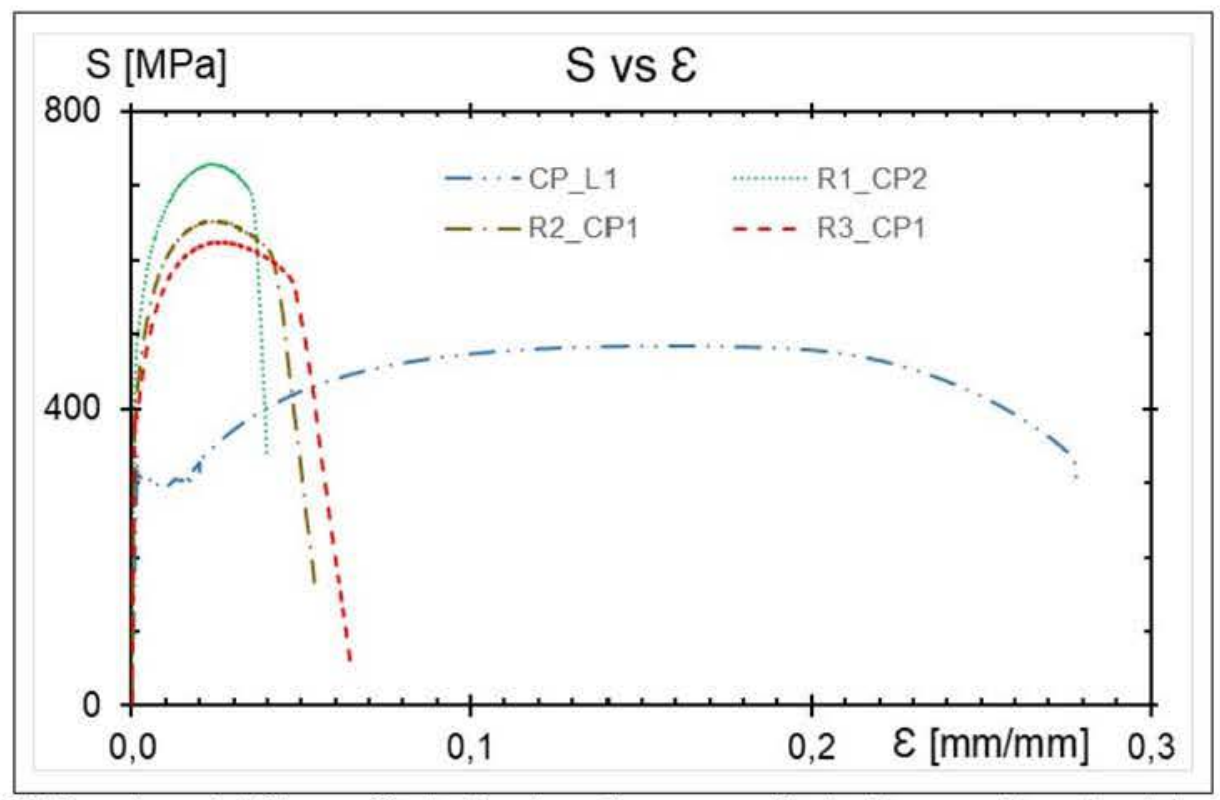

Figure 16 Experimental Stress-Strain Engineering curves for both, smooth and notched tensile specimen test

From the Smooth tests results, the first mechanical parameter of the material, the Young's Modulus was defined, and its mean value is $E=206791 \mathrm{MPa}$.

\subsubsection{Three-point bending test}

For the three-point bending tests were recorded the applied load, $P$, and the displacement at the mouth of the specimen, $C M O D$, using the same universal testing hydraulic machine used in the tensile tests adding some accessories to place the SEB specimens in the right position. Those accessories are: a base with two rigid cylinders which offer support to the specimens in two points separated $76 \mathrm{~mm}$, and a rigid coupling body with one cylinder in its extremity to apply the load at the midspan of the SEB specimen. 
To obtain the CMOD value, a "Clip gage" was used which has $3 \mathrm{~mm}$ and $6 \mathrm{~mm}$ as minimum and maximum opening capacity respectively. Total coupling system is shown in Figure 17.

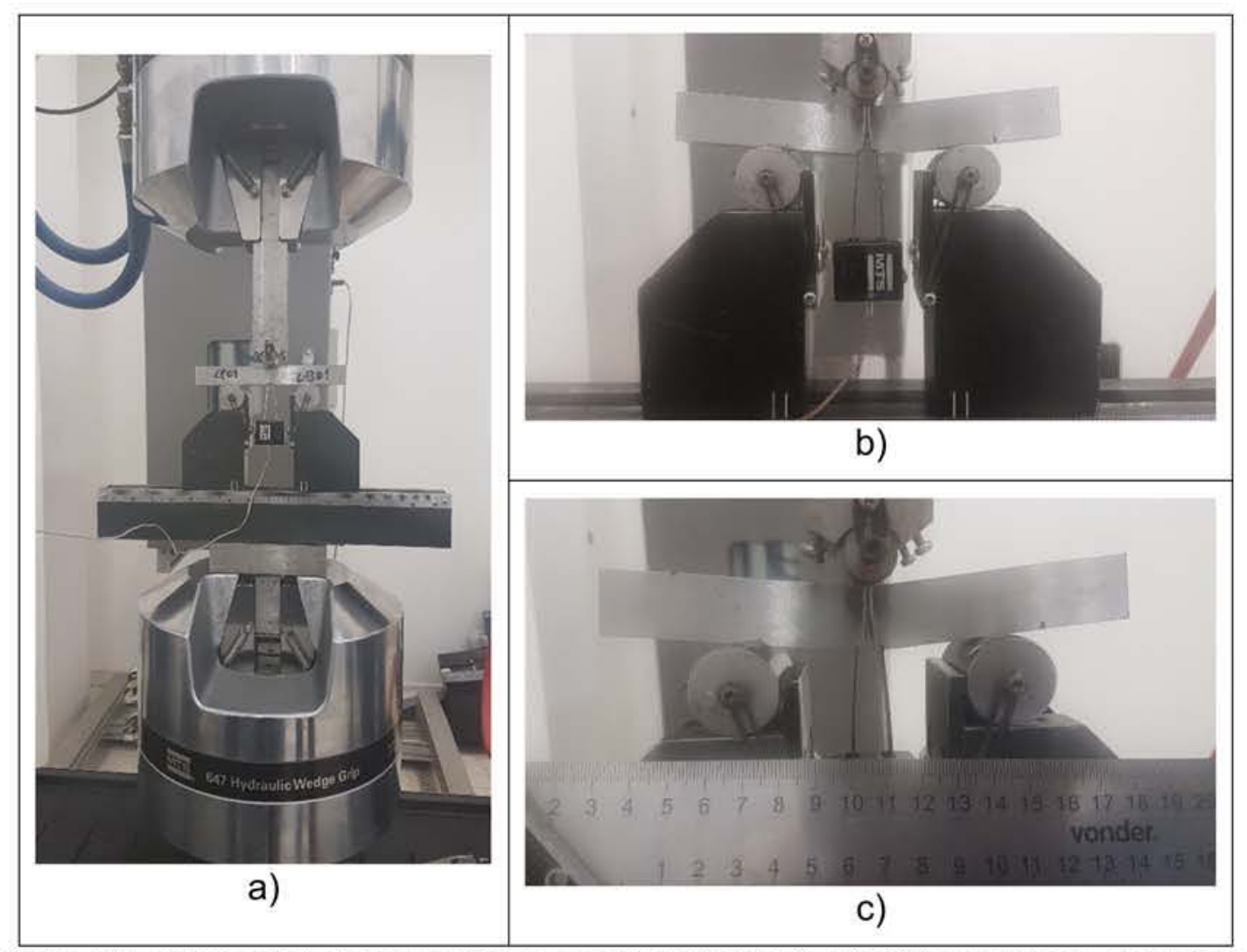

Figure 17 Load coupled system for Three-point bending tests with SEB specimen, a) total coupled system, b) local coupled system with the SEB specimen and the clip gage, and c) local coupled system with a reference dimension

Four types of SEB specimens were tested to measure the P-CMOD curves, which are described, with their respective curves in Table 5 and Figure 18:

Table 5 Type of SEB specimens tested

\begin{tabular}{|c|c|c|c|}
\hline Specimen & Type & Direction & Name of the curve \\
\hline SP 4-1 & SEB-TR-SG & Longitudinal & CP1_SEB_aw0202 \\
\hline SP 4-2 & SEB-TR-NSG & Longitudinal & CP2_SEB_aw0202 \\
\hline SP 5-1 & \multirow{2}{*}{ SEB-TP-SG } & Transversal & CP3_SEB_aw051 \\
\cline { 1 - 1 } \cline { 4 - 5 } SP 5-2 & & Longitudinal & CP4_SEB_aw051 \\
\hline
\end{tabular}




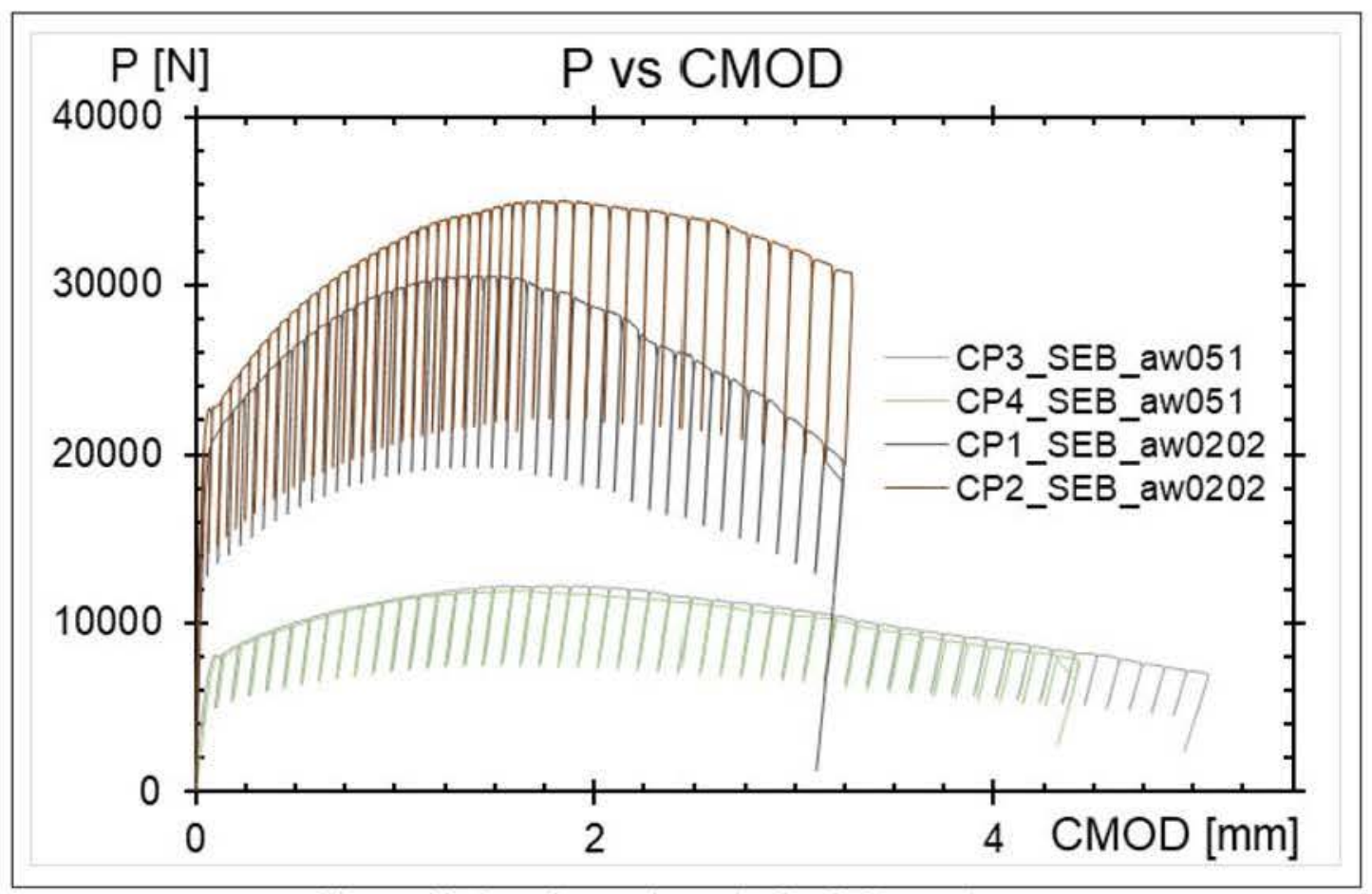

Figure 18 Experimental results for SEB specimens

In Table 5, the term "SEB-TR-SG" stands for Single Edge Bending (SEB) specimens having shallow crack and side groove; "SEB-TR-NSG" stands for SEB specimen which has a shallow crack and no side groove; and, "SEB-TP-SG" stands for SEB specimen having a deep crack and side groove.

Figure 18 reveals that the shallow cracked specimen requires more than 3 times of maximum applied load that the deeply cracked specimens. Regarding the deeply cracked specimens, Figure 18 shows the good similarity of the initial geometry of both tested specimen. The side groove effects can be seen in the shallow cracked specimen's curves by comparison of the maximum attained load. 


\subsection{GEOMETRIC MODELS}

Seven (7) different 3D models were built up in order to simulate the specimens, to match the specimens' dimension previously described. Those geometric models were designed using the ABAQUS program, and depending on the type of the specimens, symmetry planes were used to define the geometry.

\subsubsection{Tensile tests specimen (Smooth and notched specimens)}

They were modeled with their respective geometries and using three cutting planes: $X Y$ to cut the body longitudinally and vertically; $X Z$ to cut the body longitudinally and horizontally; and, $Y Z$ to cut the body at its cross section in the middle. A schematic sketch of the geometry employed for FE analysis is shown between the planes XY-XZYZ in Figure 19:

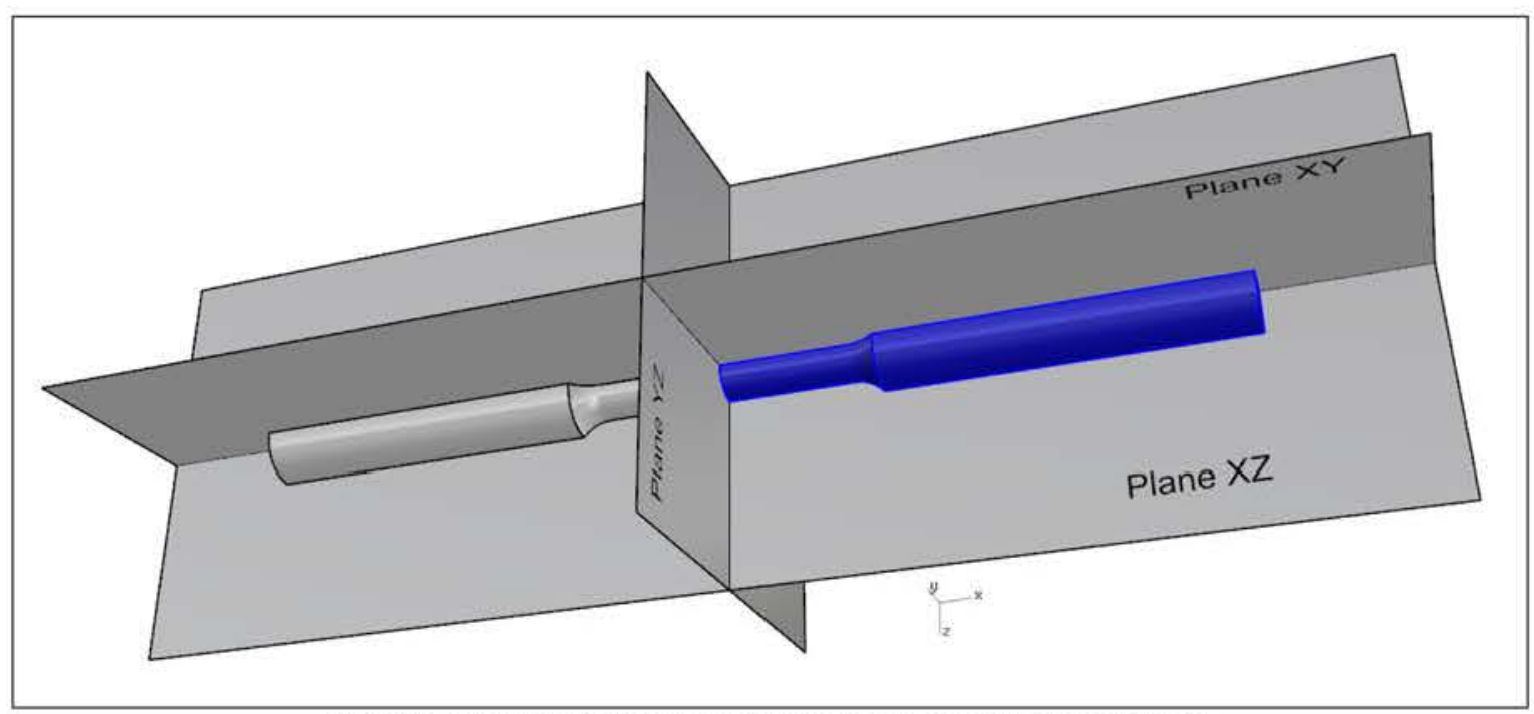

Figure 19 Tensile test specimen's schematic geometries

The gripping section of the specimen has been modelled in a simplified way as shown in Figure 20. That process results in only one eight of the total of each body. Final geometries are exposed in Figure 20. 


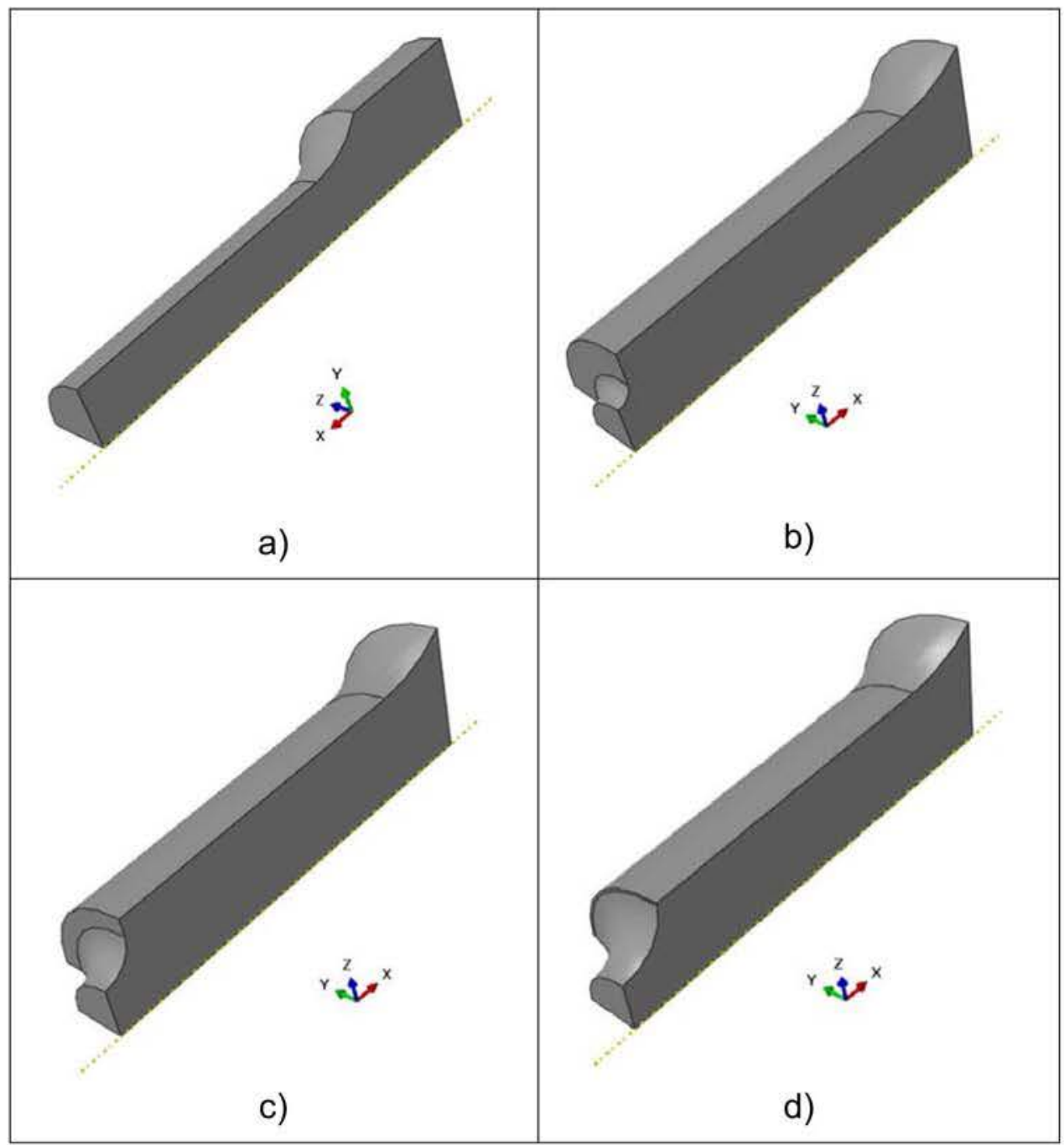

Figure 20 Tensile test specimen's geometries employed for FE analysis, a) smooth, b) R1, c) R2, and d) R3

\subsubsection{Three-point bend test geometries (SEB specimens)}

SEB specimen geometries were modeled using the total body and cutting them with only two planes: $X Y$ to cut the body longitudinally and vertically; and, $Y Z$ to cut the body at its cross section in the middle. For this type of models were added two cylinders to simulate the supports and one to add the load. The final schematic result of this process is shown in Figure 21. 


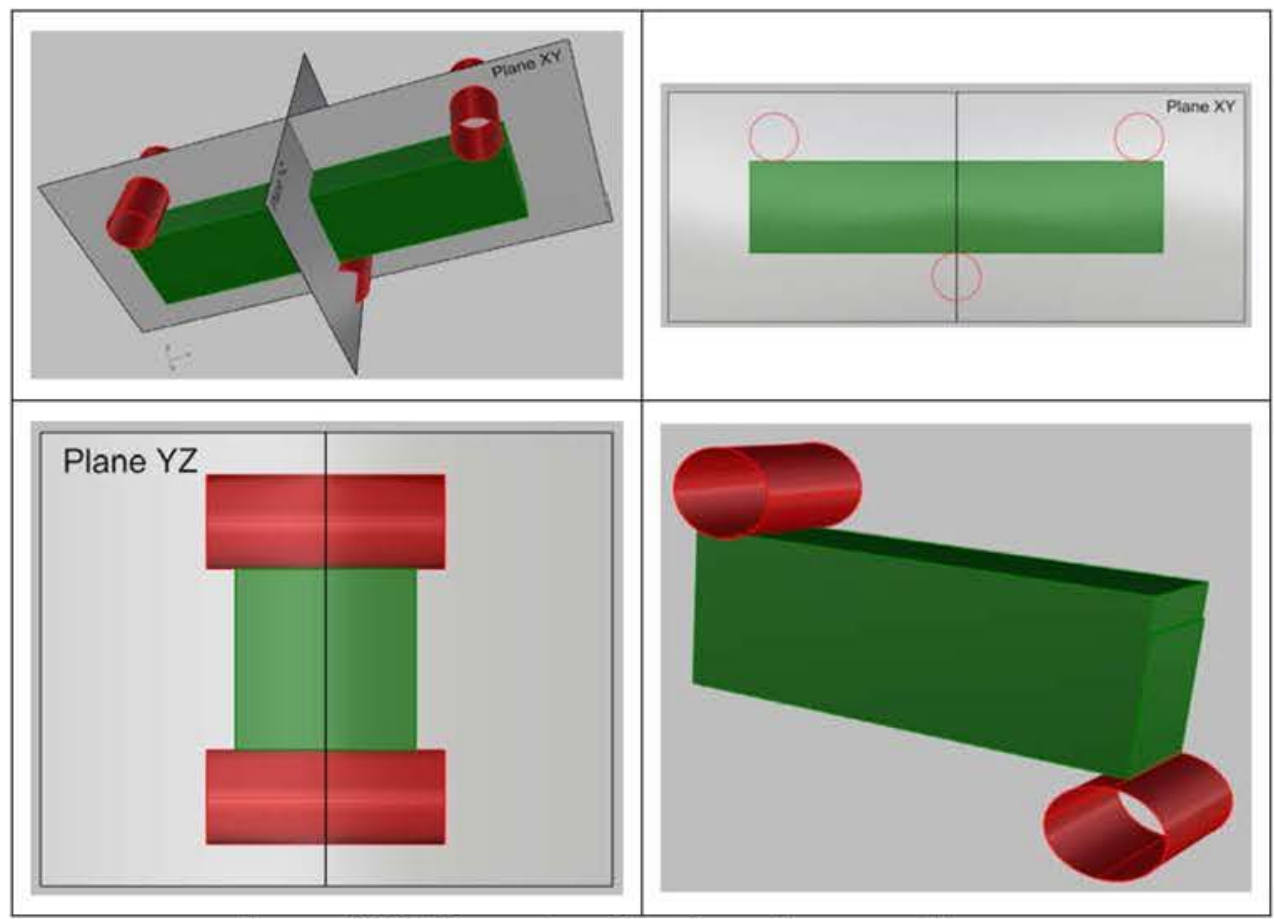

Figure 21 SEB specimen's schematic geometries

Finally, three geometries of SEB specimens were built, the shallow crack specimens with and without side grooves and the deep crack specimens with side grooves. The machined side grooves follow the recommendations of ASTM E1820-15, [32], with a total reduction of thickness equal to $15 \%$. These three final geometries, which represents only one fourth of the total body, are shown in Figure 22:

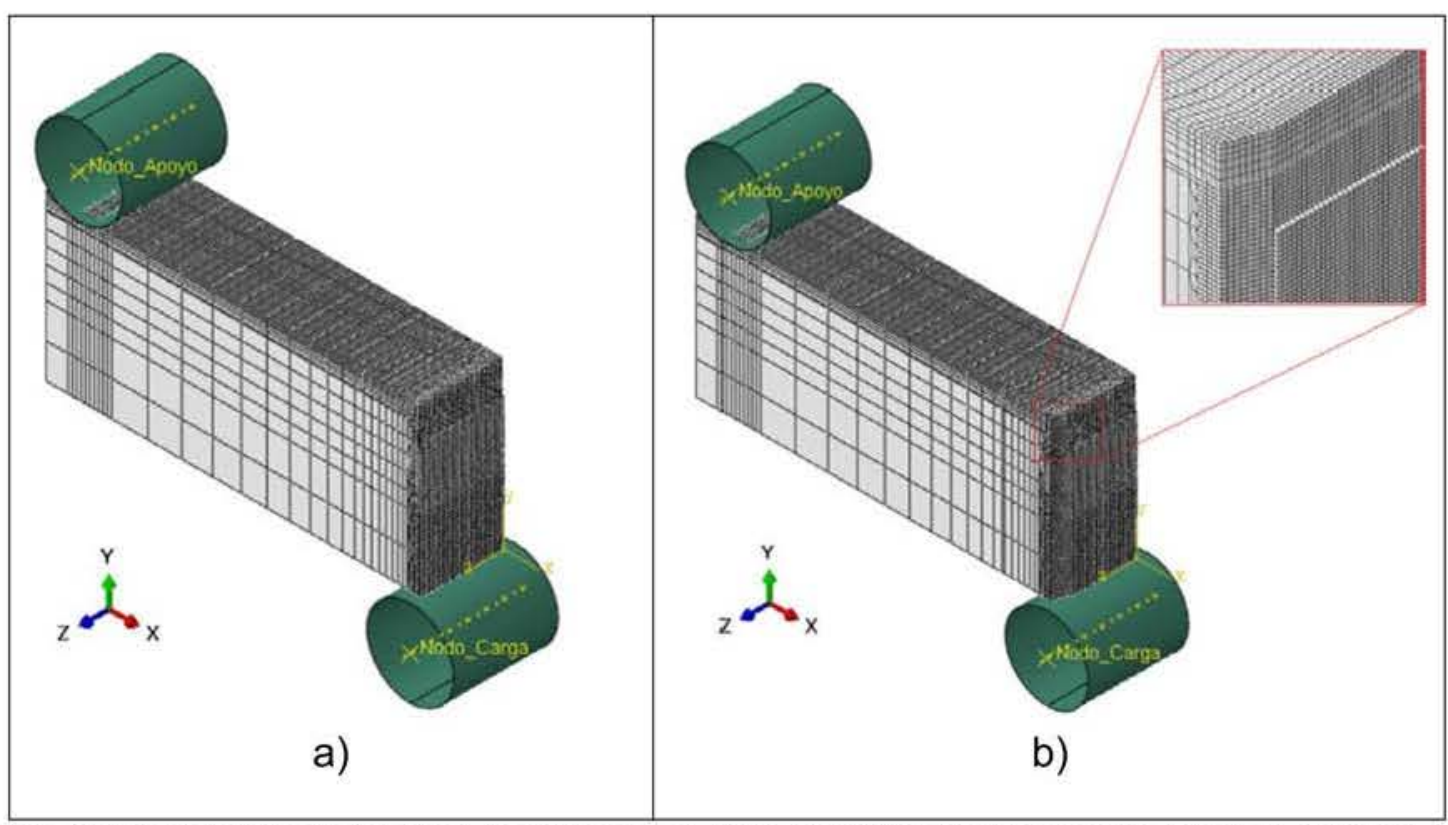

Figure 22 Geometries of the SEB specimens: a) SEB_TR without side groove, b) SEB_TR with side grooves 
For both shallow and deep crack SEB specimens with side grooved, this detail of the shape is modeled as a deletion of the material using an angle of $40^{\circ}$ and $t_{s g}=1.60 \mathrm{~mm}$ as a deep of the side groove, as seen a upper plane view of the specimen, in the Figure 23.

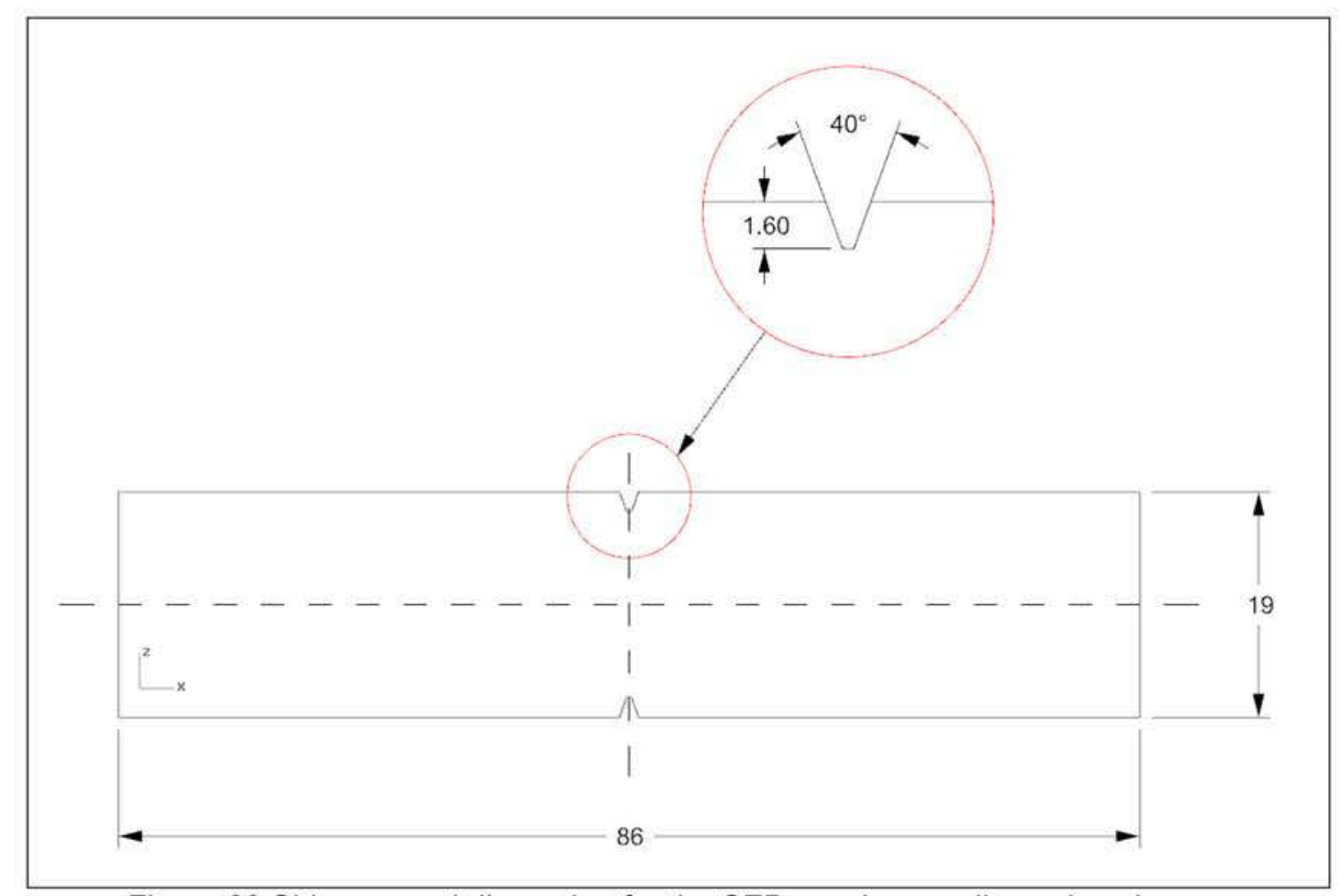

Figure 23 Side grooved dimension for the SEB specimens, dimensions in $\mathrm{mm}$.

\subsection{MATERIAL PROPERTIES}

Once geometric models have been built, it was necessary to define correctly the mechanical properties of the tested material. In this part the following properties must be described: Young's modulus, Poisson coefficient, and mass density, whose values are shown in Table 6.

Table 6 Elastic material properties for Steel A285

\begin{tabular}{|l|c|c|c|}
\hline \multicolumn{1}{|c|}{ Units } & {$\left[\mathrm{Kg} / \mathrm{mm}^{3}\right]$} & {$\left[\mathrm{N} / \mathrm{mm}^{2}\right]$} & {$[--]$} \\
\hline Material & Density & $\mathrm{E}$ & $\mathrm{V}$ \\
\hline Steel A285 & $7.8 \mathrm{E}-6$ & 206791 & 0.3 \\
\hline
\end{tabular}


About values shown in Table 6, the Young's modulus was obtained from the tested smooth specimens, and the Poisson coefficient and mass density was obtained from references tables with standard values for the A285 steel.

The chemical properties measured at room temperature where obtained from material extracted from three tested specimens and are shown in the Table 7. The complete measured chemical components of the material, obtained from a mass spectrometry, are shown in the Annex 7.1.

Table 7 Chemical properties for samples of the tested specimens

\begin{tabular}{|c|c|c|c|c|c|}
\hline Element & $\mathrm{C}$ & $\mathrm{P}$ & $\mathrm{Mn}$ & $\mathrm{Si}$ & $\mathrm{Al}$ \\
\hline SEB & 0,156 & 0,022 & 1,020 & 0,219 & 0,041 \\
\hline Smooth & 0,166 & 0,022 & 1,004 & 0,215 & 0,041 \\
\hline Notched & 0,170 & 0,021 & 1,035 & 0,232 & 0,045 \\
\hline
\end{tabular}

Elastoplastic parameters and damage behavior will be defined according a calibration process defined later in section 4.1.

\subsection{BOUNDARY CONDITIONS}

The boundary conditions are applied as shown in Table 8. The use of symmetry on modelling, whenever as possible, is very important to reduce the computational time and necessary disk space.

\begin{tabular}{|c|c|c|c|c|}
\cline { 3 - 5 } \multicolumn{2}{c|}{} & \multicolumn{3}{c|}{ Plane } \\
\hline \multirow{3}{*}{ Specimen } & Direction & $\mathrm{XY}$ & $\mathrm{XZ}$ & $\mathrm{YZ}$ \\
\hline \multirow{3}{*}{ Tensile } & $\mathrm{x}$ & FREE & FREE & 0 \\
\cline { 2 - 5 } & $\mathrm{y}$ & FREE & 0 & FREE \\
\cline { 2 - 5 } & $\mathrm{z}$ & 0 & FREE & FREE \\
\hline \multirow{3}{*}{ SEB } & $\mathrm{x}$ & FREE & N/A & 0 \\
\cline { 2 - 5 } & $\mathrm{y}$ & FREE & N/A & FREE \\
\cline { 2 - 5 } & $\mathrm{z}$ & 0 & N/A & FREE \\
\hline
\end{tabular}

Table 8 Boundary condition according specimen type

Where, "FREE" means that plane does not have any restriction in that direction and "0" value means that cut surface can have any type of movement in that direction, and, N/A means there is not a cut symmetry plane applied. This information will be resumed when the meshing part is defined. 


\subsection{MESH DEFINITION}

Next step of the process is generating the mesh to represent in a proper way the geometry and the properties of the models. There must be taken care of the quantity of the elements and nodes generated because, depending on these values the computation time can be higher or lower. Then, for all models, C3D8 elements were chosen to the mesh (3D linear elements type with 8 nodes and 3 degrees of freedom of translation per each node).

Finally, meshes were generated to model the 7 types of geometries, being the maximum quantities of nodes for two types of specimens, tensile and SEB: 32240 and 43470 respectively, and, the dimensions of the smallest element in the SEB models are $0,2 \times 0,2 \times 0,211 \mathrm{~mm}$, and in the tensile specimens are $0,072 \times 0,074 \times 0,100 \mathrm{~mm}$.

For all models there is a greater mesh refinement in the areas of interest, which are located at the plane of failure in both types of geometries. Meshes of the SEB-TR-NSG and for tensile notched R3, which have the greater mesh density for each geometry, are displayed in Figure 24. 


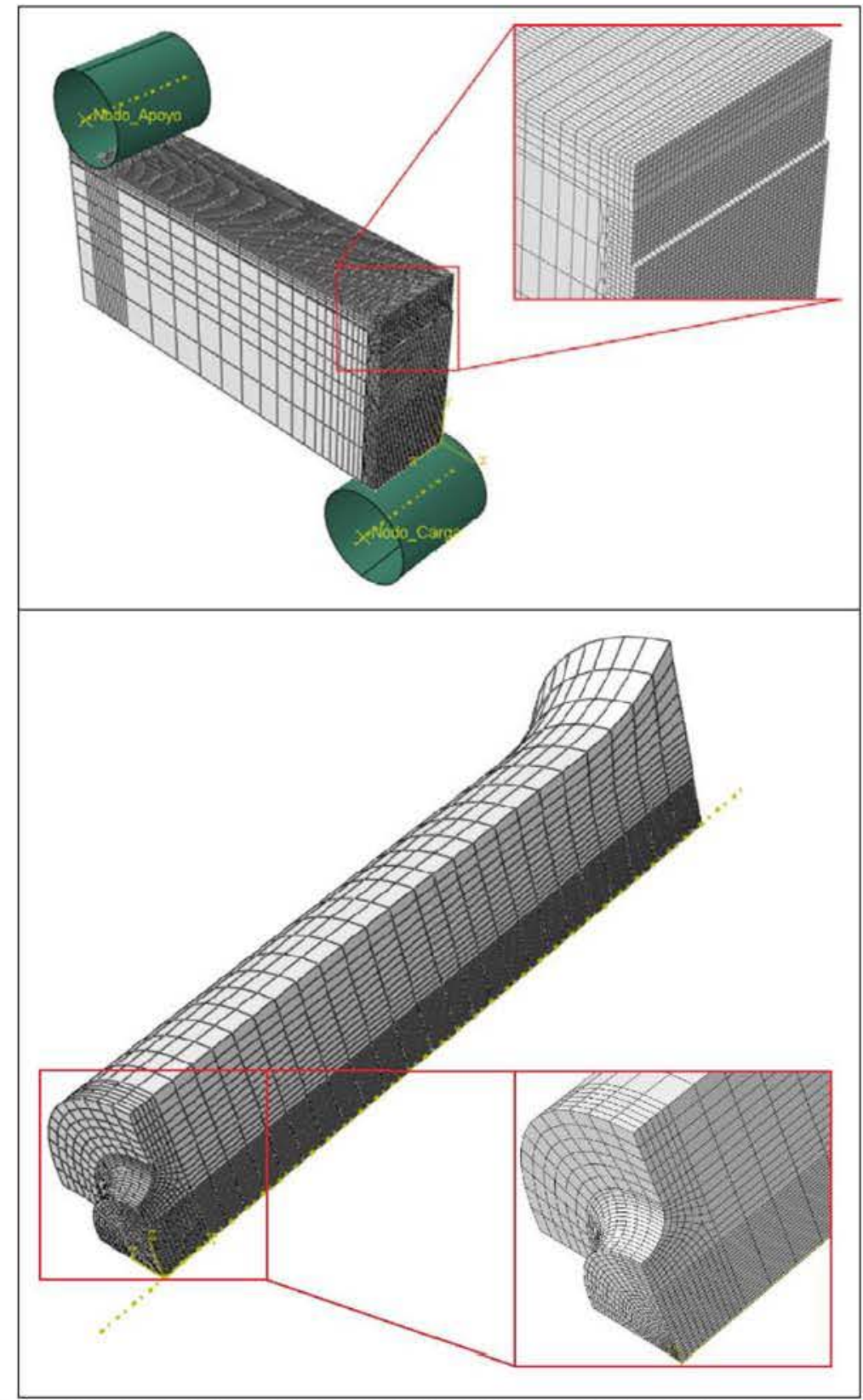

Figure 24 Mesh definition of two specimen tests, SEB and Tensile notched bar

Once the mesh density for all geometries have been developed, boundary conditions previously described in the Section 3.5 , can be added. So, the nodal points on the symmetry planes must be restricted assigning zero displacement value.

The mesh size effect will be analyzed in section 4.3 of this document. This analysis will show the influence of mesh size on the mechanical response for each specimen. Therefore, the meshes described in the present section are the final ones for the elastoplastic and damage calibration process. 


\section{RESULTS}

\subsection{CALIBRATION}

Two types of previous procedures has been implemented for the characterization of the mechanical response of the material:

1) Definition of elastoplastic behavior

2) Definition of damage initiation and damage evolution at each material point

\subsubsection{Elastoplastic calibration}

The elastoplastic calibration is performed by matching the numerical engineering stress-strain curve with the experimental engineering stress-strain curve. To obtain this calibration the process described below is followed.

\subsubsection{Calculation of the True Stress-strain curve}

The first step is to obtain the experimental true stress and true strain values which are obtained converting the engineering stress-strain curve according the following relation:

$$
\begin{aligned}
\sigma_{T} & =S(1+\varepsilon) \\
\varepsilon_{T} & =\operatorname{Ln}(1+\varepsilon)
\end{aligned}
$$

Where:

$\mathrm{S}: \quad$ is the engineering stress value.

$\varepsilon: \quad$ is the engineering strain value.

$\sigma_{T}: \quad$ is the true stress value.

$\varepsilon_{T}: \quad$ is true strain value. 
Using Eq. ( 10 ) and Eq. ( 11 ), the True Stress-Strain curve (TSSC), can be defined until the point of maximum load at the tensile test, at the onset of necking. Figure 25 compares both curves. Traditional finite element modelling just extrapolates the final portion of the true stress-true strain curve, using a power law relationship, until very large values of deformation. However, modelling of the correct necking evolution of the specimen requires a different approach. Thus, the next step is modifying the true stress-true strain curve to obtain the corrected relation between stresses and strain due to effects of necking.

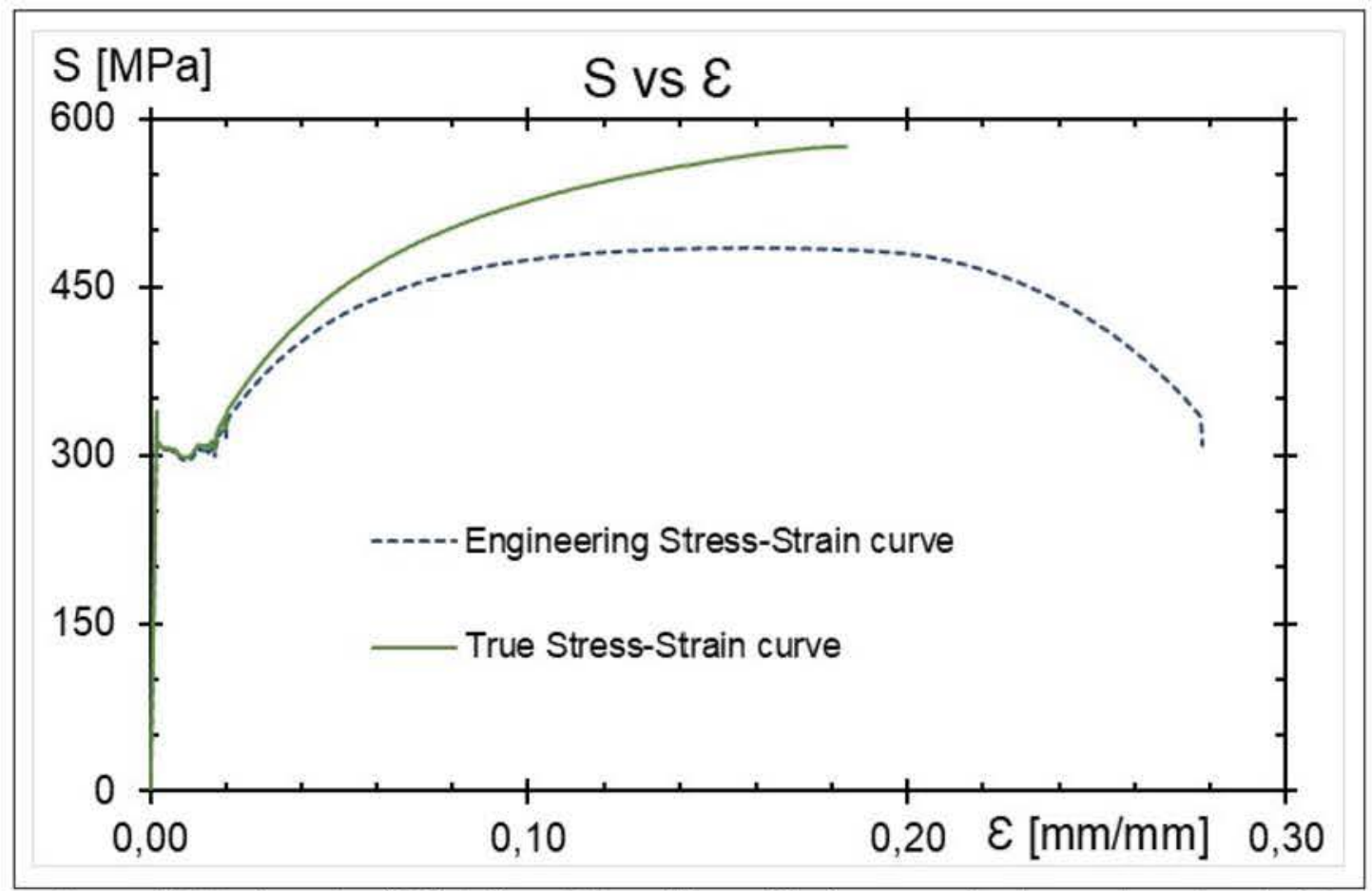

Figure 25 Engineering (CP_L1) and True Stress-Strain curves for the analyzed material

To make this correction, some attempts were made to get a unique simplified equation which represent the whole elastoplastic part of TSSC. Different attempts, using a power law equation, were made to fit the experimental true stress-true strain data, as shown in Figure 26, and described below:

- In the first attempt, all experimental data points related to the elastic and the Lüder's Plateau had been excluded. This approach is named "Attempt 1" in Figure 26. As can be seen a lot of experimental data points were lost between $0.025<\varepsilon<0.125$ and after $\varepsilon>0.135$. 
- In the second one, called "Attempt 2" in Figure 26, the approach was made using a fitting model which represent in a good way the data before $\varepsilon>0.065$, losing information after that value.

- In the third approach, called "Attempt 3" in the same figure, was used a power law equation using experimental points after $\varepsilon>0.075$, which produces bad fitting at the beginning.

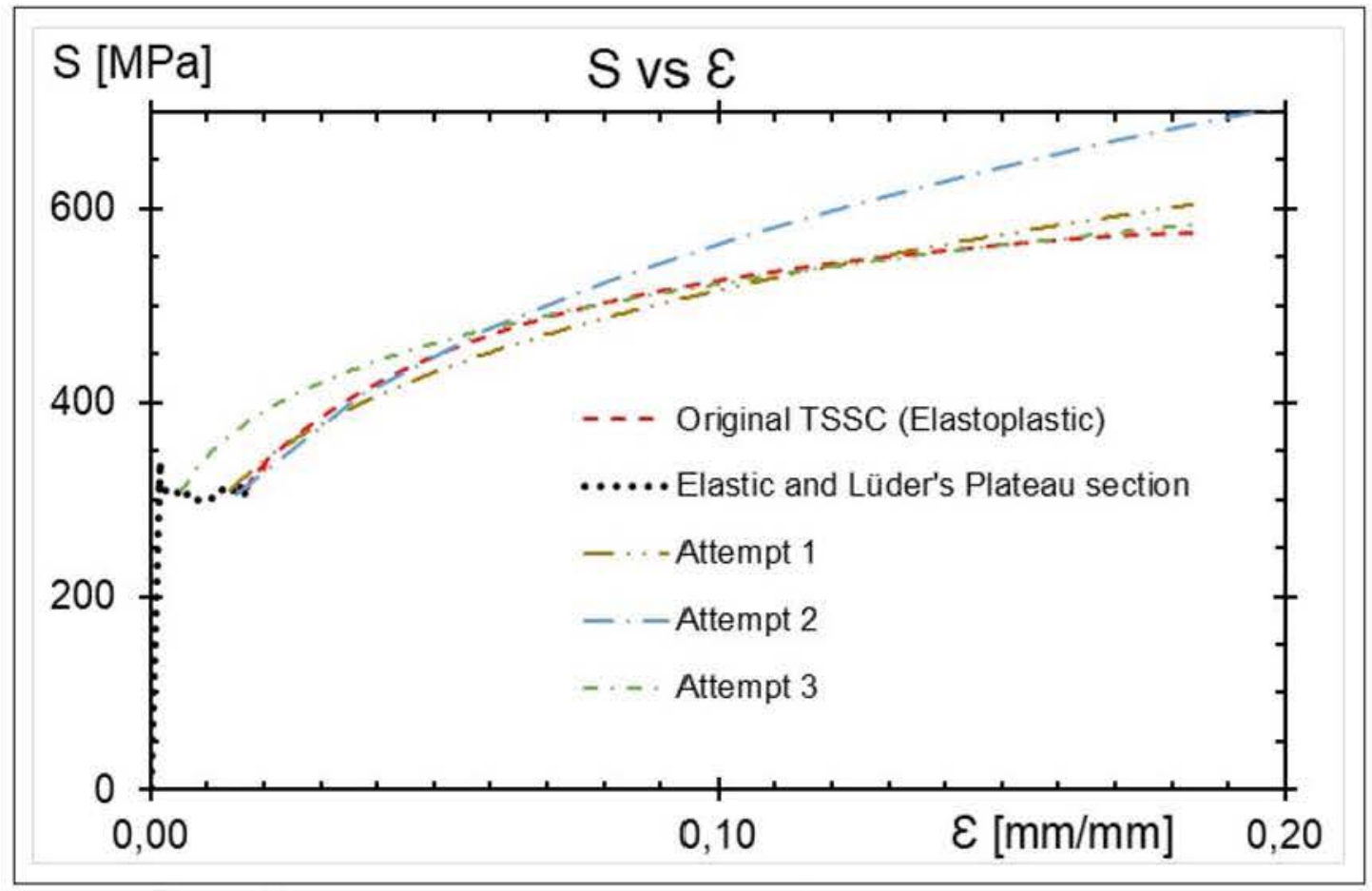

Figure 26 Attempts to model the elastoplastic true stress-true strain curve

Thus, once it was demonstrated that using only one power equation was not good enough for modelling the whole true stress-true strain curve, the next attempt, as Hertelé et al. [34], [35] suggest, was to try at least 2 different power equations to model the whole experimental data. Then, after to some attempt to fit the curve using different equations per each segment, the final approach gave satisfactory results: one segment for the elastic part, one segment for the Lüder's Plateau, and three segments for the elastoplastic part. One equation is related to each segment which let us obtain the same experimental value. The final power law equations obtained are shown in Figure 27 : 


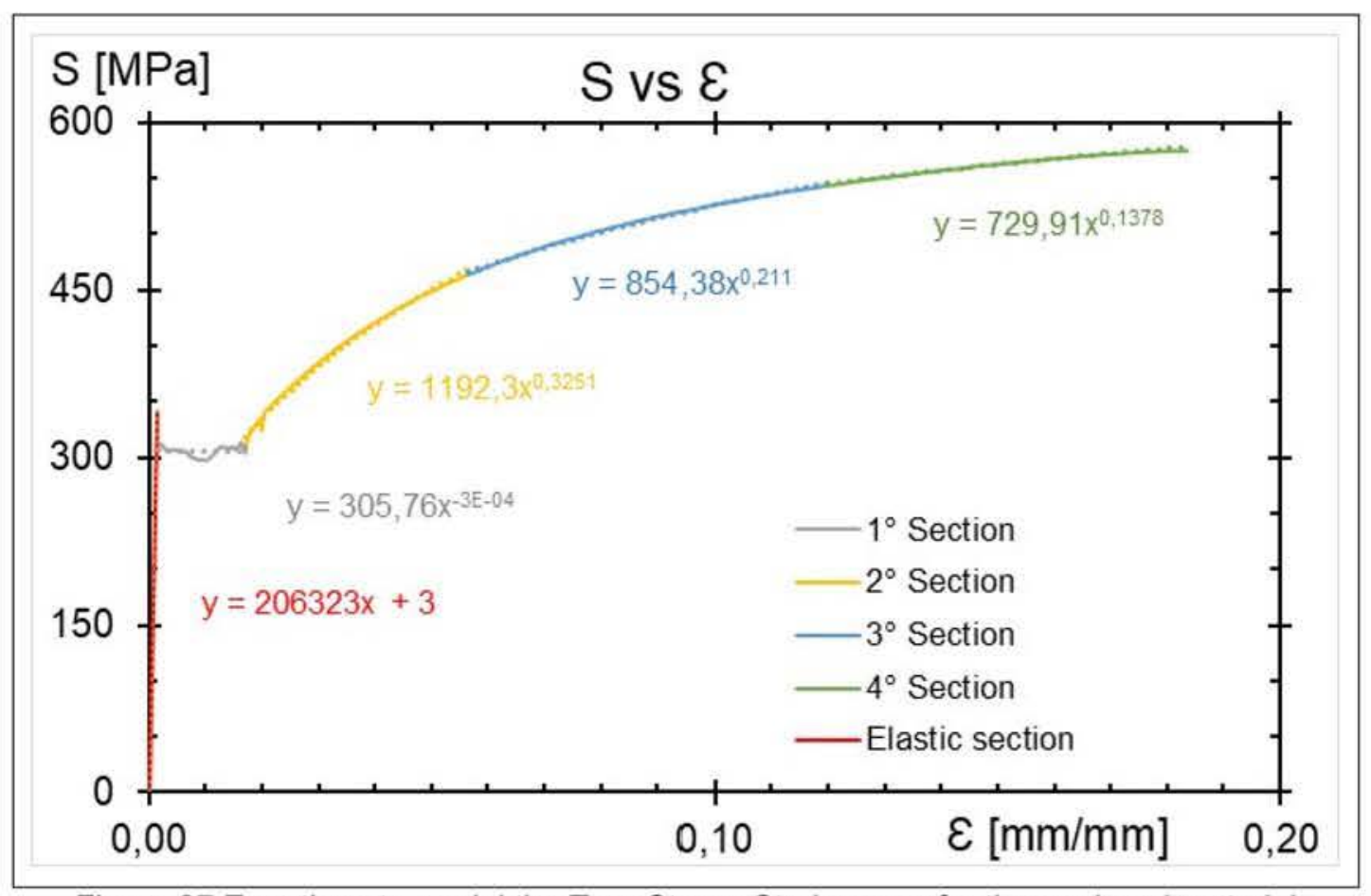

Figure 27 Equations to model the True Stress-Strain curve for the analyzed material

Analyzing those 4 equations the following information is obtained:

i. Slope of the first linear equation represents the experimental Young's Modulus of the material.

ii. The equations of the four sections that model the elastoplastic part of the behavior are represented as power equations of the type $\sigma_{T}=a \varepsilon_{T}^{n}$, where " $a$ " and " $n$ " are the base and the exponent of the function respectively.

iii. The $1^{\circ}$ Section equation has an exponent with a value close to zero, that means for that section the value is approximately constant and was fixed a value of $\sigma_{y}=305.76[\mathrm{MPa}]$, which could be considered the experimental Yield stress value.

iv. From $2^{\circ}$ to $4^{\circ}$ section, $a$ and $n$ values for the equations are shown in Table 9:

Table 9 "a" and " $\mathrm{n}$ " values for the 2 th to 4 th sections' Power functions

\begin{tabular}{|c|c|c|}
\hline Section & $\mathrm{a}$ & $\mathrm{n}$ \\
\hline 2 & 1192,33 & 0,3251 \\
\hline 3 & 854,38 & 0,2110 \\
\hline 4 & 729,91 & 0,1378 \\
\hline
\end{tabular}


Table 10 describes the validity intervals where each equation has been defined. It is important to mention that it could be possible to define many different combinations of segments to reproduce the experimental true stress-strain curve. An exhaustive procedure has been no tried. The given solution is just good enough for modelling purposes.

Table 10 Upper and lower limits to use the power equations to model the TSSC

\begin{tabular}{|c|c|c|c|c|}
\hline \multirow{2}{*}{ Section } & \multicolumn{2}{|c|}{ Limits } & \multicolumn{2}{|c|}{$\begin{array}{c}\text { Power Eq. } \\
\text { Factors }\end{array}$} \\
\hline & $\sigma_{T}$ & $\varepsilon_{T}$ & a & $\mathrm{n}$ \\
\hline \multirow{2}{*}{$1^{\circ}$} & 310,46 & 0,00149 & \multirow{2}{*}{305,76} & \multirow{2}{*}{$N / A$} \\
\hline & 310,99 & 0,01710 & & \\
\hline \multirow{2}{*}{$2^{\circ}$} & 310,99 & 0,01710 & \multirow{2}{*}{1192,33} & \multirow{2}{*}{0,3251} \\
\hline & 462,84 & 0,0 & & \\
\hline \multirow{2}{*}{3} & 462,84 & 0,05648 & \multirow{2}{*}{854,38} & \multirow{2}{*}{0,2110} \\
\hline & 543,10 & 0,11963 & & \\
\hline & 543,10 & 0,11963 & \multirow{2}{*}{729,91} & \multirow{2}{*}{0,1378} \\
\hline & 575,31 & 0,18370 & & \\
\hline
\end{tabular}

Finally, Figure 28 displays the experimental and fitted true stress-strain curve using the coefficients shown in Table 10. Note that the four-power law equations have been extrapolated for values $\varepsilon>0.2 \frac{\mathrm{mm}}{\mathrm{mm}}$.

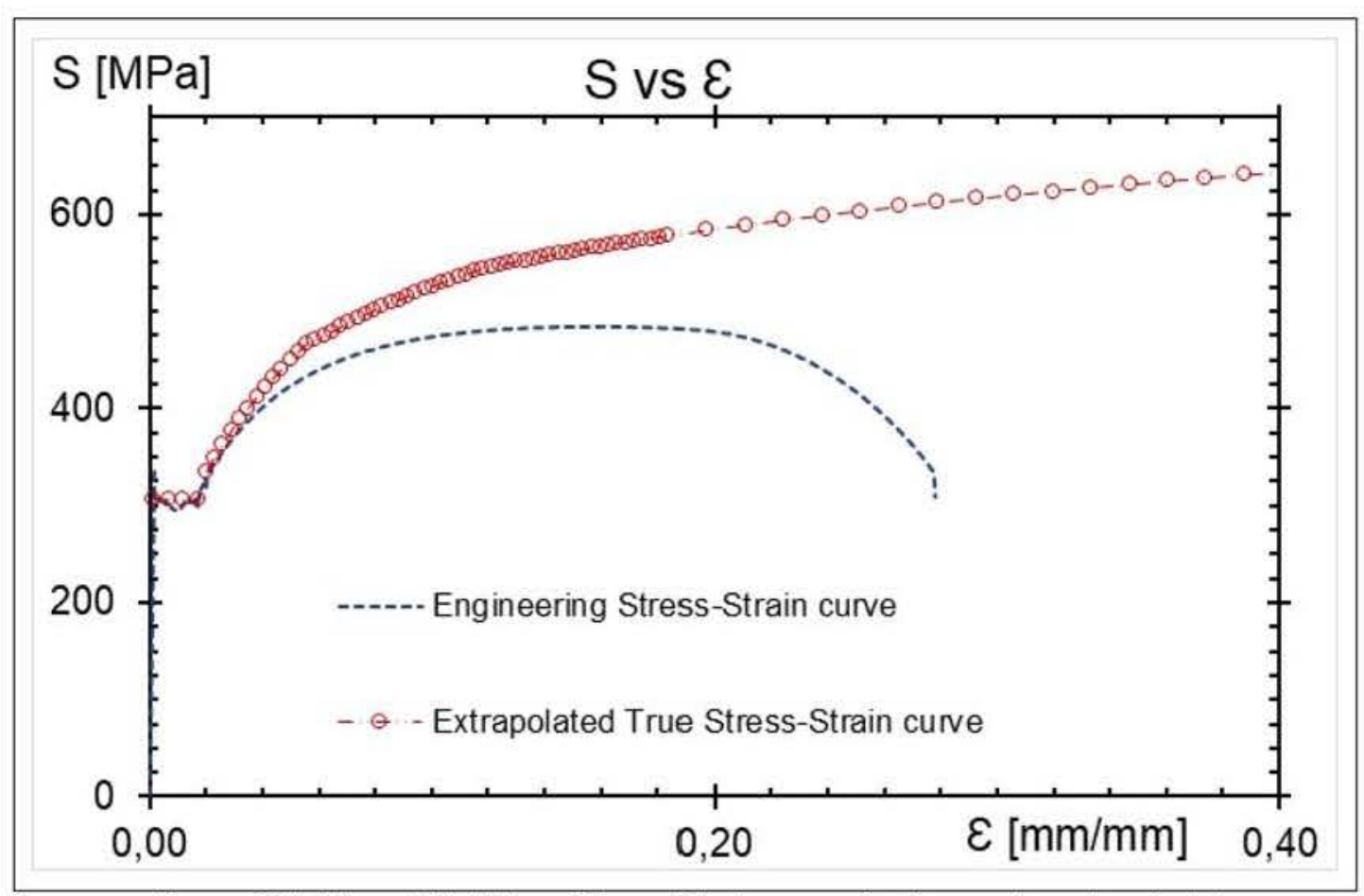

Figure 28 Extrapolated True Stress-Strain curve for the analyzed material 
The relation between true stress-true strain should be known for high values of deformation, $\varepsilon>0.4 \frac{\mathrm{mm}}{\mathrm{mm}}$. In areas close to cracks or discontinuities the expected level of deformation is extremely high. For that reason, the extrapolated curve is defined in the finite element software until $\varepsilon=2 \frac{\mathrm{mm}}{\mathrm{mm}}$ (200\%). Finally, this extrapolated curve will be used for the next steps of the analysis.

\subsubsection{Calculation of the Plastic Strain data}

In Abaqus software, the necessary input to define the plastic response is the stress versus plastic strain curve. We can calculate the plastic strain for each value of true calculated stress, which is taken from the total strain definition shown below:

$$
\varepsilon_{T}=\varepsilon_{E}+\varepsilon_{P}
$$

Where $\varepsilon_{T}, \varepsilon_{E}$ and $\varepsilon_{P}$ are total strain, elastic strain, and plastic strain, respectively. Replacing the elastic strain in function of Young's modulus and true stress, it is possible to determine the plastic strain:

$$
\varepsilon_{P}=\varepsilon_{T}-\left(\frac{\sigma_{T}}{E}\right)
$$

Using the Eq. ( 13 ) it is possible to get the data plotted at the Figure 29: 


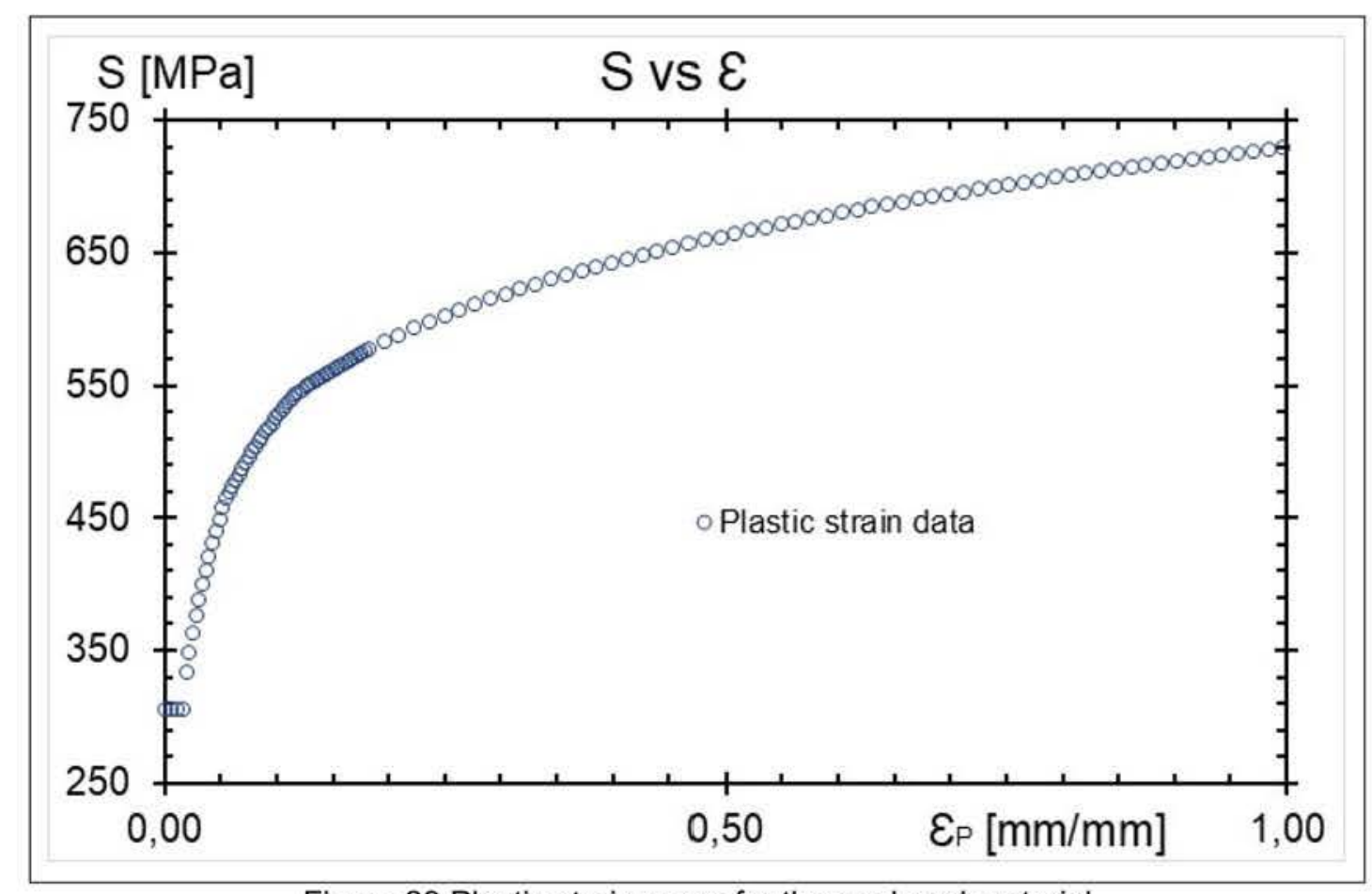

Figure 29 Plastic strain curve for the analyzed material

This information will be added as a mechanical property of the material, and this process is going to be detailed in the next step.

\subsubsection{Adding the elastic and plastic information in the numerical model}

To define the material in the numerical model, we need to add the elastic and plastic mechanical properties. The elastic properties determined from the laboratory tests are inserted as mechanical properties that will recover the elastic behavior of the analyzed material. In the same way the plastic mechanical properties are assigned as a yield stress and its respective plastic strain and let us to obtain the plastic part of the mechanical behavior of the material.

Once elastic and plastic properties have been defined, whose values were calculated from the extrapolated true stress-strain curve, we analyze one of the tensile numerical models to try to match with the experimental response. So, it was used the numerical tensile smooth specimen with their respective boundary conditions and $15 \mathrm{~mm}$ of applied displacement and the mechanical properties defined previously. This finite element model is shown in Figure 30: 


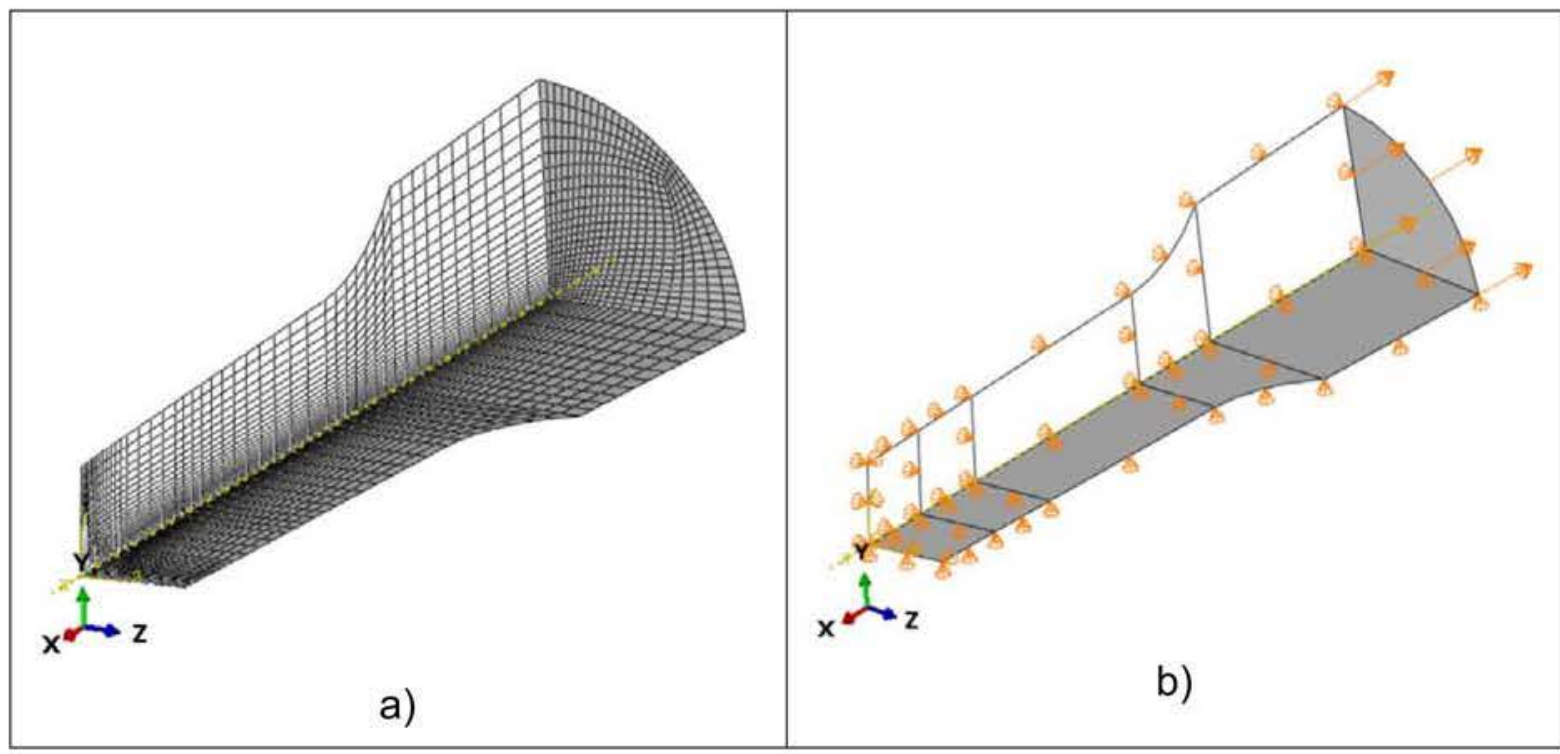

Figure 30 Numerical smooth model to be analyzed with elastic properties: a) Mesh of the FE model, and, b) Applied loads and constrains on the FE model

After the numerical model was developed by the program, including elastoplastic mechanical characteristics, graphically the results are shown as observed in Figure 31:

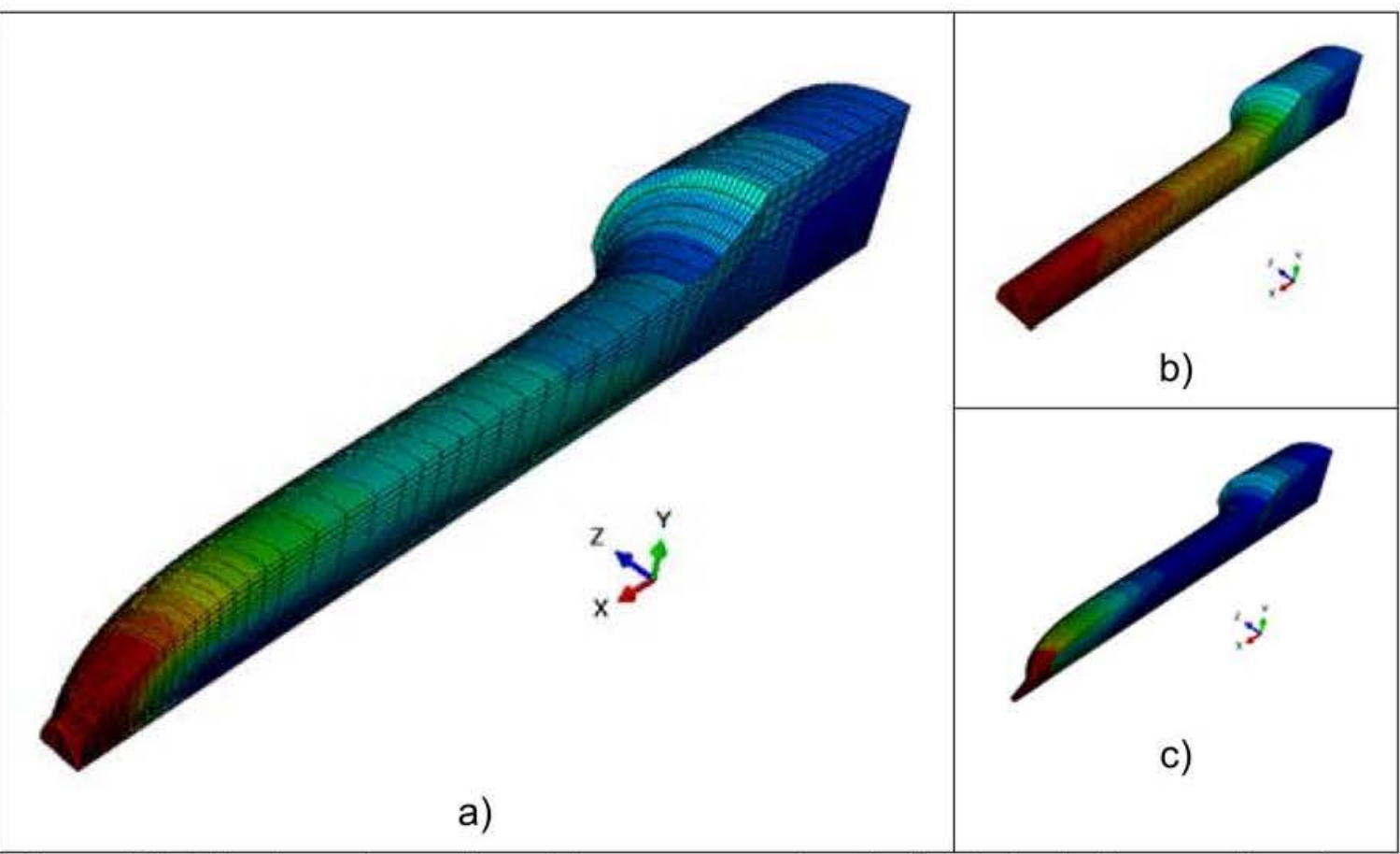

Figure 31 Finite element smooth model response, analyzed with elastoplastic properties, a) an intermediate step which shows the necking at the symmetry plane, b), c) initial and the final step respectively. 
Since the model does not have any damage property, it has a behavior given in Figure $31 \mathrm{c}$, which shows a high reduction of the section at the symmetry plane. As expected, it was obtained an axisymmetric behavior around the " $x$ " axis (radial deformation for any "x" value).

Comparison of the numerical engineering stress-strain curve with the experimental one for this specimen, is made in Figure 32.

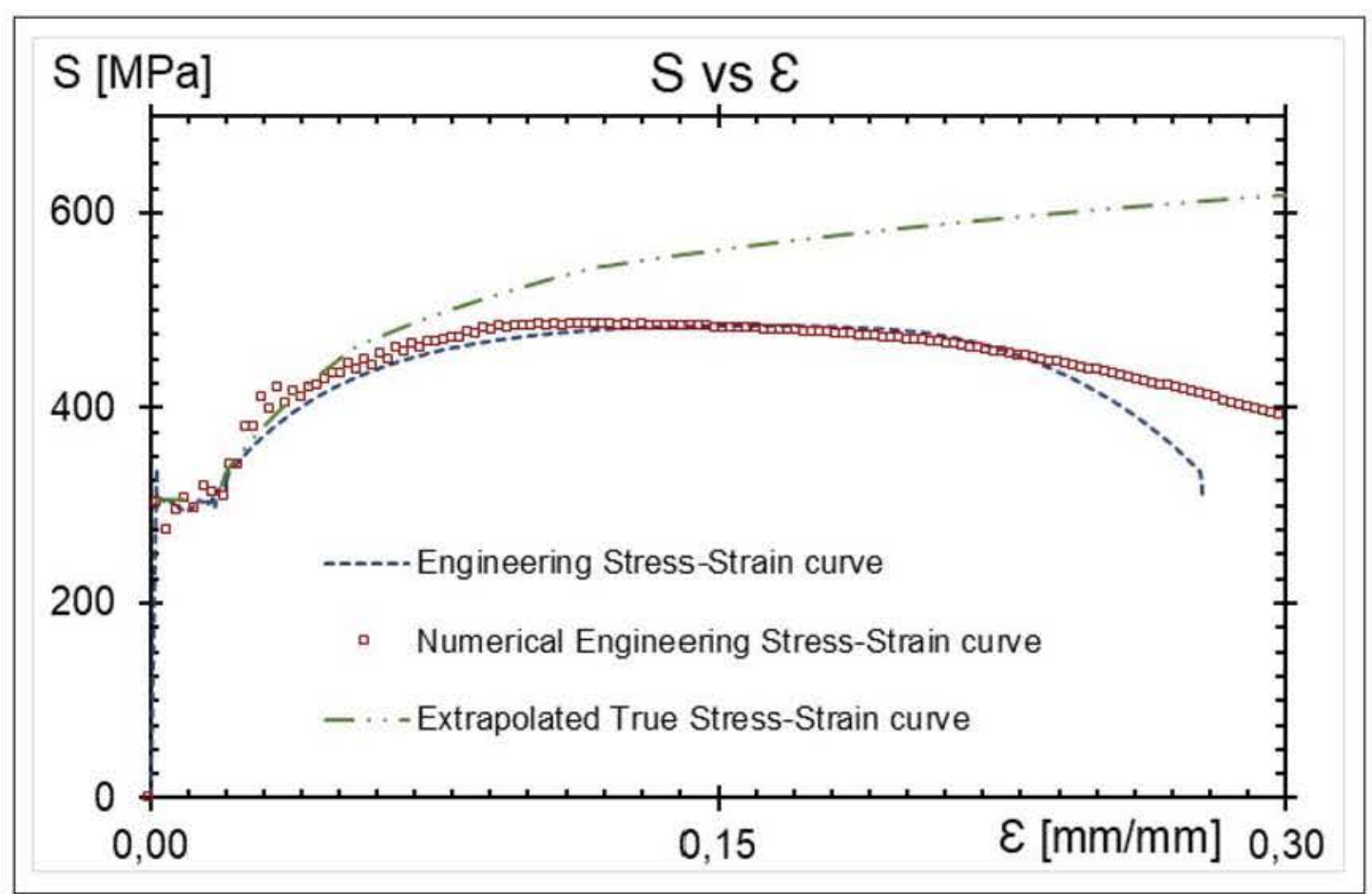

Figure 32 Comparison between Numerical and Experimental Engineering Stress-Strain curve

As it was mentioned in the last paragraph, one curve of Figure 32 shows the response due to numerical model load, which is named "Numerical Engineering Stress-Strain" curve (red dots), and the other one is its equivalent experimental response (dash line). It must be understood that if the mechanical properties inputted in the finite element program were adequate for the material, these curves should be equal which would mean it matches the real behavior of the material.

Instead of that, it is possible to observe that only the elastic and the constant part (Lüder's Plateau value) of results are equal, being in general the plastic behavior different. Despite this, it is remarkable that, due to the parameters of plastic mechanical properties were calculated from the true stress-strain curve (long dash/dot-dot line), at 
least the first part of the experimental curve should match with the numerical curve. In summary, it is needed to modify properly the TSSC with some factors to obtain the same response measured at the experimental tests. After this step is finished, the calibration process to calibrate the stress modified critical strain criterion parameter is done.

\subsubsection{Developing the elastoplastic calibration step}

As shown in Figure 32, it is necessary to modify the TSSC to obtain the numerical stress-strain values in order to match with the experimental curve. To complete this result and calibrate the plasticity of the material, the recommendation is using the smooth specimen experimental results. As seen in Kim et al. [36], using smooth specimens to characterize the elastoplastic properties without damage, the global response of the notched round bar specimens is matched very well, and the same approach was tried in this study. However, limited experimental facilities prevented to measure the plastic response after necking in the smooth specimen. The tested material has good ductility, engineering deformation at fracture $\sim 25 \%$, thus it was decided to use the notched round bar having fewer variations between experiments, to calibrate the plasticity after necking. As previously noted, the corrected true stresstrue strain should be able to reproduce well bulk response of the smooth and notch round specimens as presented in Kim et al. [31] and Paredes et al. [11], [12] for typical steels.

Therefore, it is going to use the experimental notched tensile bar results with notch radio $R=2 \mathrm{~mm}$ for the calibration process, because they have a similar response both in its longitudinal as transversal to rolling direction, as shown at Figure 15. There exist two possible extreme modifications of tensile true stress-strain curve, one with a constant value from the maximum stress value of that curve (perfectly plastic behavior); and another one with the same values, without any modification, because those are the maximum values that this curve could have for matching the behavior of the material. This is observed in Figure 33, which presents the values of the stress vs plastic strain for each extreme case. 


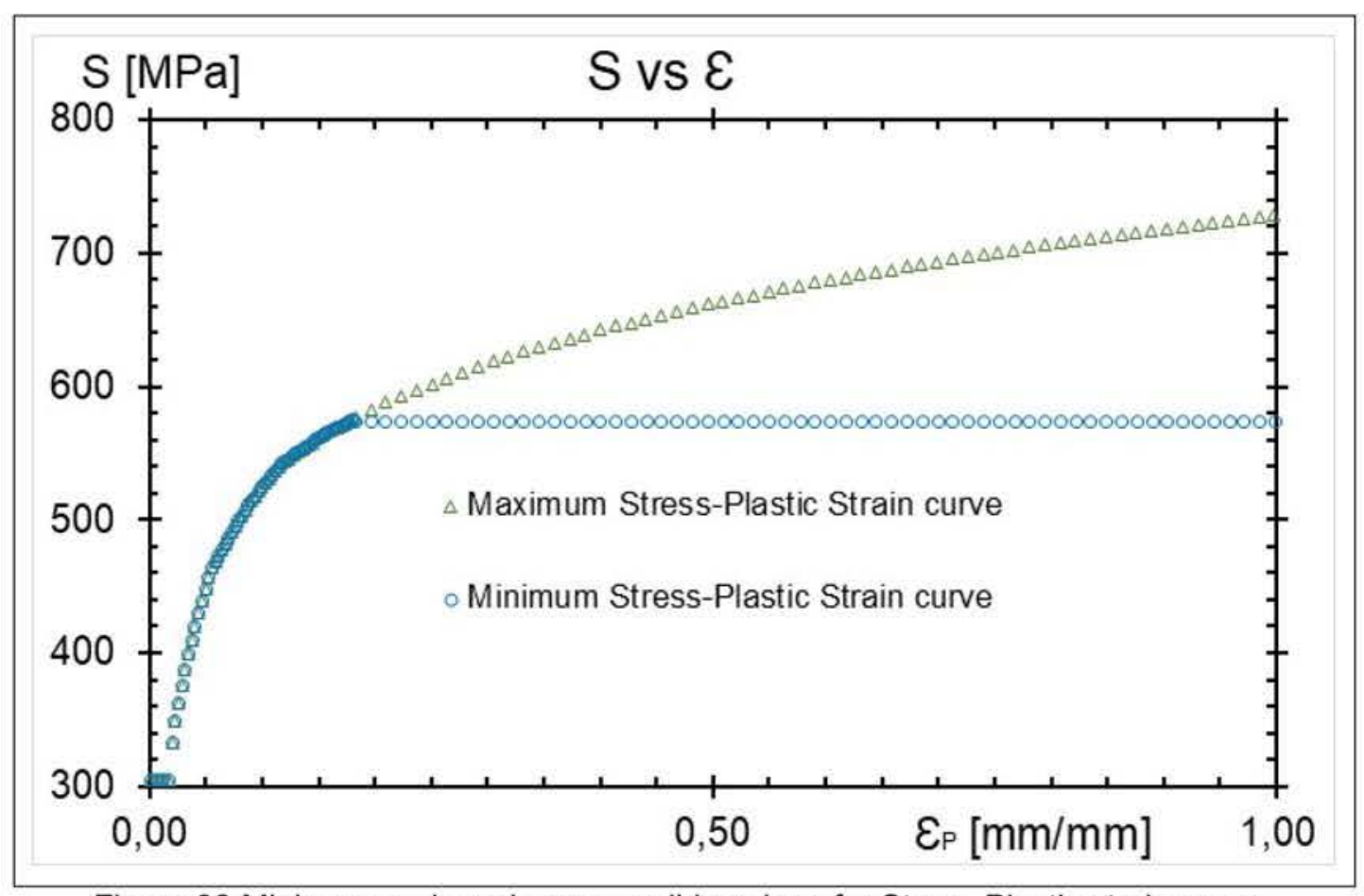

Figure 33 Minimum and maximum possible values for Stress-Plastic strain curves

Using those values, and the process mentioned in the section 4.1.1.3 of this study, it is obtained the numerical engineering stress-strain curves, remembering that now it was used the notched tensile specimen with radius $R=2 \mathrm{~mm}$. The results are shown in Figure 34.

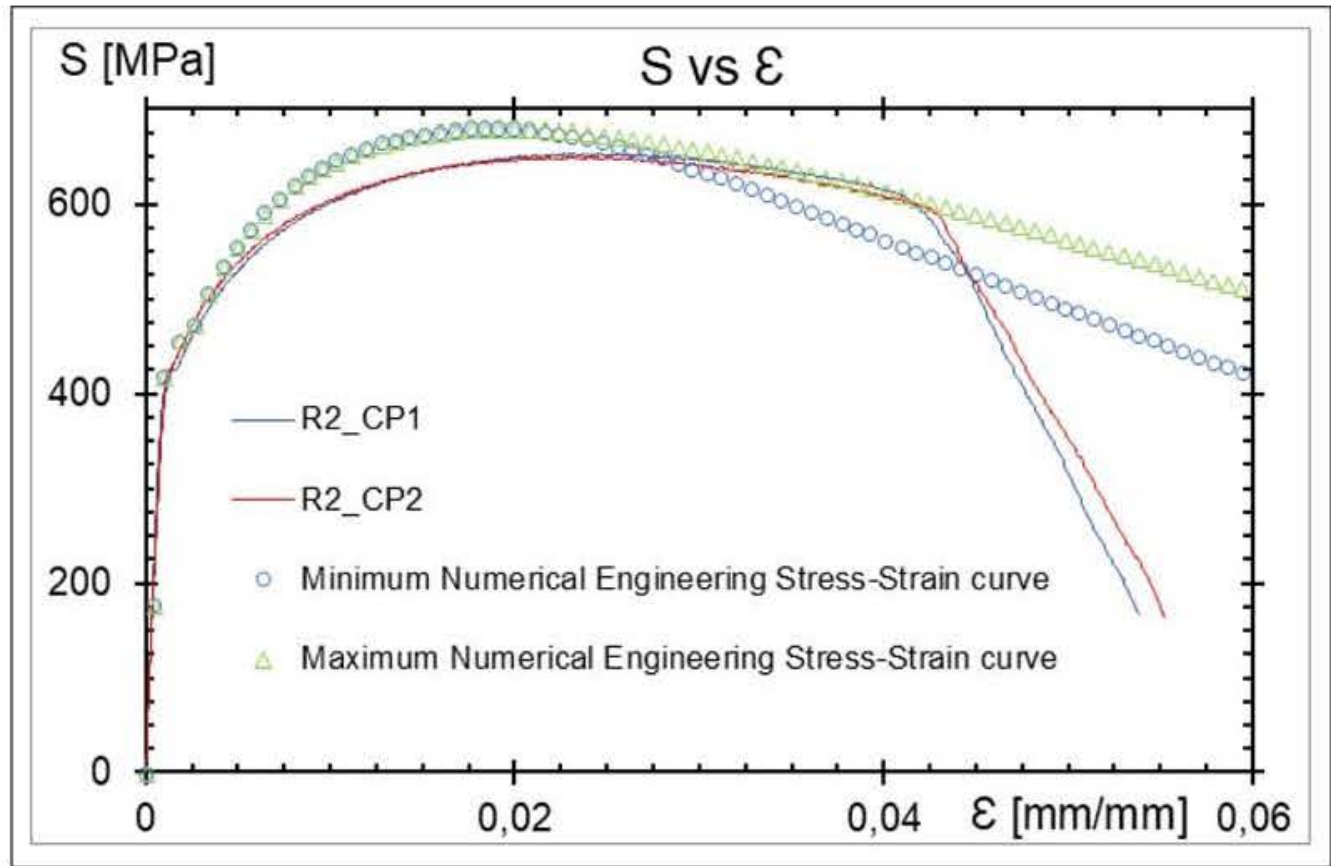

Figure 34 Minimum and maximum numerical Engineering Stress-strain curves for a notched tensile specimen, $R=2 \mathrm{~mm}$ 
Making a comparison between the numerical and the experimental response for the notched specimen $R=2 \mathrm{~mm}$, it is possible to notice the difference between modify or not the TSSC. Also, it is identifiable that if any modification is done in the first part of the plastic values then it will not be possible to match the numerical with the experimental values. Note that we should not make a big modification in the last part of the curve because it has almost the same values when it is used the stress-plastic strain curve without any modification.

With this information, it was proceeded to modify the maximum TSSC to get news stress-plastic strain values to introduce in Abaqus models to agree the numerical with the experimental values. Thus, it was used some factors "A" and "B" to modify the TSSC usign the power model:

$$
\sigma_{T M}=A \cdot a \varepsilon_{T}^{(B \cdot n)}
$$

Where: $\quad \sigma_{T M}$ : is the modified true stress value.

$A$ : is a modifier factor that affects the base of the power function "a".

$a, n:$ are the value that model a part of the TSSC, shown in section

\subsubsection{1.}

$B$ : is a modifiber factor which affects only the exponent of the power fuction "n".

$\varepsilon_{T}:$ is the true strain value.

Some different combinations of values for " $A$ " and " $B$ " had been tried, and after some trial and error attempt, it was found that the value of $A$ must be always 1 , because it severly affects the results of the equation; therefore, it must be searched only the $B$ values, where there are two possibilities which could meet the requirements, being those values shown in Table 11. 
Table 11 Values of the possible factors to modify the TSSC

\begin{tabular}{|c|c|c|}
\hline Attempt & 1 & 2 \\
\hline$A$ & \multicolumn{2}{|c|}{1,0} \\
\hline$B$ & 1,075 & 1,150 \\
\hline
\end{tabular}

Those values modify the TSSC and allow us calculate the stress-plastic strain curves to develop the numerical model of the notched tensile specimen getting the results plotted in Figure 35, which are compared with the experimental engineering stressstrain curve:

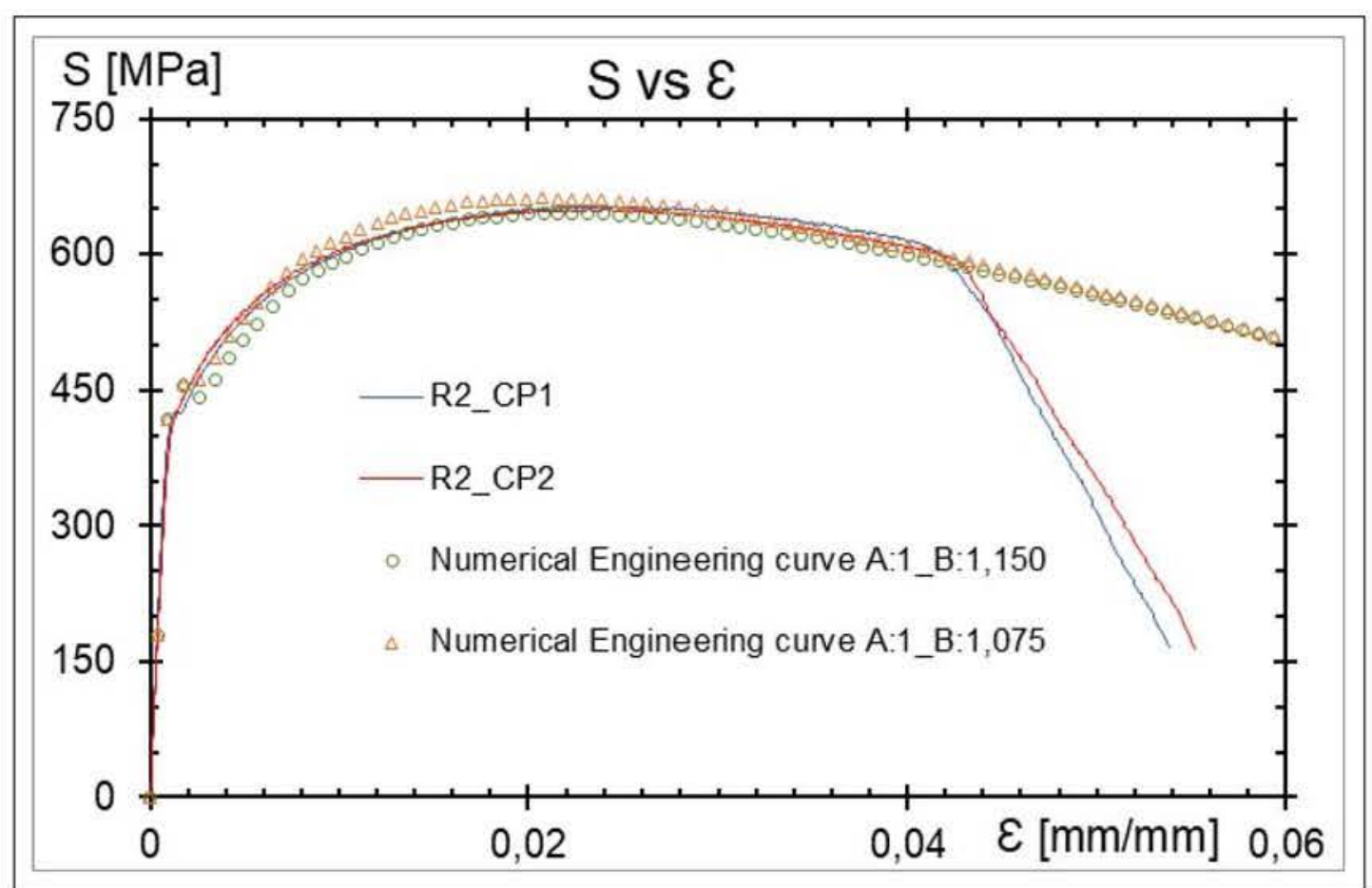

Figure 35 Numerical Engineering Stress-strain curves for a notched tensile specimen, $\mathrm{R}=2 \mathrm{~mm}$, using two different factor modifications

In Figure 35 is possible to observe that, with the factors used, one modification recovers some parts of the experimental response that the other one does not, i.e., the first attempt results match the data in the intervals $\varepsilon<0,008$ and $\varepsilon>0,021$, while the second attempt results only match data between $0,012<\varepsilon<0,025$. It means if both $B_{1}$ and $B_{2}$ factors are mixed, while $A_{1}=A_{2}=1$, then it probably will be capable to recover all the experimental engineering curve. To do this, the same intervals used to model the TSSC are used with power equations shown in the section 4.1.1.1 of this process, what results in the new modified TSSC shown in Figure 36: 


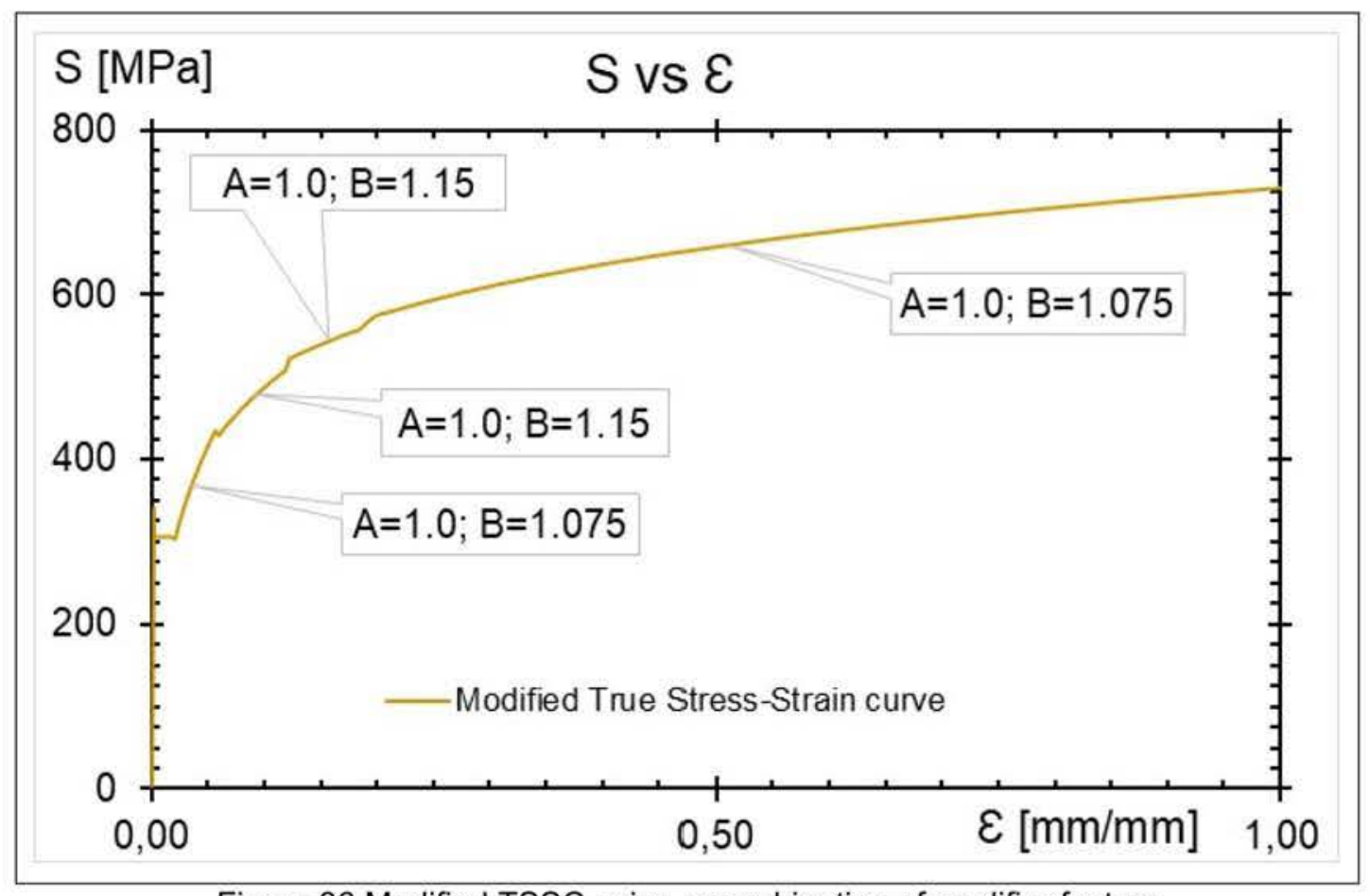

Figure 36 Modified TSSC using a combination of modifier factors

Where, the modifier parameters, $A$ and $B$, used in each section to obtain the TSSC plotted in Figure 36, are presented in the Table 12, and "N/A" means that in the interval was not applied any factor:

Table 12 Modifier factors for TSSC and intervals where they are valid

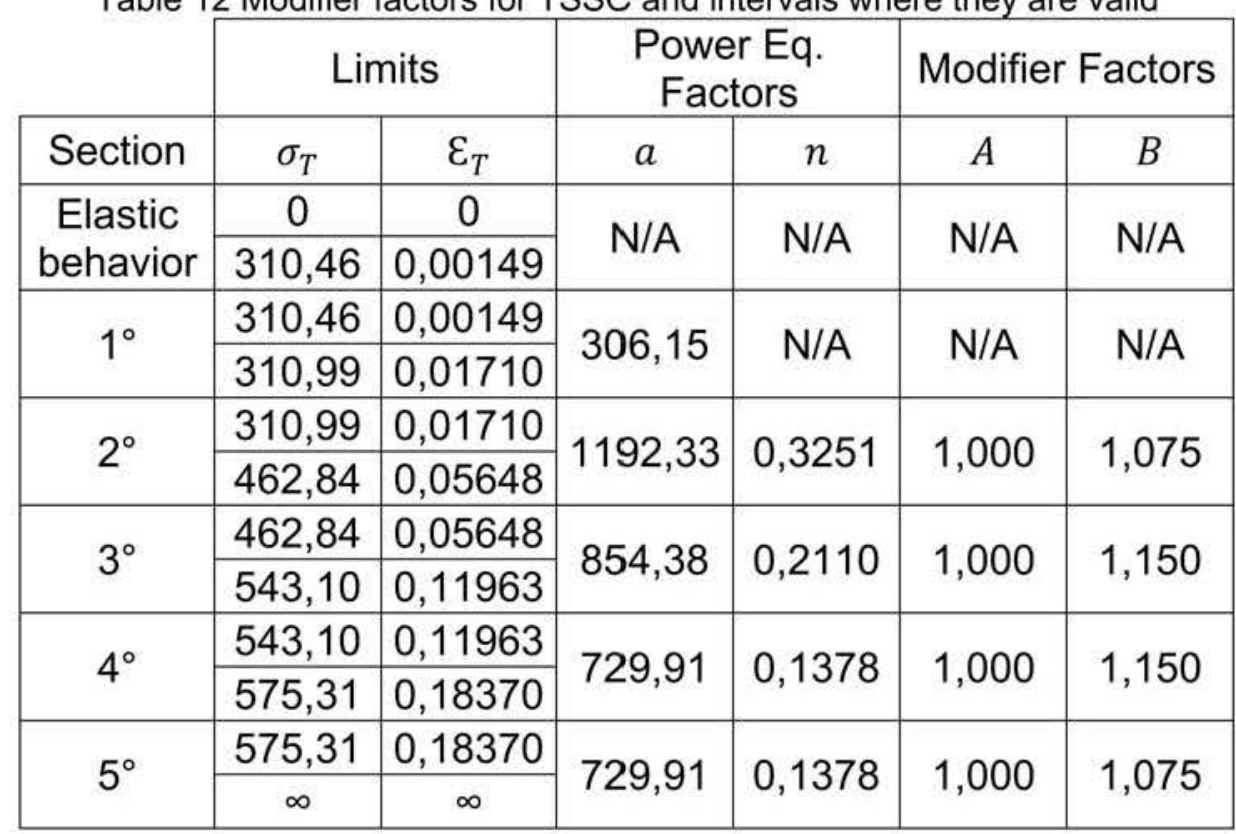


As expected, there are discontinuities on the stress-strain curve from one section to other one. To obtain a smooth curve, the intersecting values between one section and other were smoothed using a quadratic interpolation, getting the final Modified True Stress-Strain curve, which now is plotted until a Strain value $\varepsilon_{T}=2,0 \frac{\mathrm{mm}}{\mathrm{mm}}$ as shown in Figure 37.

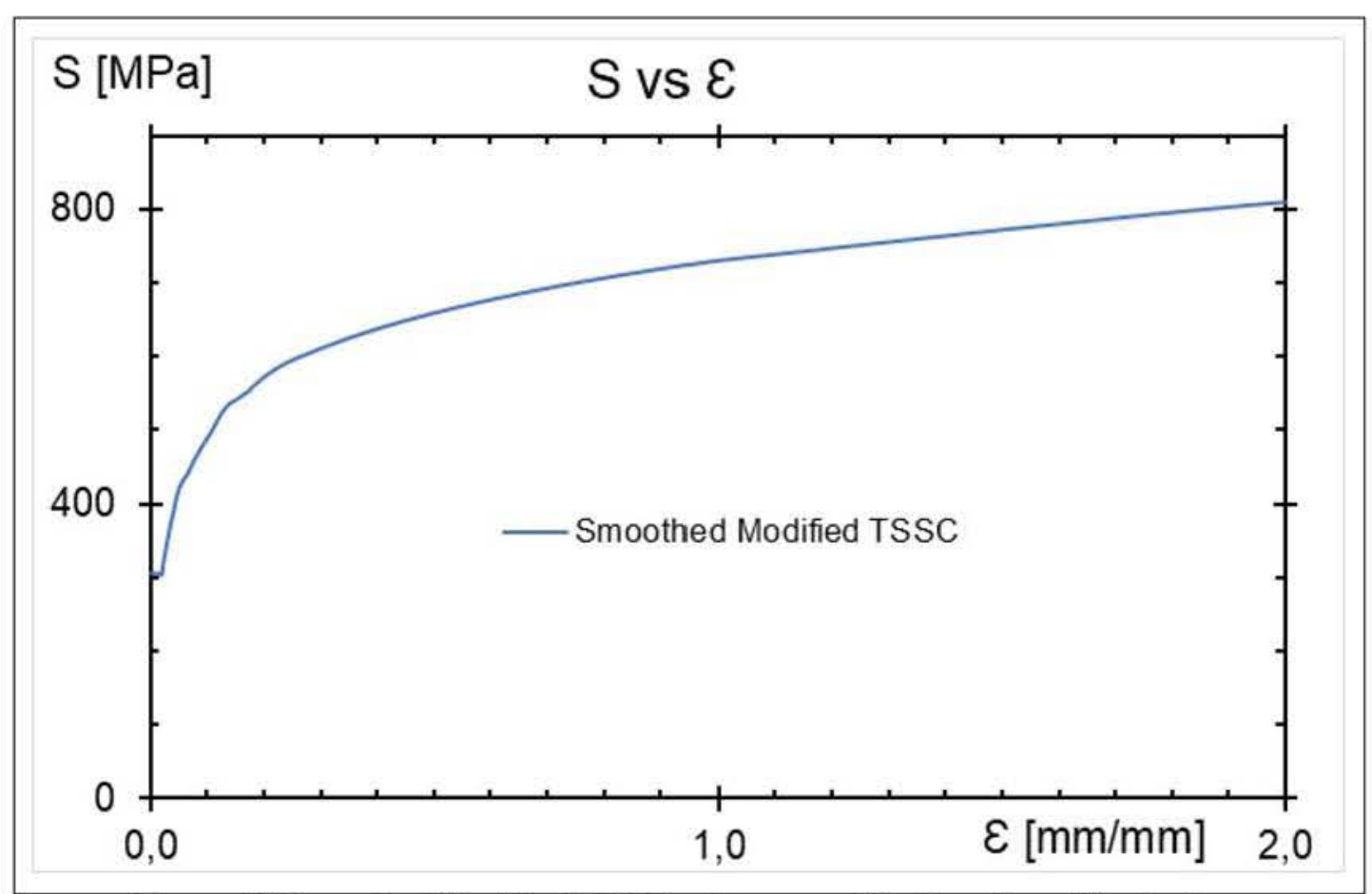

Figure 37 Smoothed Modified TSSC using a combination of modifier factors

Then, plastic stress-strain values were calculated using the Eq. ( 13 ), whose data were used to perform new Abaqus simulations.

So, using those values in Abaqus, it was obtained a new numerical engineering stressstrain response for a tensile notched specimen $R=2 \mathrm{~mm}$, getting the results presented at the Figure 38 . 


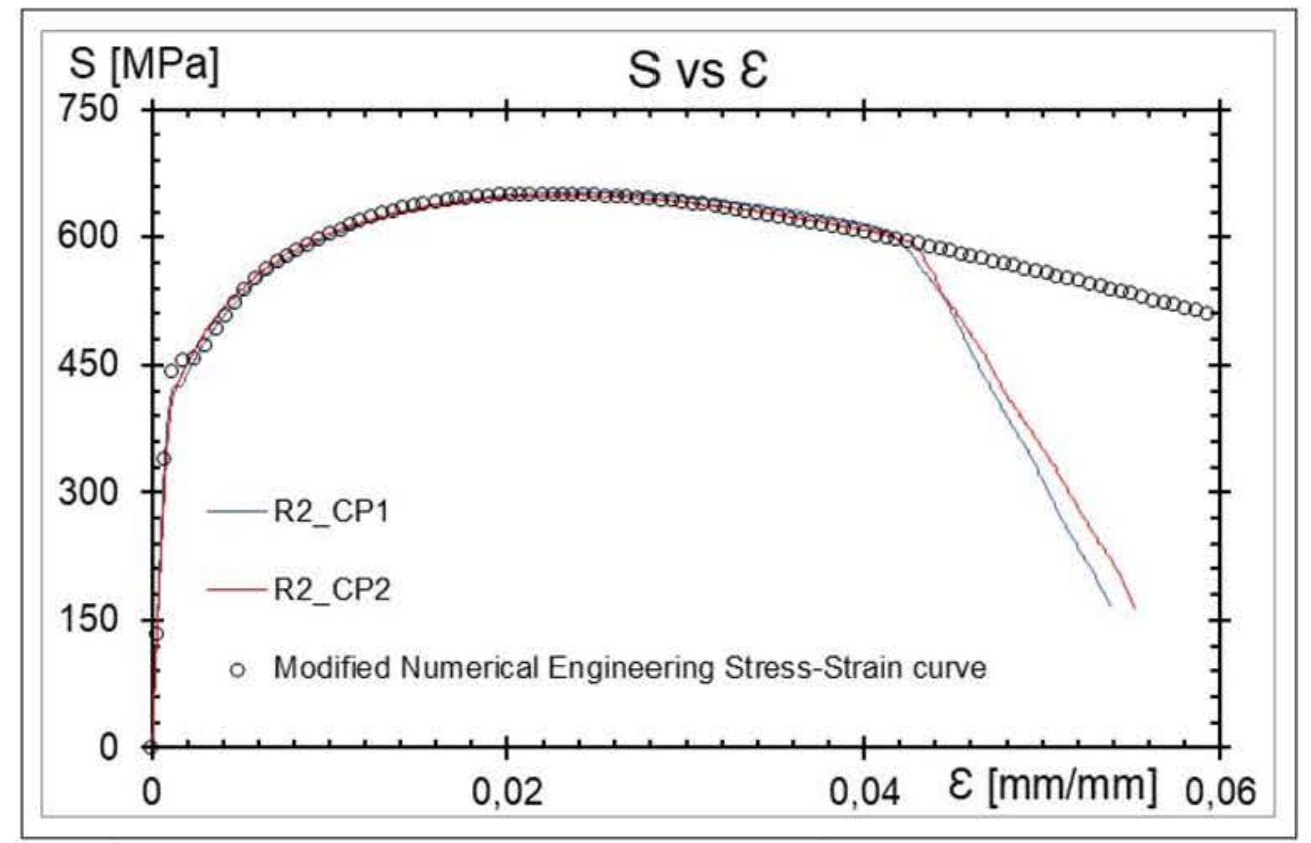

Figure 38 Modified numerical engineering stress-strain curve for a tensile notched specimen $\mathrm{R}=2 \mathrm{~mm}$

In Figure 38 the numerical response agrees with the experimental curves using the modifier factors which means that the elastoplastic behavior of the material was properly characterized. To check this assertion was performed finite element analyses of the smooth and notched bars, R1 and R3 specimen using the modified stress-plastic strain curve. The Figure 39 and Figure 40 compare the numerical and experimental results for the smooth and notched specimens, respectively.

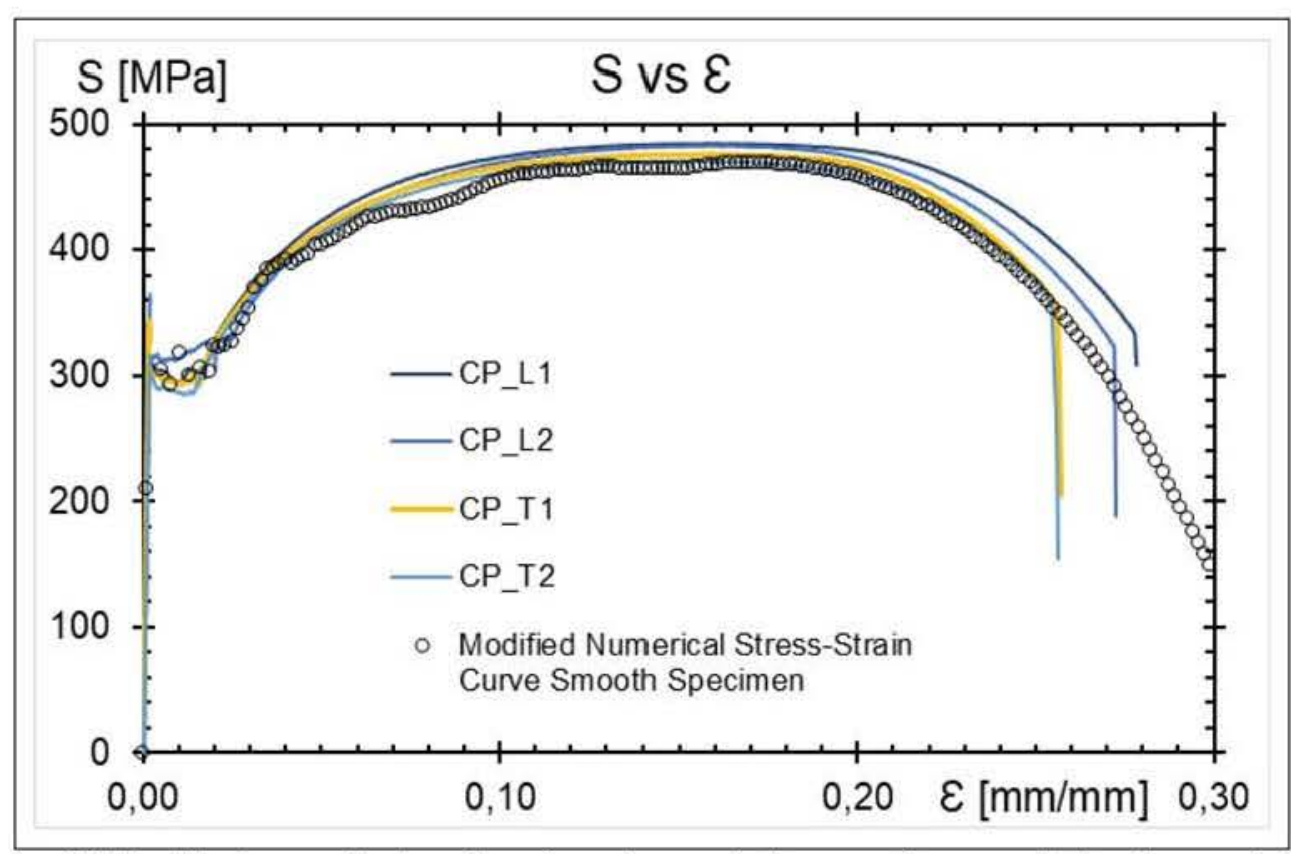

Figure 39 Modified numerical engineering stress-strain curve for smooth tensile specimens 


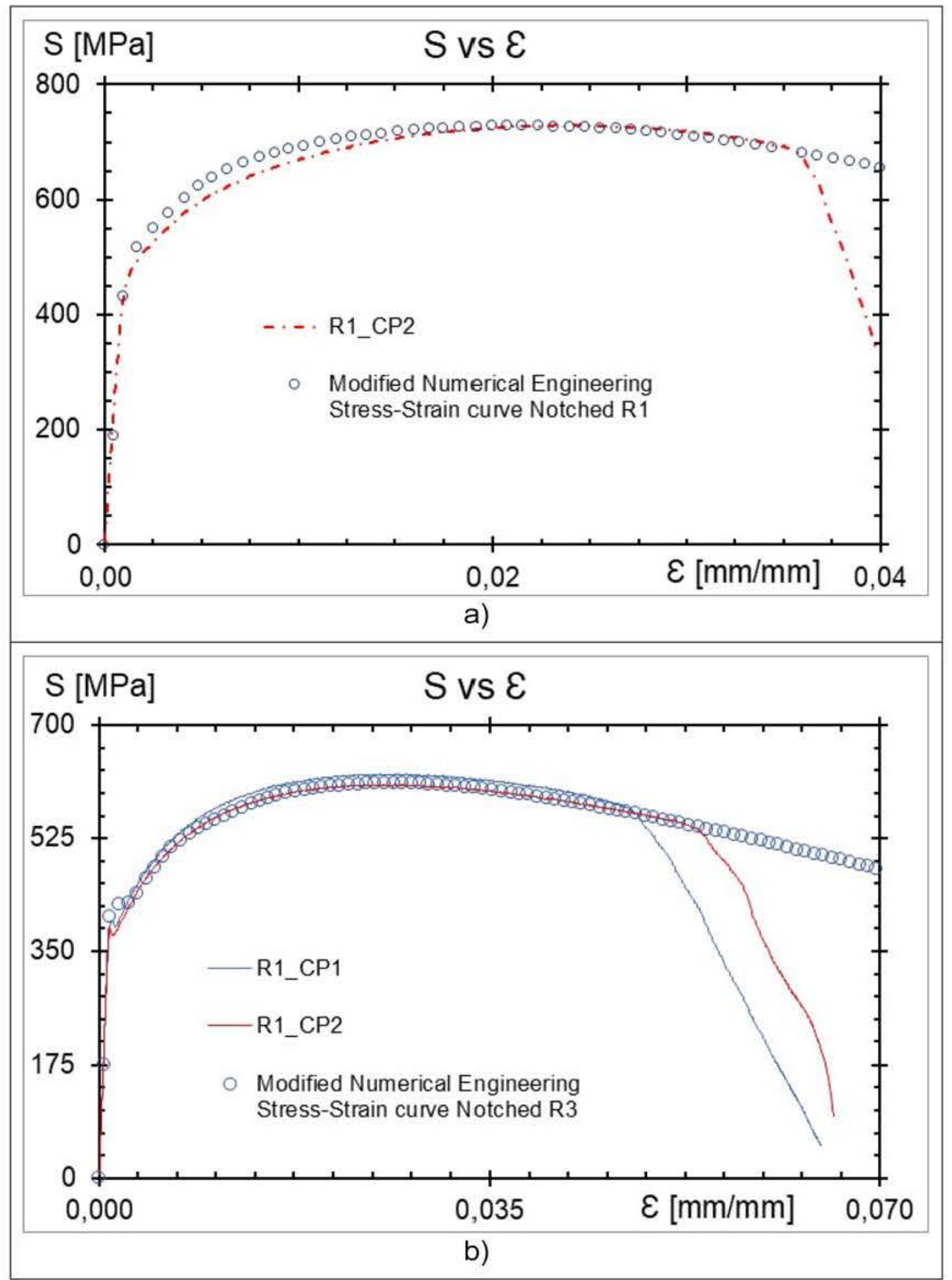

Figure 40 Modified numerical engineering stress-strain curve for tensile notched specimens, a) Notch $\mathrm{R}=1 \mathrm{~mm}$, and, b) Notch $\mathrm{R}=3 \mathrm{~mm}$

In all three cases, the elastoplastic behavior was almost completely recovered. This fact confirms the effectiveness of the proposed model to get the elastoplastic behavior. Figure 41 displays the mechanical response of the smooth specimen including visualizations of the specimen deformation through the loading path. 


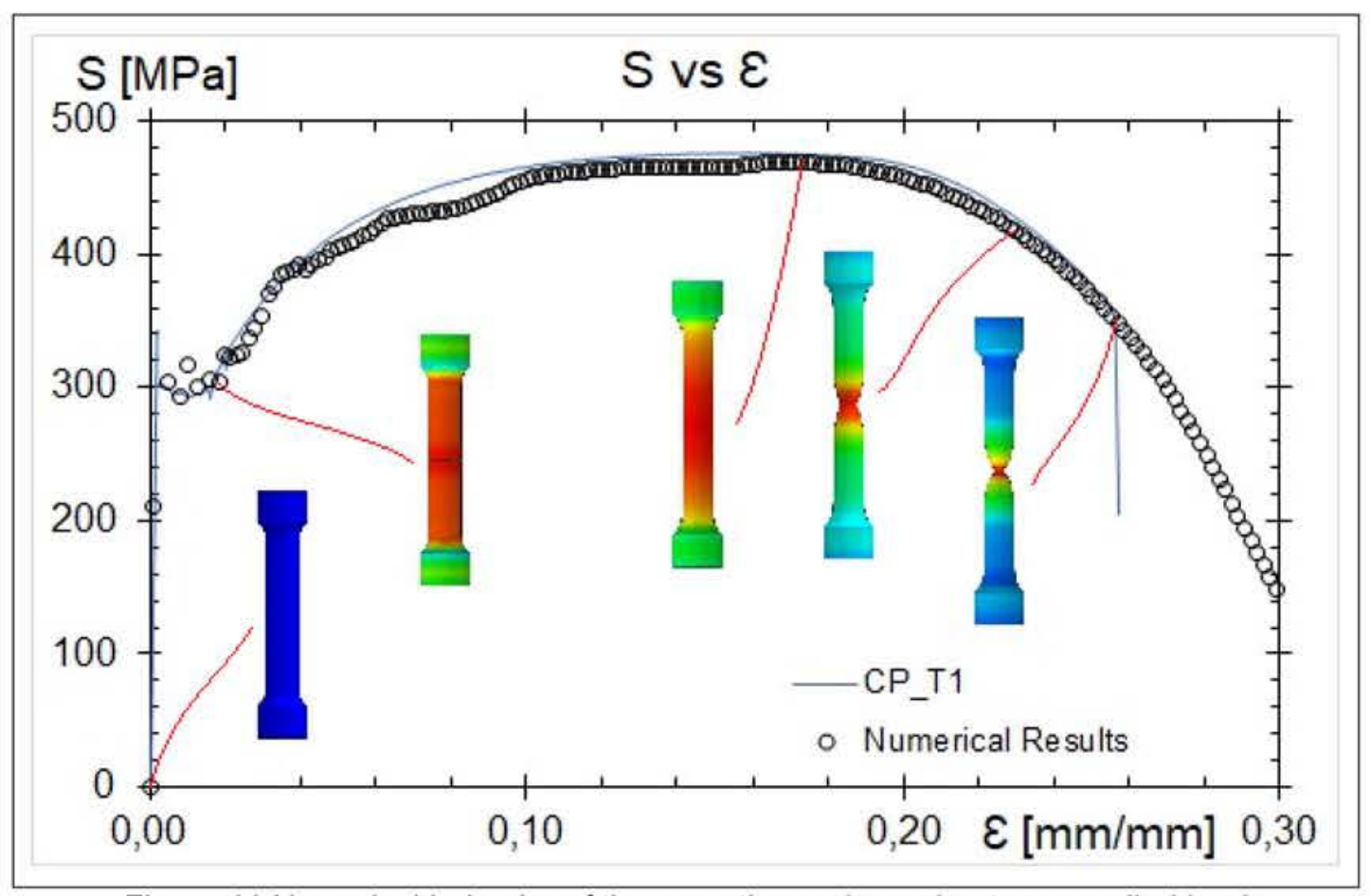

Figure 41 Numerical behavior of the smooth specimen due to an applied load

Figure 41 shows the deformed specimen at four instants of time: undeformed configuration, at the final point of the Lüder's Plateau, at the maximum stress (necking initiation), at an intermediate necking status, and, at the fracture point.

Then, once the calibrated elastoplastic model has been checked with the responses for all tensile specimens, we can continue with the next calibration, which is the damage calibration of the model, detailed in the next section.

\subsubsection{Damage calibration}

Once the elastoplastic behavior of the material has been characterized, the following step is the calibration of the damage parameters. This process which will be done using the fracture toughness data. It was adopted an independent strain rate formulation what means the velocity of the load application is not a critical parameter in the process; thus, the damage initiation criteria is only dependent on stress triaxiality and the fracture strain. Moreover, it must be defined the evolution of the damage after initiation, a process which is known as post-softening evolution. The following steps form this process. 


\subsubsection{Getting Triaxiality and Plastic strain values}

Firstly, the Equivalent Plastic Strain (PEEQ) and Stress Triaxiality $(\eta)$ values are obtained for the critical element of the FE mesh of each one of the notched tensile specimens generated, where the equivalent plastic strain in a material is a scalar variable that is used to represent the material's inelastic deformation. If this variable is greater than zero, the material has yielded [28].

For the notched round bar specimens, the critical points are located at the center of the specimen, due to it is possible to speculate those elements will be the first to fail, which is checked in section 4.4. Tracking the evolution of PEEQ and $\eta$ at the critical points during the loading, Figure 42 is defined.

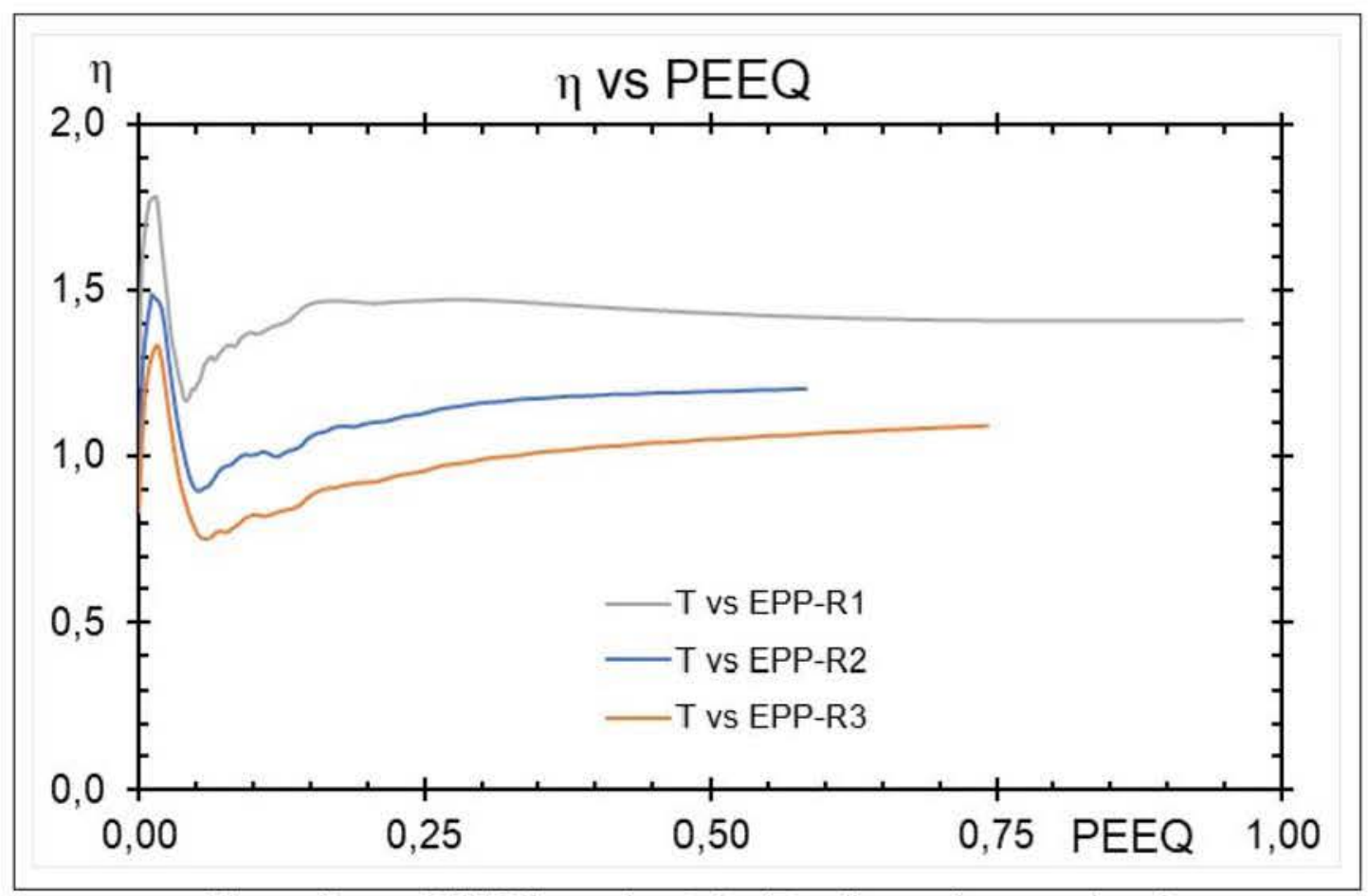

Figure $42 \eta$ vs $P E E Q$ for each notched tensile specimen analyzed

In the Figure 42 is possible to notice, as commented by Kim et al. [36], as the notch radius is increased, then the response of the stress triaxiality decreases. This similar trend can show that the triaxiality values were calculated adequately; however, to corroborate this assertion, it was analyzed the data for a tensile load smooth specimen, which is under tensile monotonic load. 
For a smooth round bar subjected to tensile load, the principal stresses, till the maximum load, are: $\sigma_{1}=\frac{\mathrm{P}}{\mathrm{A}}, \sigma_{2}=\sigma_{3}=0$. Thus, the stress triaxiality value is $\eta=$ $\frac{\left(\sigma_{1}+\sigma_{2}+\sigma_{3}\right) / 3}{\sqrt{\frac{1}{2}\left(\left(\sigma_{1}-\sigma_{2}\right)^{2}+\left(\sigma_{2}-\sigma_{3}\right)^{2}+\left(\sigma_{3}-\sigma_{1}\right)^{2}\right)}}=\frac{\sigma_{1}}{3\left[\sqrt{\frac{2 \sigma_{1}^{2}}{2}}\right]}=\frac{1}{3}$. Therefore, it was analyzed the numerical model which represent the smooth specimen to determine the triaxiality value, using the numerical results, in the symmetry element. The calculated triaxiality value is plotted as shown in Figure 43.

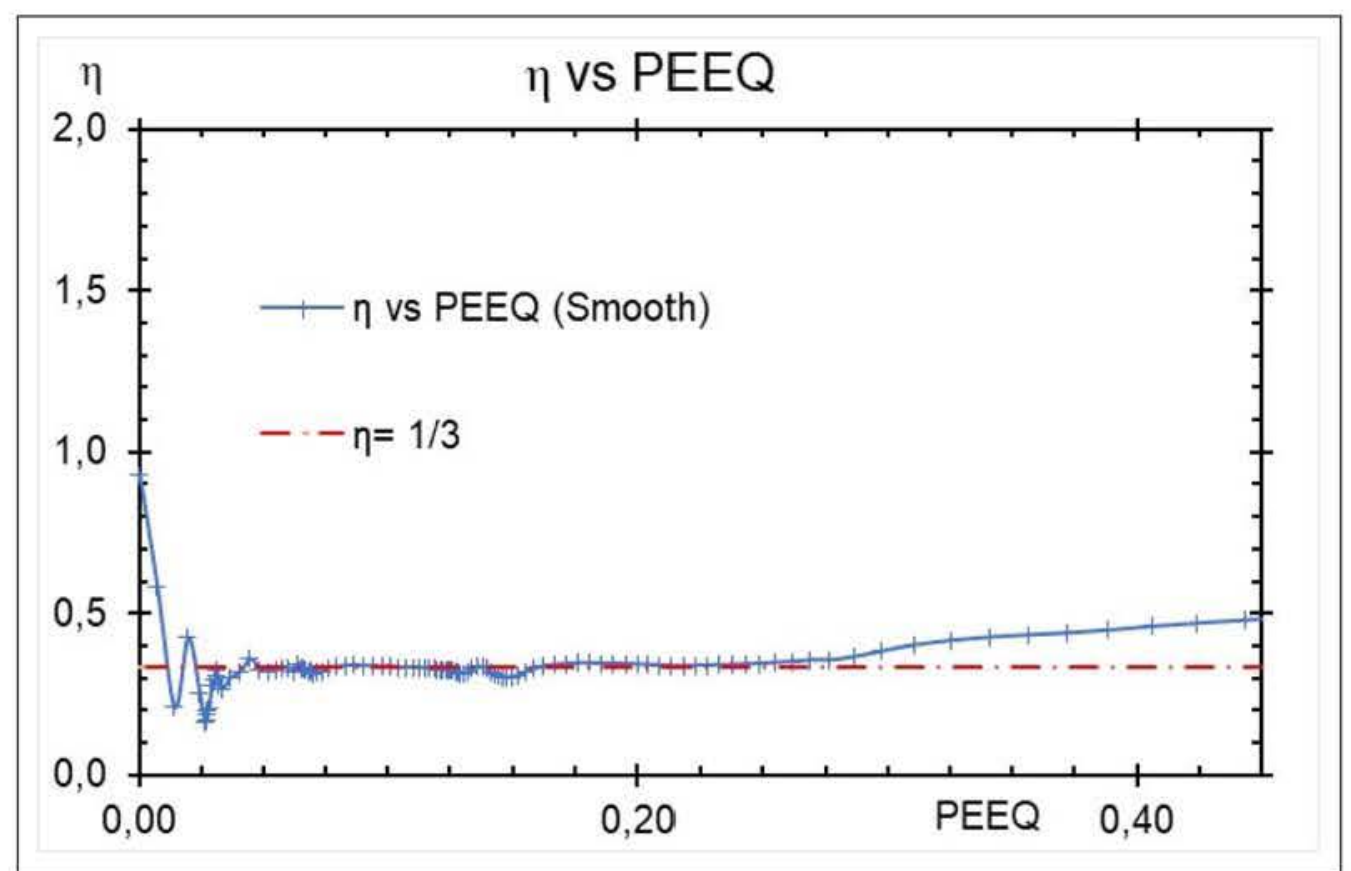

Figure $43 \eta$ vs $P E E Q$ for the smooth specimen subject a tension, numerical result and reference value taken from $\mathrm{Cao}[3]$

Results shown in Figure 43 validate our model and post-processing procedure. Then, it is possible to confirm the results showed in Figure 42. So, those triaxiality values can be used to continue the damage calibration stage.

\subsubsection{Definition of the failure initiation point}

It must be defined when is the moment that the element starts to fail, which is set by using the experimental tests of the notched specimens. Considering the previous information, for each notched specimen, the sudden drop in the stress-strain curve is used as the point to define the initiation of failure as shown in Figure 44. 


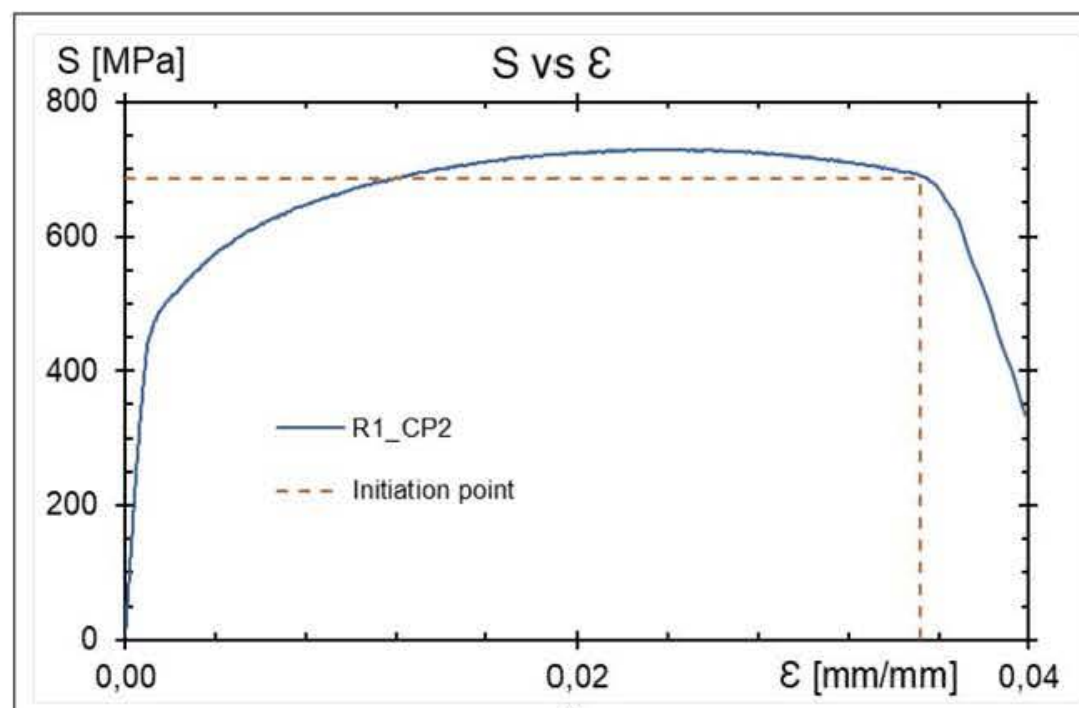

a)

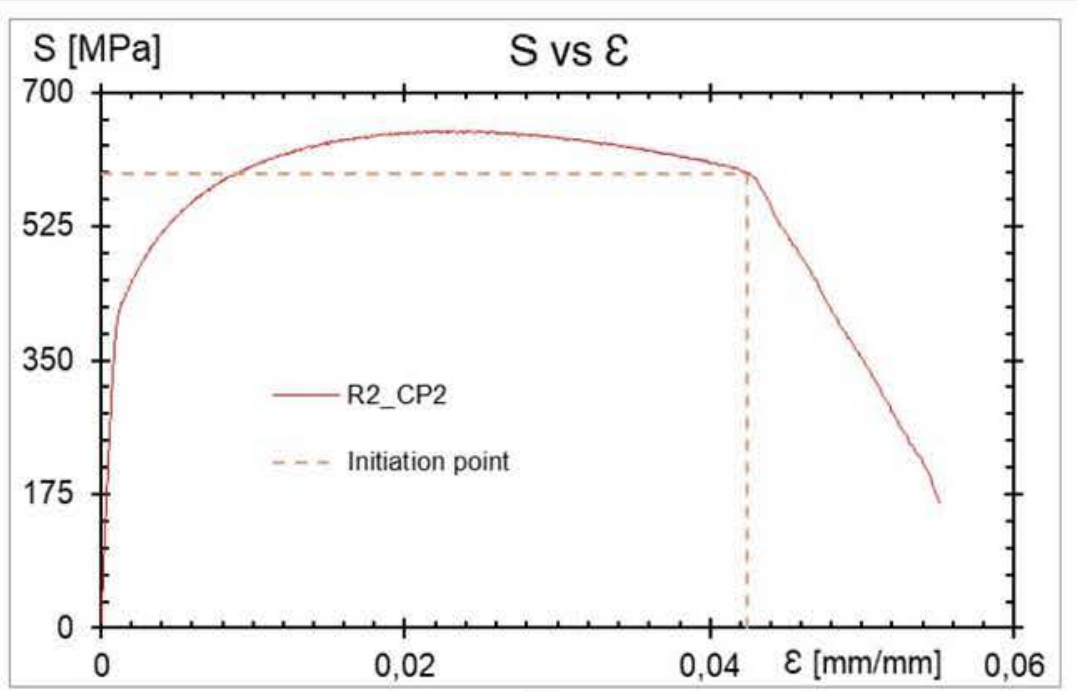

b)
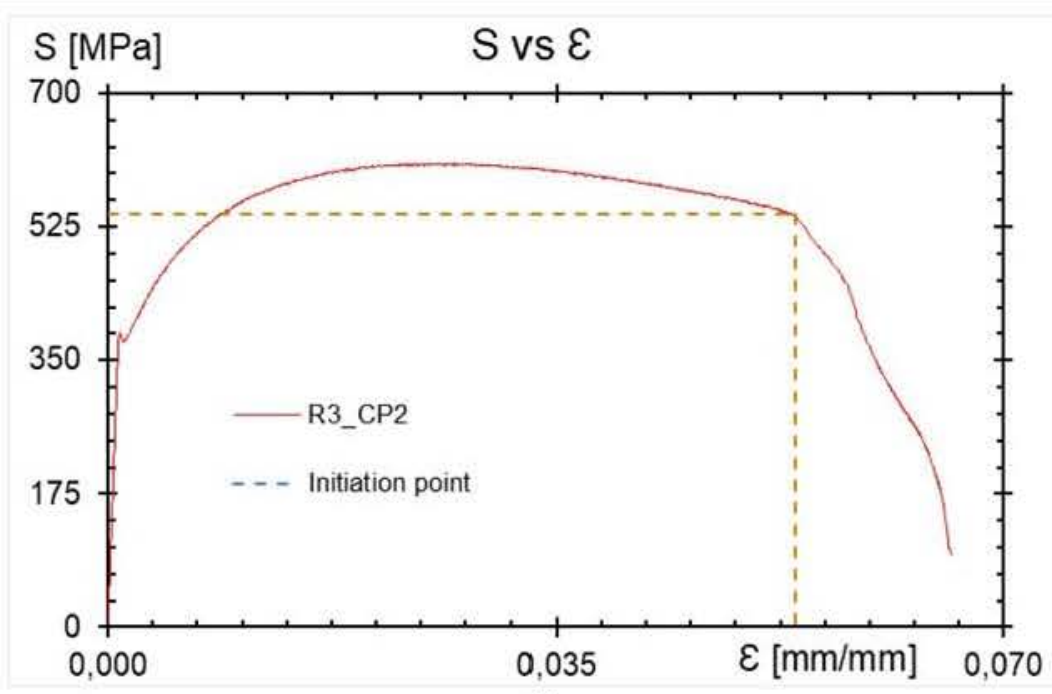

C)

Figure 44 Failure initiation point for the notched tensile specimens at the experimental data for: a) radio $\mathrm{R}=1 \mathrm{~mm}, \mathrm{~b}$ ) radio $\mathrm{R}=2 \mathrm{~mm}$, and, c) radio $\mathrm{R}=3 \mathrm{~mm}$ 
The initiation points define what is the maximum valid value for the " $\eta v S P E E Q$ ". So, we need to know the relationship between the initiation point of failure got from Figure 44 and the PEEQ value of the triaxiality stress graph. Once this process was performed, using the numerical results from Abaqus, the values of failure initiation points are shown in Table 13:

Table 13 Equivalent failure initiation points according to the analyzed graph

\begin{tabular}{|c|c|c|}
\hline $\begin{array}{c}\text { Notched } \\
\text { specimen }\end{array}$ & $\begin{array}{c}\text { Engineering } \\
\text { "S vs } \varepsilon \text { " } \\
\text { graph }\end{array}$ & $\begin{array}{c}\eta \text { vs PEEQ } \\
\text { graph }\end{array}$ \\
\cline { 2 - 3 } & $\varepsilon[\mathrm{mm} / \mathrm{mm}]$ & PEEQ \\
\hline R1 & 0,03519 & 0,1966 \\
\hline R2 & 0,04241 & 0,3508 \\
\hline R3 & 0,05369 & 0,4436 \\
\hline
\end{tabular}

Figure 45 shows the $\eta v$ s PEEQ with the initiation point defined in Table 13.

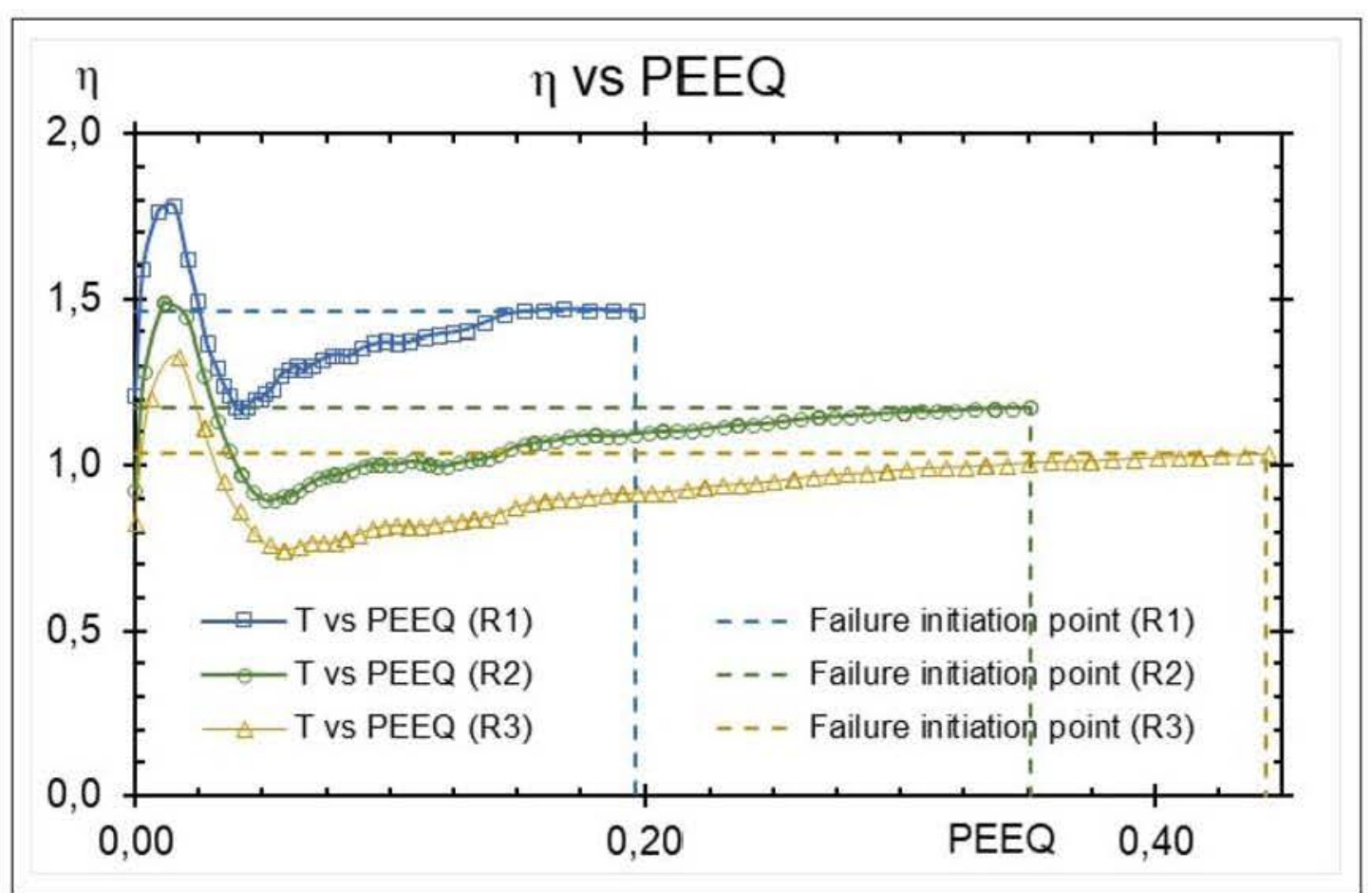

Figure $45 \mathrm{~T}$ vs $\mathrm{PEEQ}$ curves with their respective failure initiation points, for each notched tensile specimen. 
As can be seen in Figure 45, the stress triaxiality changes during the loading path, so it is necessary to define an average value of $\eta$ from the beginning of loading until the point of failure initiation displayed in Figure 44.

Using these defined values, we can continue to the next step of this process which is the calculation of the average stress triaxiality value, $\eta_{\text {ave }}$.

\subsubsection{Definition of the Mean Triaxiality stress value}

Because the triaxiality value is changing from it starts until the failure initiation points, it is required to include that variations. So, it is necessary to determine a mean stress triaxiality for each one of the notched tensile specimens. This calculation is applied to the data shown in the Figure 45 and is performed using Eq. ( 15 ).

$$
\bar{\eta}=\eta_{\text {ave }}=\left(\frac{\sigma_{m}}{\sigma_{e}}\right)_{\text {ave }}=\frac{1}{\varepsilon_{e f}} \int_{0}^{\varepsilon_{e f}} \frac{\sigma_{m}}{\sigma_{e}} d \varepsilon_{e}
$$

Once mean stress triaxiality values had been calculated for each notched specimen, their values are presented in Table 14.

Table 14 PEEQ and Mean triaxiality values for each notched tensile specimen

\begin{tabular}{|c|c|c|}
\hline $\begin{array}{c}\text { Notched } \\
\text { specimen }\end{array}$ & PEEQ & $\eta_{\text {ave }}$ \\
\hline $\mathrm{R}_{1}$ & 0,1966 & 1,4094 \\
\hline $\mathrm{R}_{2}$ & 0,3508 & 1,1021 \\
\hline $\mathrm{R}_{3}$ & 0,4436 & 0,9500 \\
\hline
\end{tabular}

Plotting those values and using a power equation regression with extrapolated value the data observed in Figure 46 are obtained. 


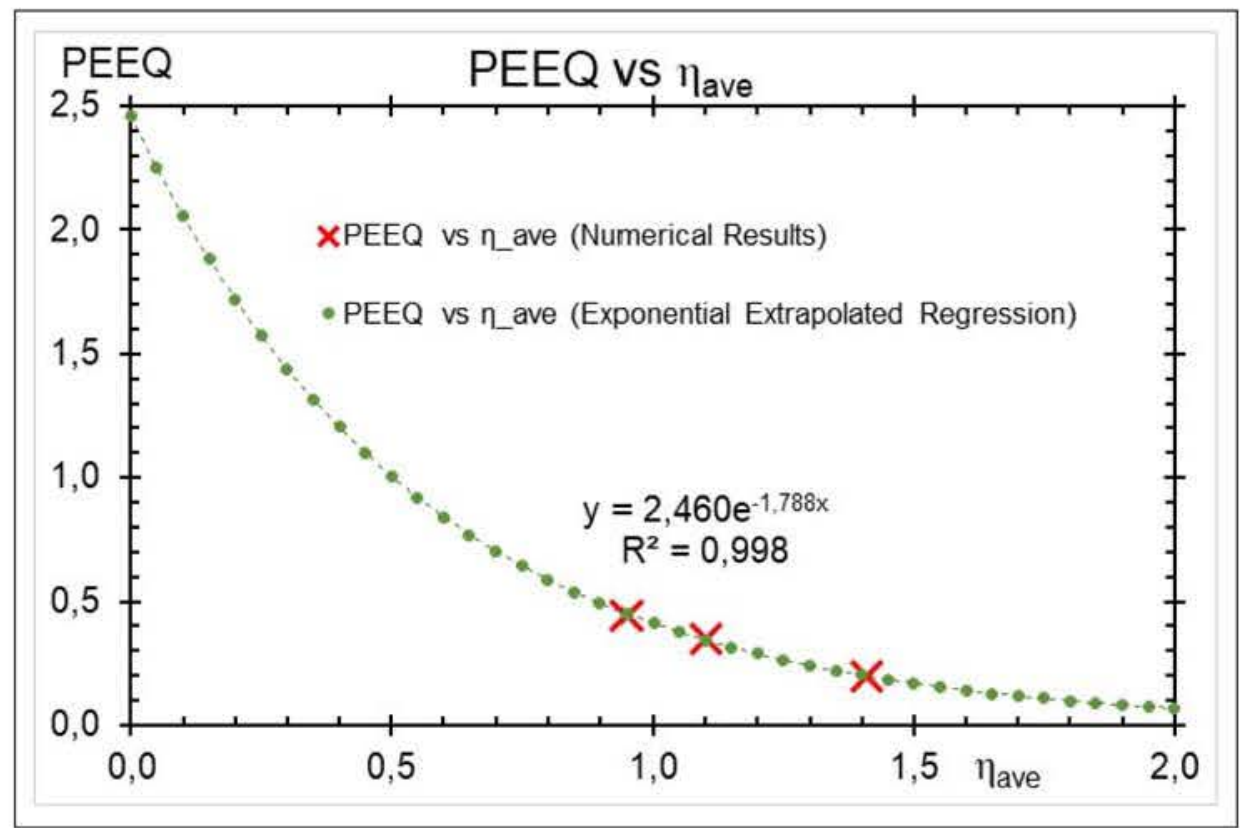

Figure 46 Numerical "PEEQ vs $\eta_{\text {ave }}$ " data and their respective exponential model regression

In Figure 46 is included the equation of the exponential model regression, that shows the correlation between the PEEQ at fracture and mean triaxiality stress values, which it is part of the next step.

\subsubsection{Definition of the SMCS factors}

As it was defined at the section 2.1, the SMCS criterion relates the critical equivalent plastic strain $\varepsilon_{P}^{c r i t}$ with the mean stress triaxiality $\eta_{\text {ave }}$, in the form:

$$
\varepsilon_{P}^{c r i t}=\alpha \exp \left(\beta \cdot\left(\frac{\sigma_{m}}{\sigma_{e}}\right)_{\text {ave }}\right)
$$

Comparing the equation obtained from the Exponential Extrapolated Regression done from the numerical "PEEQ vs $\eta_{\text {ave" }}$ data it is possible to recognize the factors $\alpha$ and $\beta$ which we must use to define the mentioned model for the material, as it is shown in the Table 15. 
Table 15 a) SMCS model equation; b) PEEQ vs $\eta_{\text {ave }}$ equation for the analyzed material

\begin{tabular}{|c|c|}
\hline$\varepsilon_{P}^{\text {crit }}=\alpha \exp \left(\beta \frac{\sigma_{m}}{\sigma_{e}}\right)$ & $\varepsilon_{P}^{\text {crit }}=2,46 \exp \left(-1,788 \frac{\sigma_{m}}{\sigma_{e}}\right)$ \\
a) & b) \\
\hline
\end{tabular}

So, factors $\alpha$ and $\beta$ values are $\alpha=2,460$ and $\beta=-1,788$; which complete the SMCS model for the studied material. Using values obtained from the equation shown in Table $15 \mathrm{~b}$ is possible to add the damage information as mechanical property of the material. After this, the last step defines the "Damage evolution" which will be done using the SEB specimens.

\subsubsection{Definition of Damage evolution}

The final step of the damage calibration is to define the damage evolution, which is made using the experimental results obtained from both deep and shallow crack SEB specimens. The damage evolution is defined as a function of the displacement at failure $\left(\delta_{C T}\right)$ and the exponential softening $(\zeta)$. This last parameter could take three different values to define it in Abaqus as shown in Figure 47.

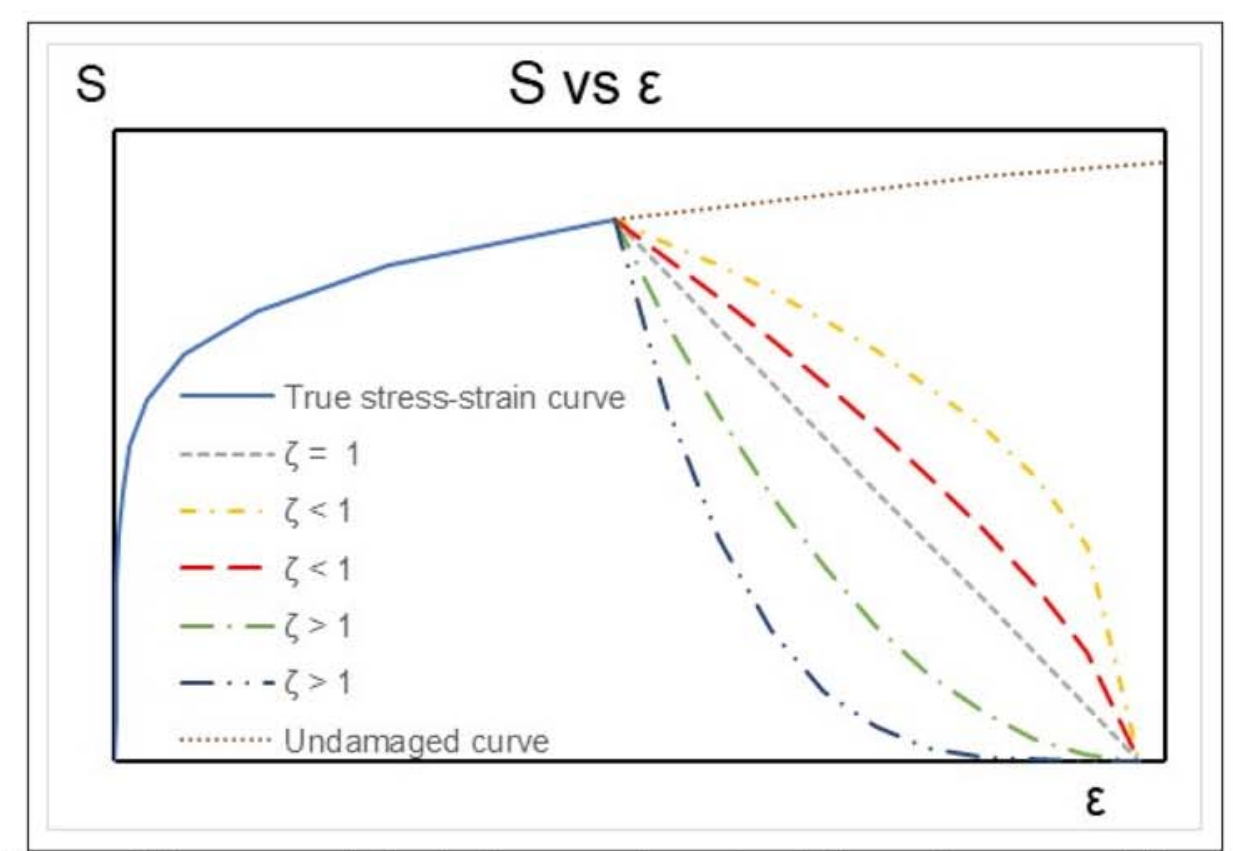

Figure 47 Types of damage evolution in Abaqus, where, $\zeta=1$ : linear damage evolution, $\zeta<1$ and, $\zeta>1$ : exponential damage evolution. 
Where, the possible options that represent the behavior after the initiation of the damage, are described below:

- "Linear" option is used to specify a linear softening stress-strain response for linear elastic materials or a linear evolution of the damage variable with deformation for elastic-plastic materials.

- "Exponential" is used to specify an exponential softening stress-strain response for linear elastic materials or an exponential evolution of the damage variable with deformation for elastic-plastic materials.

In the present study the exponential softening model was used, so it is needed to calibrate these two parameters: displacement at failure $\left(\delta_{C T}\right)$ and exponential softening factor $(\zeta)$. Assuming the exponential softening factor the damage variable (D) is given by, [28]:

$$
D=\frac{1-e^{-\zeta \cdot\left(\bar{u}^{p l} / \delta_{C T}\right)}}{1-e^{-\zeta}}
$$

Where, $\mathrm{D}$ is the damage variable, defined in section 2.2.1 and shown in Figure 8, and $\bar{u}^{p l}$ is the plastic displacement. Then using the Eq. ( 9 ) is obtained the results to continue with the calibration. This calibration is performed using the "P vs CMOD" results and for this case were used those obtained from the deep crack SEB specimens with side grooves. The basic idea is trying to obtain the values of $\delta_{C T}$ and $\zeta$ which let us match the numerical P-CMOD results with its respective experimental curve. Once this is accomplished, it is possible to confirm that the crack in the numerical models enough growing at the same rate that in the experimental one, finishing the calibration of the material. 
After some iterations, where different combinations for $\delta_{C T}$ and $\zeta$ were tried, the selected values are $\delta_{C T}=0.12$ and $\zeta=0.45$, getting the results, for the deep crack SEB specimens, shown in Figure 48.

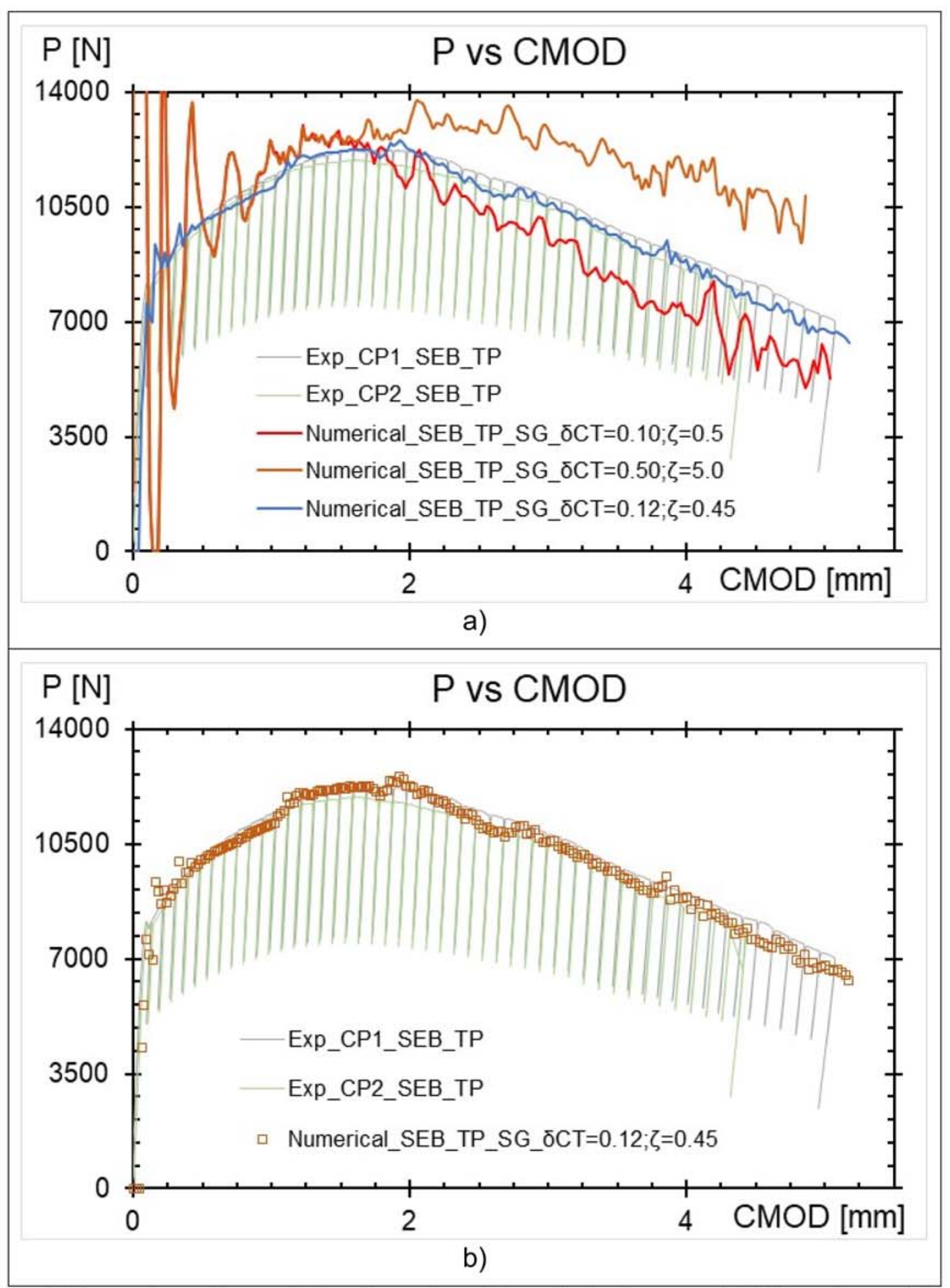

Figure 48 Comparison of numerical and experimental results for deep crack SEB specimen obtained from the calibrated values and lab test respectively: a) Some of the combinations for $\delta_{C T}$ and $\zeta$ tried, and, b) Comparison between experimental results and numerical results using $\delta_{C T}=0.12$ and $\zeta=0.45$ 
Once more, as performed in the elastoplastic calibration where was demonstrated the calibration worked for both smooth and notched tensile specimens, it is needed to check the capability of the final model, which includes damage, to predict the mechanical response for other level of stress triaxiality (constraints). So, the calibrated parameters were also used in the (SEB) shallow cracked both with side and without side grooves, getting results shown in Figure 49:

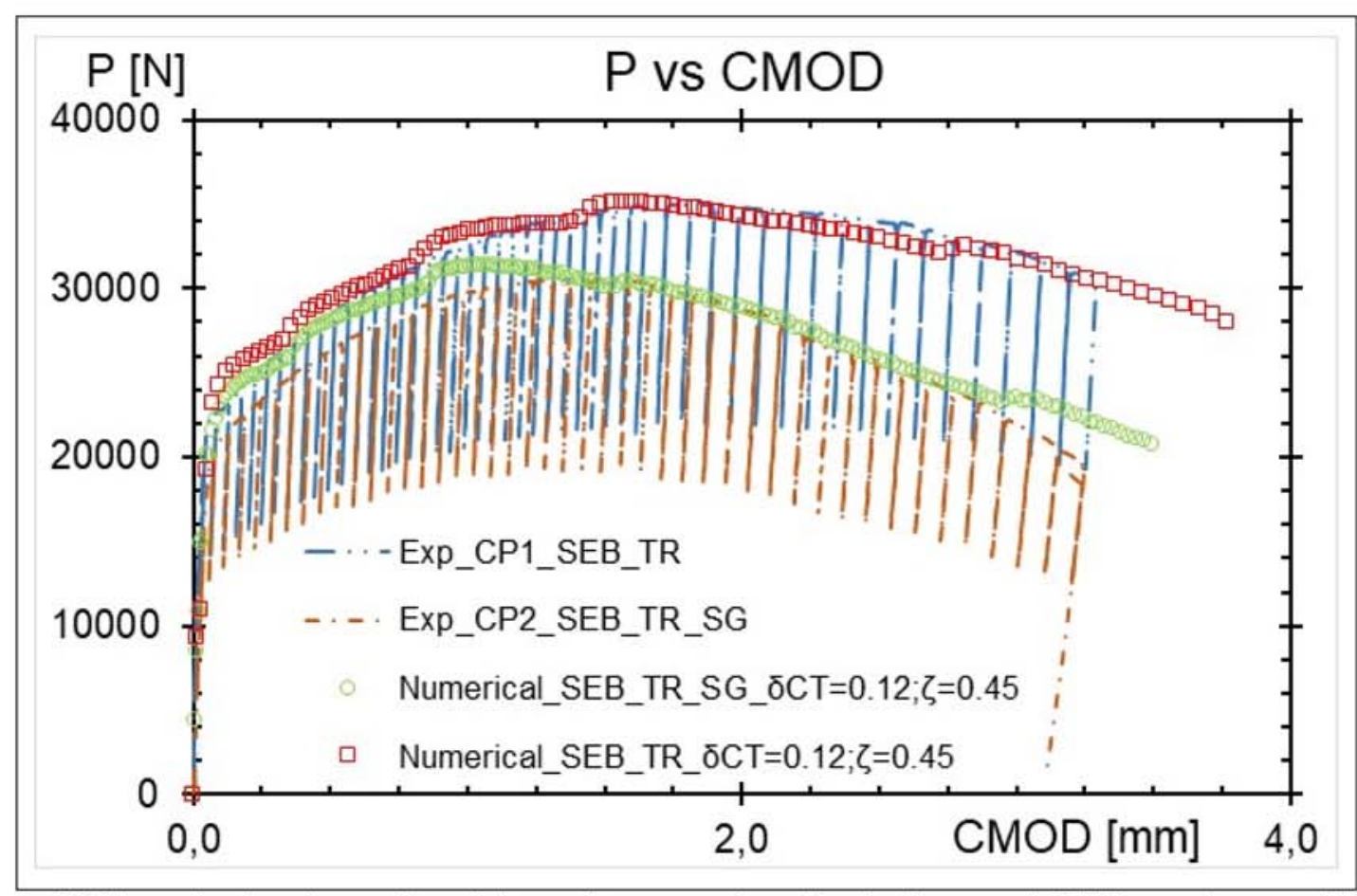

Figure 49 Numerical and experimental results comparison for shallow crack SEB specimens with and without side grooves, got from the calibrated values and lab test respectively.

Figure 49 shows that there was a good match between the numerical prediction and the experimental results. Thus, it is worth to mention the capability of the model to recover the influence of the side groove in the analyzed specimens. This lets to know that the model to characterize the elastoplastic mechanical properties of the analyzed material, steel A285, was successfully completed. 


\subsection{CRACK GROWTH PREDICTION}

Once the identification of mechanical properties for the A285 steel has been performed, a further verification of the current calibration comprehends the comparison of the final crack extension in the numerically models of SEB specimens with the experimental measurements of ductile crack growth made after testing. This check was done to determine how accurate is the model to predict the crack growth due to an applied load.

To do this, firstly the final crack size in each SEB specimen was measured using a high-resolution photo of the fracture surface. Figure 50 shows a sketch of the final crack measurement and the tested SEB specimens with the control points used to comply the measuring of the crack profile. To measure the final crack dimension, the tested SEB specimens, both type shallow and deep crack were broken in liquid nitrogen, as seen in Figure 51, where the figure shows the specimens with their respective names defined in Table 5.

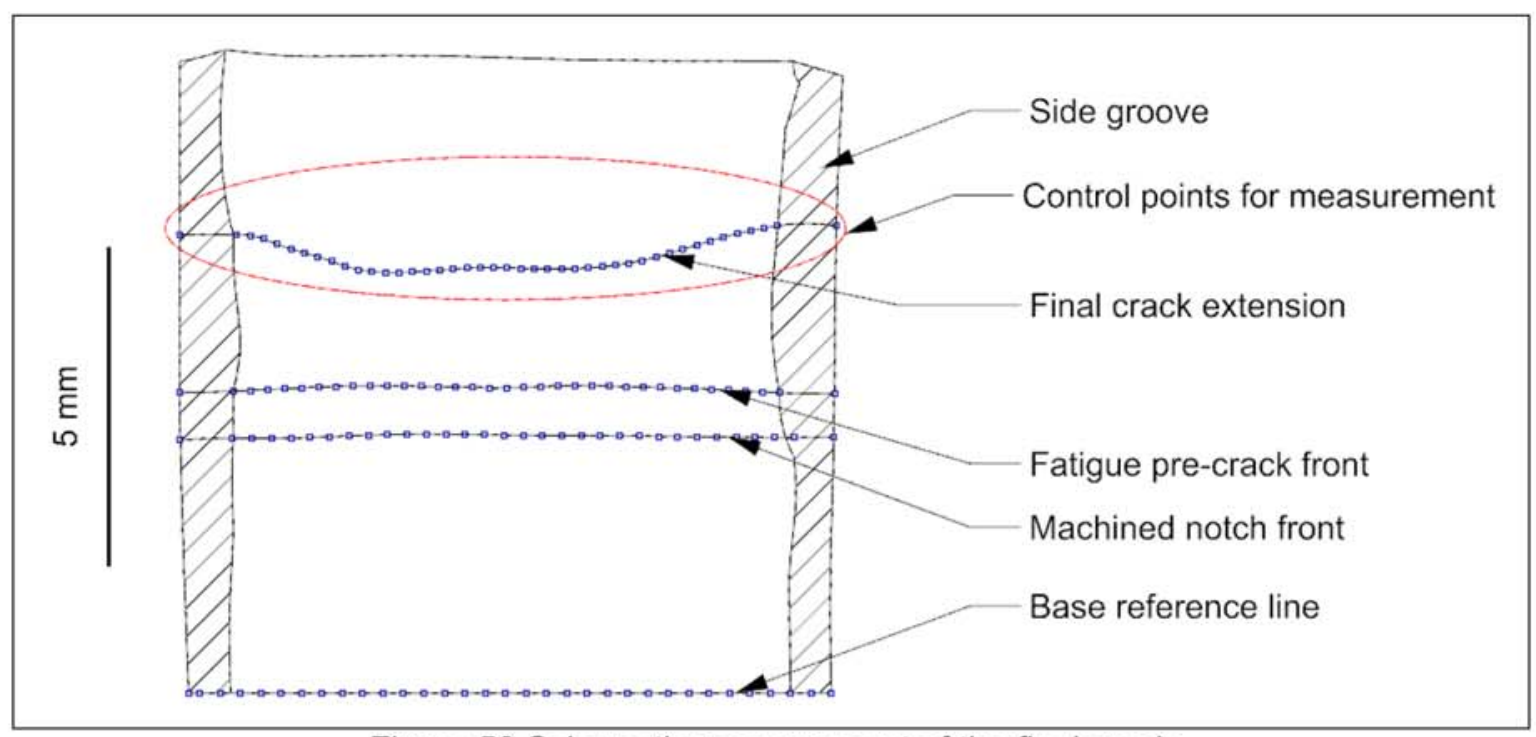

Figure 50 Schematic measurement of the final crack 


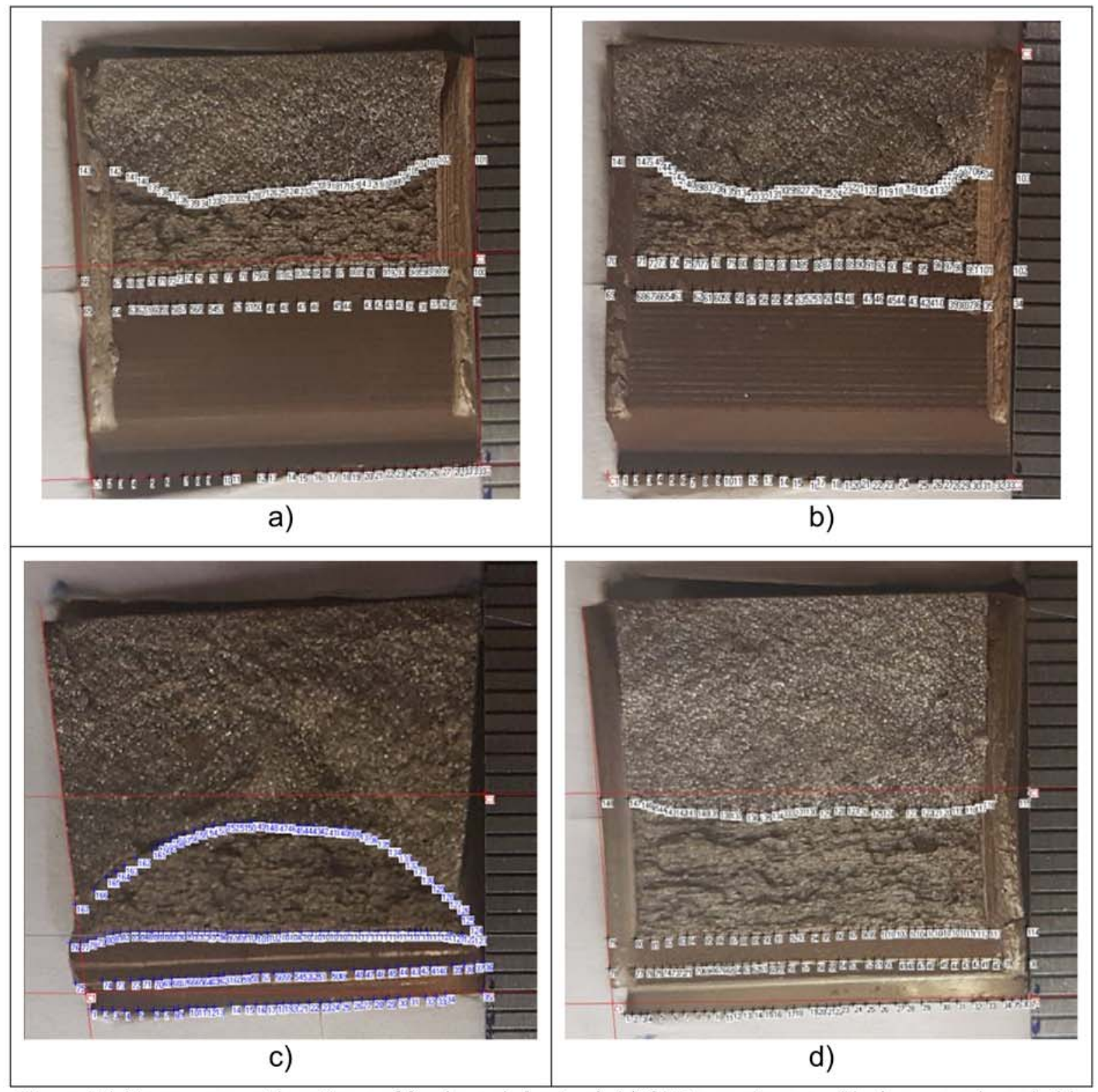

Figure 51 Measurement locations of final crack front, a), b) SEB specimens with deep crack and side grooves SP5-1 and SP5-2 respectively; c) SEB specimen with shallow crack and no side grooved SP4-2, d) SEB specimen with shallow crack and side grooved SP4-1

Figure 51 shows the difference between the final crack front extension of the specimens with and without side grooves, where the SEB specimens with side grooves has a final crack front flatter than the SEB specimens without side grooves, as described in Smith and Patchett [33].

Then, to measure technically the final crack extension was used the parameters defined in ASTM E1820 [37], which propose rules to do it, including a correction when the specimen has or not a side grooved. Once those parameters were applied, the final crack dimension for each specimen are shown in Figure 52 and Figure 53. 


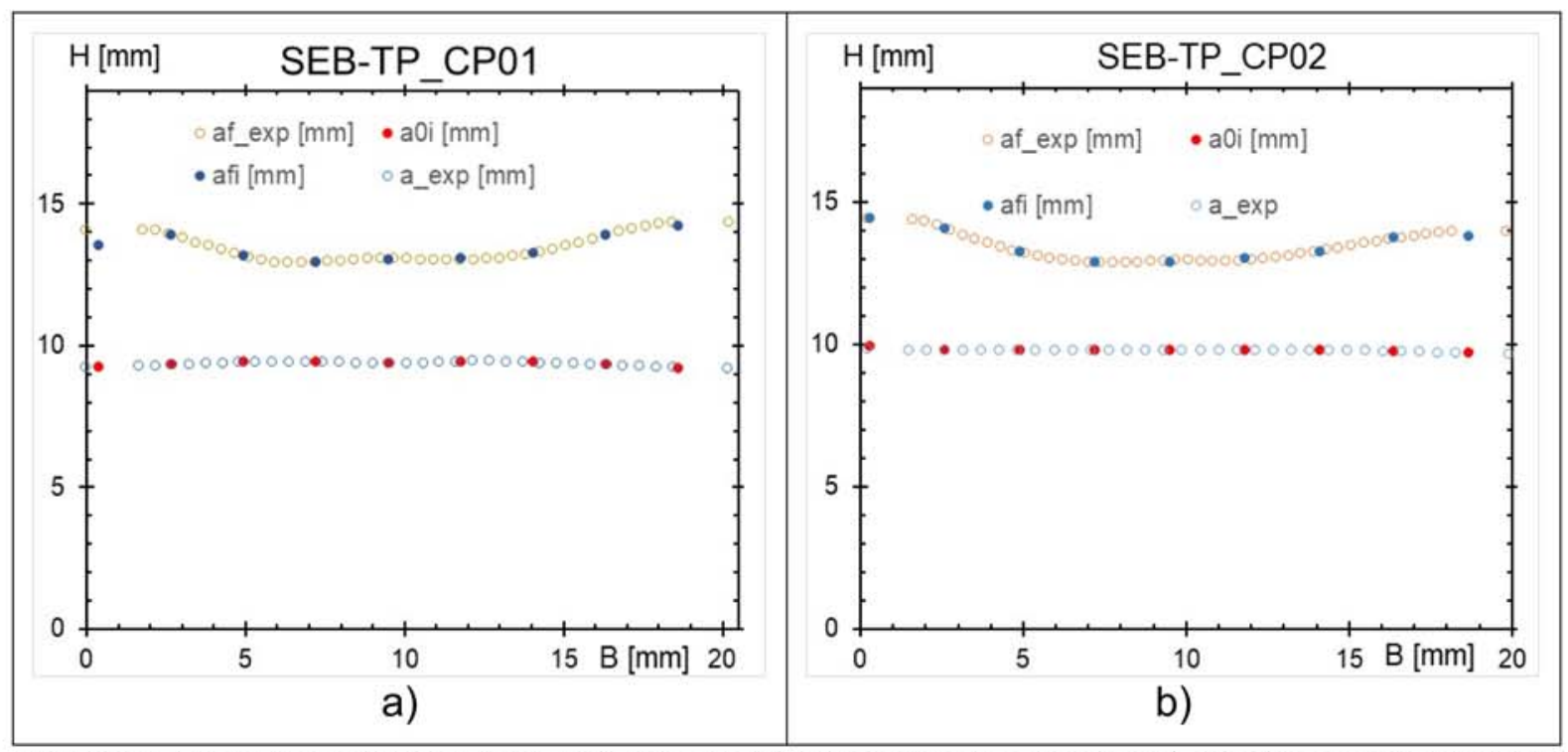

Figure 52 Experimental and calculated initial and final crack extension for, a), b) SEB specimens with deep crack and side grooves SP5-1 and SP5-2 respectively

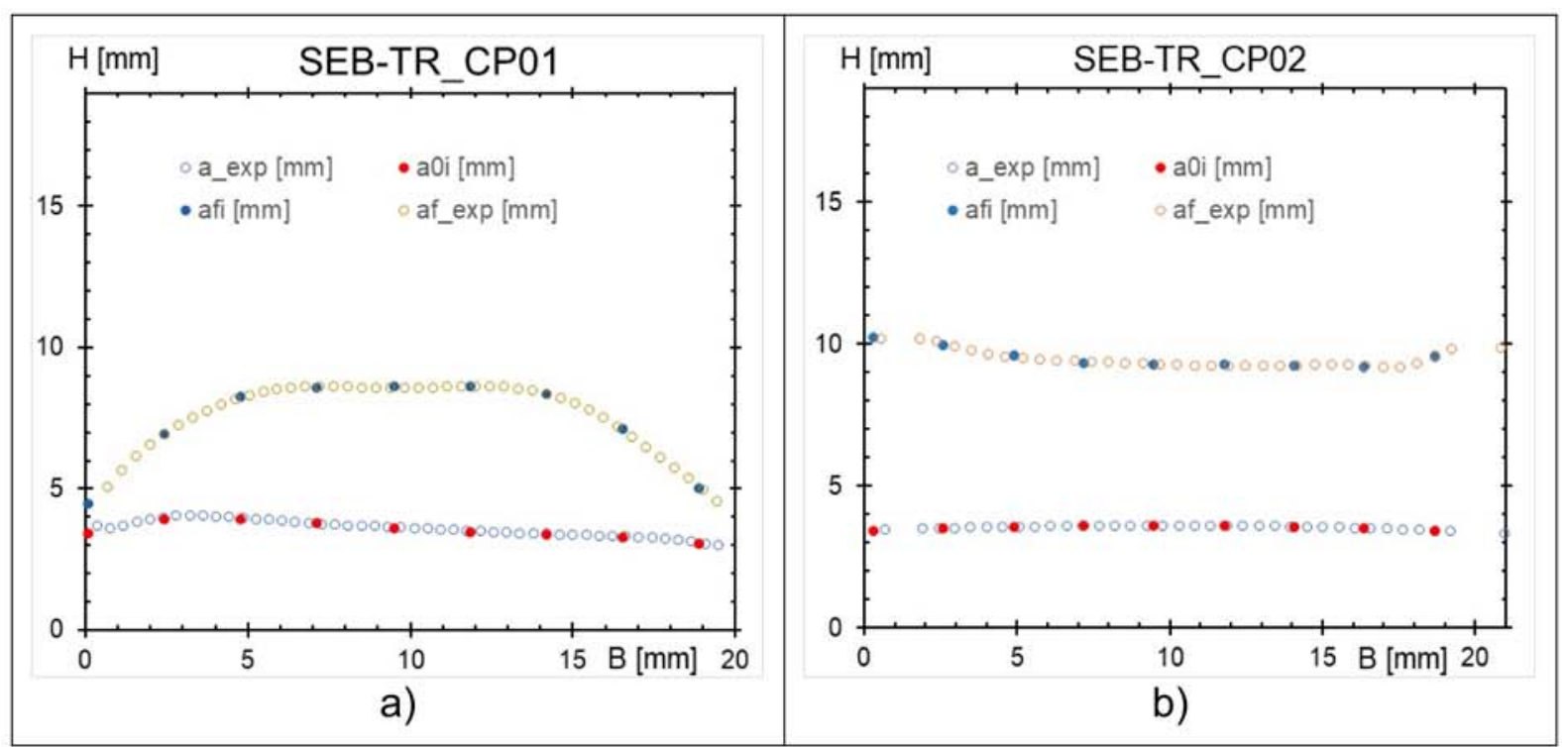

Figure 53 Experimental and calculated initial and final crack extension for a) SEB specimen with shallow crack and no side grooves SP4-2, b) SEB specimen with shallow crack and side grooves SP4-1

It is possible to observe the experimental initial crack and final crack extension represented with unfilled dots, and its respective calculated values represented with filled dots in Figure 52 and Figure 53. 
Consequently, the SEB numerical models were analyzed at the same final load applied for each specimen during the testing, to obtain the numerical final crack extension and compare those results with the shown in Figure 52, which are the experimental results. This allows us to evaluate how reliable the characterized model is to predict the crack growth under an applied load. Thus, those numerical results plotted with the experimental, are shown in Figure 54 and Figure 55.

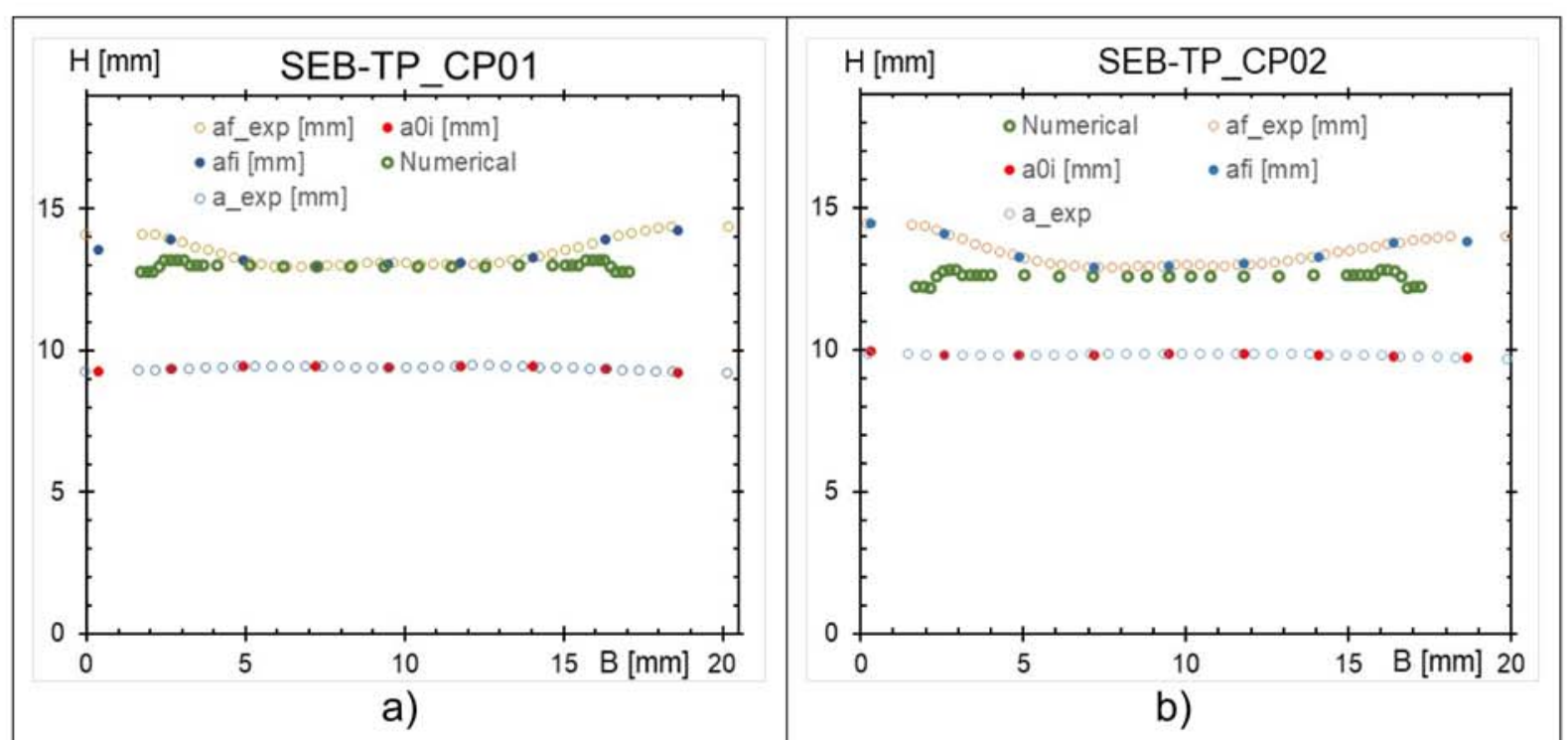

Figure 54 Experimental and numerical final crack extension for, a), b) SEB specimens with deep crack and side grooves SP5-1 and SP5-2 respectively

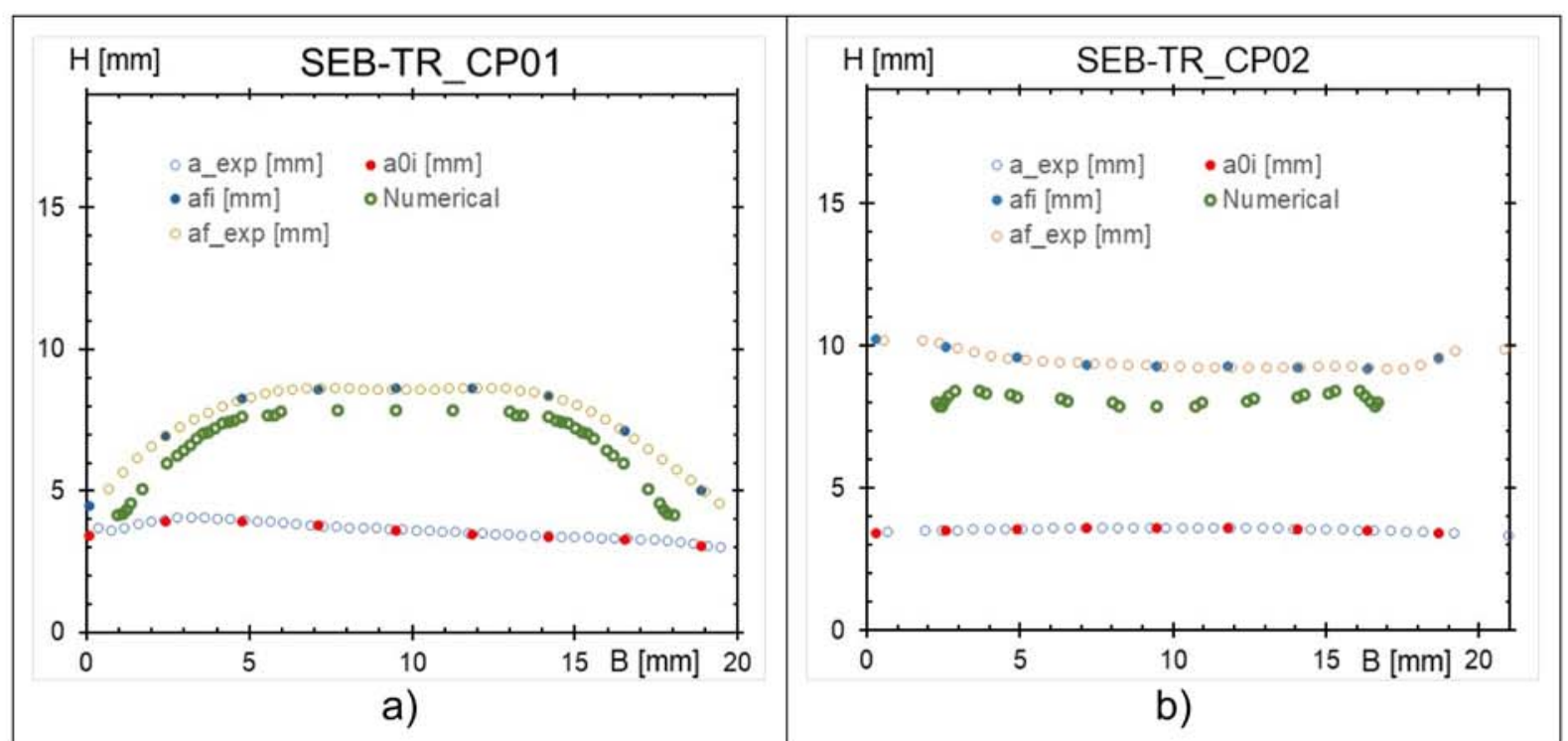

Figure 55 Experimental and numerical final crack extension for a) SEB specimen with shallow crack and no side grooves SP4-2, and b) SEB specimen with shallow crack and side grooves SP4-1 
Figure 54 and Figure 55 show the final crack extension, plotted as green dots, obtained with the numerical response of the SEB FE models, and compare those values with the experimental results. According that comparison is remarkable that better results were obtained in the deep crack SEB specimens than the shallow crack specimens, and the reasons could be the following:

- There was noticed that the initial crack of the shallow SEB model has a little difference comparing it with the experimental specimen.

- The specimens have some irregularities inherent of the machining stage which can cause a different response than if they have a perfect shape.

Finally, it is possible to affirm the characterized model was able to simulate the damage propagation and it can predict properly the final crack extension in SEB specimens having different levels of crack-tip triaxiality.

\subsection{MESH SIZE EFFECT}

It is well known that the mesh size affects directly on the results obtained in simulations performed using finite element methods. So, it is necessary to analyze what are the effects on the results of this study due to the selected mesh and their respective refinement at the area of interest, which for all models is located at the symmetry plane where the fracture occurs.

Since different numerical models are used for each process of the characterization of the material, the influence of the mesh is studied for each calibration done as it is shown below.

\subsubsection{Mesh size effect on elastoplastic calibration}

For the elastoplastic calibration the smooth and notched tensile load specimens have been used. For selections of final meshes, there were evaluated different combinations changing the mesh density with two main objectives: reduce the computational time of analysis and obtain an adequate response with the minimal error between the numerical and experimental results. 
In Figure 56 are plotted three attempts of meshing sizes to mesh the smooth specimen.

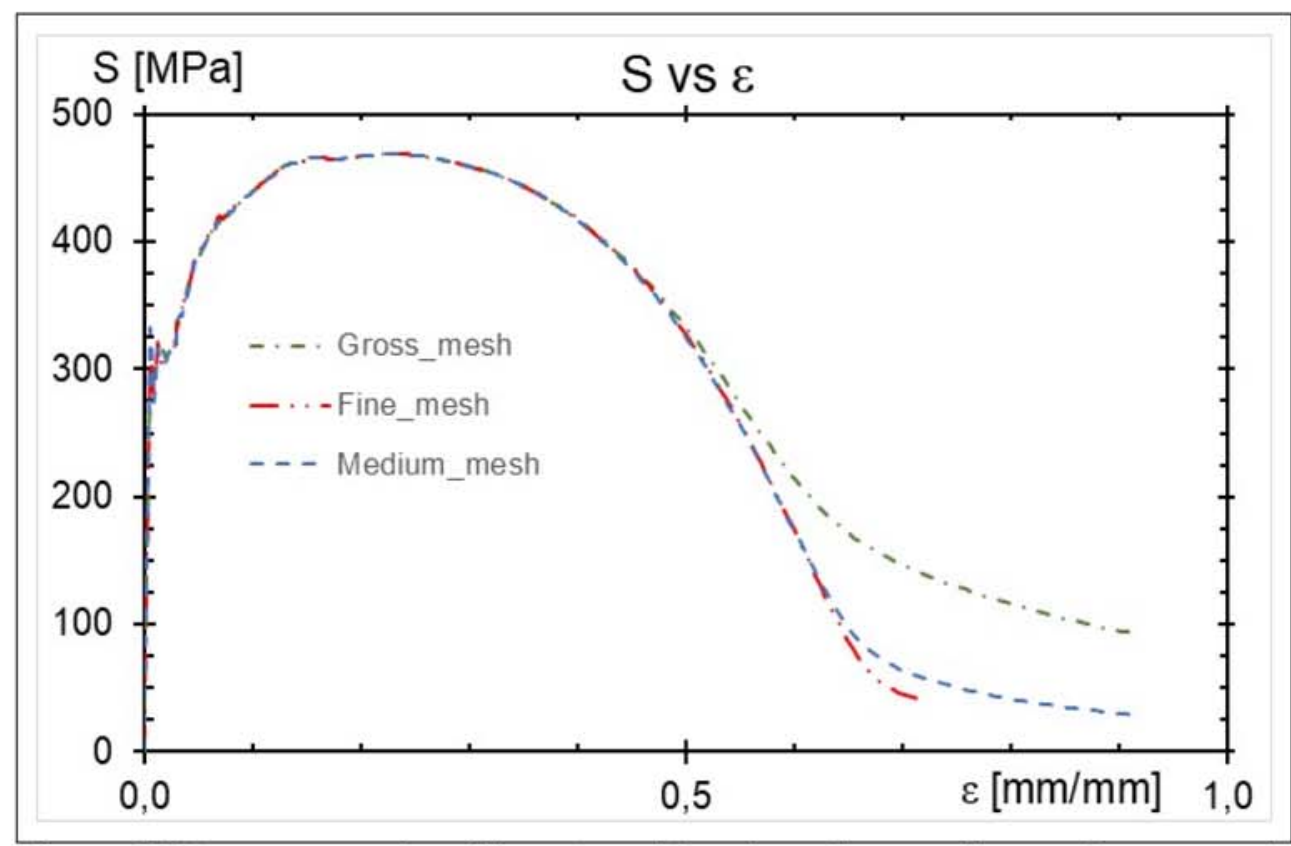

Figure 56 Responses using different meshing sizes: fine, medium and gross mesh

Where, each attempt named: gross, fine, and medium mesh, have the quantity of nodes and elements shown in Table 16.

Table 16 Quantity of nodes and elements for three attempts of meshing techniques

\begin{tabular}{|l|c|c|c|}
\cline { 2 - 4 } \multicolumn{1}{c|}{} & Gross_mesh & Medium_mesh & Fine_mesh \\
\hline Nodes & 15500 & 32240 & 102960 \\
\hline Elements & 13800 & 29325 & 96836 \\
\hline Comp. Time (hr.) & 2 & 4 & 12 \\
\hline
\end{tabular}

Making a comparison between responses obtained with each meshing technique, it is possible to determine that using a gross quantity of elements/nodes results are very different that results obtained with the fine mesh technique. However, there is a difference of almost 10 hours of computational time for those extreme opposite meshing techniques. So, analyzing the medium mesh, the response is almost similar as obtained with the fine mesh, but reducing significantly the computational time from 12 to 4 hours, which defines the mean elements quantity of 30000 as an efficient mesh for the specimens. 
So, it was chosen a medium mesh whose minimal size element is located at the symmetry plane, having size of $0,100 \times 0,075 \times 0,075 \mathrm{~mm}$. The biggest elements are in the opposite side of the symmetry where failure occurs meaning they are far away from the interest area, and its dimensions are 1,820 $\times 1,137 \times 1,044 \mathrm{~mm}$. Once these references values, which allowed to obtain good responses, were found then all numerical models to represent the tensile load specimens were developed following these specifications, what significantly reduced the computational cost of the analysis.

Finally, once the mesh size is defined, the processing time could still be optimized using other factor named "Mass scaling factor", whose value must be chosen as well. This process is detailed in the section 4.3.3.

\subsubsection{Elements size effect on damage calibration}

After the global mesh size had been defined for all models, for the damage calibration stage is necessary to define the element size which are in the symmetry plane in the SEB numerical models, where the failure occurs. According Paredes et al. [12], element size of $0,2 \mathrm{~mm}$ for damage calibration (initiation of failure and crack propagation) has a good relationship between the accuracy and computational cost. So, this element size was used to model the fracture propagation zone, obtaining good results which were shown in sections 4.1.2 and 4.2.

Then, once the calibration was performed using in the damage zone the maximum element size $0,2 \mathrm{~mm}$, there was analyzed how the results are affected due to the use of different element size at the damage area. Thus, there were elaborated two more meshes for the shallow crack SEB numerical model using different element size than used to calibrate the damage in this study, being the new elements dimensions: 0,1 and $0,4 \mathrm{~mm}$; and the results of this analysis are shown in Figure 57. 


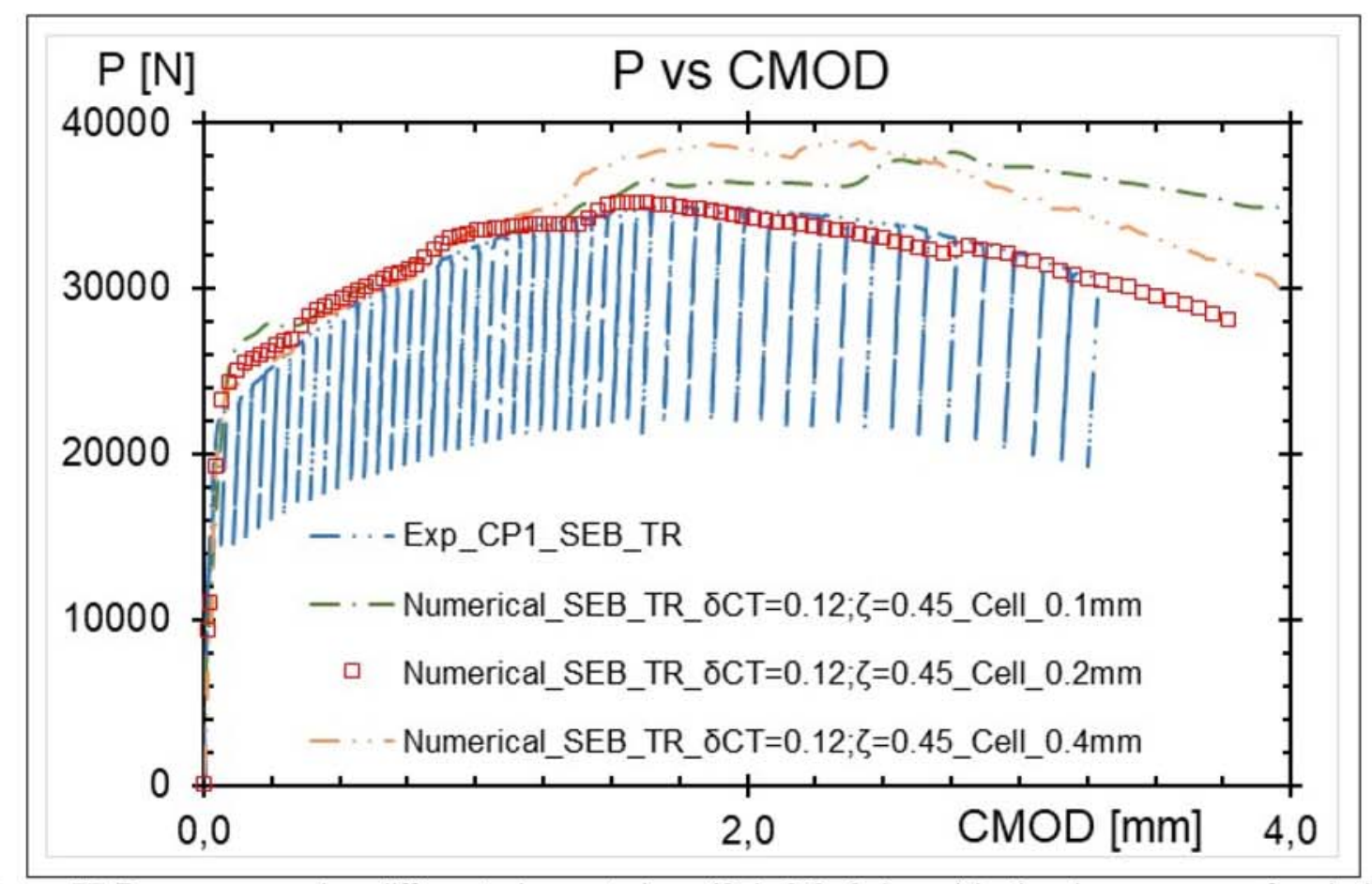

Figure 57 Responses using different element sizes $(0.1,0.2,0.4 \mathrm{~mm})$ in the damage area for shallow crack SEB numerical models

Figure 57 shows the comparison of numerical results using different element sizes to model the damage area where the crack growth happens. As seen, the results using element size $0,2 \mathrm{~mm}$ match with the experimental results, because this element size was used for performing the calibration of the softening as explained in section 4.1.2. However, the responses for the same specimen modeled with the same mechanical properties are different when the element size 0,1 and $0,4 \mathrm{~mm}$ are used. Despite using the same calibrated parameters to characterize the elastoplastic and damage behavior of the material, the numerical response is highly sensitive to the selected element size. The SMCS model can be said to be mesh-dependent. Similar results has been reported using the SMCS approach by Bae et al. [38]. The same drawback has been reported for the Gurson-Tvergaard model [39], [40].

Therefore, numerical model of complex structures, such as pressure vessels or pipelines, must be performed with mesh size elements identical to the specimens used during the calibration procedure. 


\subsubsection{Mass scaling factor definition}

Once the meshes were defined for numerical models, a "Mass scaling factor" which help us to reduce the processing time to solve the numerical models, was used in this study. According Abaqus manual [28], mass scaling is often used in Abaqus for computational efficiency (speed up) in some dynamic analysis. It is a parameter that can be used by some procedures, being used in this study to scale the mass of entire model using a constant factor to modify all elements in the numerical model.

The mass scaling is a modification in the density of the material for some elements, due to the time involved in running a simulation using explicit time integration with a given mesh is directly proportional to the time of the event. This is because numerical stability considerations restrict the time increment to Eq. ( 21 ), [41].

$$
\Delta t \leq \min \left(L e l \cdot \sqrt{\frac{\rho}{\lambda+2 \mu}}\right)
$$

Where the minimum is taken over all elements in the mesh, Lel is a characteristic length associated with an element, $\rho$ is the density of the material in the element, and $\lambda$ and $\mu$ are the effective Lamé's constants for the material in the element. Then, the cost of the simulation is directly proportional to the number of time increments required as seen in Eq. ( 19 ).

$$
n=\frac{T}{\Delta t}
$$

Where, $T$ is the time period of the event being simulated. So, finally the number of time increments is represented by the Eq. ( 20 ).

$$
n=T_{\max }\left(\frac{1}{L^{e l}} \cdot \sqrt{\frac{\lambda+2 \mu}{\rho}}\right)
$$


Thus, to reduce $n$, there are possible two options, increment the time of the simulation $(T)$, or simply add an equivalent-artificially increasing in the material density which is called the "mass scaling" [41].

To determine the right value of the mass scaling factor it is needed to understand its effect in dynamic explicit analysis. Thus, some mass scaling values were tested using the notched tensile load numerical model (R2) analyzed at the same conditions, obtaining the responses plotted in Figure 58.

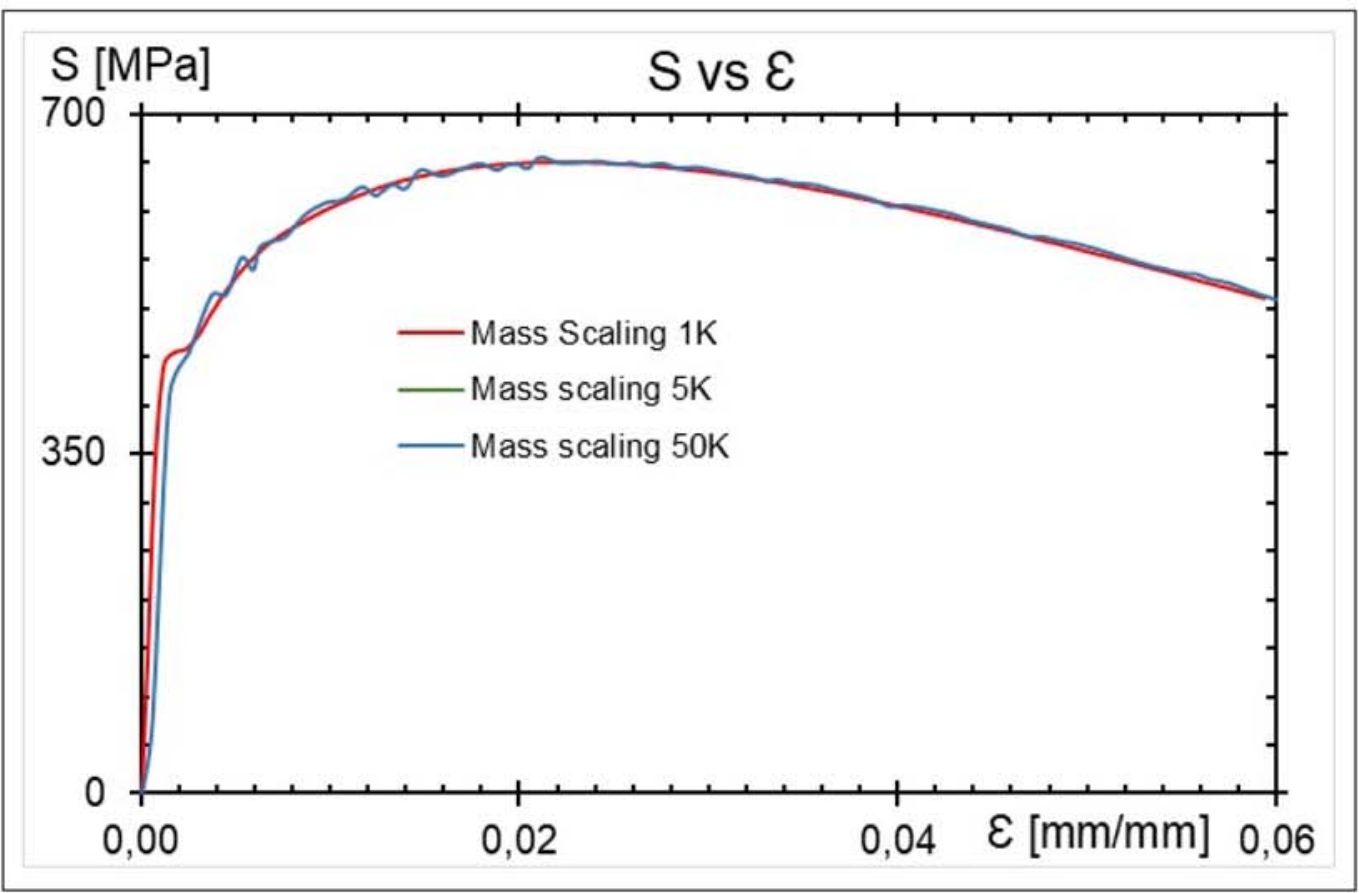

Figure 58 Responses using different mass scaling factors for notched tensile load numerical model (R2), where $\mathrm{K}=1000$

Figure 58 shows oscillations on the response for high values of the mass scaling factor and better (smooth) response for lower values. For these analyses the value 1000 was used as mass scaling factor, due to that value allow to reduce the computational time and smooth the response.

The oscillations in the response mentioned in Figure 58 are more evident in the damage calibration, which was developed using SEB numerical models. Figure 59 shows the critical impact of the mass scaling factor during this stage comparing the response between two different attempts to calibrate the model using different mass scaling factors. 


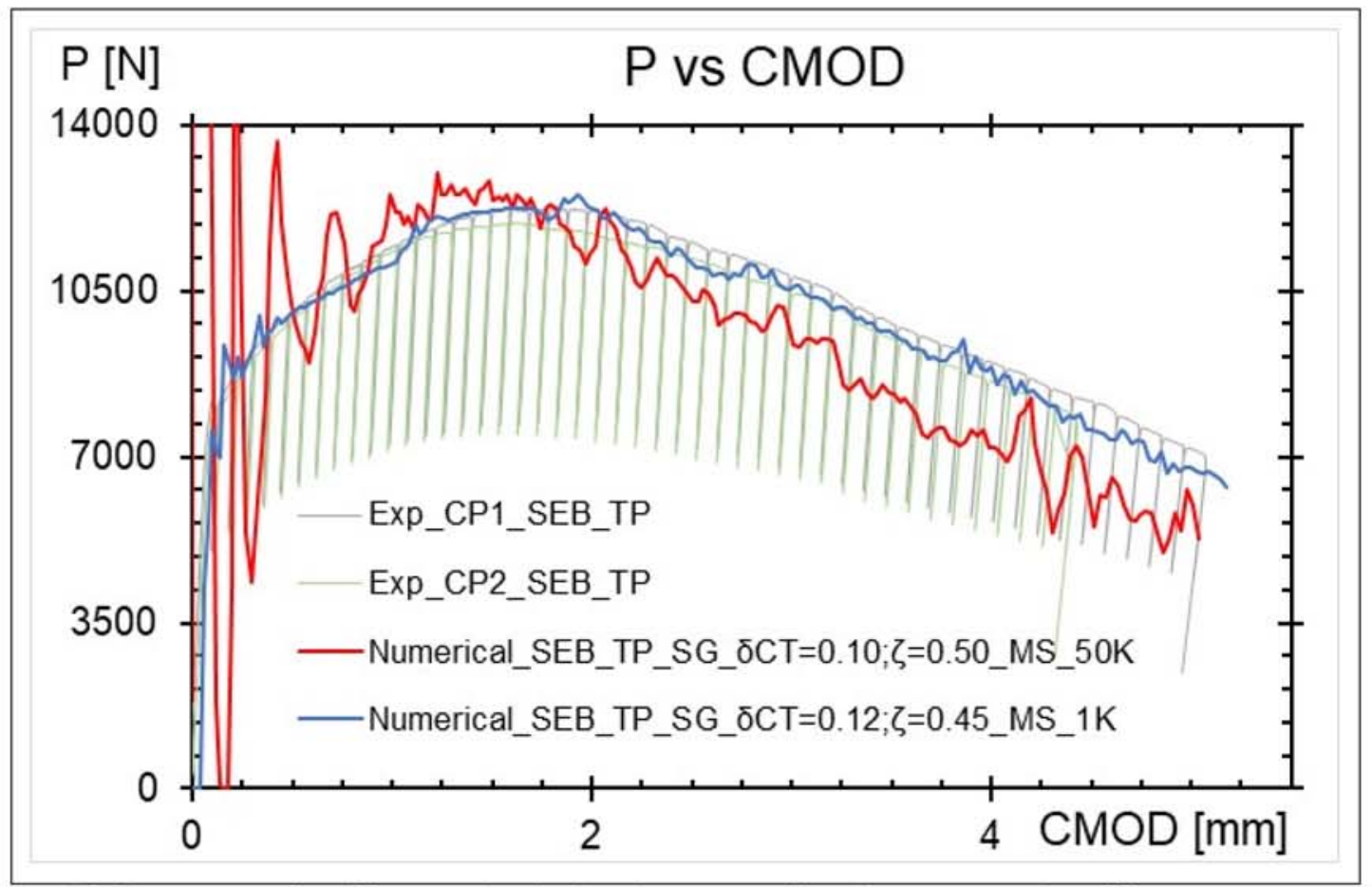

Figure 59 Responses for different tries in the damage calibration stage using different mass scaling (MS) factors, where $\mathrm{K}=1000$

Figure 59 shows two numerical results using $50 \mathrm{~K}$ and $1 \mathrm{~K}(\mathrm{~K}=1000)$ as mass scaling factor and it is possible notice the effect of this value in results, i.e. the response is smoother when the factor is decreased. So, in conclusion the mass scaling factor helps to optimize the computational time, but its value should be selected rationally to take advantage using it and not losing data due to oscillations in results. 


\subsection{DAMAGE INDICATOR FACTOR ANALYSIS}

As mentioned at section 2.2.1, Eq. ( 7 ) describes the damage indicator factor (DI), which is a value based upon Rice \& Tracey [42] and used to determine the most damaged site for failure initiation [36]. Replacing values in the damage indicator equation, using the SMCS criterion characterized in the present study for the A285 steel, the level of damage as function of the applied loading is obtained [36].

$$
D I=\omega_{D}=\int \frac{d \bar{\varepsilon}^{p l}}{\bar{\varepsilon}_{D}^{p l}\left(\eta, \dot{\bar{\varepsilon}}^{p l}\right)}=\int \frac{d \varepsilon_{e}^{p l}}{\varepsilon_{P}^{c r i t}}=\int \frac{d \varepsilon_{e}^{p l}}{\alpha \exp \left(\beta \frac{\sigma_{m}}{\sigma_{e}}\right)}
$$

Using $\alpha=2,460$ and $\beta=-1,788$, the $D I$ equation is set as:

$$
D I=\int \frac{1}{2,46} \cdot \exp \left(1,788 \frac{\sigma_{m}}{\sigma_{e}}\right) \cdot d \varepsilon_{e}^{p l}
$$

Where $\varepsilon_{e}^{p l}$ is defined as equivalent plastic strain which was denoted as PEEQ in this document.

Thus, analyzing the $D I$ for the round bar specimens to identify what point is more sensitive to failure, comparing the center and the free surface point at symmetry plane ( $x=0$, see Figure 20 for reference of coordinate system) where crack occurs. The distances " $r$ " of those points are normalized with respect " $R$ " which is the radius of a round bar at the notch. So $\frac{r}{R}=0$ and $\frac{r}{R}=1$ are points located at the center and the free surface, respectively, as seen in the schema shown in Figure 60. Figure 61 shows the $D I$ as function of the normalized load, $N L^{9}$, which starts at $N L=0$ and finish at $N L=1$, what means the minimum and maximum tensile load applied to each specimen. For each round bar specimen, the maximum tensional axial applied loads are $15 \mathrm{~mm}$ for the smooth specimen, and $1 \mathrm{~mm}$ for the NRB_R1, NRB_R2 and NRB_R3 specimens.

${ }^{9} N L=\frac{L_{i}}{L_{\max }} ; L_{i}$ is the instantaneous load applied, and, $L_{\max }$ is the maximum applied load 


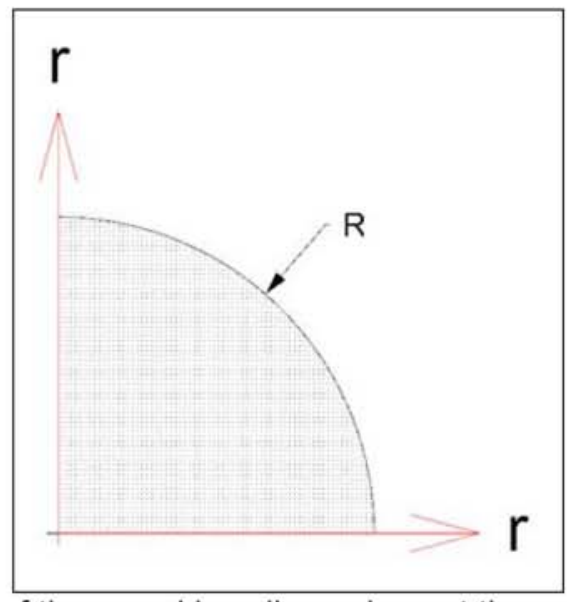

Figure 60 Schema of the round bar dimensions at the symmetry plane $(x=0)$

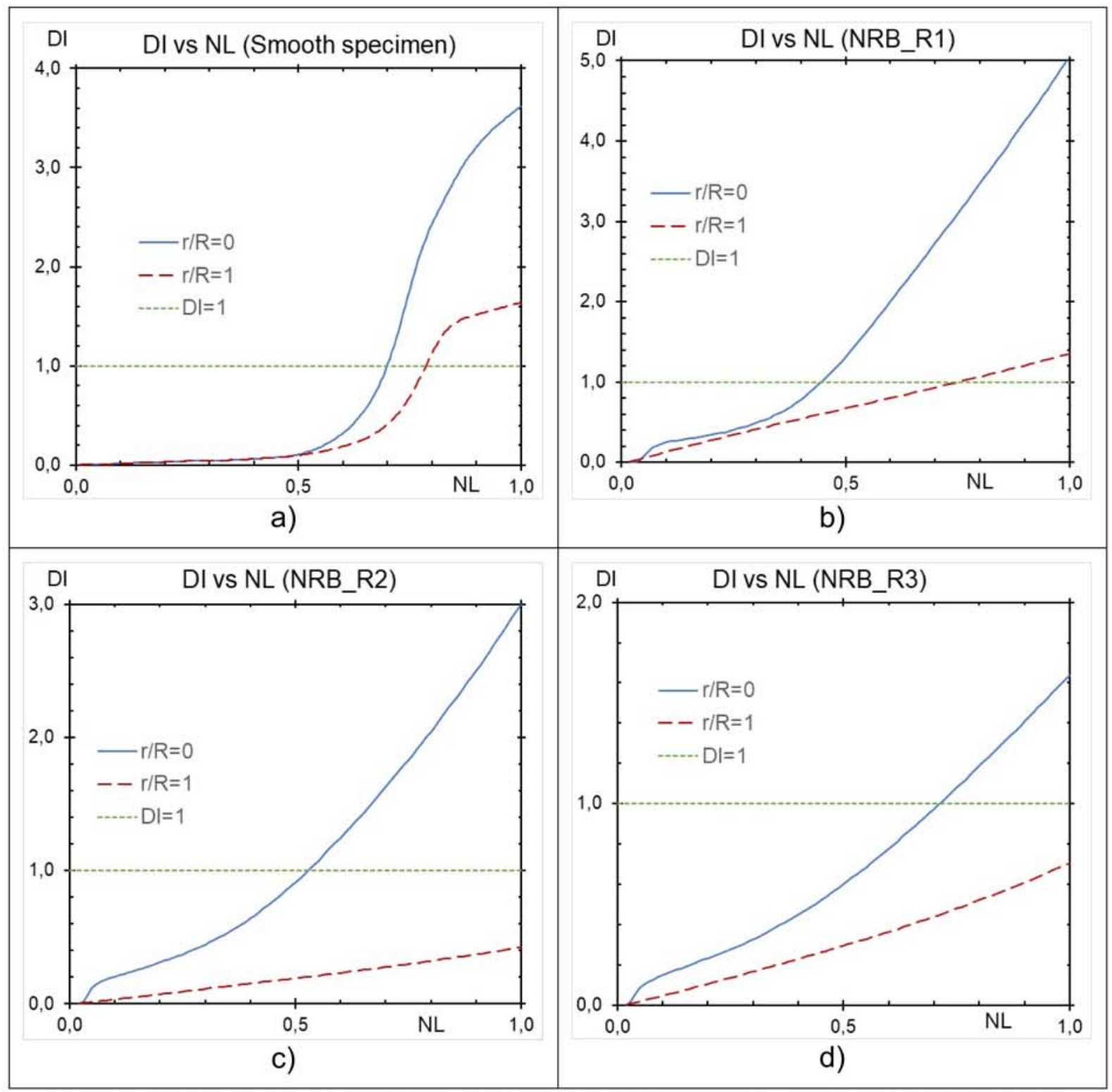

Figure 61 Damage indicator plotted as function of the normalized load applied for tensile load specimens, a) Smooth specimen, b), c), d) R1, R2 and R3 notched specimens, respectively 
In Figure 61 is possible to notice that, for all round bar specimens, the damage indicator of the point which is located at the center has a faster increase when compared to the point located at the surface of the specimen's surface. It means that the center of the specimen is the most damaged zone for failure initiation, so the crack starts at center and it growths radially toward the surface of the specimen.

Analyzing similarly the $D I$ for both deep and shallow crack SEB specimens for some selected points at the onset of element deletion of the first element from the model (first failure), the results plotted in Figure 64 are obtained, which are based in the reference points shown in the Figure 62 and Figure 63. When an element is deleted, all stresses in the element are set to zero and the element no longer has any energetic contribution to the simulation.

Reference points number from 1-6 are located on the specimen ligament and points number from 7-10 are located on the initial crack front.

Figure 62 References points to analyze the DI for the deep crack SEB specimen with side groove 


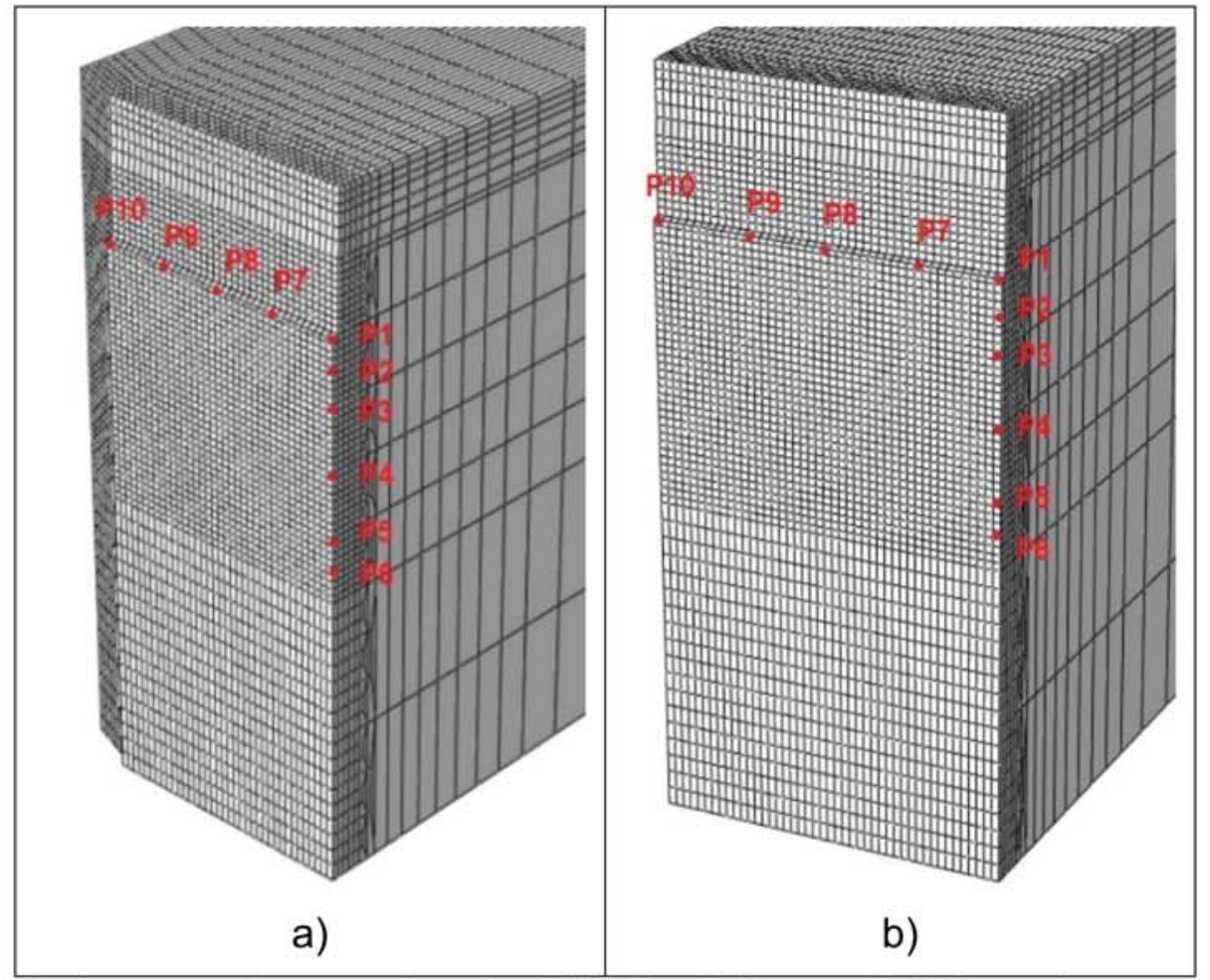

Figure 63 References points to analyze the DI for the shallow crack SEB specimens, a) with side groove, and, b) with no side groove

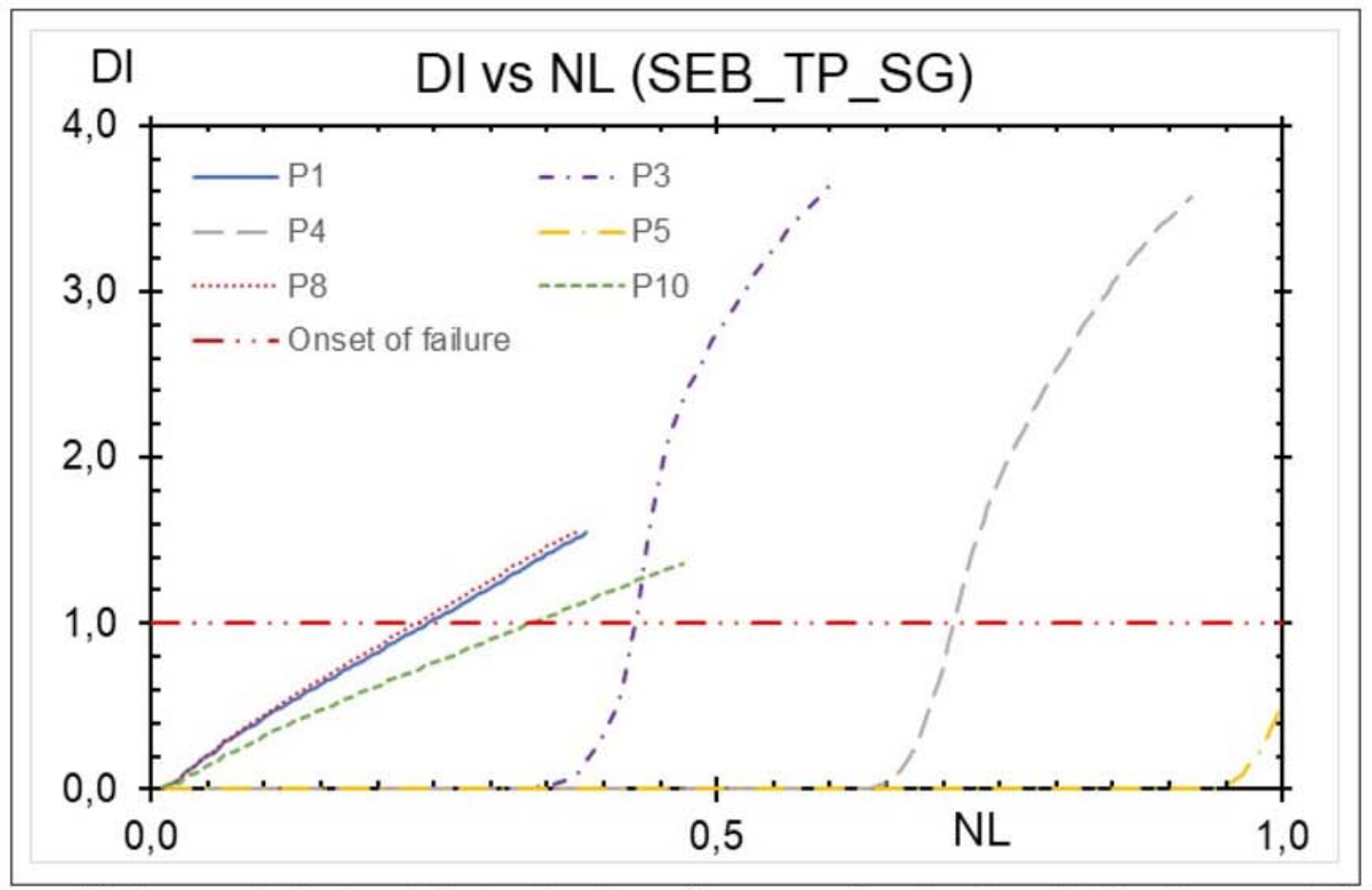

Figure 64 Damage indicator plotted as function of the normalized load applied for deep crack SEB specimens, with side groove 


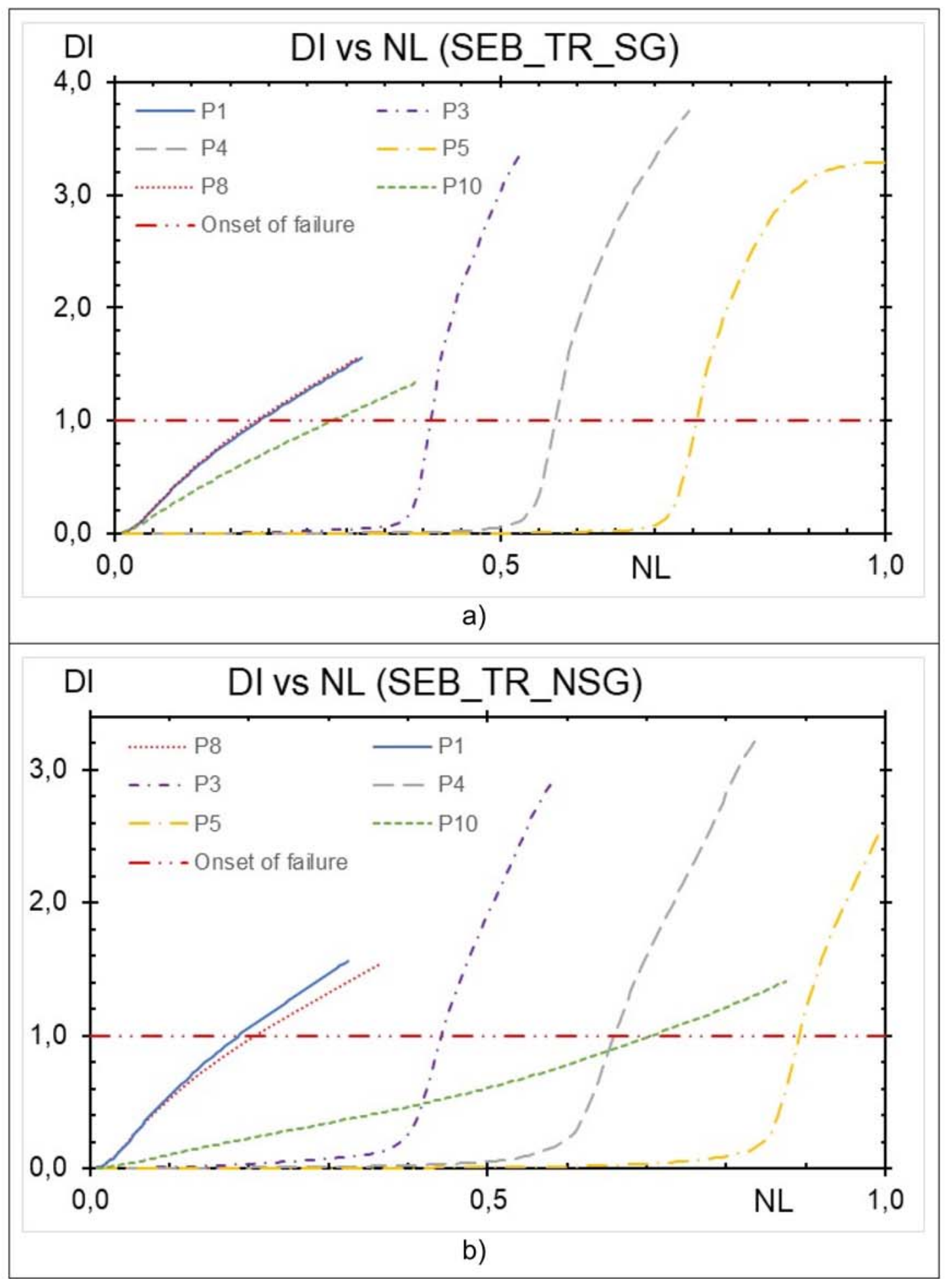

Figure 65 Damage indicator plotted as function of the normalized load applied for shallow crack SEB specimens, a) side groove, and, b) without side groove

By mean of Figure 64 and Figure 65 the points which are in the most damaged zone for failure initiation can be compared. These points are the ones that reach faster to the value of $D I=1$, that means the onset of failure. 
Also, it was analyzed, when the onset of failure for P1 occurs, the stress triaxiality distribution through the crack front and specimen ligament as depicted in Figure 66. So, according to this, these two direction axes are formed as described below:

- $(\mathrm{P} 1, \mathrm{P} 2, \mathrm{P} 3, \mathrm{P} 4, \mathrm{P} 5, \mathrm{P} 6)$ which are located in the vertical axis and are measured as a distance " $a$ " which is normalized with respect to " $t$ ", which is the total specimen width, and " $a$ " is measured along the ligament of the model. Thus, the minimum $\frac{a}{t}$ value corresponds to the initial crack point and the maximum $\frac{a}{t}$ value is a point which is through the ligament dimension of the specimen.

- $(\mathrm{P} 1, \mathrm{P} 7, \mathrm{P} 8, \mathrm{P} 9, \mathrm{P} 10)$ which are located in the horizontal axis at the initial crack front. They are measured as a distance " $\mathrm{s}$ " which is normalized with respect to "b/2", which is the half of the thickness of the specimen, and "s" is measured from the symmetry plane. Thus, $\frac{s}{\left(\frac{b}{2}\right)}=0$ is in the symmetry plane point, and, $\frac{s}{\left(\frac{b}{2}\right)}=1$ is the free specimen surface, respectively.

Figure 66 shows the reference described before, where, the red line represents the horizontal axis (axis "s") and the blue line represents the vertical axis (axis "a").

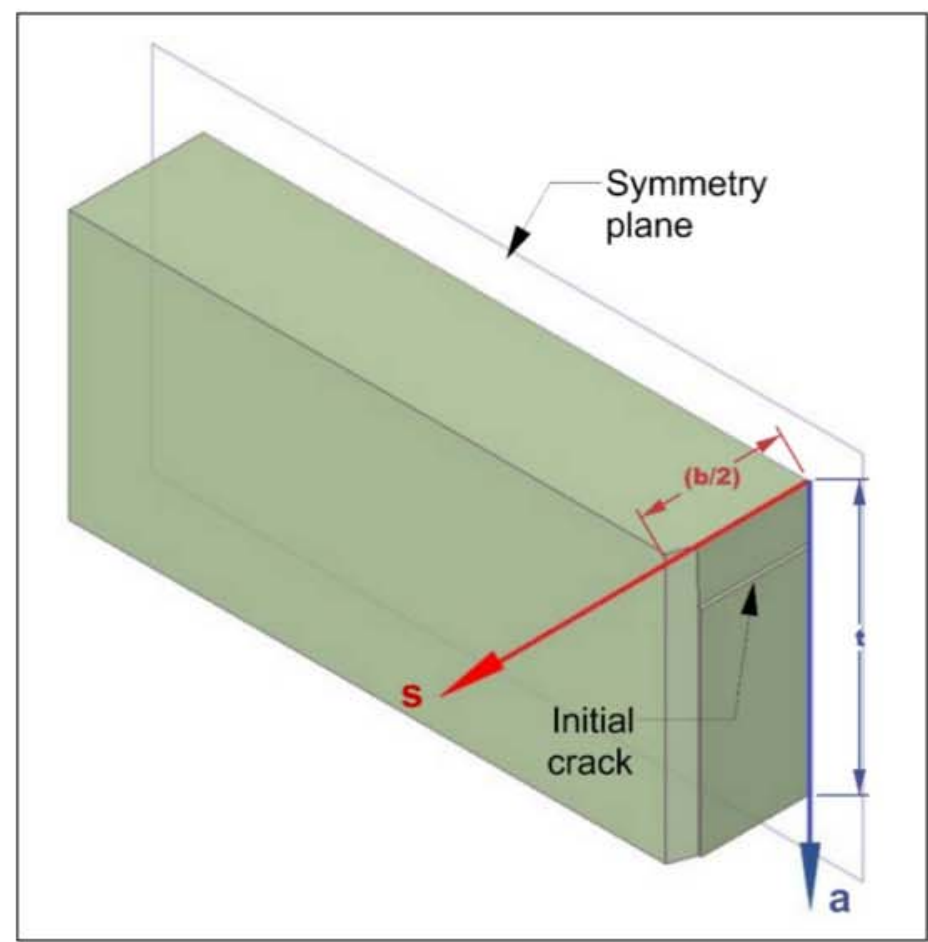

Figure 66 Schematic reference axis to analyze the triaxiality distribution at the first element deletion 
The stress triaxiality and the equivalent plastic strain (PEEQ) distribution for each analyzed specimen at the instant of the first element deletion from the model, are shown in Figure 67 to Figure 72 . These values are exposed in pairs, where the literals a), and b) corresponds to those distributions through "t" and "s" axes respectively, measured for each numerical specimen. These data, combined with results shown in Figure 64, allow us to determine how the element deletion will occur on these models, where element deletion is when an element is deleted from the model and after that it does not have any energetic contribution to the simulation.

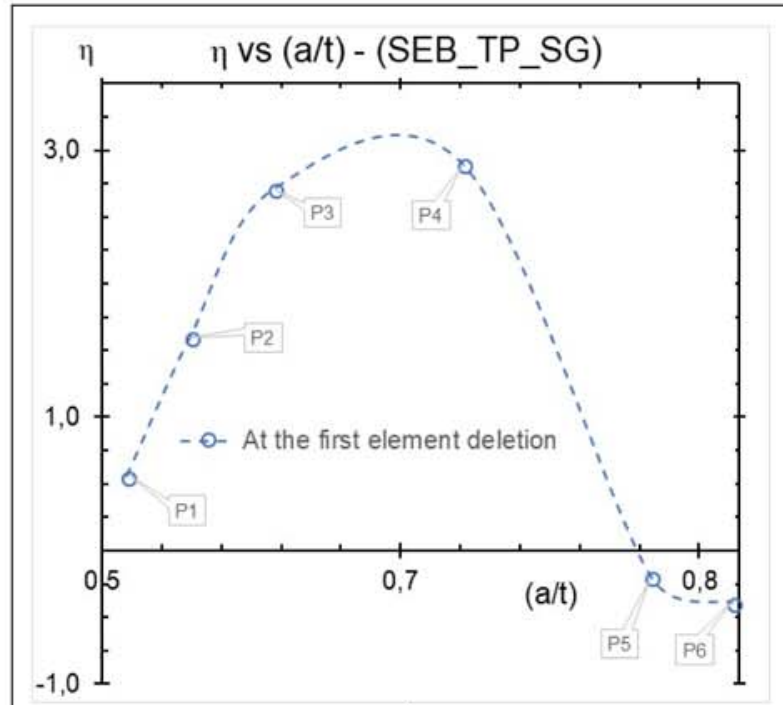

a)

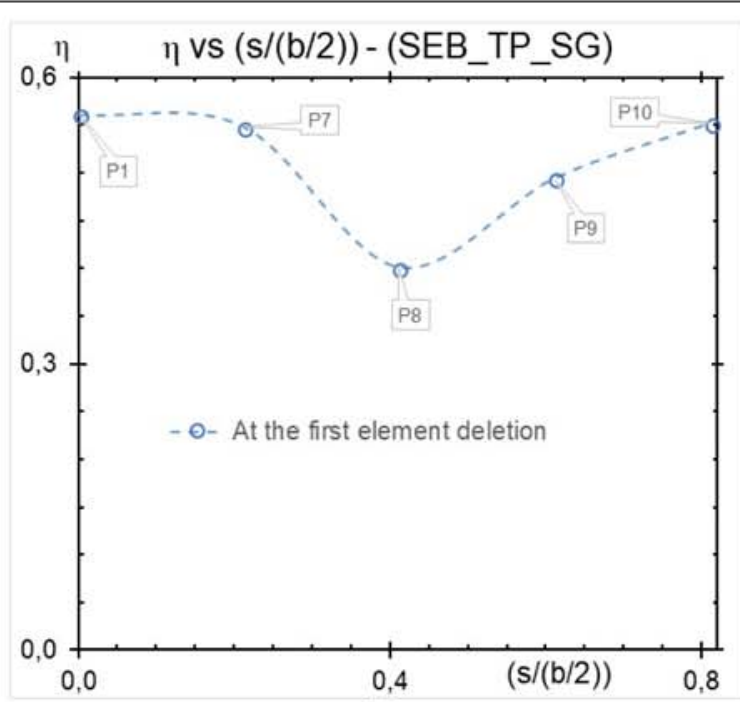

b)

Figure 67 Triaxiality distributions for deep crack SEB specimen with side grooves, analyzed at the first element deletion through: a) "t" axis, and b) "s" axis

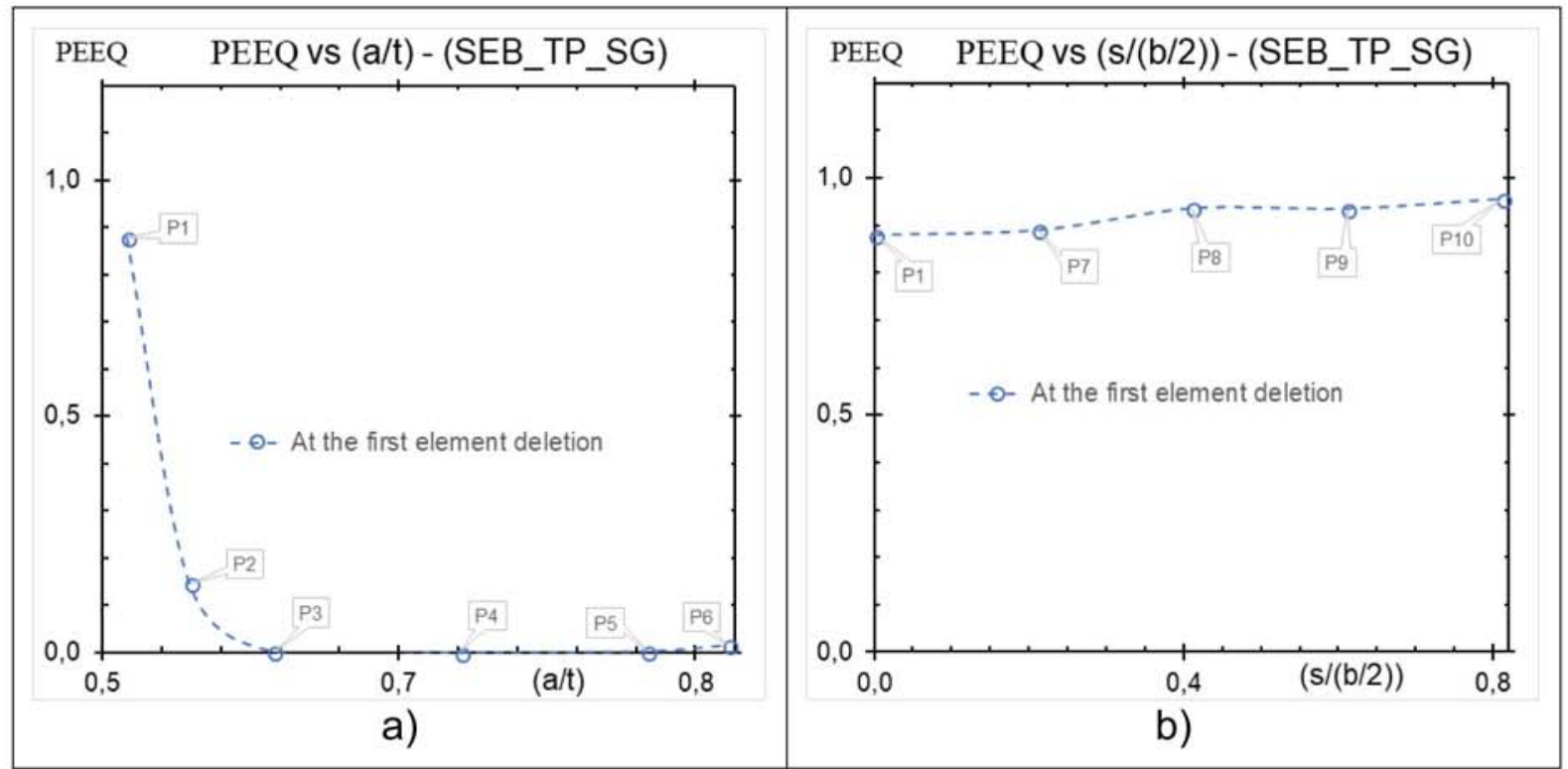

Figure 68 PEEQ distributions for deep crack SEB specimen with side grooves, analyzed at the first element deletion through: a) "t" axis, and b) "s" axis 


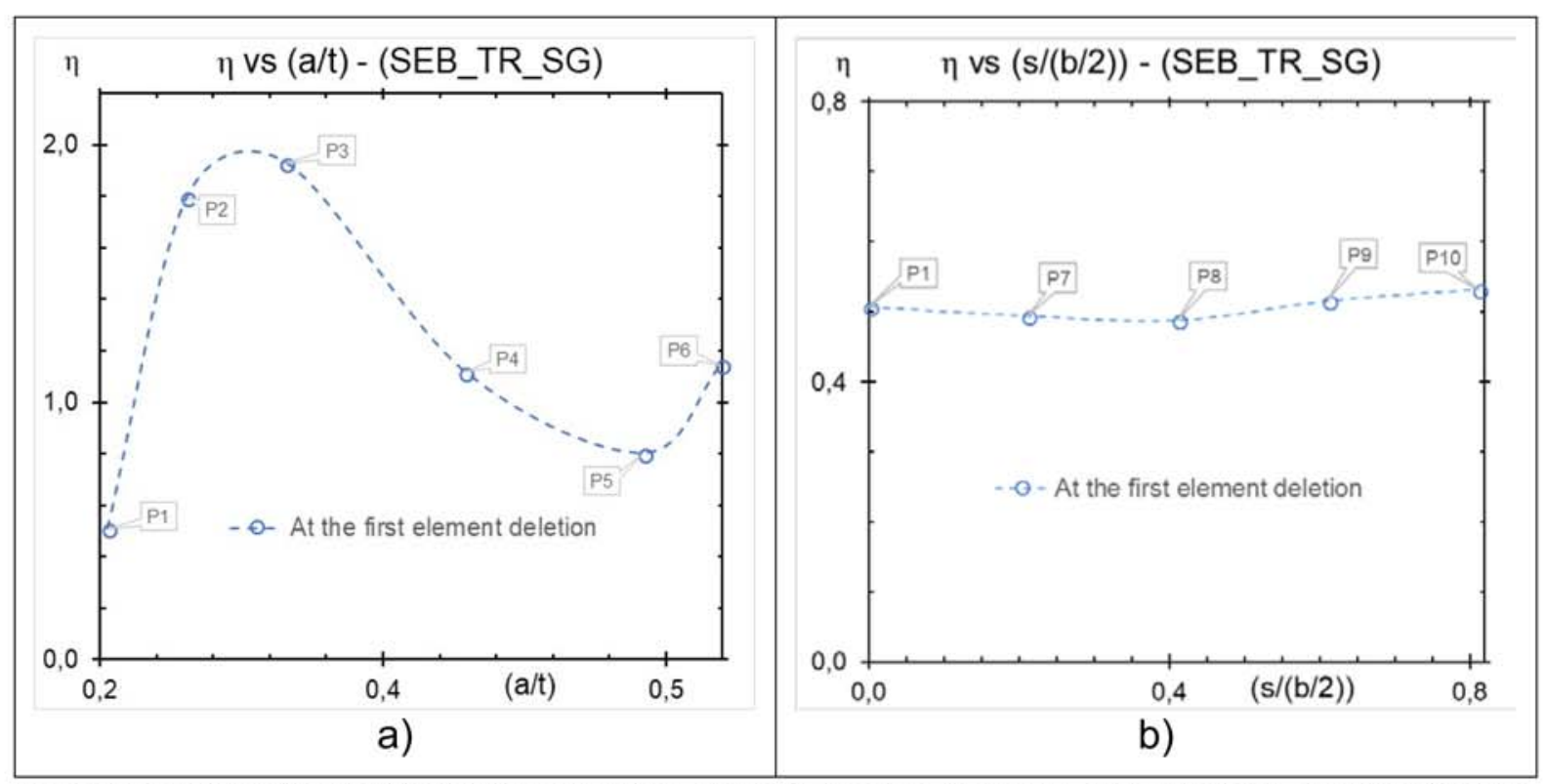

Figure 69 Triaxiality distributions for shallow crack SEB specimen with side grooves, analyzed at the first element deletion through: a) "t" axis, and b) "s" axis

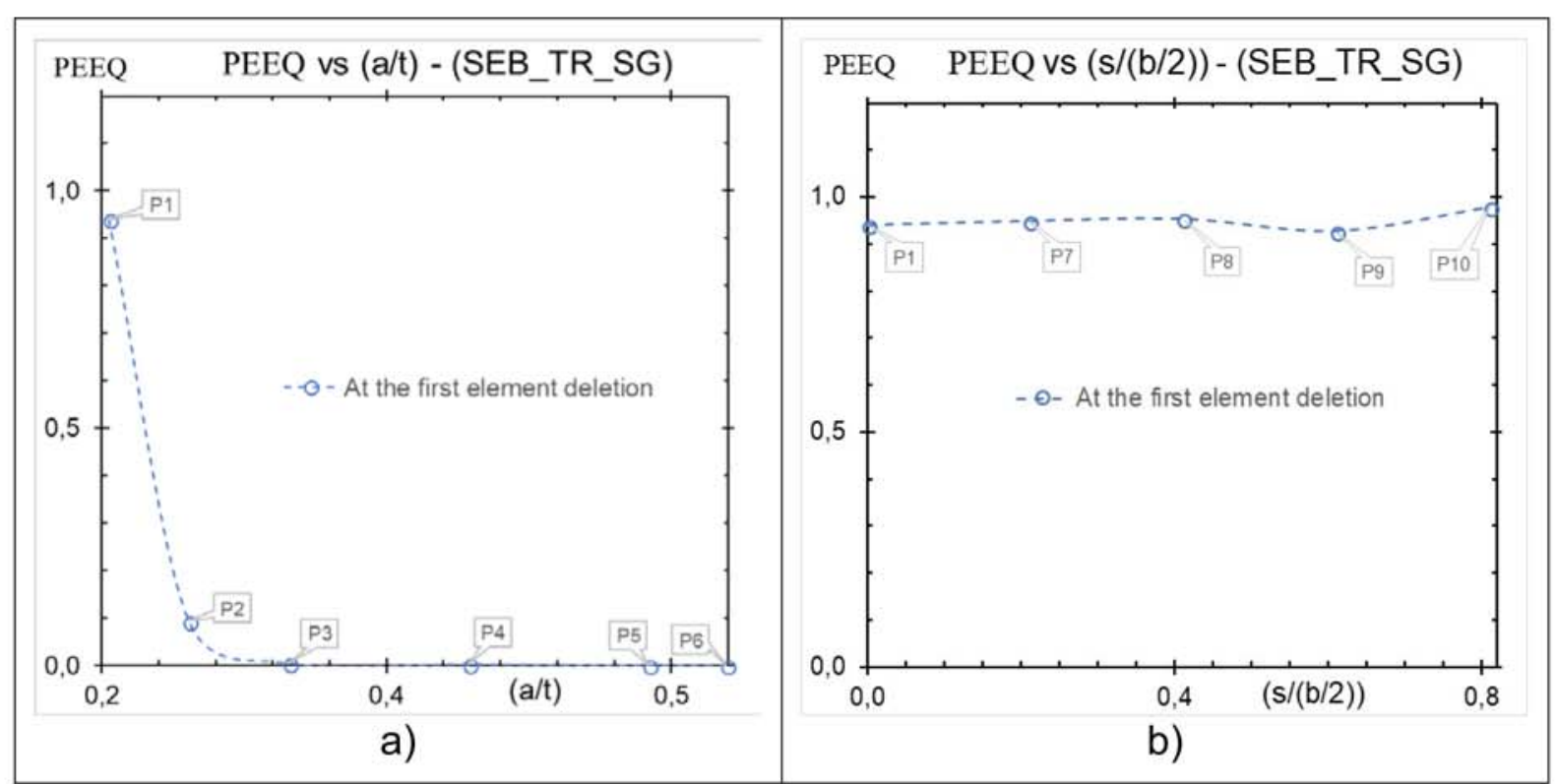

Figure 70 PEEQ distributions for shallow crack SEB specimen with side grooves, analyzed at the first element deletion through: a) "t" axis, and b) "s" axis 


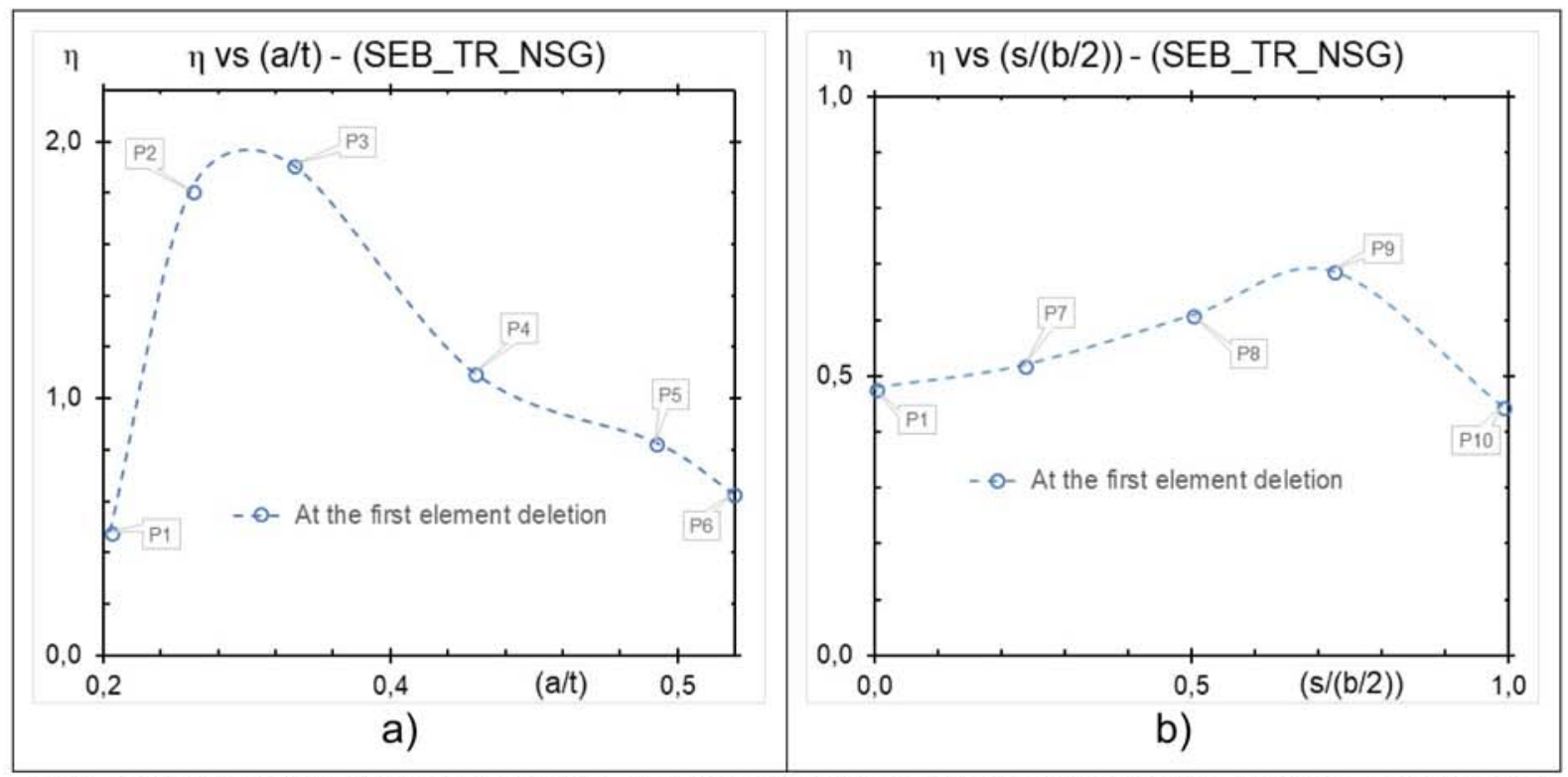

Figure 71 Triaxiality distributions for shallow crack SEB specimen without side grooves, analyzed at the first element deletion through: a) "t" axis, and b) "s" axis

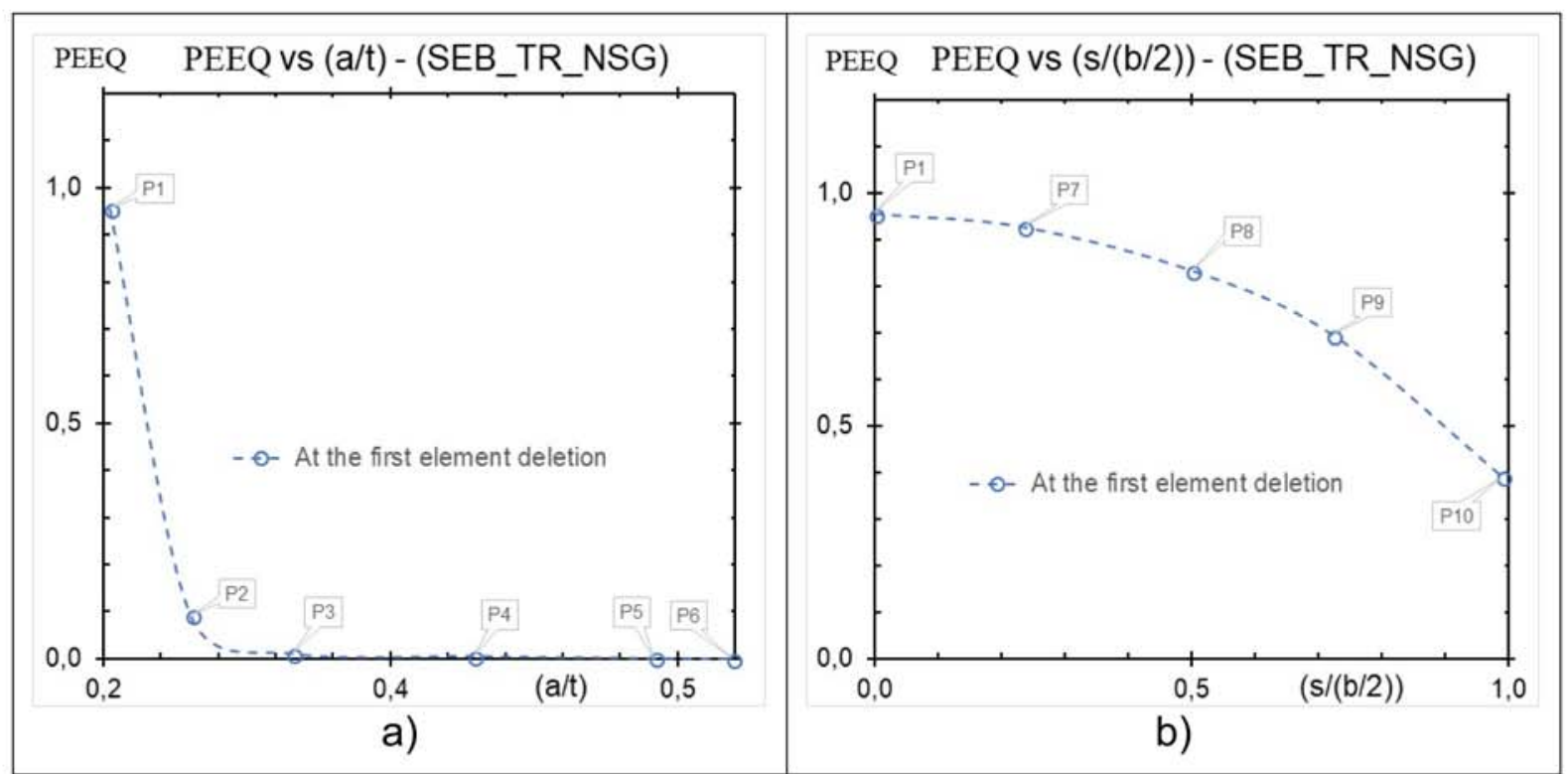

Figure 72 PEEQ distributions for shallow crack SEB specimen with no side grooves, analyzed at the first element deletion through: a) "t" axis, and b) "s" axis

Comparing triaxiality and PEEQ distribution through the crack front for each SEB specimen, it is possible to notice that when the specimens have side grooves, the distribution is more uniform than the specimens without side groove. This assertion is more evident in the PEEQ distribution of the Figure $72 \mathrm{~b}$ which shows a higher plastic strain value at the center of the SEB specimen without side groove than in its free surface, whereas that results of Figure $68 \mathrm{~b}$ and Figure $70 \mathrm{~b}$ the PEEQ values are similar in both the center and the free surface of the SEB specimen with side grooves. 
For better understanding of the ductile failure process in the SEB specimens, let us plot the deformation history of the specimen, which results from the combination of the triaxiality and PEEQ results, and compare it with the critical curve defined in Table 15b. Performing this comparison will allow us to speculate how the crack extension is going to happen in the numerical model. The combined results are shown in Figure 73 to Figure 75.

So, for the SEB_TP_SG, according to Figure 73 the deletion is going to happen in the following order: $\mathrm{P} 8 \rightarrow \mathrm{P} 9 \rightarrow \mathrm{P} 7 \rightarrow \mathrm{P} 1 \rightarrow \mathrm{P} 10$. This information can be confirmed using the information in Figure 64, which shows the first element deleted is the P8, and the elements which would be subsequently deleted are the P1 and P10.

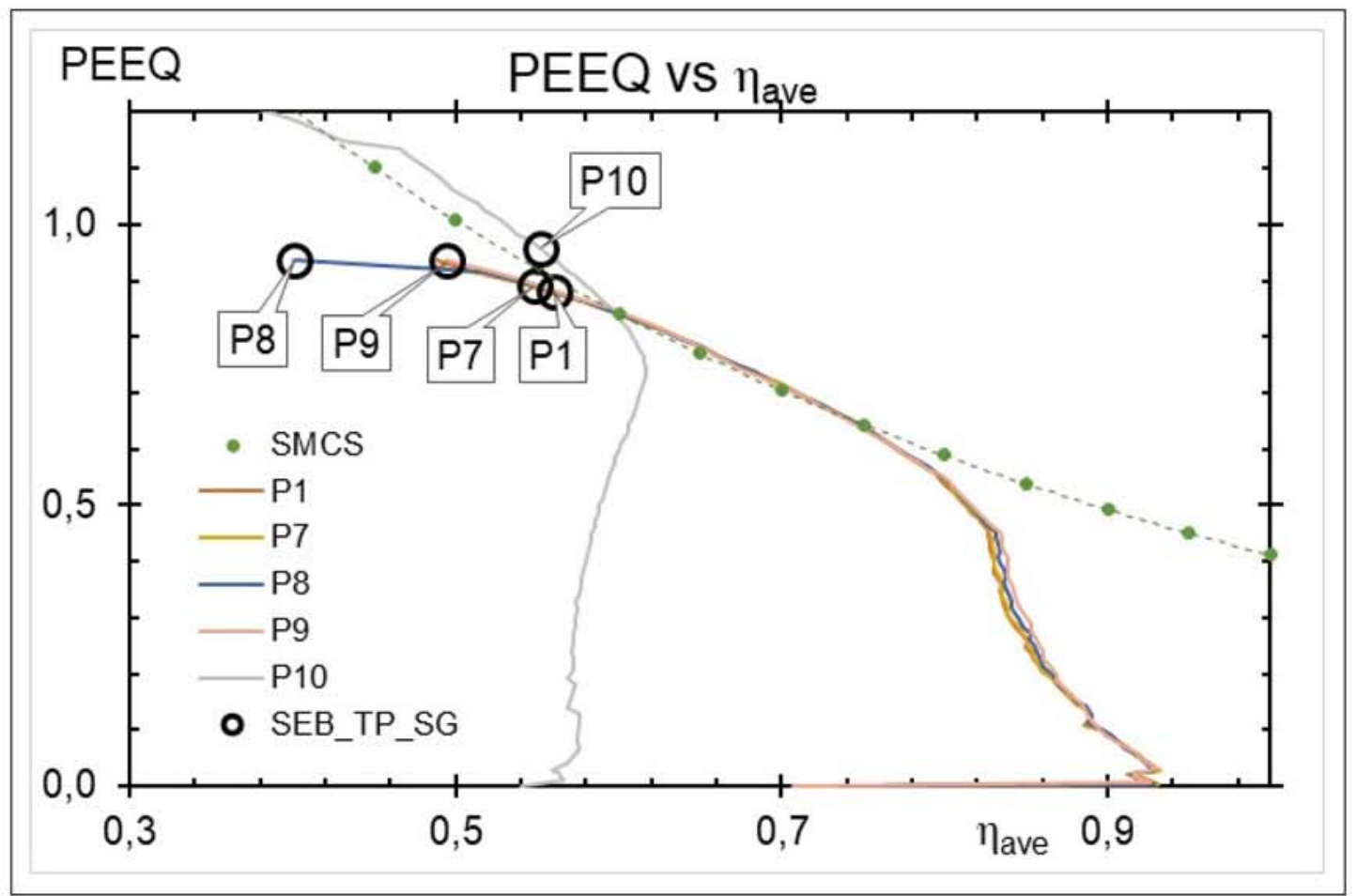

Figure 73 PEEQ vs $\eta$ historic values for the deep crack SEB specimen with side grooves, analyzed at the first element deletion, for elements located at "s" axis

Similarly, for the SEB_TR_SG, using the Figure 74, the deletion is going to happen in the following order: $\mathrm{P} 8 \rightarrow \mathrm{P} 7 \rightarrow \mathrm{P} 1 \rightarrow \mathrm{P} 9 \rightarrow \mathrm{P} 10$. This can be checked using the Figure $65 a$, which shows the first element deleted is the P8, and the elements which would be subsequently deleted are the $\mathrm{P} 1$ and $\mathrm{P} 10$. 


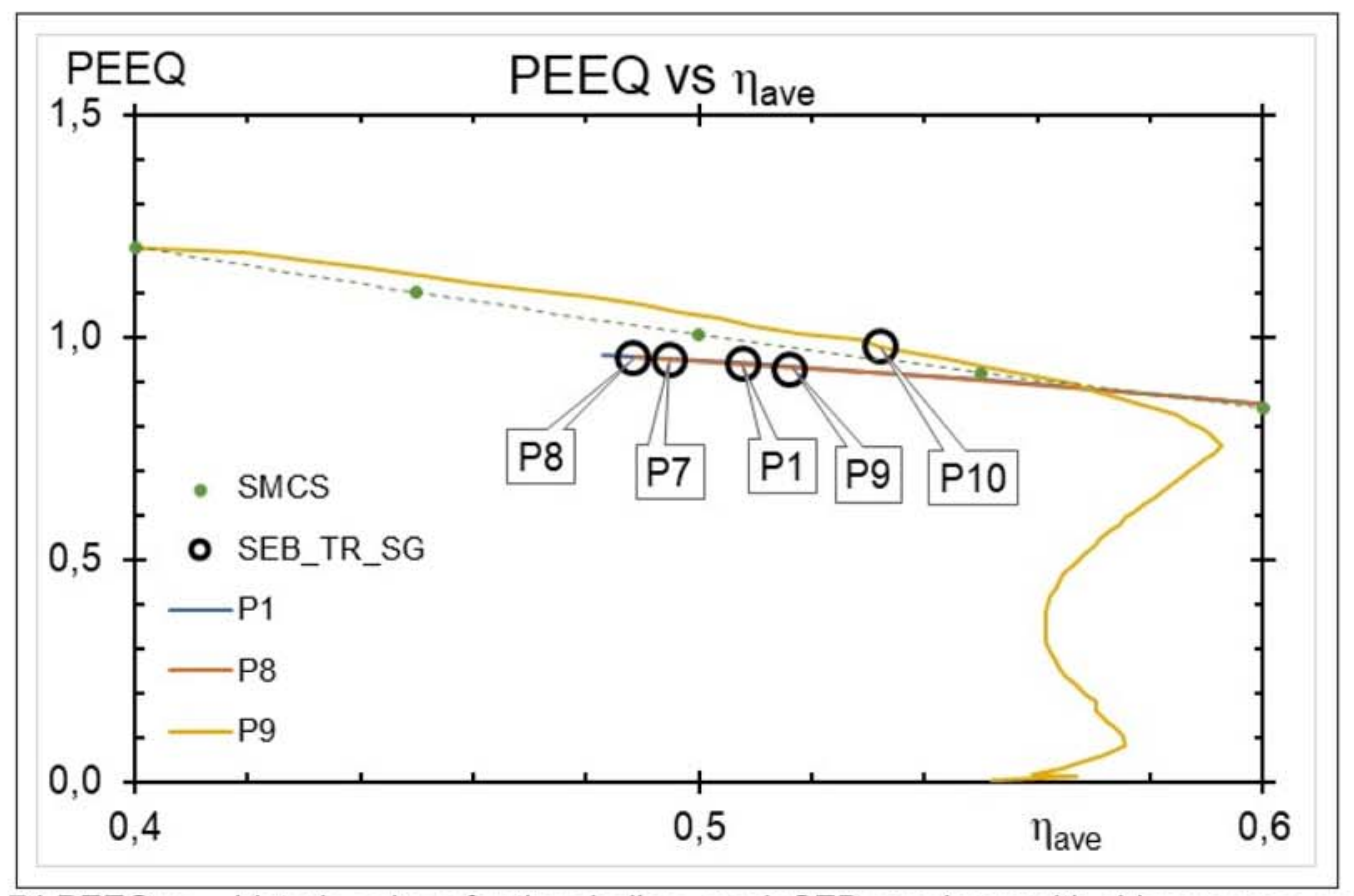

Figure 74 PEEQ vs $\eta$ historic values for the shallow crack SEB specimen with side grooves, analyzed at the first element deletion through, for elements located at "s" axis

Finally, Figure 75 shows the process of the element deletion for the SEB_TR_SG, being it in the following order: $\mathrm{P} 1 \rightarrow \mathrm{P} 7 \rightarrow \mathrm{P} 8 \rightarrow \mathrm{P} 9 \rightarrow \mathrm{P} 10$, which the last one, $\mathrm{P} 10$ have even not reach the damage conditions to be deleted. This can be checked using the Figure $65 \mathrm{~b}$, which shows the first element deleted is the $\mathrm{P} 1$, and the elements which would be subsequently deleted are the P8 and P10.

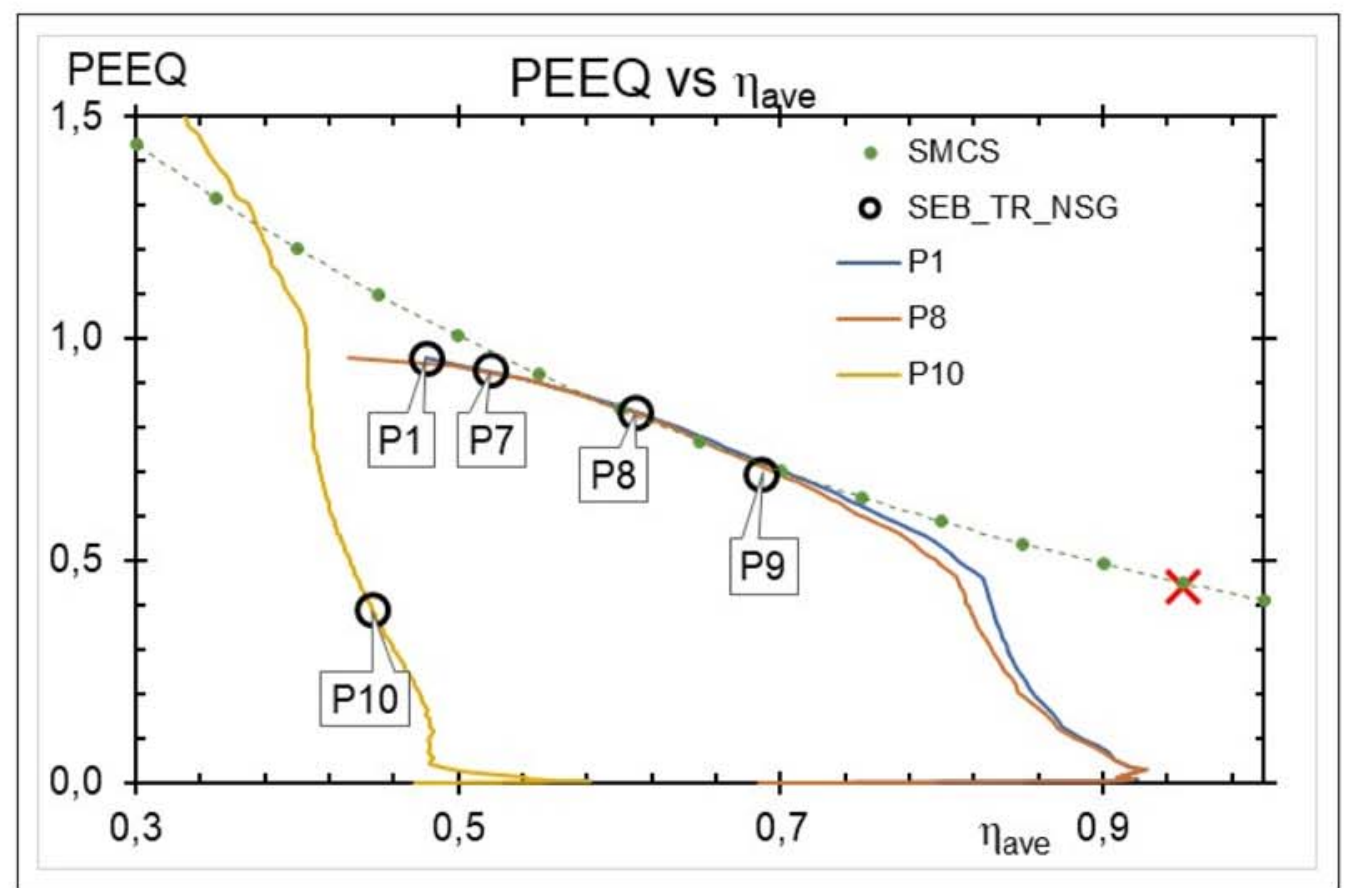

Figure 75 PEEQ vs $\eta$ historic values for the shallow crack SEB specimen with no side grooves, analyzed at the first element deletion through, for elements located at "s" axis 


\section{APPLICATION}

The analyzed material in this study, as was mentioned in 3.1, is steel A285, which is usually used in non-critical pressure vessel applications, such as pressure vessels and industrial boilers, [43]. After characterization and validation of material parameters, the calibrated model will be used in an exploratory study of a complex structure, which has an initial crack.

It was modeled a cracked pipe which is considered a more complex structure than small fracture specimens. Each model has an external initial girth elliptical crack, being the first one a pipe with an initial shallow crack, and the second one is a pipe with an initial deep crack. The pipes were submitted to tensile axial loads to predict the ductile damage behavior.

\subsection{MAIN DIMENSIONS OF THE PIPES}

The first step was to select the main dimensions of the pipes, which must include: the external and internal diameter, the length, and dimensions of elliptical crack: the crack length and the crack depth. To define this, Figure 76 shows a general schema for the dimensions. 


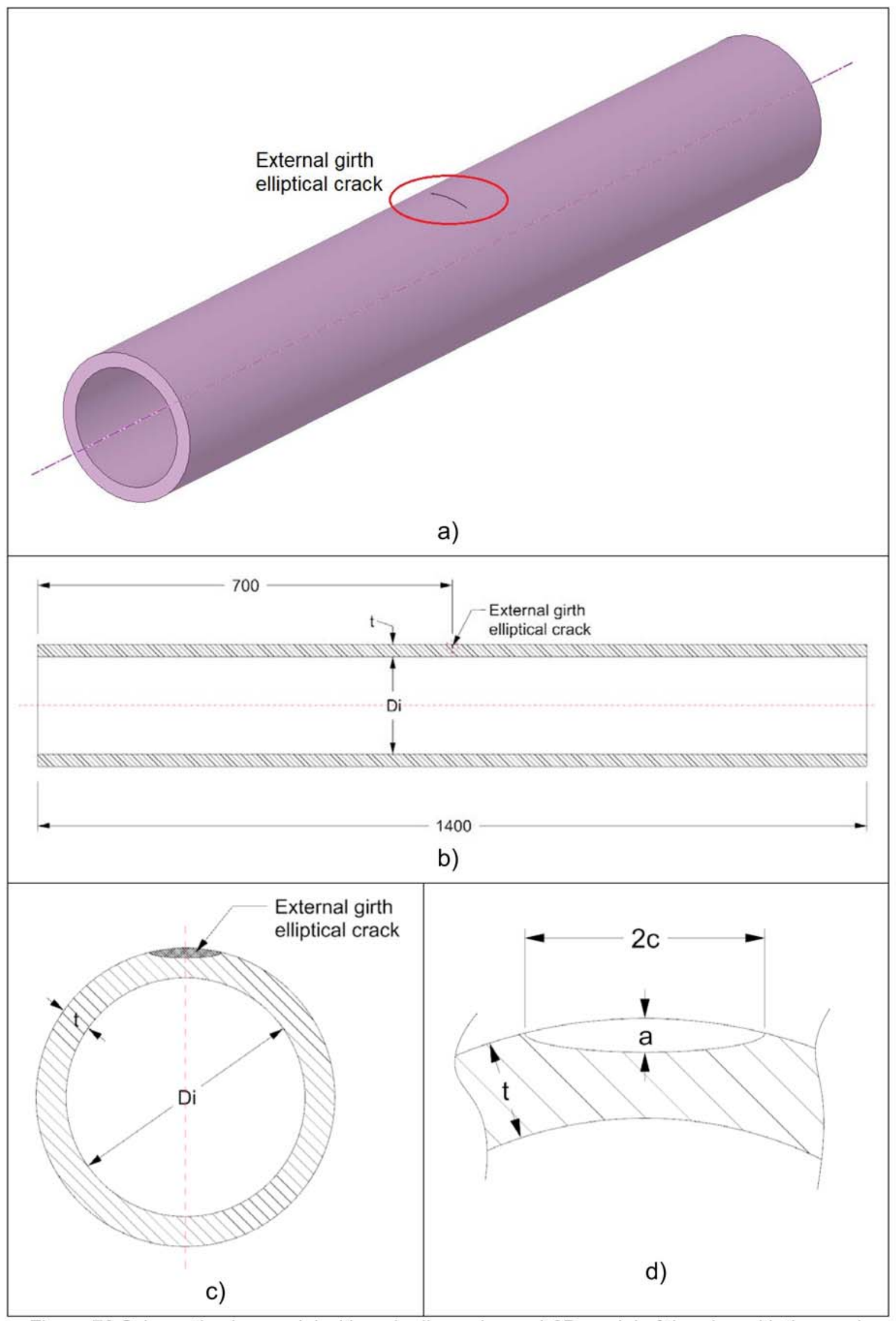

Figure 76 Schematic pipe model with main dimensions, a) 3D model of the pipe with the crack location, b) longitudinal dimensions, c) transversal view, d) initial external girth elliptical crack dimensions 
The chosen dimensions based on the Figure 76 for each analyzed pipeline, are as follow:

Table 17 Main dimensions for the pipes having an initial external girth elliptical crack

\begin{tabular}{|l|r|r|}
\hline \multicolumn{1}{|c|}{$\begin{array}{c}\text { Crack } \\
\text { type }\end{array}$} & $\begin{array}{c}\text { Shallow } \\
\text { initial } \\
\text { crack }\end{array}$ & $\begin{array}{c}\text { Deep } \\
\text { initial } \\
\text { crack }\end{array}$ \\
\hline $\mathrm{L}[\mathrm{mm}]$ & 1400 & 1400 \\
\hline $\mathrm{Di}[\mathrm{mm}]$ & 164,8 & 164,8 \\
\hline $\mathrm{t}[\mathrm{mm}]$ & 20,6 & 20,6 \\
\hline $2 \mathrm{c}[\mathrm{mm}]$ & 20,6 & 82,4 \\
\hline $\mathrm{a}[\mathrm{mm}]$ & 2,06 & 8,24 \\
\hline $\mathrm{a} / \mathrm{t}$ & 0,1 & 0,4 \\
\hline $\mathrm{c} / \mathrm{a}$ & 5 & 5 \\
\hline $\mathrm{Di} / \mathrm{t}$ & 8 & 8 \\
\hline $\mathrm{L} / \mathrm{Di}$ & 8,5 & 8,5 \\
\hline
\end{tabular}

Using these dimensions, it is possible to pass to the next step which is definition of the numerical model to be analyzed, for each one of the selected pipes.

\subsection{NUMERICAL MODELS OF PIPES}

Once the main dimensions had been selected, the next step was to set the numerical models which include the effective dimension used to model the structure, the material properties, the mesh of the model, the boundary conditions, and the applied load. All these characteristics are described below.

Firstly, dimensions of the numerical models that will be used in the finite element program must be chosen. So, because a standard pipe has radial and longitudinal symmetry, it is possible to use numerical models which are $1 / 4$ symmetric which are the result to cut the total pipe with 2 planes as shown in Figure 77a. The final section of the pipe which will be analyzed is shown in Figure $77 \mathrm{~b}$. 


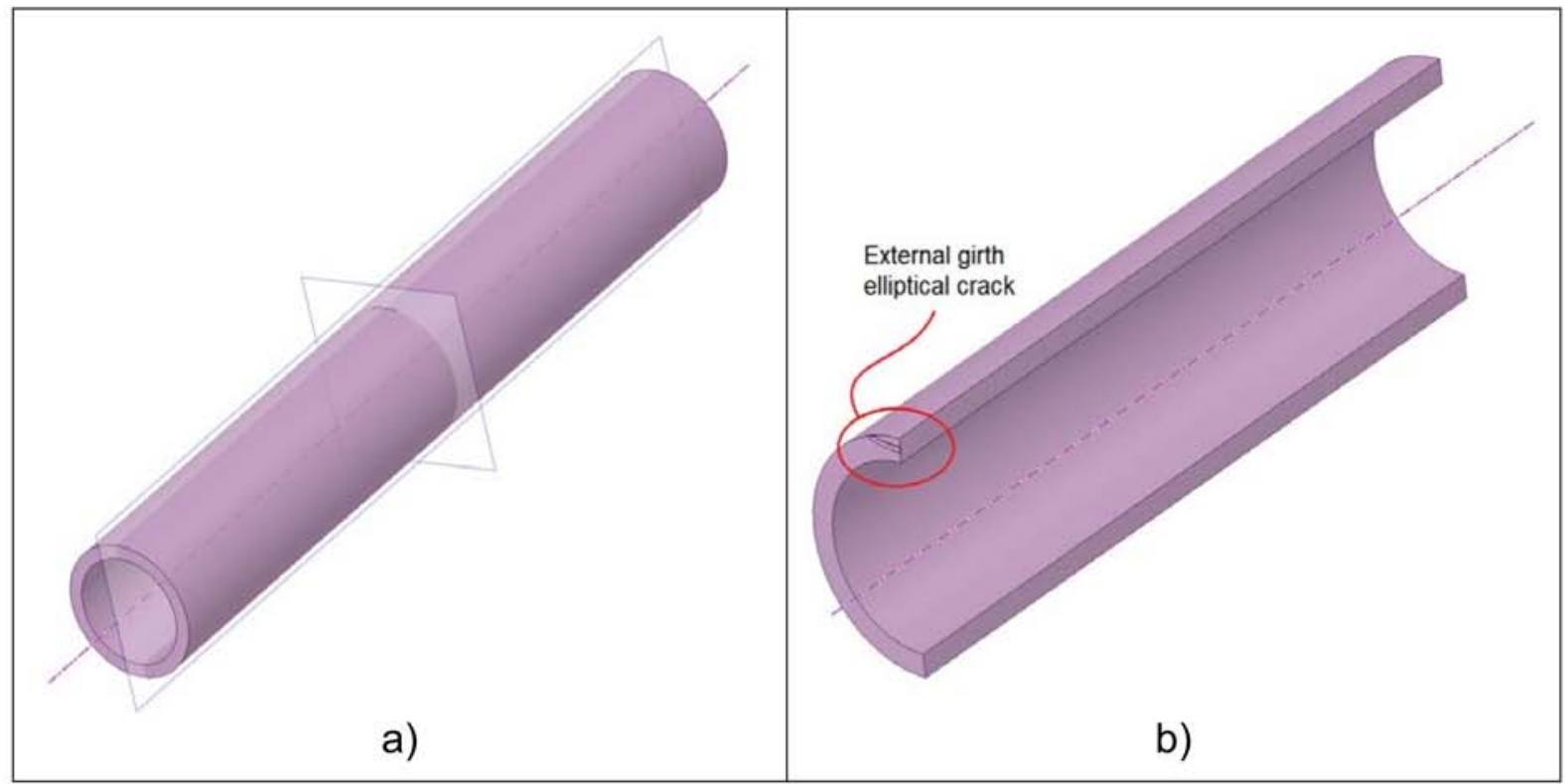

Figure 77 Definition of the numerical model, a) Total pipe with the two planes of symmetry, b) $1 / 4$ symmetry model

So, the numerical model that will be meshed and which the boundary conditions and the loads will be added is only the $1 / 4$ symmetry of the total pipe for each case described in Table 17.

The next step is defining how the material will be applied, for which has been defined three zones, that are represented by three colors in Figure 78 and described below:

- The elastoplastic zone, in purple, and this will have included only the data that recover the elastoplastic response of the material, without damage.

- The damage zone, in blue, which include all the characterized model of the material, and allow to obtain both the elastoplastic and the damage behavior.

- The fixed base, in green, is a representation of the clamp of one universal testing machine. It has a rigid behavior that is modeled using the same elastoplastic material but increasing the Young's modulus and the yield strength. It is only used to apply and transmit the load, and it measures $l=$ $65 \mathrm{~mm}$ from the free extreme of the pipe.

This was done to simulate two effects on the simulation: the rigid coupled part to add the displacement load at the extreme of the pipe, and to restrain the damage in the critical area which is close to the initial crack. 


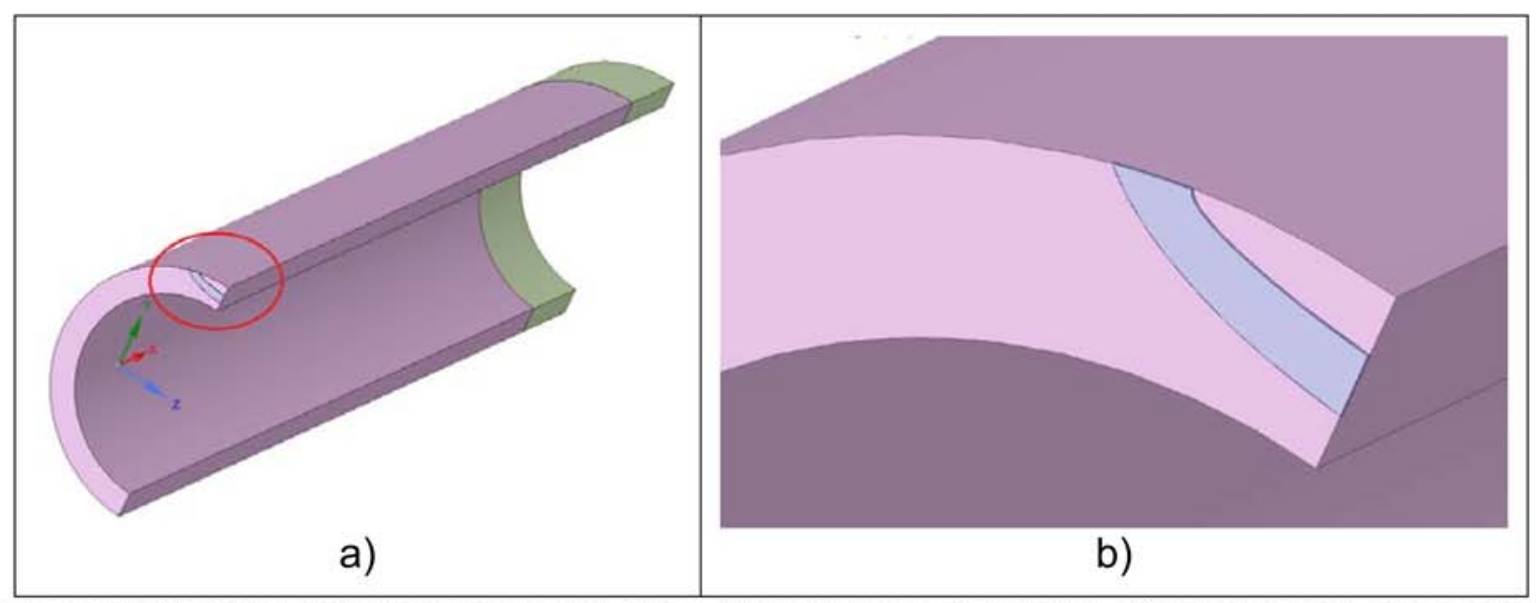

Figure 78 Material definition sketch with three different types of material, a) general view of the three zones, b) zoom of the part enclosed in red to observe the damage area

Now is the turn of defining the meshing of the model, for which there must be remembered that the characterized material is affected by the element size chosen to model the damage zone, as described in section 4.3.2. So, as at the present study the material was calibrated using an element size of $0,2 \mathrm{~mm}$ then the damage zone of the pipes must have the same element size, which also defines the thickness of the crack.

8-node C3D8 solid elements (brick elements in Abaqus) are used to mesh each structure, which has a more refined mesh at the symmetry plane nearly to the initial crack as shown in Figure 79. After both pipes have been meshed, the number of nodes and elements are exposed in Table 18.

Table 18 Quantity of nodes and elements for each analyzed pipe

\begin{tabular}{|c|c|c|}
\hline & \multicolumn{2}{|c|}{ Pipe } \\
\hline Quantity & $\begin{array}{c}\text { Shallow } \\
\text { initial crack }\end{array}$ & $\begin{array}{l}\text { Deep initial } \\
\text { crack }\end{array}$ \\
\hline Elen & 36884 & 56245 \\
\hline Nodes & 42827 & 63620 \\
\hline
\end{tabular}




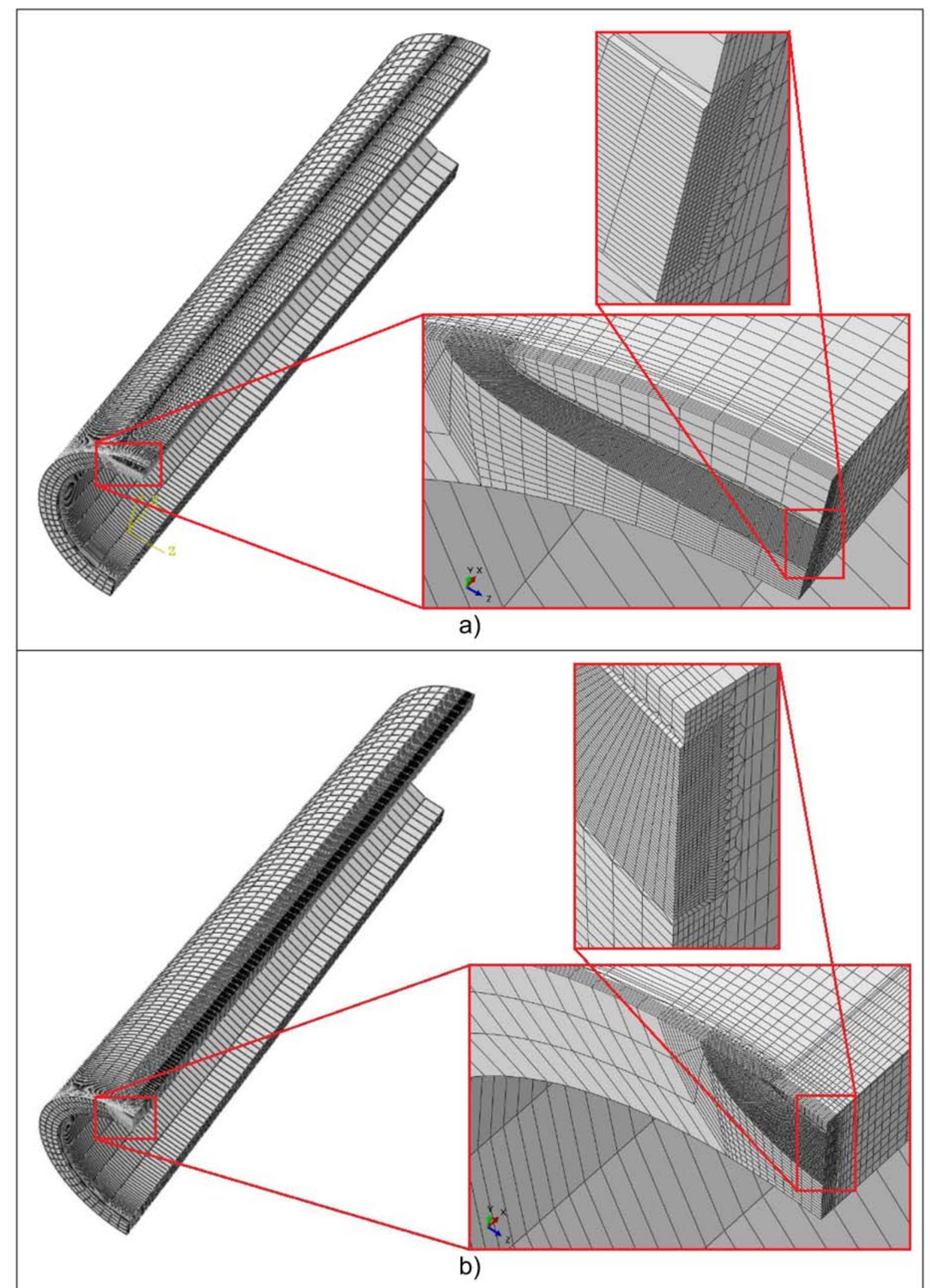

Figure 79 Mesh definition for the structures, a) pipe with initial deep crack, b) pipe with initial shallow crack 
Finally, to complete the numerical models of both shallow and deep initial crack pipes, the boundary conditions, constraints, and the external loads must be added. Since the numerical models are using symmetry, so boundary conditions must be applied at the symmetry planes where the total model was cut. Those boundary conditions are represented as a displacement constraint, $u_{z}=u_{x}=0$, acting only in the perpendicular direction for each symmetry surface. Then, the external tension load is applied as a displacement, whose direction is parallel to the normal vector of the surface at free extreme of the model, and to complete the equilibrium of the model within the tensile load condition is added a constraint in the " $\mathrm{y}$ " direction, as $u_{y}=0$, as shown in the Figure 80.

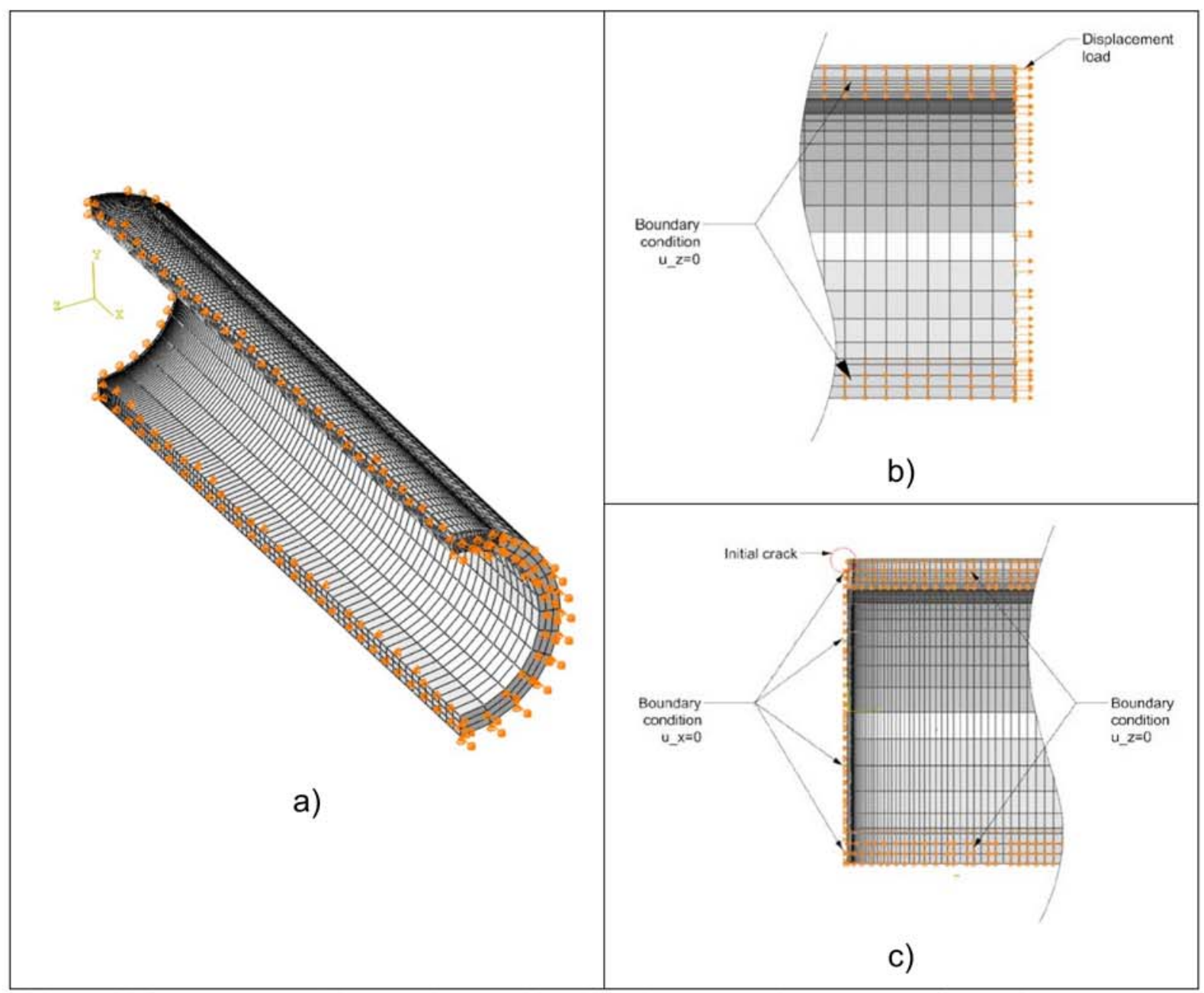

Figure 80 Boundary conditions and applied load for the analyzed structures, a) complete numerical model with the boundary conditions and the applied load, b) detailed view of the free extreme with the applied load and boundary conditions, c) detailed view of the symmetry plane with the boundary conditions 


\subsection{NUMERICAL RESULTS FOR THE ANALYZED PIPES}

After both numerical models are solved, the results for the crack propagation are analyzed. First, the damage indicator factor was analyzed for some references points as had been made in section 4.4. The reference points for each pipe with shallow and deep initial crack, are illustrated in Figure 81.

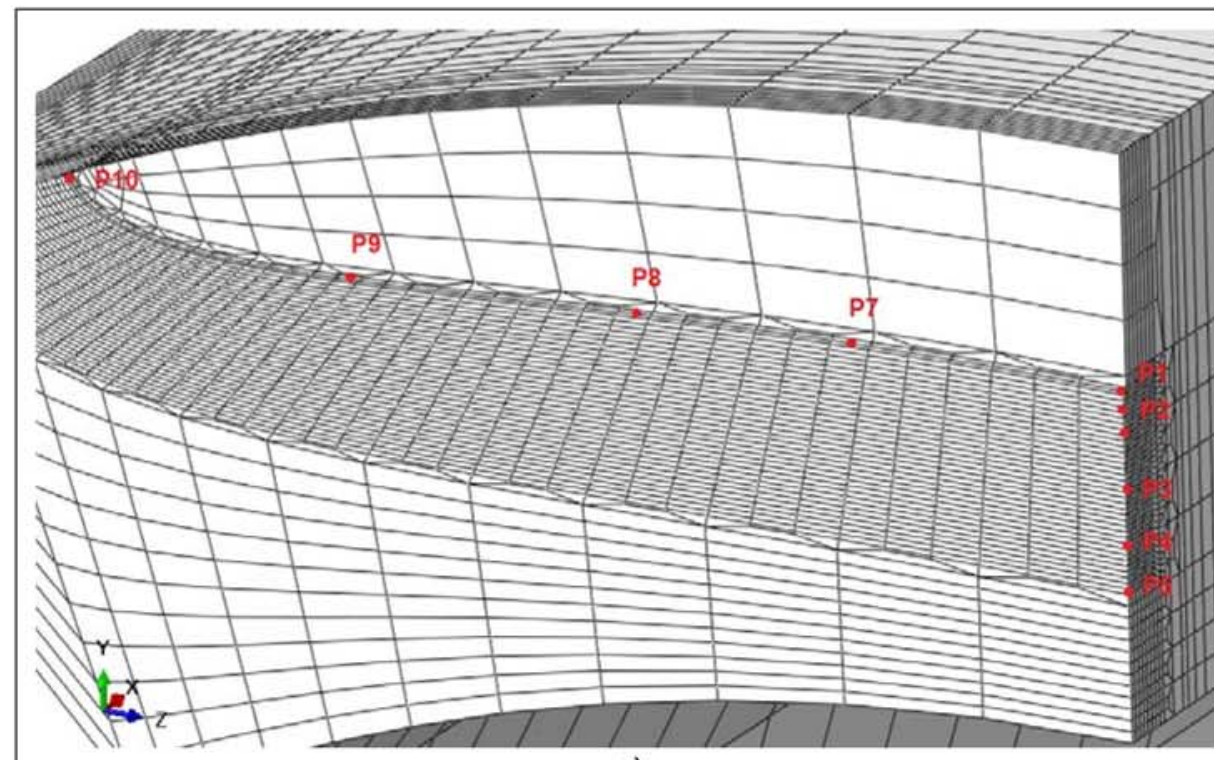

a)

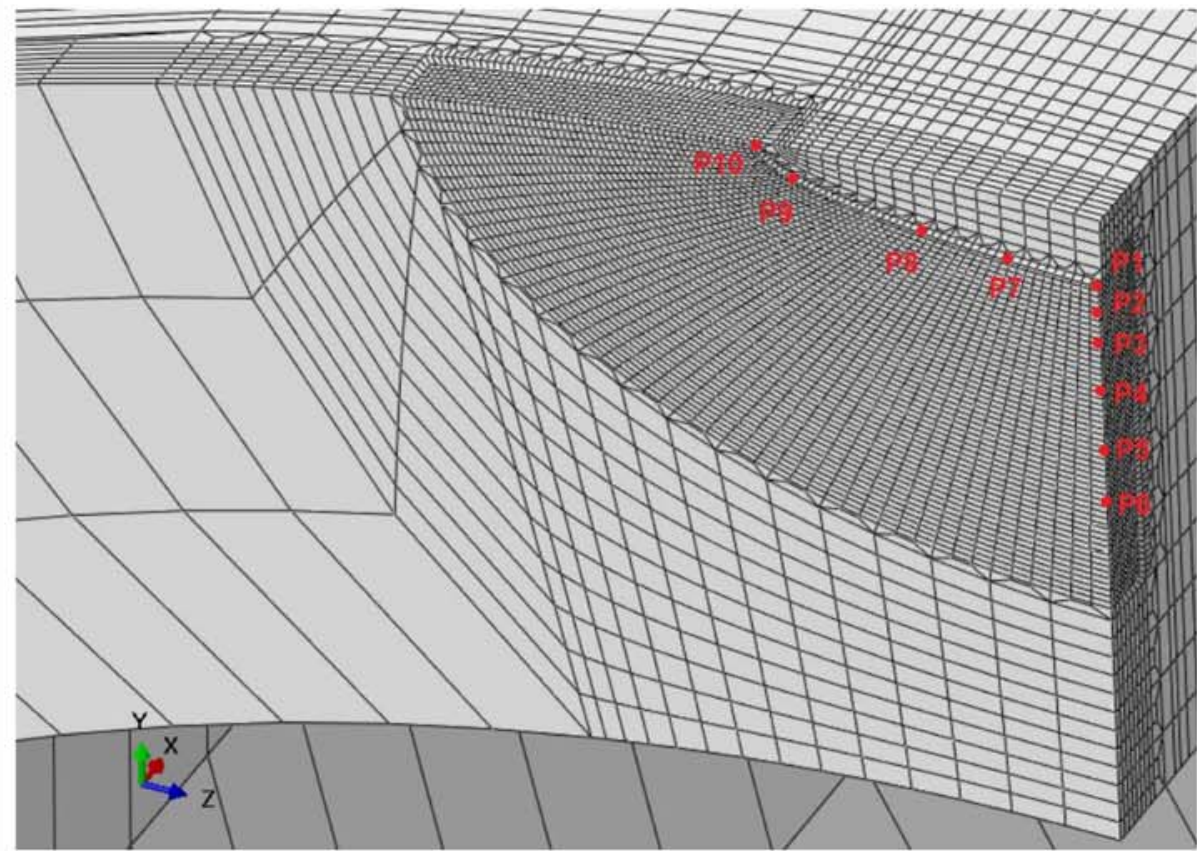

b)

Figure 81 References points to analyze the DI for the pipes, a) deep initial crack pipe, b) shallow initial crack pipe 
Figure 82 displays the evolution of the damage indicator value as a function of the normalized tensile axial load applied for each analyzed pipe with an initial external girth elliptical crack, where the maximum applied loads $\left(L_{\max }\right)$ were $6 \mathrm{~mm}$ and $130 \mathrm{~mm}$ for the pipe with deep initial crack and pipe with the shallow initial crack respectively.

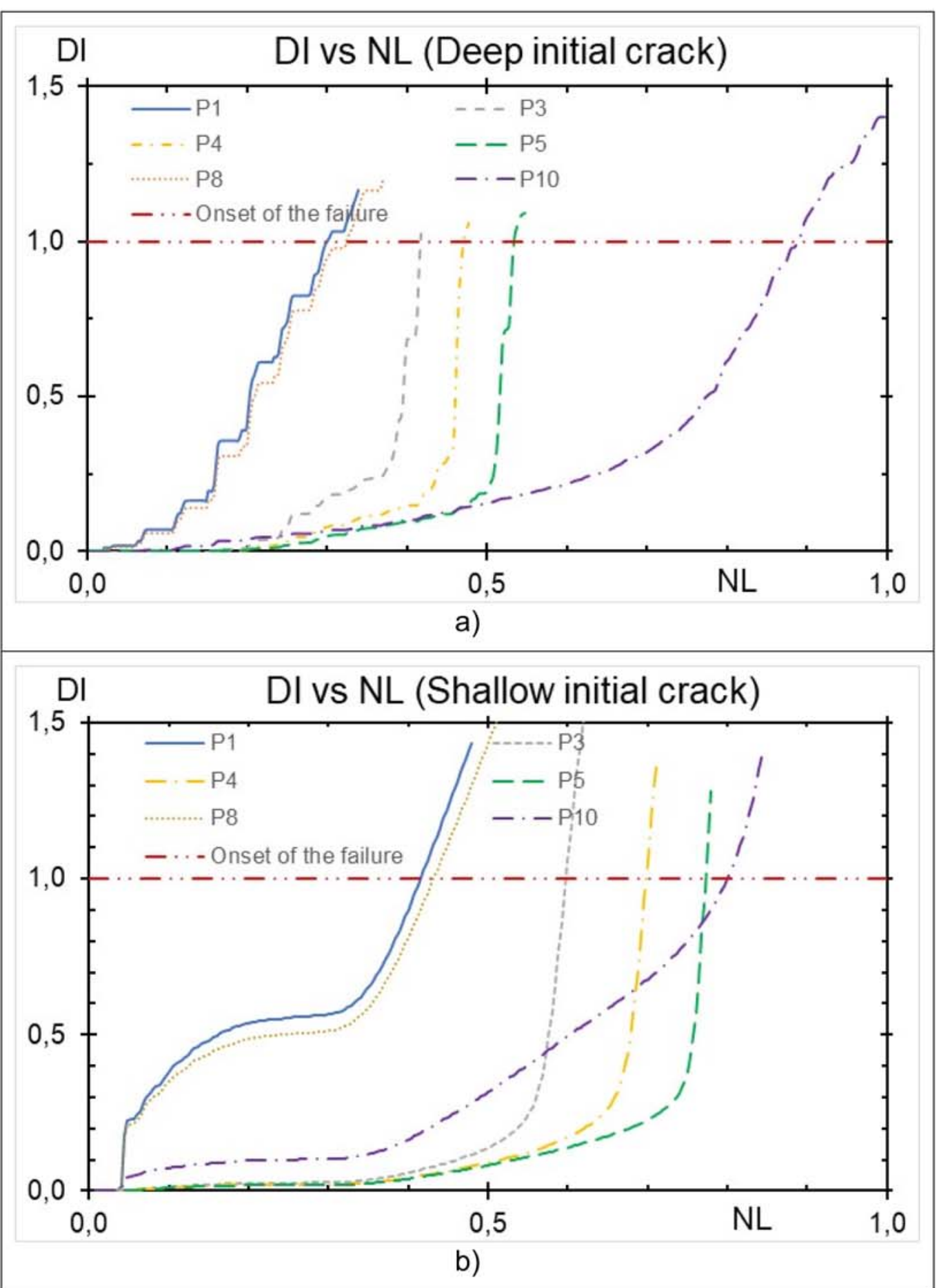

Figure 82 Damage indicator plotted as function of the normalized load applied for both pipes, a) pipe with deep crack, b) pipe with shallow initial crack 
Using the data shown in Figure 82, it is possible to compare the points that are located in the most damaged zone for failure initiation, which are those that reach more quickly the value $D I=1$, that means the onset of failure.

Finally, to finish the study of the results for the pipes, was analyzed the variation triaxiality value at the onset of failure for the point $\mathrm{P} 1$, because for both analyzed pipes it was the first element deleted of the model. Those variations are measured along the two main axes formed by the direction of the references points. The main axes, shown in Figure 83, are defined similarly than the section 4.4, and they have the following characteristics:

- Axis "a" contains the points (P1, P2, P3, P4, P5, P6) and represents the vertical axis. The distance from the external diameter to each reference point is measured as a distance " $a$ " that is normalized with respect " $t$ ", which is the thickness of the pipe. Thus, the minimum $\frac{a}{t}$ value corresponds to the initial crack point and the maximum $\frac{a}{t}$ value is a point which is through the thickness of the pipe.

- Axis "s" is tangential to the upper point at the external diameter and it is used as a reference to measure the points $(\mathrm{P} 1, \mathrm{P} 7, \mathrm{P} 8, \mathrm{P} 9, \mathrm{P} 10)$ which are in the front of the initial crack of the elliptical circumferential crack. They are measured from the symmetry longitudinal plane as a distance " $\mathrm{s}$ " that is normalized with respect "c", which is the half of the width of the elliptical circumferential crack. Thus, $\frac{s}{c}=0$ is the symmetry plane point and $\frac{s}{c}=1$ is the extreme of initial front crack.

In the Figure 83, the red line represents the horizontal axis (axis "s") and the blue line represents the vertical axis (axis "a"). 


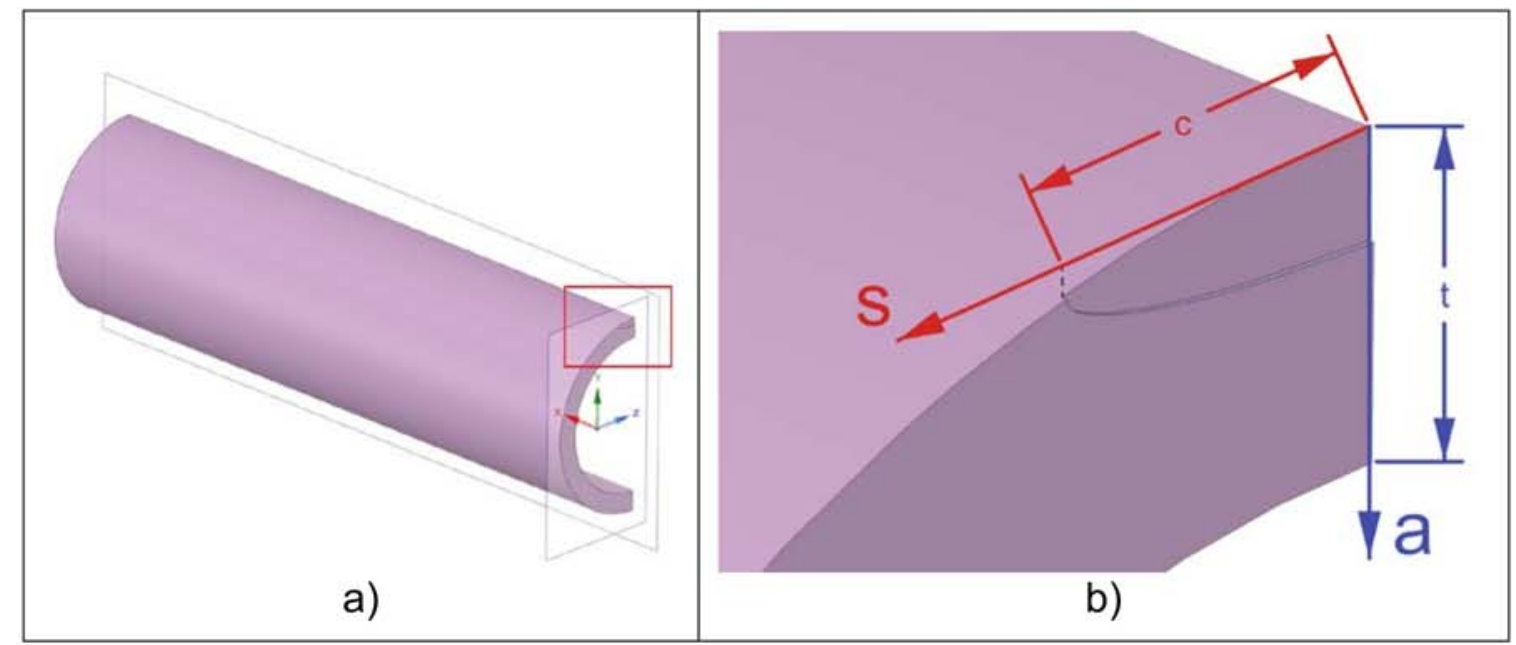

Figure 83 Schematic reference axis to analyze the triaxiality distribution at onset of failure for P1 for the pipes, a) Numerical model for the pipe with the interest area enclosed in the red rectangle, b) zoom of the enclosed area in the red rectangle

So, plotting the triaxiality distribution for each main axis described before, it is obtained the results plotted in Figure 84 and Figure 86.

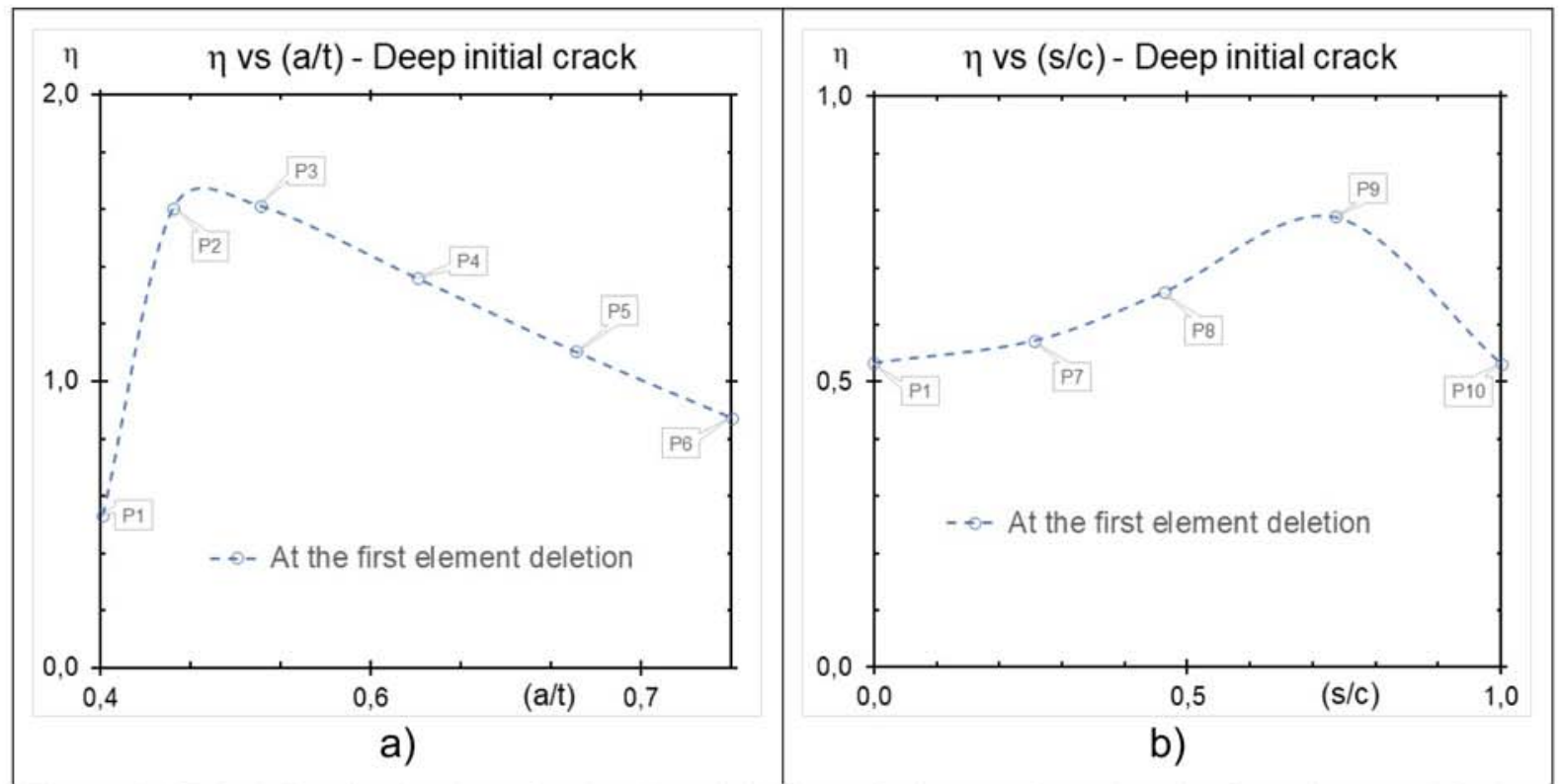

Figure 84 Triaxiality distributions for the deep initial crack pipe, analyzed at the first element deletion through: a) "t" axis, and b) "s" axis 


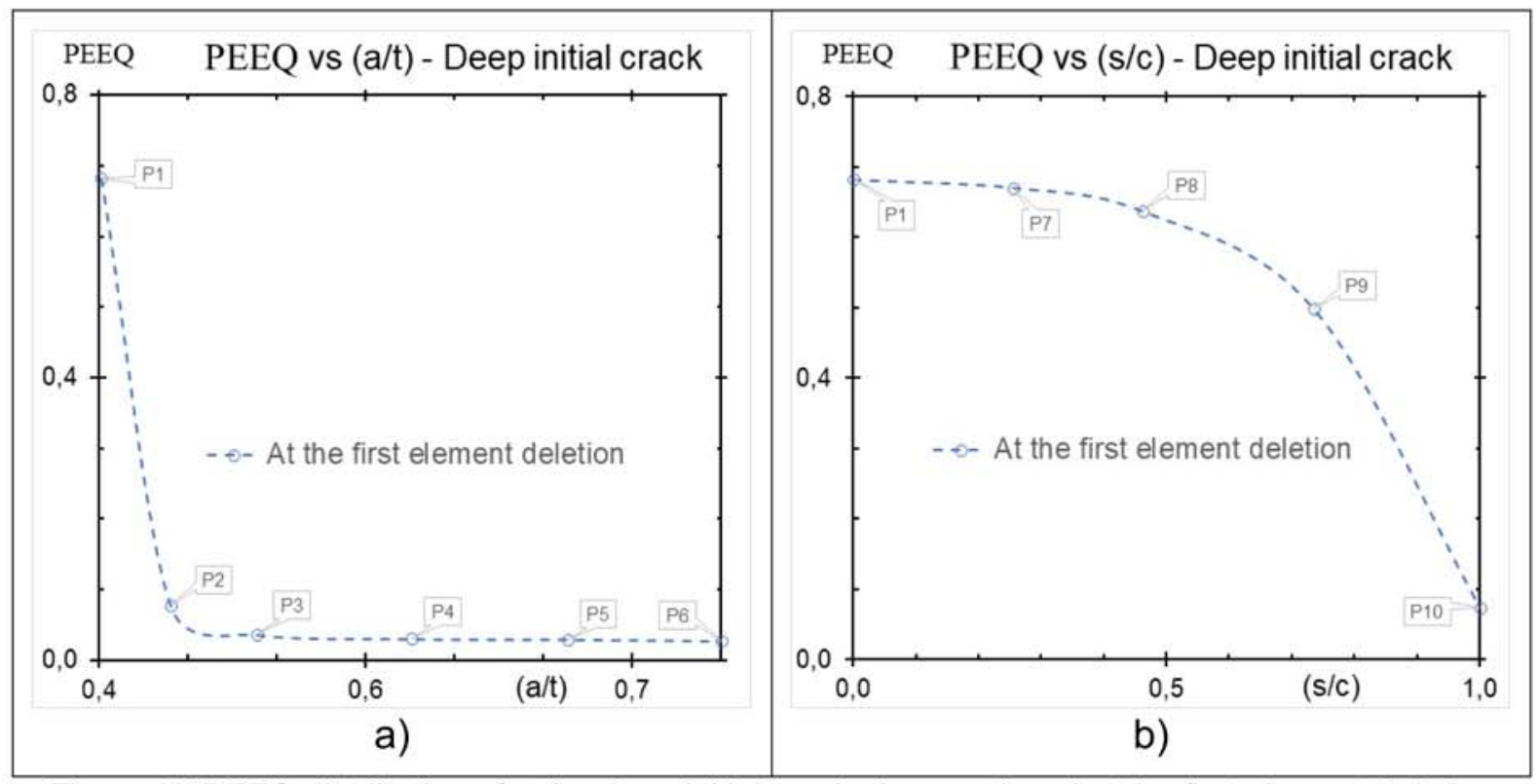

Figure 85 PEEQ distributions for the deep initial crack pipe, analyzed at the first element deletion through: a) "t" axis, and b) "s" axis

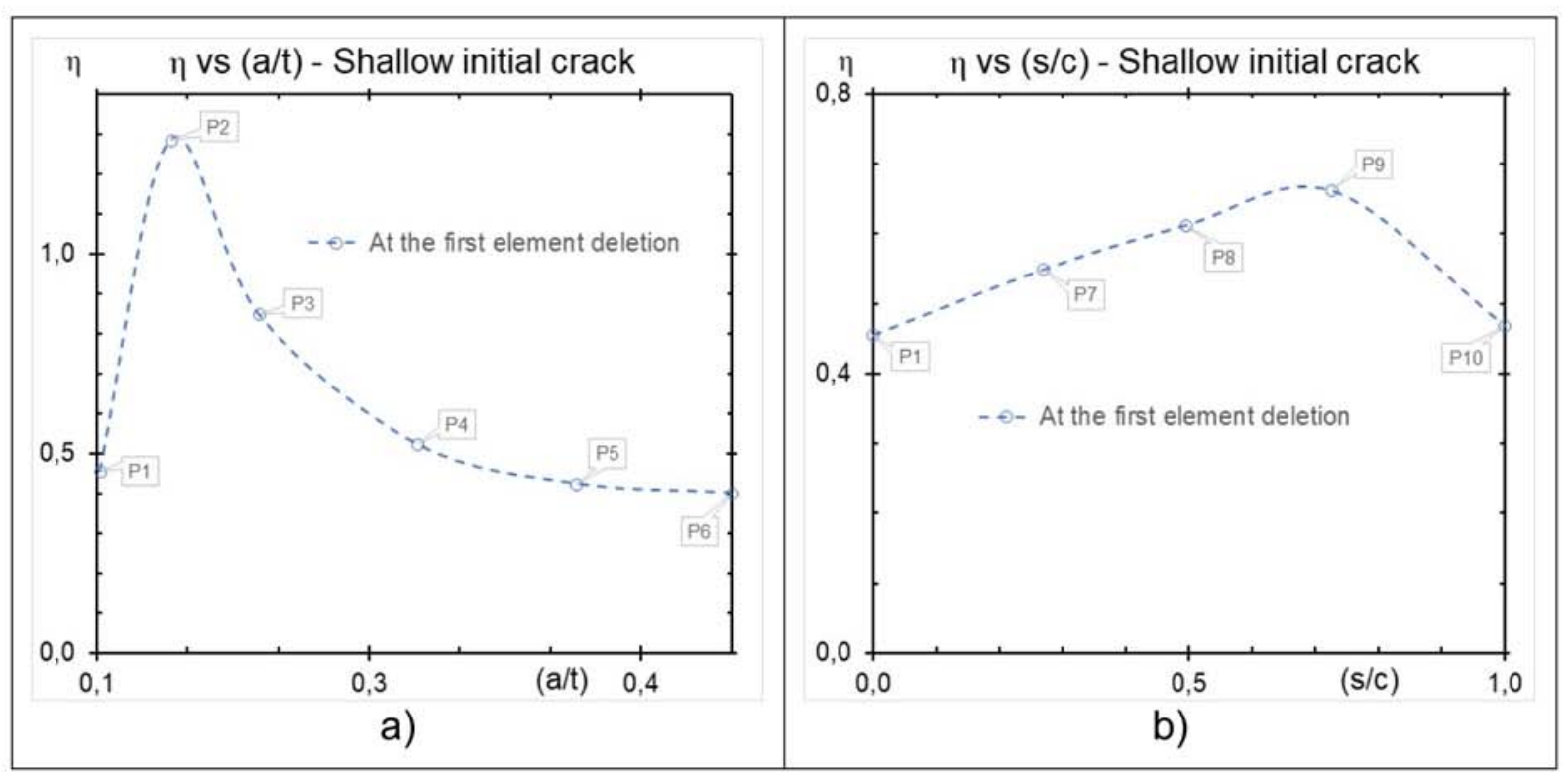

Figure 86 Triaxiality distributions for the shallow initial crack pipe, analyzed at the first element deletion through: a) "t" axis, and b) "s" axis 


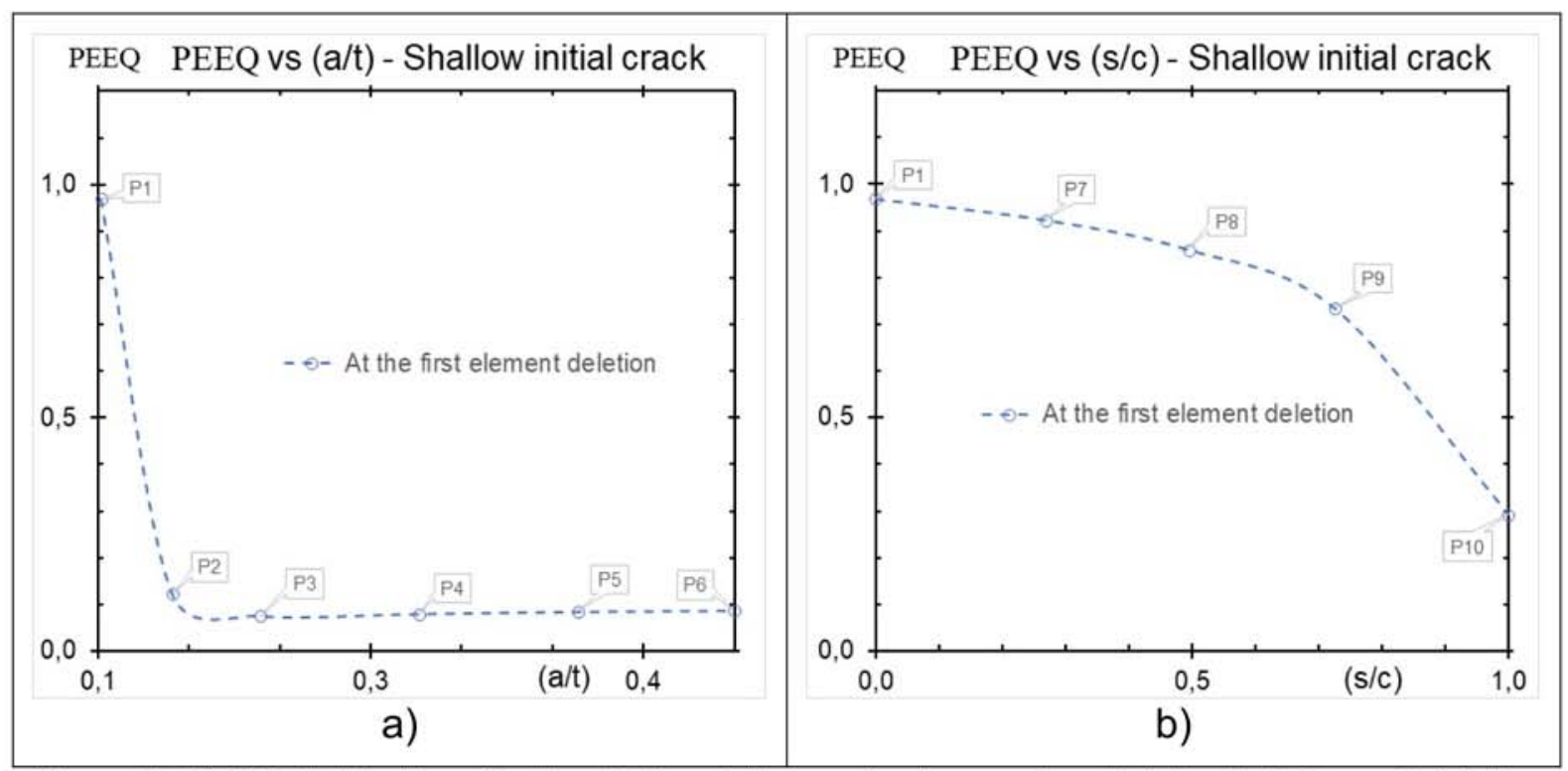

Figure 87 PEEQ distributions for the shallow initial crack pipe, analyzed at the first element deletion through: a) "t" axis, and b) "s" axis

Analyzing the triaxiality distribution obtained for each studied pipe, by comparison of Figure 84 and Figure 86, was observed the responses have the same behavior through both reference axis "s" and "a", defined in Figure 83. However, the triaxiality magnitudes are higher in the response obtained for the deep initial crack pipe than the shallow initial crack pipe, what could be related to the dimensions of the initial crack applied for each studied case. That means for the structure with a deep initial crack the elements located in the crack front easily reach higher triaxiality values that make it fail submitted to a lower load than the pipe with the shallow initial crack.

So, combining these results it is possible to predict how the elements will be deleted in the crack front for both analyzed pipes, being the response for each pipeline:

- With deep initial crack, elements deletion in the crack front is going to happen in the following order: $\mathrm{P} 1 \rightarrow \mathrm{P} 8 \rightarrow \mathrm{P} 10$; since is notable that the $\mathrm{P} 10$ needs a lot more load than P1 to be deleted from the numerical model. Figure 88 shows this assertion, since in an intermediate loading status, the zone close to the element $\mathrm{P} 10$ is not damaged even with the deletion growing through the thickness of pipe. 
- With shallow initial crack, elements deletion in the crack front will happen in the following order: $\mathrm{P} 1 \rightarrow \mathrm{P} 8 \rightarrow \mathrm{P} 10$; similar to the pipe with deep initial crack. However, it is possible to notice that, unlike the first case, the load needed to delete the P10 is lower than in the deep initial crack pipe. Also, it is possible to analyze that the load needed to delete P10 is almost equal than the load to delete the P5, which means that crack is growing faster through the " $t$ " axis than through the "s" axis, as seen in Figure 89.

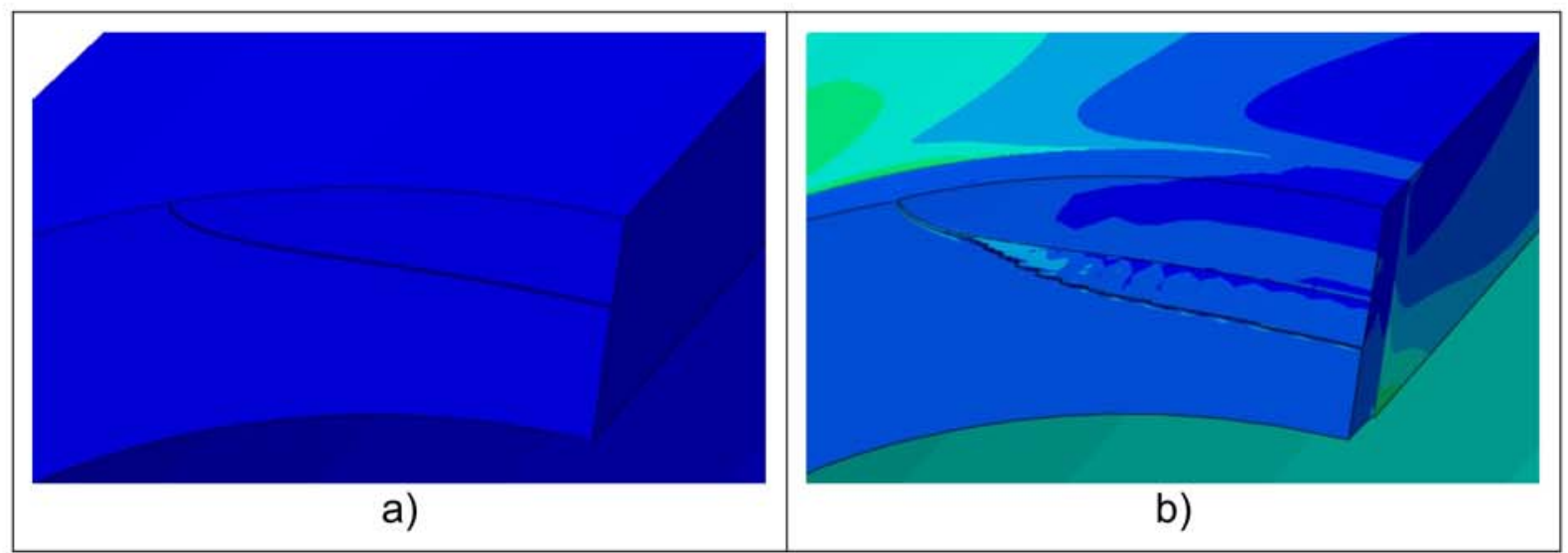

Figure 88 Crack growing process in the deep initial crack pipe, a) initial configuration, b) intermediate crack growth status

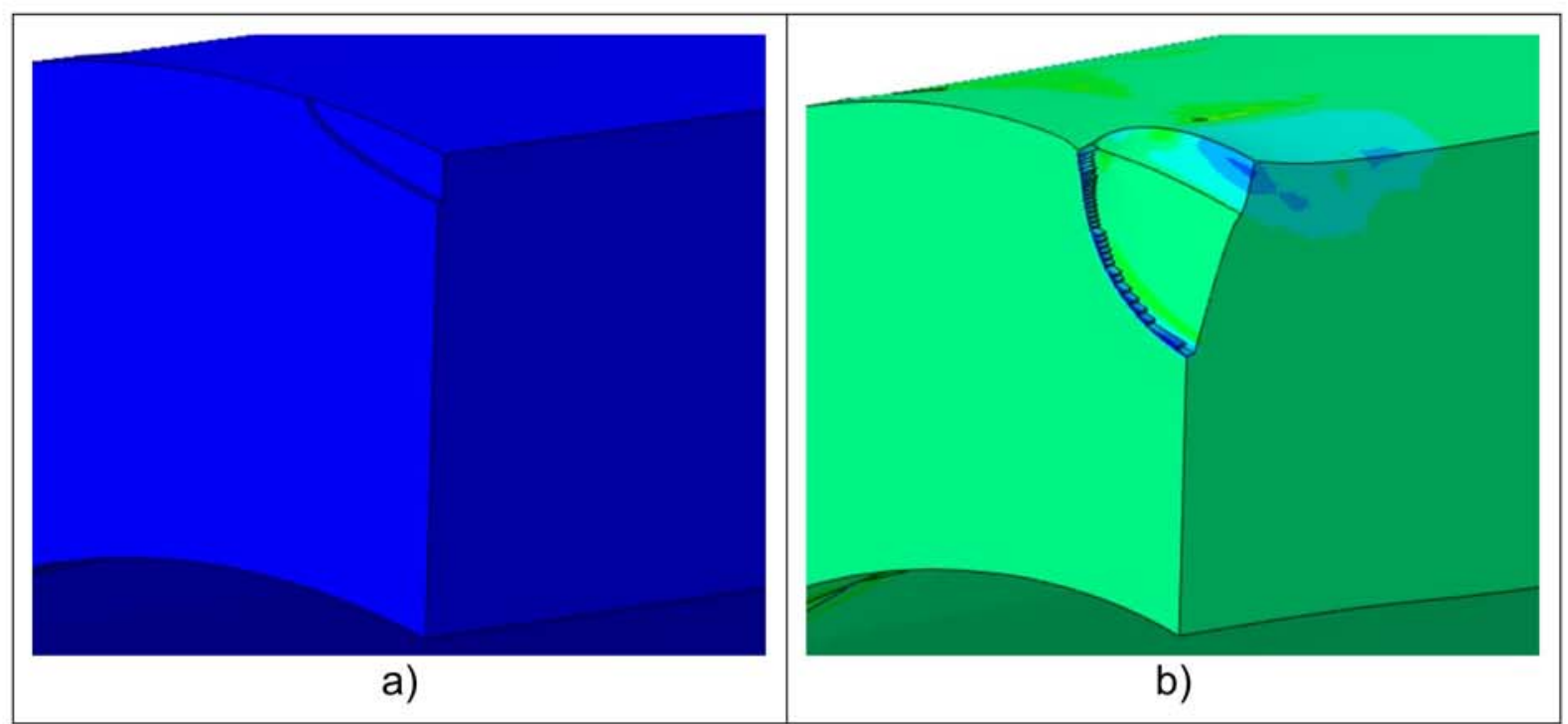

Figure 89 Crack growing process in the shallow initial crack pipe, a) initial configuration, b) intermediate crack growth status 
Finally, analyzing the relationship between the applied load and the displacement in the free extreme of each for both, shallow and deep initial crack pipe, is obtained the response observed in Figure 90.

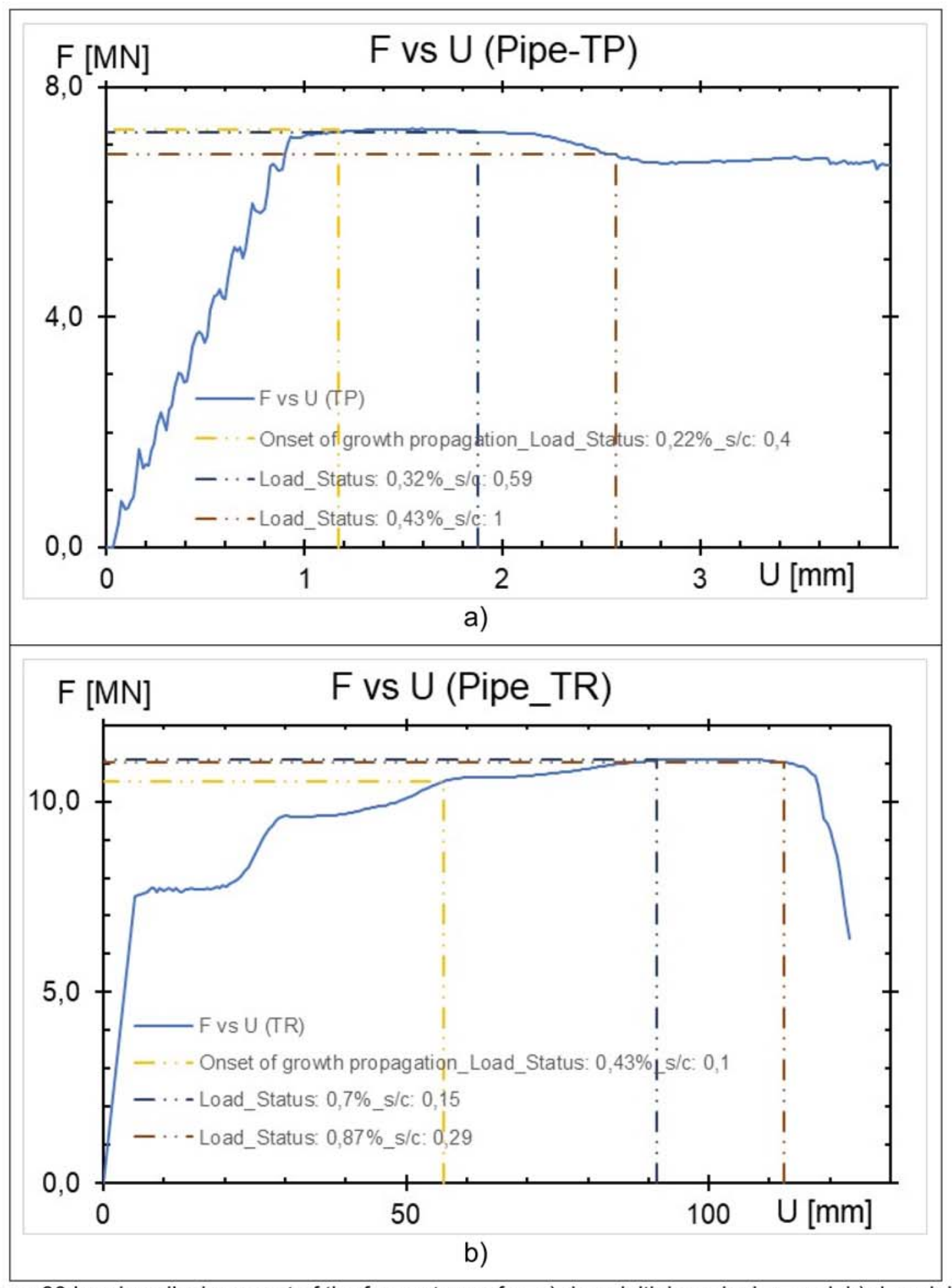

Figure 90 Load vs displacement of the free extreme for: a) deep initial crack pipe, and, b) deep initial crack pipe 
Figure 90 shows the applied force and the displacement measured the extreme of each pipe. Both, Figure 90a and Figure 90b, have three references points obtained in three times of loading: initial time with a null crack propagation, an intermediate load status, and a applied high level load. Each reference point is named using the applied percentage load and its equivalent $s / c$ crack dimension at the measured instant, where $s / c$ was defined in Figure 83. 


\section{CONCLUSIONS AND RECOMMENDATIONS}

\subsection{CONCLUSIONS}

In this research was characterized and studied in detail the process to calibrate the A285 steel ductile behavior, using the Stress Modified Critical Strain criteria (SMCS), using tensile and SEB laboratory tests, and a finite element program. The final obtained model includes the elastoplastic behavior of the steel A285, its initiation points of failure and its respective damage evolution. According to achieved results it is possible to conclude:

1. The SMCS criterion combined with a softening evolution law were able to predict the ductile failure of tensile smooth and notched specimens and cracked bending specimens.

2. Five specimens were needed to calibrate the model parameters.

3. Four (4) Finite Element models (FEm) were elaborated for the tensile test specimens, both notched and smooth, and $3 \mathrm{FEm}$ more for SEB specimens, subdivided in shallow crack specimens with and without side grooves, and deep crack specimen with side grooves. These finite element models faithfully represent the main dimensions of the laboratory specimens, which were used to calibrate the material analyzed using the SMCS criterion.

4. The Stress Modified Critical Strain criterion was applied successfully using the experimental results of all specimens in conjunction with the finite element models, as a result the total calibration of the elastoplastic behavior of the material and their ductile damage mechanical properties. The result of characterization of the material includes the SMCS factors, $\alpha=2,46$ and $\beta=-1,788$, and the Damage Evolution properties, which are 0.12 and 0.45 for Displacement at failure and Exponential factor respectively.

5. The calibrated material (A285 steel) was successfully applied to analyze two pipelines with an initial circumferential elliptical crack, one with an initial shallow crack and another one with an initial deep crack. The pipes were modeled as a $1 / 4$ symmetry of the total dimensions and were meshed using "brick" elements C3D8 whose minimum dimension is $0,2 \mathrm{~mm}$. From these analyses it is possible 
to predict, for each pipe, the applied load when the failure starts and, the growth of the crack.

6. To apply the calibrated model presented in this document, to predict the ductile behavior in any heavy structure, its respective finite element model must be meshed using brick elements with $0,2 \mathrm{~mm}$ as mean dimension, since that was the element used in the calibration of the material. This is because to the SMCS model can be said to be mesh-dependent.

7. The SMCS criterion works well for materials that have a well-defined necking behavior.

\subsection{RECOMMENDATIONS}

According to the study carried out in this thesis, the following can be recommended:

1. It must be tried to perform a greater amount of laboratory tests in order to confirm the data obtained, in addition to increasing the number of geometries of test bodies, both notch round bar type and SEB, to increase the effectiveness of the model characterized.

2. The calibration should be attempted using a smaller element size on the crack front, $(I=0.1 \mathrm{~mm})$; and apply this calibration in a complex structure to identify how much different is the response, comparing it with the present calibration. 


\section{REFERENCES}

[1] T. L. Anderson, Fracture Mechanics: Fundamentals and Applications, vol. 58, no. 5. 2010.

[2] R. H. . Peerlings, Enhanced damage modelling for fracture and fatigue. 1999.

[3] T. S. Cao, "Modeling ductile damage for complex loading paths," Ecole Nationale Supérieure des Mines de Paris, 2013.

[4] G. F. Vander Voort, "Use of Failure Analysis in Materials Selection," Georg. Vander Voort Consult. Serv., p. 18, 1997.

[5] S. Kweon, a. J. Beaudoin, and R. J. McDonald, "Experimental Characterization of Damage Processes in Aluminum AA2024-O," J. Eng. Mater. Technol., vol. 132, no. 3, p. 031008, 2010.

[6] Y. Bai and T. Wierzbicki, "Application of extended Mohr-Coulomb criterion to ductile fracture," Int. J. Fract., vol. 161, no. 1, pp. 1-20, 2010.

[7] T. Coppola, L. Cortese, and P. Folgarait, "The effect of stress invariants on ductile fracture limit in steels," Eng. Fract. Mech., vol. 76, no. 9, pp. 1288-1302, 2009.

[8] K. Nahshon and J. W. Hutchinson, "Modification of the Gurson Model for shear failure," Eur. J. Mech. A/Solids, vol. 27, no. 1, pp. 1-17, 2008.

[9] L. Xue, "Ductile Fracture Modeling - Theory, Experimental Investigation and Numerical Verification," Computer (Long. Beach. Calif)., no. January 2009, p. 252, 2007.

[10] L. Xue, "Constitutive modeling of void shearing effect in ductile fracture of porous materials," Eng. Fract. Mech., vol. 75, no. 11, pp. 3343-3366, 2008.

[11] M. Paredes, D. F. B. Sarzosa, R. Savioli, T. Wierzbicki, D. Y. Jeong, and D. C. Tyrell, "Ductile tearing analysis of TC128 tank car steel under mode I loading condition," Theor. Appl. Fract. Mech., Nov. 2017.

[12] M. Paredes, T. Wierzbicki, and P. Zelenak, "Prediction of crack initiation and propagation in X70 pipeline steels," Eng. Fract. Mech., vol. 168, 2016. 
[13] A. Needleman and V. Tvergaard, "An analysis of ductile rupture modes at a crack tip," J. Mech. Phys. Solids, vol. 35, no. 2, pp. 151-183, 1987.

[14] V. Tvergaard, "Influence of Voids on Shear Band Instability Under Plane Strain Conditions," Int. J. Fract., vol. 17, no. 4, pp. 389-407, 1981.

[15] V. Tvergaard, "On localization in ductile materials containing spherical voids," Int. J. Fract., vol. 18, no. 4, pp. 237-252, 1982.

[16] A. L. Gurson, "Continuum Theory of Ductile Rupture by Void Nucleation and Growth: Part I- Yield criteria and Flow Rules for Porous Ductile Media," J. Eng. Mater. Technol., vol. 99, no. 76, pp. 2-15, 1977.

[17] A. P. Gulyaev, "Brittle and ductile fracture," Plenum Publ. Corp., pp. 7-8, 1988.

[18] G. R. Irwin, "Structural aspects of brittle fracture," Appl. Mater. Res., vol. 3, no. 2, pp. 65-81, 1964.

[19] J. L. H. Richard W. Hertzberg, Richard P. Vinci, Deformation and Fracture Mechanics of Engineering Materials, Fifth Edit. John Wiley \& Sons, 2012.

[20] A. Saxena, "Nonlinear Fracture Mechanics for Engineers." CRC Press, p. 484, 1998.

[21] A. Öchsner, Continuum Damage and Fracture Mechanics. Singapore: Springer Singapore, 2016.

[22] A. C. Mackenzie, J. W. Hancock, and D. K. Brown, "On the influence of state of stress on ductile failure initiation in high strength steels," Eng. Fract. Mech., vol. 9 , no. 1, 1977.

[23] J. W. Hancock and M. J. Cowling, "Role of state of stress in crack-tip failure processes," Met. Sci., vol. 14, no. 8-9, pp. 293-304, 1980.

[24] T. Panontin and S. Sheppard, "The Relationship Between Constraint and Ductile Fracture Initiation as Defined by Micromechanical Analyses," in Fracture Mechanics: 26th Volume, 100 Barr Harbor Drive, PO Box C700, West Conshohocken, PA 19428-2959: ASTM International, 1995, pp. 54-54-32.

[25] J. Lemaitre, "Coupled elasto-plasticity and damage constitutive equations," Comput. Methods Appl. Mech. Eng., vol. 51, no. 1-3, pp. 31-49, 1985. 
[26] V. Tvergaard, "Influence of Voids on Shear Band Instability Under Plane Strain Conditions," Int. J. Fract., vol. 17, no. 4, pp. 389-407, 1981.

[27] J. W. Hancock and A. C. Mackenzie, "On the mechanisms of ductile failure in high-strength steels subjected to multi-axial stress-states," J. Mech. Phys. Solids, vol. 24, no. 2-3, pp. 147-160, 1976.

[28] Simulia, "Abaqus Analysis User's Guide." Dassault Systèmes, 2009.

[29] H. Hooputra, H. Gese, H. Dell, and H. Werner, "A comprehensive failure model for crashworthiness simulation of aluminium extrusions," Int. J. Crashworthiness, vol. 9, no. 5, pp. 449-463, 2004.

[30] ASTM Int., "Standard Test Methods for Tension Testing of Metallic Materials 1," Astm, no. C, pp. 1-27, 2009.

[31] Y.-J. Kim, C.-K. Oh, C.-Y. Park, and K. Hasegawa, "Net-section limit load approach for failure strength estimates of pipes with local wall thinning," Int. J. Press. Vessel. Pip., vol. 83, no. 7, pp. 546-555, Jul. 2006.

[32] ASTM, "Standard Test Method for Measurement of Fracture Toughness E1820-15a," ASTM B. Stand., vol. N/A, no. 2000, pp. 1-56, 2015.

[33] E. Smith and B. M. Patchett, "Effects of Notch Acuity and Side Grooving on Fracture Toughness," Suppl. to Weld. J., no. June, pp. 169-177, 1975.

[34] S. Hertelé, W. De Waele, and R. Denys, "A generic stress-strain model for metallic materials with two-stage strain hardening behaviour," Int. J. Non. Linear. Mech., vol. 46, no. 3, pp. 519-531, Apr. 2011.

[35] S. Hertelé, W. De Waele, R. Denys, and M. Verstraete, "Full-range stressstrain behaviour of contemporary pipeline steels: Part I. Model description," Int. J. Press. Vessel. Pip., vol. 92, pp. 34-40, 2012.

[36] Y.-J. Kim, C.-K. Oh, J.-H. Baek, and W. Kim, "Development of stress-modified fracture strain for ductile failure of API X65 steel," Int. J. Fract., vol. 143, no. 2 , pp. 119-133, Apr. 2007.

[37] T. Pussegoda, Nick; Sanjay, Tiku; Bill, "Test Protocol : Measurement of CrackTip Opening Displacement ( CTOD ) and J-Fracture Resistance Curves Using 
Single-Edge Notched Tension ( SENT ) Specimens," BMT Fleet Technol. Ltd., vol. 30166-001, p. 44, 2014.

[38] K.-D. Bae, H.-W. Ryu, J.-J. Han, and Y.-J. Kim, "Ductile fracture simulation of full-scale circumferential cracked pipes: (I) Carbon steel," Procedia Mater. Sci., vol. 3, pp. 1056-1061, 2014.

[39] D. F. B. Sarzosa and C. Ruggieri, "A numerical investigation of constraint effects in circumferentially cracked pipes and fracture specimens including ductile tearing," Int. J. Press. Vessel. Pip., vol. 120-121, no. 1, pp. 1-18, 2014.

[40] C. Ruggieri, T. L. Panontin, and R. H. Dodds Jr, "Numerical modelling of ductile crack growth in 3-D using computational cell elements," Int. J. Fract., vol. 18, no. 1, pp. 99-116, 1996.

[41] SIMULIA, "Abaqus Example Problems Guide," in Abaqus 6.13, SIMULIA, Ed. 2013.

[42] J. R. Rice and D. M. Tracey, "On the ductile enlargement of voids in triaxial stress fields," J. Mech. Phys. Solids, vol. 17, no. 3, pp. 201-217, 1969.

[43] ASTM, "Standard Specification for Pressure Vessel Plates, Carbon Steel, Lowand Intermediate-Tensile Strength," ASTM B. Stand., vol. 90, no. Reapproved 1996, pp. 1-2, 1999. 


\section{ANEXOS}

\subsection{CHEMICAL PROPERTIES OF THE MATERIAL}

SE P 711/2017 13:49:06 Amostra: RE: SEA 23 "C $50 \%$ LB10257-rev 7 ARL
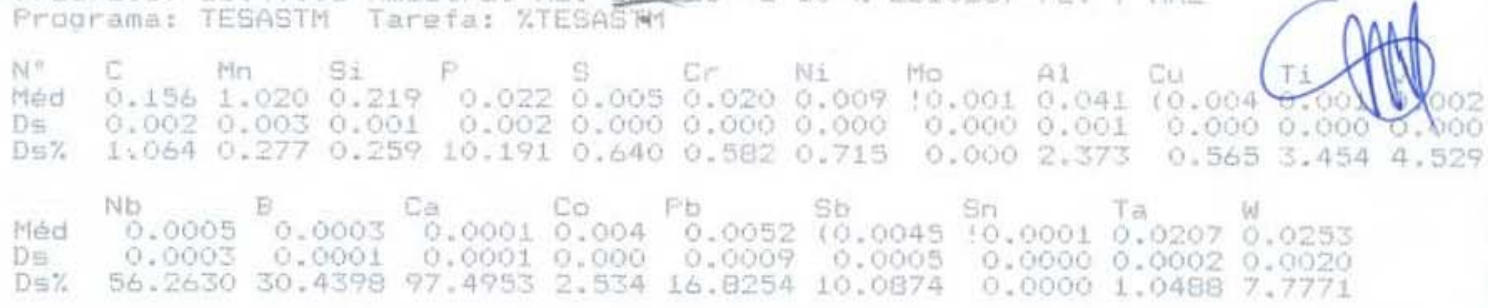

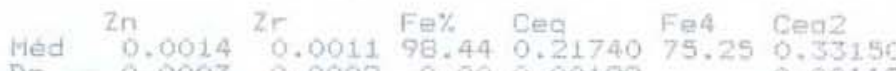

$\begin{array}{llllll}\text { De } & 0.0003 & 0.0002 & 0.00 & 0.00199 & 0.00119\end{array}$

Ds\% $22.1825 \quad 20.1071 \quad 0.00 \quad 0.91342 \quad 0.35973$ S1. 7/11/2017 13a51:58 Anostra: RE: T1 23 "C $50 \%$ LB10257-reV 7 ARL
Programa: TESASTM Tarefa: \%TESASTM

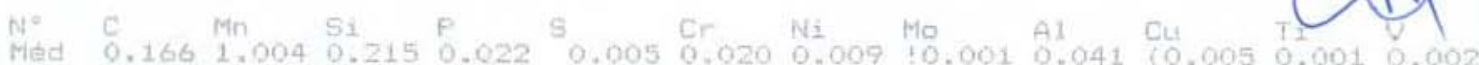

$\begin{array}{llllllllllllll}\text { Ds } & 0.003 & 0.013 & 0.003 & 0.001 & 0.001 & 0.000 & 0.000 & 0.000 & 0.001 & 0.001 & 0.000 & 0.000\end{array}$ Ds\% $\quad 2.0251 .2621 .176 \quad 3.393 \quad 12.417 \quad 2.404 \quad 0.856 \quad 0.000 \quad 3.051 \quad 13.911$ 1.875 7.891

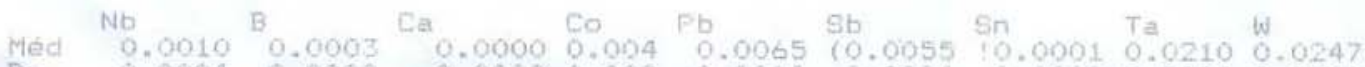

$\begin{array}{llllllllll}\text { D5 } & 0.0004 & 0.0000 & 0.0000 & 0.000 & 0.0010 & 0.0004 & 0.0001000 & 0.0004 & 0.0247\end{array}$

DE\% 41.9925 11.9875 $945.9140 \quad 0.925 \quad 15.5863 \quad 7.2720 \quad 0.59472 .05002 .3242$

Med $\quad \begin{array}{llllll}\mathrm{Zn} & \mathrm{Zr} & \mathrm{Fe} \% & \mathrm{Ceq} & \mathrm{Fe} 4 & \mathrm{Ceg} 2 \\ 0.0015 & 0.0014 & 98.44 & 0.22634 & 73.76 & 0.33902\end{array}$

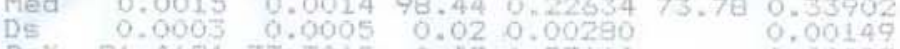

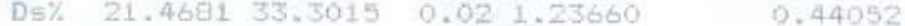

R1. 7/11/2017 13:54:18 Amostra: RE: RI 23 ०C $50 \%$ LB10257-rev 7 ARL
Proarama: TESASTM Tarefa: \%TESASTM

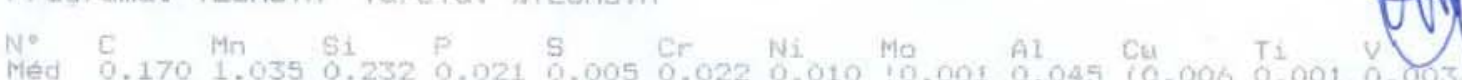

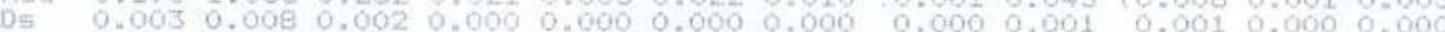

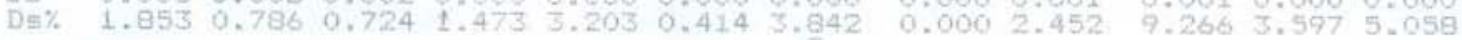

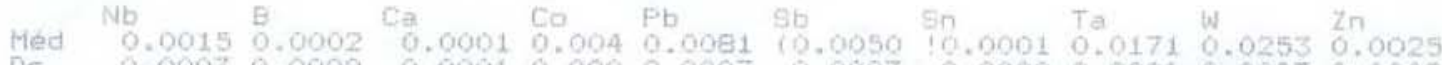

$\begin{array}{llllllllllll}\text { Ds } & 0.0003 & 0.0000 & 0.0001 & 0.000 & 0.0007 & 0.0003 & 0.0000 & 0.0001 & 0.0003 & 0.0007\end{array}$

$\begin{array}{lllllllllll}\text { D.7\% } & 19.1261 & 0.3710 & 51.4725 & 1.693 & 8.0767 & 5.7335 & 0.0000 & 0.6630 & 1.1712 & 6.2073\end{array}$

\begin{tabular}{|c|c|c|c|c|c|}
\hline $\begin{array}{l}M \notin d \\
D S \\
D=\%\end{array}$ & $\begin{array}{r}25 \\
0.0025 \\
0.0904 \\
17.3498\end{array}$ & $\begin{array}{l}\mathrm{Fe} \% \\
98.38 \\
0.01 \\
0.01\end{array}$ & $\begin{array}{l}\text { Cen } \\
0.23313 \\
0.00266 \\
1.4163\end{array}$ & $\begin{array}{l}\mathrm{Fe}^{4} \\
6 \mathrm{~B} .3 \mathrm{3}\end{array}$ & $\begin{array}{l}\text { Ceg2 } \\
0.34943 \\
0.00175\end{array}$ \\
\hline
\end{tabular}




\subsection{CRACK GROWING PROCESS IN THE DEEP INITIAL CRACK PIPE}

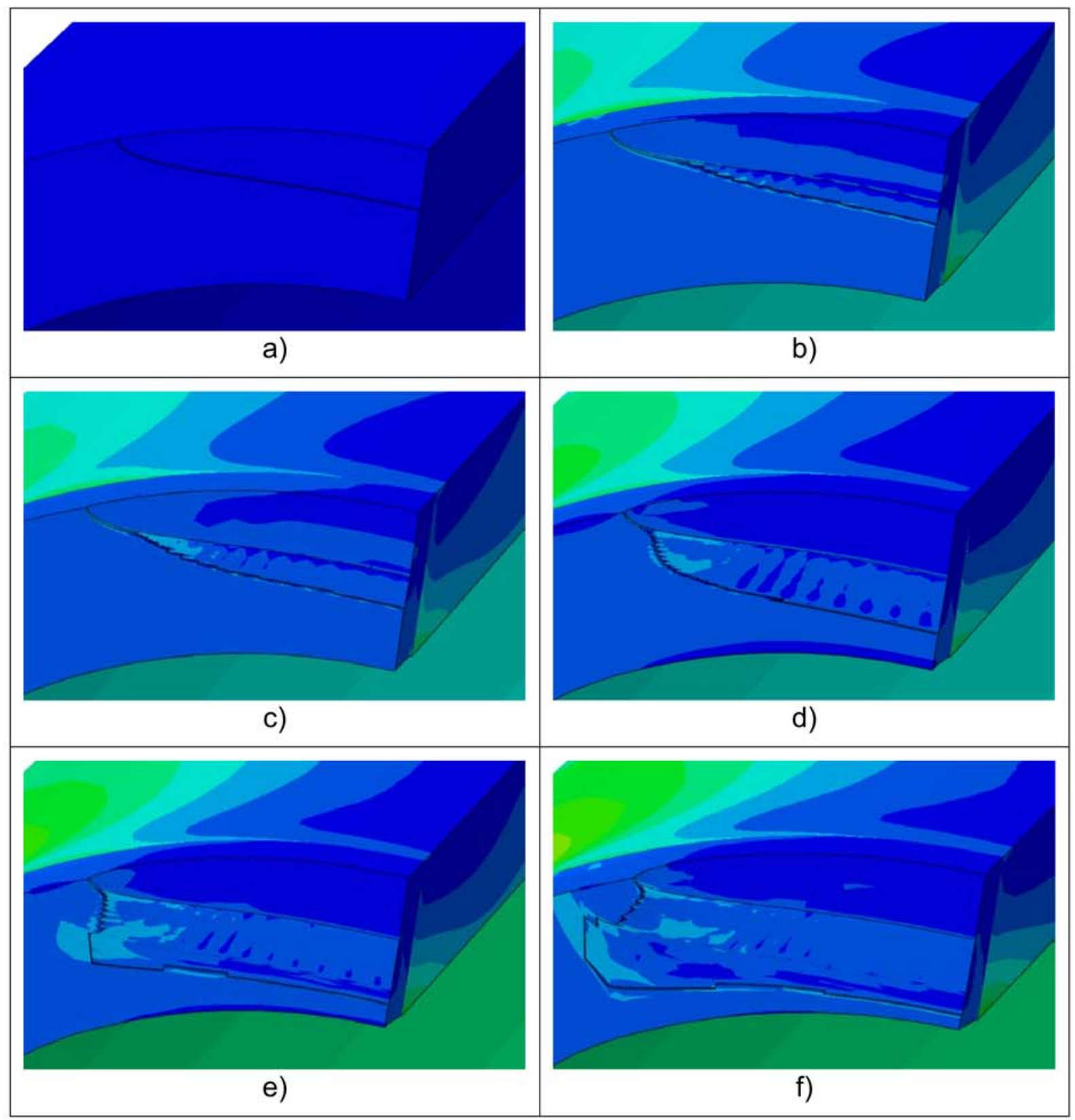

Figure 91 Crack growing process in the deep initial crack pipe in different Load Status (LS), a) LS=0; b) $L S=0,44$; c) $L S=0,50$; d) $L S=0,63$; e) $L S=0,68$; and f) $L S=0,75$ 


\subsection{CRACK GROWING PROCESS IN THE SHALLOW INITIAL CRACK}

PIPE

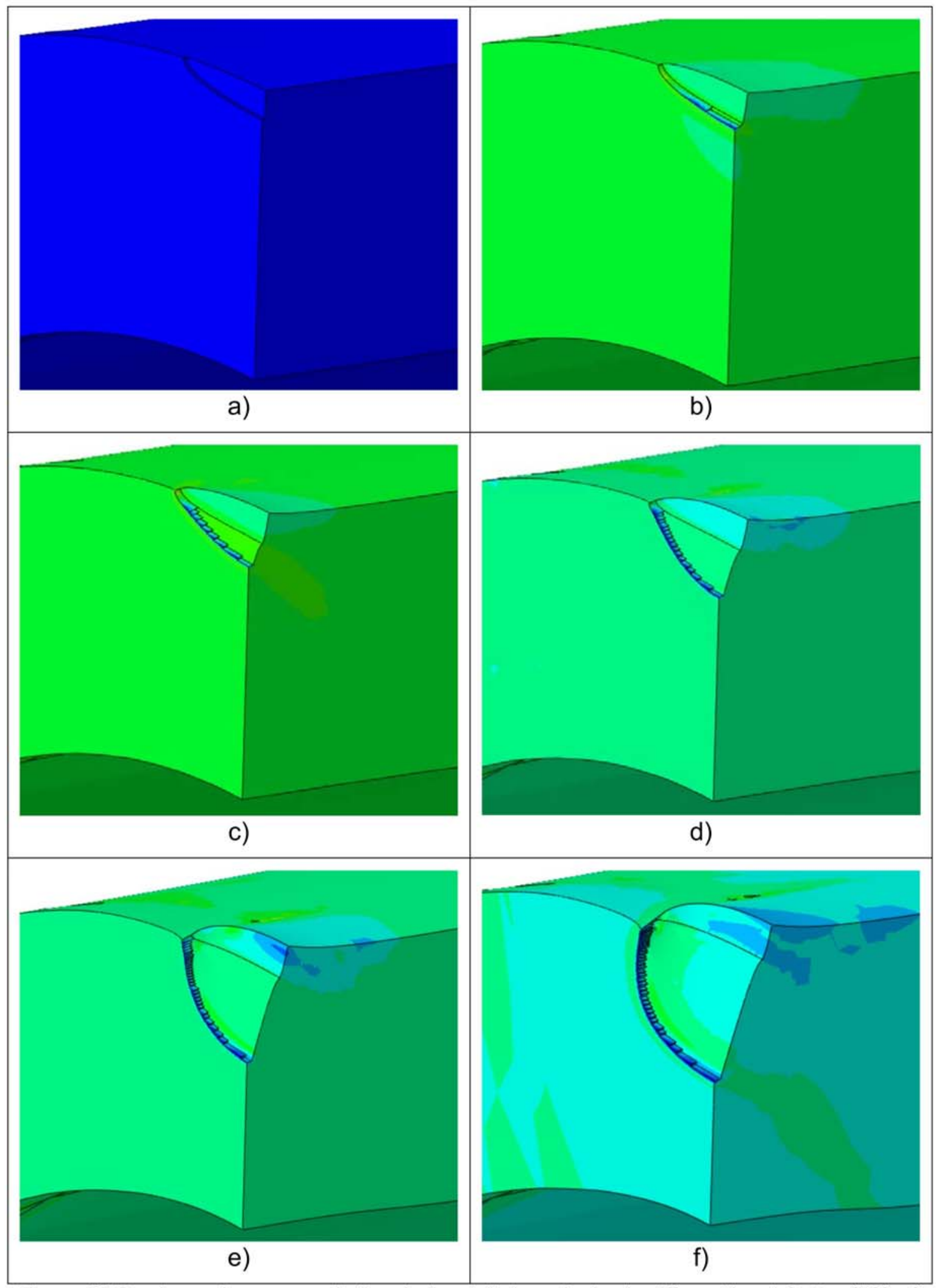

Figure 92 Crack growing process in the shallow initial crack pipe in different Load Status (LS), a) LS=0; b) LS=0,50; LS=0,60; LS=0,70; LS=0,80; and LS=0,84 